\title{
New horizons in nonpolypoid colorectal carcinogenesis
}

Citation for published version (APA):

Rondagh, E. J. A. (2012). New horizons in nonpolypoid colorectal carcinogenesis. [Doctoral Thesis, Maastricht University]. CPI - Wöhrmann Print Service. https://doi.org/10.26481/dis.20120905er

Document status and date:

Published: 01/01/2012

DOI:

10.26481/dis.20120905er

Document Version:

Publisher's PDF, also known as Version of record

\section{Please check the document version of this publication:}

- A submitted manuscript is the version of the article upon submission and before peer-review. There can be important differences between the submitted version and the official published version of record.

People interested in the research are advised to contact the author for the final version of the publication, or visit the DOI to the publisher's website.

- The final author version and the galley proof are versions of the publication after peer review.

- The final published version features the final layout of the paper including the volume, issue and page numbers.

Link to publication

\footnotetext{
General rights rights.

- You may freely distribute the URL identifying the publication in the public portal. please follow below link for the End User Agreement:

www.umlib.nl/taverne-license

Take down policy

If you believe that this document breaches copyright please contact us at:

repository@maastrichtuniversity.nl

providing details and we will investigate your claim.
}

Copyright and moral rights for the publications made accessible in the public portal are retained by the authors and/or other copyright owners and it is a condition of accessing publications that users recognise and abide by the legal requirements associated with these

- Users may download and print one copy of any publication from the public portal for the purpose of private study or research.

- You may not further distribute the material or use it for any profit-making activity or commercial gain

If the publication is distributed under the terms of Article $25 \mathrm{fa}$ of the Dutch Copyright Act, indicated by the "Taverne" license above, 


\title{
New horizons in nonpolypoid
}

\author{
colorectal carcinogenesis
}

Eveline Rondagh 
(C) Eveline Rondagh, Maastricht 2012

Layout: Tiny Wouters

Cover: Samira Bekraoui I El Mundo Verde Travel

Production: CPI - Wöhrmann Print Service, Zutphen

ISBN: 978-94-6203-053-4

Printing of this thesis was financially supported by Tramedico B.V., ABBOTT Immunology, ERBE Nederland BV, Pentax B.V., Olympus Nederland B.V., Roche and Nederlandse Vereniging voor Gastroenterologie. 


\title{
New horizons in nonpolypoid
}

\section{colorectal carcinogenesis}

\author{
PROEFSCHRIFT \\ Ter verkrijging van de graad van doctor aan de Universiteit Maastricht, \\ op gezag van de Rector Magnificus, Prof. dr. L.L.G. Soete, \\ volgens het besluit van het College van Decanen, \\ in het openbaar te verdedigen \\ op woensdag 5 september 2012 om 14:00 uur
}

door

Eveline Josepha Augusta Rondagh 


\section{Promotor}

Prof. dr. AAM Masclee

\section{Co-promotor}

Dr. S. Sanduleanu

\section{Beoordelingscommissie}

Prof. dr. F. Ramaekers (voorzitter)

Prof. dr. A. de Bruïne

Prof. dr. M. van Engeland

Dr. E. Dekker, AMC Amsterdam

Dr. R. Soetikno, VA Palo Alto Health Care System 
"We see only what we know" Johann Wolfgang von Goethe (1749-1832) 



\section{Contents}

Chapter 1 Introduction 9

Chapter 2 Development of expertise in the detection and classification of nonpolypoid colorectal neoplasia: experience-based data at an academic Gl unit

Chapter 3 Nonpolypoid colorectal neoplasms: gender differences in prevalence and malignant potential

Chapter 4 Endoscopic red flags for the detection of high-risk serrated polyps: an observational study

Chapter 5 Endoscopic appearance of proximal colorectal neoplasms and potential implications for colonoscopy in cancer prevention

Chapter 6 Nonpolypoid colorectal neoplasms in patients with Lynch syndrome: potential implications for surveillance strategies

Chapter 7 Diverticulosis and colorectal polyps at young age: a possible link?

Chapter 8 Tracking the molecular features of nonpolypoid colorectal neoplasms: a systematic review and meta-analysis

Chapter 9 Promoter hypermethylation in colorectal neoplasms according to their clinicopathologic features

Chapter 10 General discussion

Summary

Samenvatting

Dankwoord

Curriculum vitae 

Chapter 1

General introduction 


\section{General introduction}

Colorectal cancer (CRC) is a major healthcare issue with worldwide more than $1,200,000$ new cases and 600,000 deaths per year. ${ }^{1}$ In the Netherlands, each year 13,000 new patients are diagnosed and 5,000 die from the disease, which makes CRC the second most common cancer and cause of cancer-related death. ${ }^{2}$ The majority of CRCs are considered to evolve from adenomatous colorectal polyps. ${ }^{3}$ This development through precursor lesions, combined with the accessibility of the colon, offers excellent potential to reduce the CRC incidence and mortality by early detection and removal of precancerous lesions. Already in 1993, the National Polyp Study showed that colonoscopy with polypectomy may reduce the incidence of CRC by 76 to $90 \% .{ }^{4}$ It is therefore not surprising that a worldwide concern was raised when recent studies, reflecting routine practice, showed that colonoscopy has its limitations in the prevention of CRC incidence and mortality, in particular in the proximal colon (Table $1.1)^{5-8}$

Table 1.1 Recent studies addressing the association of colonoscopy with colorectal cancer incidence or mortality according to location.

\begin{tabular}{|c|c|c|c|c|c|c|}
\hline Study & Country & Study population & Design & Outcome & $\begin{array}{l}\text { Proximal } \\
\text { colon }\end{array}$ & $\begin{array}{l}\text { Distal } \\
\text { colon }\end{array}$ \\
\hline $\begin{array}{l}\text { Brenner et al, } \\
2011^{8}\end{array}$ & Germany & $\begin{array}{l}\text { CRC patients }(n=1,688) \\
\text { Control: subjects older } \\
\text { than } 50 \text { years }(n=1,932)\end{array}$ & $\begin{array}{l}\text { Colonoscopy in } \\
\text { the previous } \\
10 \text { years }\end{array}$ & $\begin{array}{l}\text { CRC } \\
\text { incidence }\end{array}$ & $\begin{array}{l}\text { OR } 0.44 \\
(0.35-0.55)\end{array}$ & $\begin{array}{l}\text { OR } 0.16 \\
(0.12-0.20)\end{array}$ \\
\hline $\begin{array}{l}\text { Singh et al, } \\
2010^{7}\end{array}$ & Canada & $\begin{array}{l}\text { Subjects who underwent } \\
\text { colonoscopy }(n=54,803) \\
\text { Control: general } \\
\text { population }\end{array}$ & Follow-up data & $\begin{array}{l}\text { CRC } \\
\text { mortality }\end{array}$ & $\begin{array}{l}\text { SMR } 0.94 \\
(0.77-1.17)\end{array}$ & $\begin{array}{l}\text { SMR } 0.53 \\
(0.42-0.67)\end{array}$ \\
\hline $\begin{array}{l}\text { Baxter et al, } \\
2009^{6}\end{array}$ & Canada & $\begin{array}{l}\text { Patients who died from } \\
\text { CRC }(n=10,292) \\
\text { Control: matched for age } \\
\text { and sex }(n=51,460)\end{array}$ & $\begin{array}{l}\text { Previous } \\
\text { complete } \\
\text { colonoscopy }\end{array}$ & $\begin{array}{l}\text { CRC } \\
\text { mortality }\end{array}$ & $\begin{array}{l}\text { OR } 0.99 \\
(0.86-1.14)\end{array}$ & $\begin{array}{l}\text { OR } 0.33 \\
(0.28-0.39)\end{array}$ \\
\hline $\begin{array}{l}\text { Lakoff et al, } \\
2008^{5}\end{array}$ & Canada & $\begin{array}{l}\text { Subjects with negative } \\
\text { colonoscopy }(n=110,402) \\
\text { Control: general } \\
\text { population }\end{array}$ & Follow-up data & $\begin{array}{l}\text { CRC } \\
\text { incidence }\end{array}$ & $\begin{array}{l}\text { RR } 0.72^{a} \\
(0.50-0.94)\end{array}$ & $\begin{array}{l}\text { RR } 0.36^{a} \\
(0.25-0.47)\end{array}$ \\
\hline
\end{tabular}

$\mathrm{CRC}=$ colorectal cancer, $\mathrm{OR}=$ odds ratio, $\mathrm{SMR}=$ standardized mortality ratios, $\mathrm{RR}=$ relative risk ${ }^{\mathrm{a}}$ Data after 5 years of follow up.

Two major categories of explanations are considered to be responsible for the occurrence of post-colonoscopy CRCs, that is, failure to detect or completely remove colorectal neoplasms during colonoscopy as well as a more aggressive or alternative biology of colorectal neoplasms. ${ }^{9}$ In both cases, nonpolypoid (flat and depressed) colorectal neoplasms (NP-CRNs) may play a critical role. ${ }^{10} \mathrm{NP}-\mathrm{CRNs}$ have a subtle endoscopic appearance, which makes them easy to overlook, particularly in suboptimal circumstances, i.e. endoscopists who are unaware of the significance of these lesions ${ }^{11}$ or in cases of suboptimal bowel preparation. ${ }^{12}$ Moreover, complete 
removal of NP-CRNs may require selective chromoendoscopy and endoscopic mucosal resection (EMR), techniques which were just recently introduced in the Western endoscopy practice. ${ }^{10}$

In addition to a more challenging detection and treatment, some subtypes of nonpolypoid adenomas have been suspected to harbor a more aggressive biologic behavior. ${ }^{10,13}$ This could worsen the consequences of overlooking or incompletely removing these lesions and result in the development of a cancer in the window between two examinations. Finally, the precursors of the serrated neoplastic pathway, which has now been recognized as an alternative carcinogenic route, ${ }^{14,15}$ frequently have a nonpolypoid appearance. ${ }^{16}$ Recognition of these lesions during colonoscopy is especially difficult because of their pale and transparent appearance, and guidelines for surveillance of patients having these lesions are not yet available. ${ }^{17}$

Although NP-CRNs were initially thought to be confined to the Japanese population, ${ }^{18}$ over the past decade these lesions have been described and recognized worldwide, ${ }^{10}$ with prevalences ranging from 4 to $24 \% .{ }^{19}$ So far, no studies examined the prevalence of these lesions in the Netherlands. In 2013, a nationwide CRC screening program for subjects at average-risk for CRC will be implemented in the Netherlands. ${ }^{20}$ Healthy individuals with a positive fecal occult blood test will undergo colonoscopy and will be exposed to its potential complications $(0.14 \%$ risk of bleeding; $0.1 \%$ risk of perforation) ${ }^{20}$ which emphasizes the need for safe and highly effective procedures. For high-risk subjects, such as patients with Lynch syndrome, colonoscopic surveillance is already current practice. However, despite undergoing frequent colonoscopic examinations, these patients have a 6 to $10 \%$ risk to develop CRC during 10 years of surveillance. ${ }^{21-24}$ For both average- and high-risk individuals, more knowledge on the prevalence and clinicopathologic features of NP-CRNs may be useful for improving current educational programs and defining targets for quality of colonoscopy in order to ultimately optimize cancer prevention by colonoscopy.

The adenoma-carcinoma sequence caused by several genetic and epigenetic alterations is mainly based on findings in polypoid adenomas. As some subtypes of nonpolypoid adenomas have an increased risk to contain advanced histology (i.e. highgrade dysplasia and early cancer), ${ }^{10,13}$ it is possible that these lesions may progress through biologic pathways other than the traditional adenoma-carcinoma sequence. Previous studies addressed the genetic characteristics of NP-CRNs, ${ }^{25}$ but findings are controversial, ${ }^{26}$ whereas data on epigenetic alterations are even more limited. Additional knowledge on the molecular profile of NP-CRNs may bring more insight into the nonpolypoid colorectal carcinogenesis and may potentially provide the basis for adequate management and follow-up of patients having these lesions.

Many of the previous Western studies addressing the prevalence and malignant potential of NP-CRNs included only a limited number of (expert) endoscopists. ${ }^{27-32}$ Furthermore, most of these studies did not specifically address differences with regard to anatomic location, while this aspect may be very relevant given the predominant 
proximal location of post-colonoscopy CRCs. ${ }^{33,34}$ Moreover, epidemiological and molecular differences have been described to exist between proximal and distal colorectal neoplasms (Figure 1.1). ${ }^{35-37}$ Also with regard to gender, differences in prevalence and anatomic location of colorectal neoplasms exist. ${ }^{38}$ Although less consistently described as for the proximal location, women have been suggested to be at an increased risk for post-colonoscopy CRCs. ${ }^{33,34}$ The nonpolypoid colorectal carcinogenesis should therefore be explored according to anatomical location and gender, as this may lead to a better understanding of the nonpolypoid colorectal carcinogenesis and the development of post-colonoscopy CRCs.

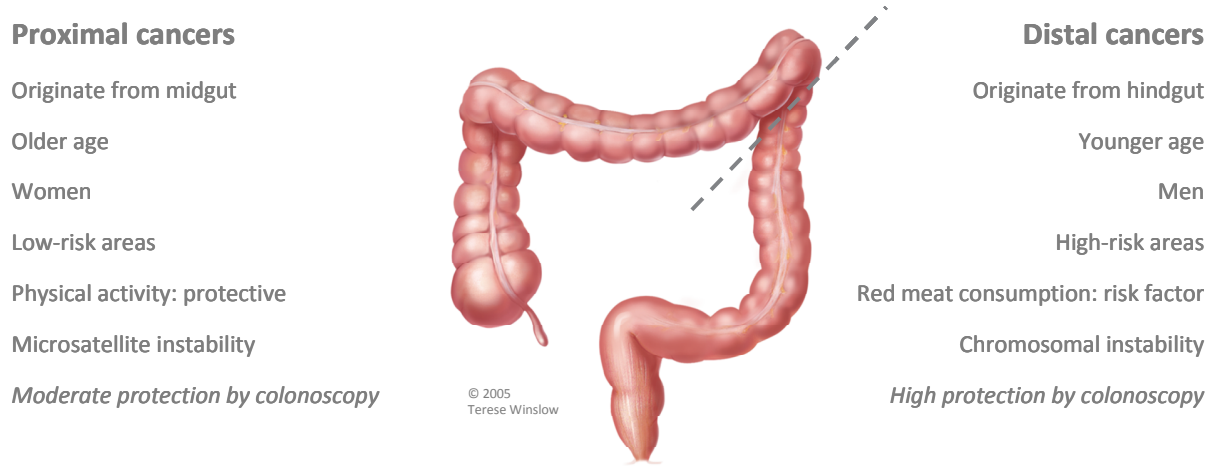

Figure 1.1 Differences between proximal and distal colorectal cancers

It has been estimated that only five per cent of all adenomas eventually evolve into CRC. $^{39}$ Unfortunately, we cannot predict which adenomas will eventually become malignant and which will not. ${ }^{40}$ Nevertheless, it has been shown that adenomas with large size, high-grade dysplasia or villous histology have a higher chance to contain carcinoma, ${ }^{3}$ and are therefore regarded as advanced adenomas. Although (epi)genomic profiling may be promising for the future ${ }^{40}$ histology is currently the best available approach to distinguish adenomas at low risk from adenomas at high risk for progression. Pathologists are currently able to accurately distinguish adenomatous from serrated lesions and malignant from benign lesions, however, they have much more difficulties in uniformly determining the grade of dysplasia or the histological subtype (i.e. extend of villous histology). ${ }^{41}$ The simplification of the grade of dysplasia into two grades (high or low) has substantially improved the interobserver agreement, ${ }^{41,42}$ rendering presence of high-grade dysplasia or invasive cancer thereby a more reliable feature than the histological subtype. Taking into account the above mentioned considerations, we defined adenomas with advanced histology in this thesis by the presence of high-grade dysplasia or early cancer. 


\section{Aim and outlines of the thesis}

In this thesis, we aimed to investigate the prevalence of NP-CRNs in average- and highrisk populations in the Netherlands and explore their clinicopathologic and molecular characteristics. We studied the contribution of the two major carcinogenic pathways, that is, the traditional adenoma-carcinoma route as well as the recently described serrated neoplastic pathway. Furthermore, we examined factors which may assist endoscopic detection of (nonpolypoid) colorectal neoplasms.

As a key feature, before initiating the studies, all endoscopists at the Maastricht University Medical Center were familiarized on the recognition, classification (Figure 1.2) and endoscopic treatment of nonpolypoid colorectal lesions (Chapter 2). This allowed us to study the role of nonpolypoid mechanisms in colorectal carcinogenesis in routine practice, making the results generalizable to other endoscopy practices.

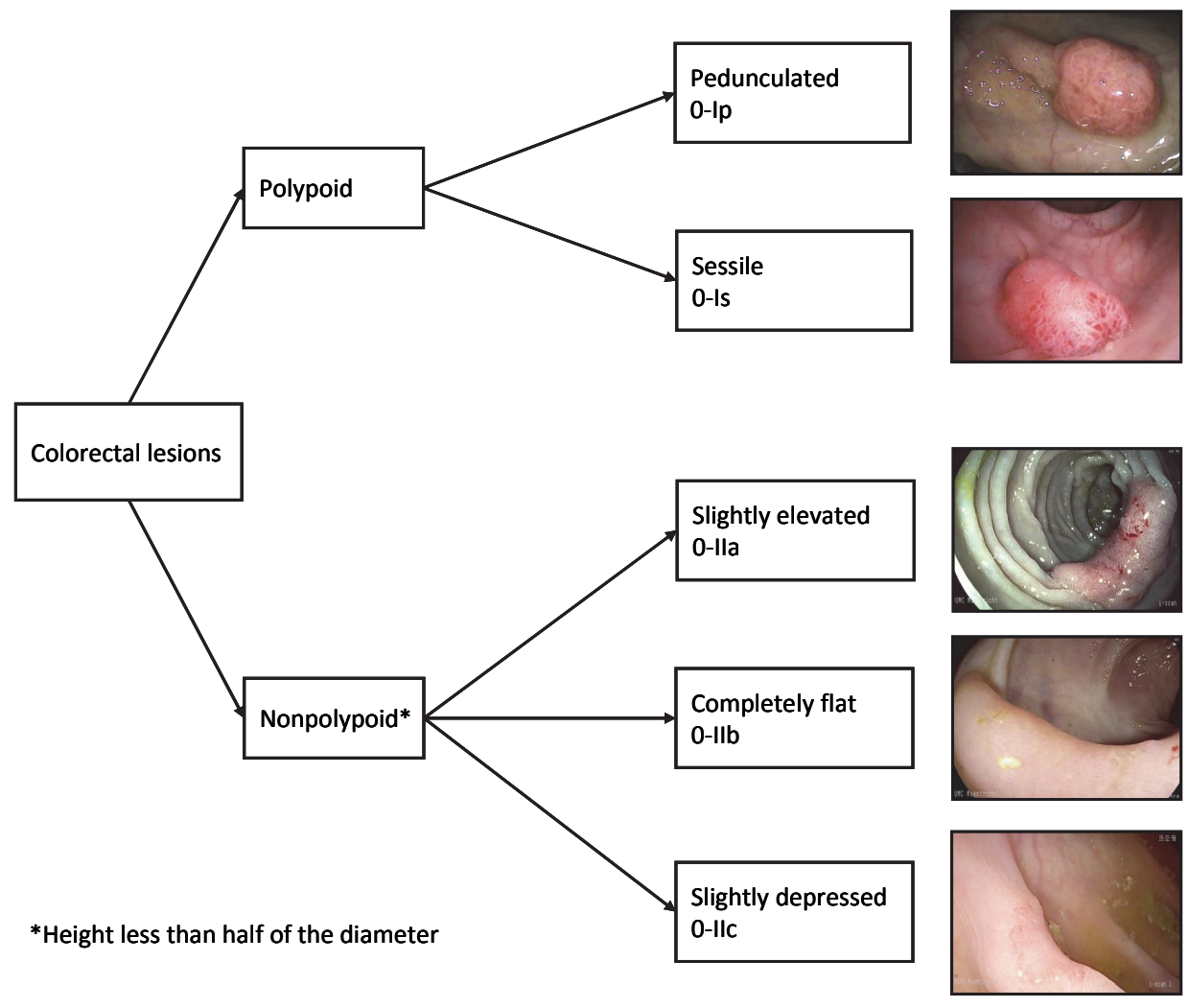

Figure 1.2 Endoscopic classification of colorectal neoplasms 
In Chapter 3, we describe the prevalence and malignant potential of nonpolypoid colorectal adenomas in the Netherlands with focus on gender differences. In Chapter 4, we address the endoscopic appearance of serrated colorectal lesions, in particular of those that harbor risk for malignant transformation, i.e. high-risk serrated lesions. Moreover, we analyze the association of these high-risk serrated lesions with synchronous adenomatous colorectal neoplasms. Chapter $\mathbf{5}$ focuses on differences in endoscopic appearance of colorectal neoplasms according to colonic location. We specifically examine this for adenomas with advanced histology and high-risk serrated lesions. In order to understand the role of the nonpolypoid colorectal carcinogenesis in patients at high-risk for CRC, we examine in Chapter $\mathbf{6}$ the endoscopic appearance of colorectal neoplasms in patients with Lynch syndrome versus subjects at average-risk for CRC. Chapter $\mathbf{7}$ addresses the association between (advanced) colorectal neoplasms and presence of diverticulosis, as a possible indicator of a risk-phenotype. In the last section of this thesis, we explore the molecular profile of NP-CRNs. In Chapter 8, we conduct a systematic review and meta-analysis of current studies on genetic and epigenetic alterations in NP-CRNs. In Chapter 9 we describe the results of a study addressing the frequency of promoter hypermethylation of prominent CRC specific genes in relation to the phenotype of colorectal neoplasms, i.e. nonpolypoid appearance, advanced histology and anatomic location.

Finally, in Chapter 10 we discuss the main findings of this thesis and suggest potential implications for the endoscopy practice and for future research in this area. 


\section{References}

1. Ferlay J, Shin HR, Bray F, Forman D, Mathers C, DM Parkin (2010). "GLOBOCAN 2008 v1.2, Cancer Incidence and Mortality Worldwide: IARC CancerBase No. 10 [Internet]." Retrieved 29/03/2012, from http://globocan.iarc.fr.

2. Integraal Kankercentrum Nederland (2010). "Cijfers over kanker." Retrieved 29-03-2012, from http://cijfersoverkanker.nl/.

3. Muto T, Bussey HJ, Morson BC. The evolution of cancer of the colon and rectum. Cancer 1975;36:2251-70.

4. Winawer SJ, Zauber AG, Ho MN, O'Brien MJ, Gottlieb LS, Sternberg SS, Waye JD, Schapiro M, Bond JH, Panish JF, Ackroyd F, Shike M, Kurtz RC, Hornsby-Lewis L, Gerdes H, Stewart ET, and The National Polyp Study Workgroup. Prevention of colorectal cancer by colonoscopic polypectomy. New Engl J Med 1993;329:1977-81.

5. Lakoff J, Paszat LF, Saskin R, Rabeneck L. Risk of developing proximal versus distal colorectal cancer after a negative colonoscopy: a population-based study. Clin Gastroenterol Hepatol. 2008;6:1117-21

6. Baxter NN, Goldwasser MA, Paszat LF, Saskin R, Urbach DR, Rabeneck L. Association of colonoscopy and death from colorectal cancer. Ann Intern Med 2009;150:1-8.

7. Singh H, Nugent Z, Demers AA, Kliewer EV, Mahmud SM, Bernstein CN. The reduction in colorectal cancer mortality after colonoscopy varies by site of the cancer. Gastroenterology 2010;139:1128-37.

8. Brenner H, Chang-Claude J, Seiler CM, Rickert A, Hoffmeister M. Protection from colorectal cancer after colonoscopy: a population-based, case-control study. Ann Intern Med 2011;154:22-30.

9. Rex DK. Preventing colorectal cancer and cancer mortality with colonoscopy: what we know and what we don't know. Endoscopy 2010;42:320-3.

10. Soetikno R, Friedland S, Kaltenbach T, Chayama K, Tanaka S. Nonpolypoid (flat and depressed) colorectal neoplasms. Gastroenterology 2006;130:566-576.

11. Kaltenbach T, McGill SK, Kalidindi V, Friedland S, Soetikno R. Proficiency in the diagnosis of nonpolypoid colorectal neoplasm yields high adenoma detection rates. Dig Dis Sci 2012;57:764-70.

12. Chiu HM, Lin JT, Lee YC, Liang JT, Shun CT, Wang HP, Wu MS. Different bowel preparation schedule leads to different diagnostic yield of proximal and nonpolypoid colorectal neoplasm at screening colonoscopy in average-risk population. Diseases of the colon and rectum 2011;54:1570-7.

13. Kudo S, Lambert R, Allen JI, Fujii H, Fujii T, Kashida H, Matsuda T, Mori M, Saito H, Shimoda T, Tanaka S, Watanabe H, Sung JJ, Feld AD, Inadomi JM, O'Brien MJ, Lieberman DA, Ransohoff DF, Soetikno RM, Triadafilopoulos G, Zauber A, Teixeira CR, Rey JF, Jaramillo E, Rubio CA, Van Gossum A, Jung M, Vieth $M$, Jass JR, Hurlstone PD. Nonpolypoid neoplastic lesions of the colorectal mucosa. Gastrointest Endosc 2008;68 (Suppl October):S3-47.

14. East JE, Saunders BP, Jass JR. Sporadic and syndromic hyperplastic polyps and serrated adenomas of the colon: classification, molecular genetics, natural history, and clinical management. Gastroenterol Clin North Am 2008;37:25-46.

15. Makinen MJ. Colorectal serrated adenocarcinoma. Histopathology 2007;50:131-50.

16. Kahi CJ, Hewett DG, Norton DL, Eckert GJ, Rex DK. Prevalence and variable detection of proximal colon serrated polyps during screening colonoscopy. Clin Gastroenterol Hepatol 2011;9:42-6.

17. Levin B, Lieberman DA, McFarland B, Andrews KS, Brooks D, Bond J, Dash C, Giardiello FM, Glick S, Johnson D, Johnson CD, Levin TR, Pickhardt PJ, Rex DK, Smith RA, Thorson A, Winawer SJ. Screening and surveillance for the early detection of colorectal cancer and adenomatous polyps, 2008: a joint guideline from the American Cancer Society, the US Multi-Society Task Force on Colorectal Cancer, and the American College of Radiology. Gastroenterology 2008;134:1570-95.

18. Muto T, Kamiya J, Sawada T, Konishi F, Sugihara K, Kubota Y, Adachi M, Agawa S, Saito Y, Morioka Y, Tanprayoon T. Small "flat adenoma" of the large bowel with special reference to its clinicopathologic features. Dis Colon Rectum 1985;28:847-51.

19. Sanduleanu S, Rondagh EJ, Masclee AA. Development of expertise in the detection and classification of non-polypoid colorectal neoplasia: Experience-based data at an academic GI unit. Gastrointest Endosc Clin N Am. 2010;20:449-60.

20. Health Council of the Netherlands. A national colorectal cancer screening programme. The Hague: Health Council of the Netherlands, 2009; publication no. 2009/13E. 
21. Vasen HF, Abdirahman M, Brohet R, Langers AM, Kleibeuker JH, van Kouwen M, Koornstra JJ, Boot $H$, Cats A, Dekker E, Sanduleanu S, Poley JW, Hardwick JC, de Vos Tot Nederveen Cappel WH, van der Meulen-de Jong AE, Tan TG, Jacobs MA, Mohamed FL, de Boer SY, van de Meeberg PC, Verhulst ML, Salemans JM, van Bentem N, Westerveld BD, Vecht J, Nagengast FM. One to 2-year surveillance intervals reduce risk of colorectal cancer in families with Lynch syndrome. Gastroenterology 2010;138:2300-6.

22. de Vos tot Nederveen Cappel WH, Nagengast FM, Griffioen G, Menko FH, Taal BG, Kleibeuker JH, Vasen HF. Surveillance for hereditary nonpolyposis colorectal cancer: a long-term study on 114 families. Dis Colon Rectum 2002;45:1588-94.

23. Jarvinen HJ, Renkonen-Sinisalo L, Aktan-Collan K, Peltomaki P, Aaltonen LA, Mecklin JP. Ten years after mutation testing for Lynch syndrome: cancer incidence and outcome in mutation-positive and mutation-negative family members. J Clin Oncol 2009;27:4793-7.

24. Mecklin JP, Aarnio M, Laara E, Kairaluoma MV, Pylvanainen K, Peltomaki P, Aaltonen LA, Jarvinen HJ. Development of colorectal tumors in colonoscopic surveillance in Lynch syndrome. Gastroenterology 2007;133:1093-8.

25. Watanabe T, Muto T. Colorectal carcinogenesis based on molecular biology of early colorectal cancer, with special reference to nonpolypoid (superficial) lesions. World J Surg 2000;24:1091-1097.

26. Takahashi T, Nosho K, Yamamoto H, Mikami M, Taniguchi H, Miyamoto N, Adachi Y, Itoh F, Imai K, Shinomura Y. Flat-type colorectal advanced adenomas (laterally spreading tumors) have different genetic and epigenetic alterations from protruded-type advanced adenomas. Mod Pathol 2007;20:139-47.

27. Fujii T, Rembacken BJ, Dixon MF, Yoshida S, Axon AT. Flat adenomas in the United Kingdom: are treatable cancers being missed? Endoscopy 1998;30:437-443.

28. Hurlstone DP, Cross SS, Adam I, Shorthouse AJ, Brown S, Sanders DS, Lobo AJ. A prospective clinicopathological and endoscopic evaluation of flat and depressed colorectal lesions in the United Kingdom. Am J Gastroenterol 2003;98:2543-2549.

29. Rembacken BJ, Fujii T, Cairns A, Dixon MF, Yoshida S, Chalmers DM, Axon AT. Flat and depressed colonic neoplasms: a prospective study of 1000 colonoscopies in the UK. Lancet 2000;355:1211-1214.

30. Saitoh Y, Waxman I, West AB, Popnikolov NK, Gatalica Z, Watari J, Obara T, Kohgo Y, Pasricha PJ. Prevalence and distinctive biologic features of flat colorectal adenomas in a North American population. Gastroenterology 2001;120:1657-1665.

31. Soetikno RM, Kaltenbach T, Rouse RV, Park W, Maheshwari A, Sato T, Matsui S, Friedland S. Prevalence of nonpolypoid (flat and depressed) colorectal neoplasms in asymptomatic and symptomatic adults. JAMA 2008;299:1027-1035.

32. Tsuda S, Veress B, Toth E, Fork FT. Flat and depressed colorectal tumours in a southern Swedish population: a prospective chromoendoscopic and histopathological study. Gut 2002;51:550-555.

33. Singh $\mathrm{H}$, Nugent $\mathrm{Z}$, Demers AA, Bernstein $\mathrm{CN}$. Rate and predictors of early/missed colorectal cancers after colonoscopy in manitoba: a population-based study. Am J Gastroenterol 2010;105:2588-96.

34. Bressler B, Paszat LF, Chen Z, Rothwell DM, Vinden C, Rabeneck L. Rates of New or Missed Colorectal Cancers After Colonoscopy and Their Risk Factors: A Population-Based Analysis. Gastroenterology 2007;132:96-102.

35. Distler P, Holt PR. Are right- and left-sided colon neoplasms distinct tumors? Dig Dis 1997;15:302-11.

36. lacopetta B. Are there two sides to colorectal cancer? Int J Cancer 2002;101:403-8.

37. Li FY, Lai MD. Colorectal cancer, one entity or three. J Zhejiang Univ Sci B 2009;10:219-29.

38. Roy HK, Bianchi LK. Differences in colon adenomas and carcinomas among women and men: potential clinical implications. JAMA 2009;302:1696-1697.

39. Shinya H, Wolff WI. Morphology, anatomic distribution and cancer potential of colonic polyps. Ann Surg 1979;190:679-83.

40. Sillars-Hardebol AH, Carvalho B, van Engeland M, Fijneman RJ, Meijer GA. The adenoma hunt in colorectal cancer screening: defining the target. J Pathol 2012;226:1-6.

41. Terry MB, Neugut AI, Bostick RM, Potter JD, Haile RW, Fenoglio-Preiser CM. Reliability in the classification of advanced colorectal adenomas. Cancer Epidemiol Biomarkers Prev 2002;11:660-3. 
Chapter 1

42. Costantini M, Sciallero S, Giannini A, Gatteschi B, Rinaldi P, Lanzanova G, Bonelli L, Casetti T, Bertinelli E, Giuliani O, Castiglione G, Mantellini P, Naldoni C, Bruzzi P. Interobserver agreement in the histologic diagnosis of colorectal polyps. the experience of the multicenter adenoma colorectal study (SMAC). J Clin Epidemiol 2003;56:209-14. 


\section{Chapter 2}

Development of expertise in the detection and classification of nonpolypoid colorectal neoplasia:

experience-based data at an academic GI unit 


\section{Introduction}

Colorectal cancer (CRC) is an important healthcare issue worldwide. ${ }^{1}$ According to the World Health Organization, there are approximately 1,000,000 new diagnoses of CRC each year, with mortality of more than $500,000 .^{2}$ The socioeconomic impact of this problem provided the drive for rapidly expanding screening programs. In general, accurate detection and removal of the precursor lesions - colorectal adenomas - are considered to be powerful tools for fighting against CRC. ${ }^{3}$ Unexpectedly, however, in routine practice, the protection against CRC offered by colonoscopic screening is far from perfect. ${ }^{4,7} \mathrm{~A}$ recent study by Baxter and colleagues demonstrated that although colonoscopy was associated with decreased risk of subsequent CRC in the left side, no protective effect was found against cancers located on the right side of the colon. ${ }^{7}$ Why may colonoscopy so far fail to prevent CRCs?

Some polyps are simply not recognized because of patient-related factors, e.g. suboptimal bowel preparation, inefficient withdrawal technique, or difficult anatomical conditions. ${ }^{8,9}$ Other polyps are missed as a consequence of insufficient awareness and training of the endoscopist, nonpolypoid colorectal neoplasms (NPCRNs) being an illustrative example in this regard. ${ }^{10,11}$ An increasing body of evidence presently indicates that NP-CRNs are common lesions worldwide. ${ }^{12-25}$ Detection and management of some of these lesions may prove to be more challenging, raising the hypothesis that these lesions may be at the origin of interval cancers.

In addition, surveillance practices after polypectomy are based on clinicopathologic features of adenomas, namely size, multiplicity, presence of any villous component and grade of dysplasia. ${ }^{3,26}$ Unfortunately, evaluation and recording of these features in routine practice frequently lack precision and proper standardization, making it difficult to draw firm conclusions regarding follow-up intervals. All of these practical limitations eventually highlight the need to secure the quality of colonoscopic examination, if interval cancers are to be prevented. It is reasonable to presume that high-quality colonoscopic practices will offer in turn considerable potential to refine the diagnosis of colorectal neoplasia, and hence, to delineate subgroups of patients truly at risk for developing CRC. Implementation of such risk-stratification strategies and personalized medical care can ultimately lead to appropriate redirection of the limited economic resources. ${ }^{26}$

At its core, quality improvement in gastrointestinal (GI) practice relies on continuous training, education and information among all health care providers, whether gastroenterologists, GI trainees, endoscopy nurses, or Gl pathologists. Over the past few years, it became clear that objective criteria are needed to assess the quality of colonoscopy, such as cecum intubation rate, quality of bowel preparation, withdrawal time and adenoma detection rate. ${ }^{8}$ In this context, development of competence among practicing endoscopists to adequately detect and treat NP-CRNs deserves 
special attention. We describe a summary of the path to develop expertise in detection and management of NP-CRNs, based on experience at our academic GI unit.

\section{The learning pyramid}

For simplicity, let's look at the well-known learning-pyramid, by Miller, ${ }^{27}$ as illustrated in Figure 2.1. In general, development of practical skills is a stepwise process, starting with acquisition of basic knowledge, followed by in-depth information and development of practical skills - the so-called know-how and show-how -, and finally exposure to concrete practical situations. If we extrapolate this model to the practice of GI endoscopy, in particular development of expertise in diagnosis of NP-CRN, the following scenarios are possible:

- Imagine you are supervising a young GI trainee who performs a colonoscopy. The trainee tells you he or she identified a lesion in the right colon, but cannot find it again during withdrawal. You take over, but also without success. Three years later the patient is diagnosed with an interval cancer, probably emerging from a missed lesion at the same location. What would you do now? You would probably seek to review literature data pertaining to origins of interval cancers and discuss these with your students, to improve clinical awareness in this regard.

- Image again you are supervising a more experienced trainee. The trainee detects a large lesion with apparently flat morphology, but unfortunately he or she is not able to find it again during withdrawal. You tell the trainee that some of these lesions may herald the risk to more rapidly evolve into CRC. You take over and after careful inspection and selective chromoendoscopy, find a lateral spreading polyp, and remove it. It turns out to be a high-grade dysplastic adenoma. It is clear that mastering know-how about detection and showing-how these lesions should be correctly managed are essential steps in providing endoscopy training in this regard.

- Now imagine that the same trainee (meanwhile in the past year) detects a lesion and after evaluation with selective chromoendoscopy, describes it as a flat lesion with a central depression. The trainee properly lifts it with $\mathrm{NaCl} 9 \%$ and removes it in toto. It turns out to be a high-grade dysplastic adenoma. You tell the trainee that he or she did a very good job! 


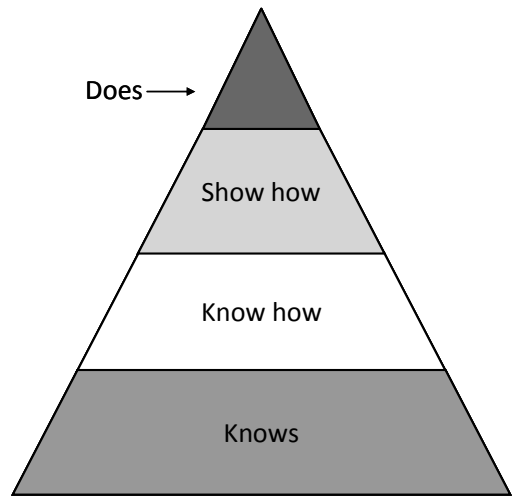

Figure $2.1 \quad$ Learning pyramid by Miller (adapted) ${ }^{27}$

\section{The development of the De Novo Expertise in NP-CRN at Maastricht}

In real life, the issue of developing expertise in detection and management of NP-CRN in current practice can be broken down into a number of questions:

\section{Why is knowledge about NP-CRN important?}

Without a proper understanding of the clinical relevance of NP-CRNs, it is impossible to say whether concerns related to underdetection of these lesions are legitimate or whether these reflect semantic differences only. The earliest reports concerning NP-CRNs coincided with technological progress in Gl endoscopy, namely use of chromoendoscopy, magnification techniques, and high-resolution imaging. ${ }^{13,28-30}$ Numerous studies, dating back in the early 1990s correlated some of these lesions with more aggressive histopathological features. ${ }^{12,31}$ Table 2.1 provides an overview of some of these studies, with focus on methodology, prevalence of CRNs in general, prevalence of NP-CRNs, and association with severe histopathology. Pooling data from these studies, it appears that prevalence of NP-CRNs ranges from 3 to $24 \%$ (mean, $8.1 \%$ ), while prevalence of Paris type II-c $\mathrm{c}^{32}$ lesions is very low (1-2\%), however, a large proportion of Paris type II-c lesions harbor advanced histopathology (mean prevalence, $55.4 \%$, range $0-100 \%)$. 


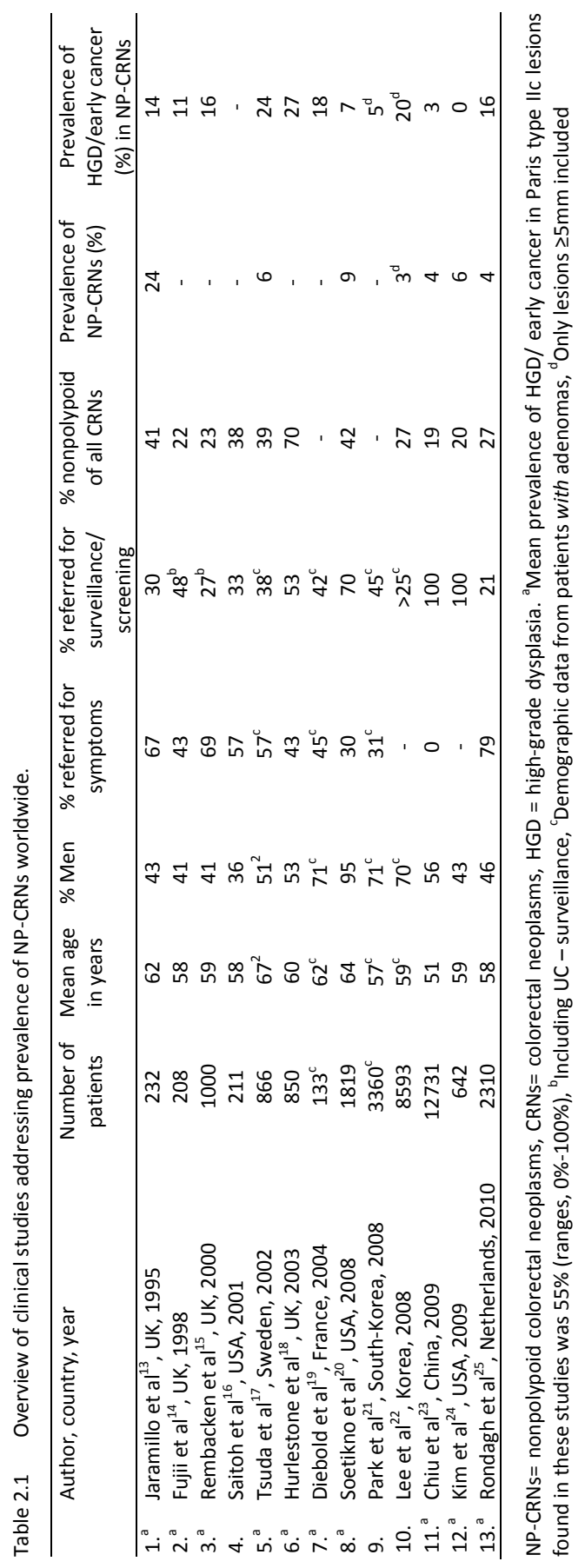


The clinical message emerging from these studies is that i) prevalence of NP-CRNs in the Western population is comparable with the initially reported data from Japan: the relatively wide variation in prevalence among different studies may reflect dissent in endoscopic definition and geographic differences, but most probably different levels of clinical awareness, education and training; ii) a subset of these lesions is more difficult to detect and to manage endoscopically; iii) also, a subset of these lesions, especially Paris type II-c, although relatively uncommon, are more frequently associated with advanced histopathology. Given the expected increase in incidence of CRC in the foreseeable future, and the major impact of colonoscopic screening on Gl practices worldwide, it is mandatory to provide our trainees with appropriate education in this regard.

\section{How can we develop expertise in detection of flat adenomas?}

Traditionally, education and training in Gl endoscopy were practice-based. Nowadays, the theory and practice of education are undergoing fundamental changes. Multimedia information systems are facilitating continuous updating and pooling of information and knowledge. The expansion of tele-teaching, tele-learning and teleconferencing over the past years permits virtual connection and real-time dialog of gastroenterologists, worldwide. ${ }^{33,34}$ This allows transfer of knowledge and experience from expertise centers to academic or nonacademic Gl practices, without limits of distance or borders. In an original study, Kaltenbach and colleagues ${ }^{35}$ addressed the role of tele-teaching in Gl endoscopy. Live, interactive, high-resolution, uncompressed video transmission was used, by means of Digital Video Transport Systems. Trainees, faculty, and staff at 3 international endoscopy units participated in this prospective study. Pre-lecture and post-lecture scores were recorded, showing that this model is technically feasible and highly efficient in Gl endoscopy training, at affordable costs. Alternatively, simulator training has evolved over the past years faster than before ${ }^{36} \mathrm{~A}$ Dutch study using the Symbionix GI Mentor II simulator (Simbionix Ltd., Israel) advocates implementation of this program in training of novice endoscopists. ${ }^{37}$ Further development of this software may also help endoscopists achieve competence regarding recognition and treatment of NP-CRNs. Conceivably, testing and continuous evaluation of knowledge and practical skills in this field are essential to maintain adequate educational level.

In an attempt to improve the quality of colonoscopic examination, with emphasis on detection of NP-CRNs, we have undertaken a prospective study at our academic center. Figure 2.2 depicts the study design. Before beginning this study, a series of topic lectures were presented by a dedicated colonoscopist (S.S.), to provide general theoretical insight into the epidemiology, and pathophysiology, including molecular aspects, clinical detection and endoscopic removal of these lesions. Video-training was then offered using accredited programs, ${ }^{38,39}$ as well as continuous feed-back and 
supervision during endoscopy. Finally, all 16 endoscopists at our GI unit, 9 staffmembers and 7 trainees, embarked on this study, addressing the prevalence and clinicopathologic features of NP-CRNs in a Dutch population. Between February 2008 and February 2009, clinical, endoscopic and histopathological data from 2310 consecutive patients referred for routine colonoscopy were recorded. Standardized endoscopy reports, including digital photographic documentation were available from all patients. Special attention was paid to recording of quality indicators. Our GI endoscopy unit offers secondary, and tertiary care, and serves a total population of approximately 200,000 . To ensure accurate classification of flat lesions in this nonexpert setting, a simplified definition was used, as previously proposed. ${ }^{11}$ Table 2.2 summarizes the characteristics of the study population.

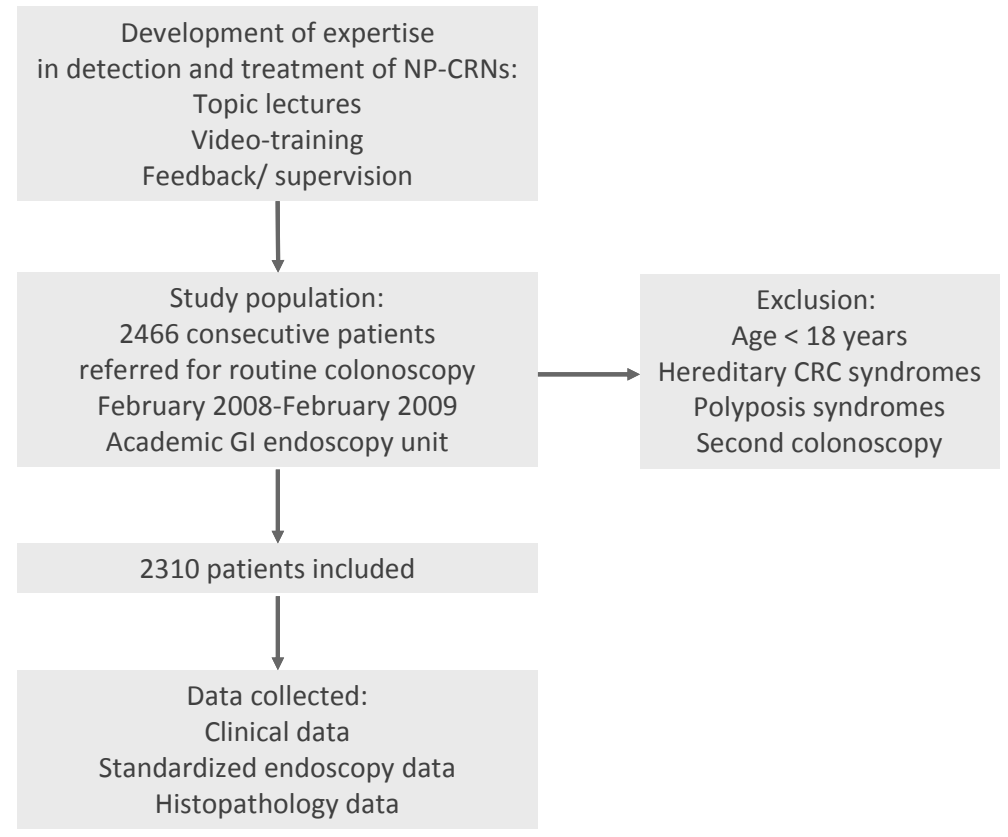

Figure 2.2 Algorithm of study design.

\section{What do we have to know about treatment of these lesions?}

Several literature data are available on the treatment of nonpolypoid lesions. ${ }^{40-43}$ Before beginning our study, we reviewed basic principles regarding detection, classification and management of nonpolypoid lesions. In addition, using video-training programs, we learned some practical tips regarding detection of NP-CRNs. Besides careful inspection, dynamic evaluation of focal lesions after insufflation/ desufflation of air can assist in evaluation of morphology, and eventually allow visualization of a 
central depression. Selective chromoendoscopy using indigo-carmine $0.4 \%$ was used to better delineate the borders before endoscopic removal (Figure 2.3). To reduce peristalsis, enhance visualization of lesions, and facilitate their removal, buthylscopolamine was injected intravenously, when indicated. Finally, we used the inject and cut endoscopic mucosal resection (EMR) technique to resect NP-CRNs, as described elsewhere. ${ }^{20}$ Lesions that could not be managed endoscopically were marked with ink to assist the surgeon during subsequent intraoperative removal.

Table 2.2 Characteristics of study population.

\begin{tabular}{ll}
\hline Number of patients & 2310 \\
Males (\%) & 46.1 \\
Age (mean, range), years & 58.4 (18-93) \\
Indication colonoscopy & \\
$\quad$ - Symptoms (\%) & 79.4 \\
$\quad$ - Screening/ surveillance (\%) & 20.6 \\
Previous history of CRC (\%) & 3.1 \\
Familial CRC (\%) & 1.9 \\
Inflammatory bowel diseases (\%) & 9.8 \\
Patients with $\geq 1$ adenoma (\%) & 26.8 \\
Patients with $\geq 1$ flat adenoma (\%) & 4.2 \\
\hline
\end{tabular}

$\mathrm{CRC}=$ colorectal cancer .

\section{What is the learning curve for the endoscopist?}

So far, studies that systematically address this issue have not been published. Nevertheless, given rapidly growing literature data within this field, this question should be relatively easy and inexpensive to answer.

Perhaps not surprisingly, in our experience, after relatively short, intensive training with regard to recognition of NP-CRNs, similar detection rates were found among staff gastroenterologists and GI trainees (Figure 2.4). Hence, it appears that clinical awareness rather than general experience of the endoscopist is likely to play a critical role in the detection of these lesions. Another interesting aspect is that prevalence of flat lesions in our study population (4.2\%) was comparable with prevalence data reported in other Western populations, further supporting the efficacy of this training model. 


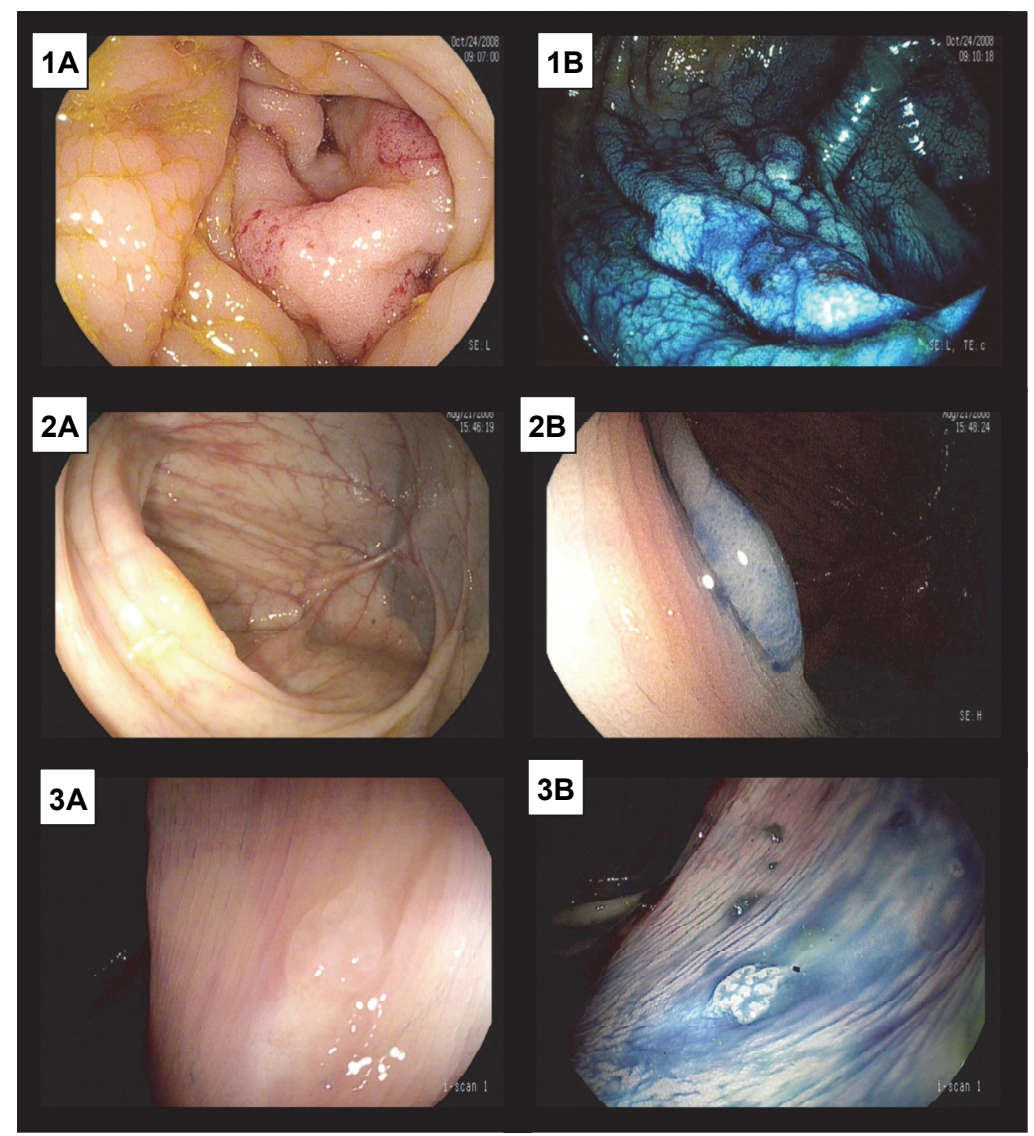

Figure 2.3 Nonpolypoid colorectal lesions before (A) and after (B) selective chromoendoscopy. 1 Lateral spreading tumor of granular type detected in the cecum. Histological examination of the surgical specimen showed a tubulovillous adenoma with high-grade dysplasia. 2 Nonpolypoid lesion detected at the hepatic flexure after applying selective chromoendoscopy. Histological examination showed a hyperplastic polyp. 3 Diminutive nonpolypoid lesion detected in the ascending colon. Histological examination showed a tubular adenoma with low-grade dysplasia.

\section{Should detection of flat adenomas be a quality indicator in training of Gl endoscopists?}

Probably yes, albeit the expected prevalence may be subject to large variation and remains to be further defined. Reporting of prevalence of flat adenomas should be probably related to other quality indicators. In our experience, the cecum intubation rate was $90.2 \%$ in the symptomatic population, and $95.0 \%$ in the screening/ 
surveillance population, which is in agreement with international recommendations. Also, we reported an adenoma prevalence of $40.4 \%$ in males and of $28.2 \%$ in females older than 50 years of age, which is higher than the reported average data. ${ }^{9}$

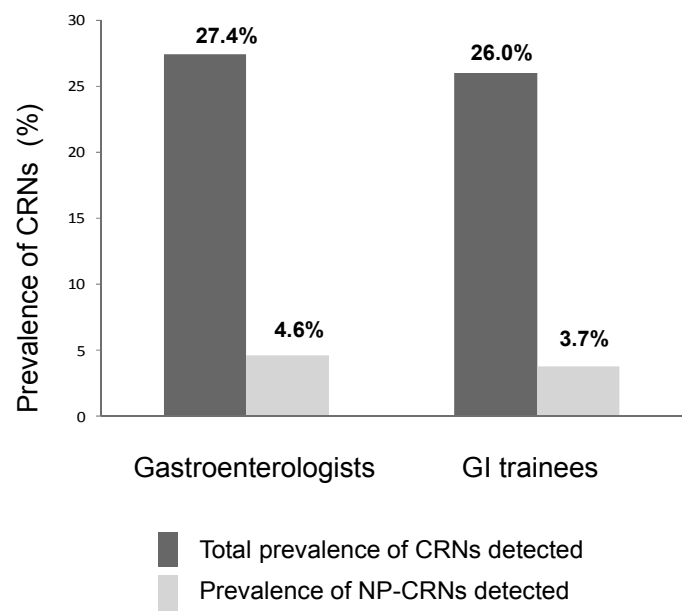

Figure 2.4 Similar detection rates of total CRNs and of NP-CRNs were found among staffgastroenterologists and $\mathrm{Gl}$ trainees.

$\mathrm{GI}=$ gastrointestinal, $\mathrm{CRNs}=$ colorectal neoplasms, $\mathrm{NP}-\mathrm{CRNs}=$ nonpolypoid colorectal neoplasms

\section{What are some of the unanswered questions about NP-CRN today?}

First, the question arises whether morphologic classification of colorectal lesions, according to the Paris classification, should be regarded as a valuable clinical instrument or rather a scientific one. As this classification is based on expert opinions, its prospective validation is needed in the future. One may argue that proper classification of colorectal lesions is likely to increase precision and uniformity in recording of data, and hence may allow fine tuning of surveillance programs. In view of this, it is probably also an important step in education of Gl trainees. A second question is whether flat or sessile morphology makes any difference in small lesions. Because there is relatively much room for subjective interpretation in this regard, it is reasonable to assume that such differentiation is less important, when it concerns Paris type II-a (flat-elevated) lesions. Efforts should be made, however, to detect, accurately classify, and completely remove even small type II-b or II-c lesions, as these are associated with more severe histopathology. Third, it would be desirable to define in the future risk groups that are more likely to herald nonpolypoid colorectal lesions. Special attention should be offered to patients with hereditary forms of CRC, in 
particular those with Lynch syndrome, as they seem to frequently harbor such lesions. ${ }^{44,45}$ Associations of NP-CRNs with different phenotypic or genotypic features may permit customizing of screening recommendations, and hence, increase the efficiency of screening programs. Finally, prospective, follow-up studies of patients harboring NP-CRNs are needed to bring more light on the biologic behavior of these lesions. Needless to say, all these issues can be clarified only if gastroenterologists and pathologists will join in their efforts to diagnose and classify colorectal neoplasia as objectively, uniformly and reliably as possible.

\section{Summary}

Based on sound clinical data, we can conclude that accurate detection of NP-CRNs is important and should be incorporated into Gl educational programs. Diagnosis and management of some of these lesions in routine practice may be technically challenging. Also, a subset of these lesions may herald advanced histopathology. Our experience in this field adds a further piece of evidence to the mosaic of clinical data indicating that worldwide training in recognition and management of NP-CRNs warrants further consideration if prevention of CRC is to be optimized. It is plausible that clinical awareness prevails upon experience in diagnosis of these lesions, although this hypothesis should be further tested. Finally, the key-message for the endoscopist, irrespective of level of education and practical experience, is that continuously training and "retraining our eyes" is important not only for saving more lives, but also for learning new essential lessons about CRC prevention. 


\section{References}

1. Jemal A., Siegel R., Ward E., Hao Y., Xu J., Thun M. J. Cancer statistics, 2009. CA Cancer J Clin 2009;59:225-49.

2. Ferlay J, Bray Freddie, Pisani Paola, Parkin D Max GLOBOCAN 2002: Cancer Incidence, Mortality and Prevalence Worldwide IARC CancerBase No. 5. version 2.0. IARCPress, Lyon 2004.

3. Winawer S. J., Zauber A. G., Ho M. N., O'Brien M. J., Gottlieb L. S., Sternberg S. S., Waye J. D., Schapiro M., Bond J. H., Panish J. F. Prevention of colorectal cancer by colonoscopic polypectomy. The National Polyp Study Workgroup. N Engl J Med 1993;329:1977-81.

4. Singh H., Turner D., Xue L., Targownik L. E., Bernstein C. N. Risk of developing colorectal cancer following a negative colonoscopy examination: evidence for a 10-year interval between colonoscopies. JAMA 2006;295:2366-73.

5. Bressler Brian, Paszat Lawrence F., Chen Zhongliang, Rothwell Deanna M., Vinden Chris, Rabeneck Linda. Rates of New or Missed Colorectal Cancers After Colonoscopy and Their Risk Factors: A Population-Based Analysis. Gastroenterology 2007;132:96-102.

6. Lakoff Josh, Paszat Lawrence F., Saskin Refik, Rabeneck Linda. Risk of Developing Proximal Versus Distal Colorectal Cancer After a Negative Colonoscopy: A Population-Based Study. Clinical Gastroenterology and Hepatology 2008;6:1117-21.

7. Baxter N. N., Goldwasser M. A., Paszat L. F., Saskin R., Urbach D. R., Rabeneck L. Association of colonoscopy and death from colorectal cancer. Ann Intern Med 2009;150:1-8.

8. Rex D. K., Cutler C. S., Lemmel G. T., Rahmani E. Y., Clark D. W., Helper D. J., Lehman G. A., Mark D. G. Colonoscopic miss rates of adenomas determined by back-to-back colonoscopies. Gastroenterology 1997;112:24-8.

9. Rex Douglas K., Petrini John L., Baron Todd H., Chak Amitabh, Cohen Jonathan, Deal Stephen E., Hoffman Brenda, Jacobson Brian C., Mergener Klaus, Petersen Bret T., Safdi Michael A., Faigel Douglas O., Pike Irving M. Quality indicators for colonoscopy. Gastrointestinal Endoscopy 2006;63:S16-S28.

10. Kudo S., Lambert R., Allen J. I., Fujii H., Fujii T., Kashida H., Matsuda T., Mori M., Saito H., Shimoda T., Tanaka S., Watanabe H., Sung J. J., Feld A. D., Inadomi J. M., O'Brien M. J., Lieberman D. A., Ransohoff D. F., Soetikno R. M., Triadafilopoulos G., Zauber A., Teixeira C. R., Rey J. F., Jaramillo E., Rubio C. A., Van Gossum A., Jung M., Vieth M., Jass J. R., Hurlstone P. D. Nonpolypoid neoplastic lesions of the colorectal mucosa. Gastrointest Endosc 2008;68:S3-47.

11. Soetikno R., Friedland S., Kaltenbach T., Chayama K., Tanaka S. Nonpolypoid (flat and depressed) colorectal neoplasms. Gastroenterology 2006;130:566-76; quiz 588-9.

12. Kudo S., Kashida H., Tamura T., Kogure E., Imai Y., Yamano H., Hart A. R. Colonoscopic diagnosis and management of nonpolypoid early colorectal cancer. World J Surg 2000;24:1081-90.

13. Jaramillo E., Watanabe M., Slezak P., Rubio C. Flat neoplastic lesions of the colon and rectum detected by high-resolution video endoscopy and chromoscopy. Gastrointest Endosc 1995;42:114-22.

14. Fujii T., Rembacken B. J., Dixon M. F., Yoshida S., Axon A. T. Flat adenomas in the United Kingdom: are treatable cancers being missed? Endoscopy 1998;30:437-43.

15. Rembacken B. J., Fujii T., Cairns A., Dixon M. F., Yoshida S., Chalmers D. M., Axon A. T. R. Flat and depressed colonic neoplasms: a prospective study of 1000 colonoscopies in the UK. The Lancet 2000;355:1211-4.

16. Saitoh Y., Waxman I., West A. B., Popnikolov N. K., Gatalica Z., Watari J., Obara T., Kohgo Y., Pasricha P. J. Prevalence and distinctive biologic features of flat colorectal adenomas in a North American population. Gastroenterology 2001;120:1657-65.

17. Tsuda S., Veress B., Toth E., Fork F. T. Flat and depressed colorectal tumours in a southern Swedish population: a prospective chromoendoscopic and histopathological study. Gut 2002;51:550-5.

18. Hurlstone David P., Cross Simon S., Adam Ian, Shorthouse Andrew J., Brown Steven, Sanders David S., Lobo Alan J. A prospective clinicopathological and endoscopic evaluation of flat and depressed colorectal lesions in the United Kingdom. Am J Gastroenterol 2003;98:2543-9.

19. Diebold Marie-Danile, Samalin Emmanuelle, Merle Corinne, Bouche Olivier, Higuero Thierry, Jolly Damien, Ramaholimihaso Fidy, Renard Pascal, Yaziji Nahla, Thiefin Grard, Cadiot Guillaume. Colonic Flat Neoplasia: Frequency and Concordance Between Endoscopic Appearance and Histological Diagnosis in a French Prospective Series. Am J Gastroenterol 2004;99:1795-1800. 
20. Soetikno R. M., Kaltenbach T., Rouse R. V., Park W., Maheshwari A., Sato T., Matsui S., Friedland S. Prevalence of nonpolypoid (flat and depressed) colorectal neoplasms in asymptomatic and symptomatic adults. Jama 2008;299:1027-35.

21. Park D. H., Kim H. S., Kim W. H., Kim T. I., Kim Y. H., Park D. I., Kim H. J., Yang S. K., Byeon J. S., Lee M. S., Chung I. K., Jung S. A., Jeen Y. T., Choi J. H., Choi H., Han D. S. Clinicopathologic characteristics and malignant potential of colorectal flat neoplasia compared with that of polypoid neoplasia. Dis Colon Rectum 2008;51:43-9; discussion 49.

22. Kil Lee S., II Kim T., Kwan Shin S., Ho Kim W., Kim H., Kyu Kim N. Comparison of the clinicopathologic features between flat and polypoid adenoma. Scand J Gastroenterol 2008;43:1116-21.

23. Chiu Han-Mo, Lin Jaw-Town, Chen Chien-Chuan, Lee Yi-Chia, Liao Wei-Chih, Liang Jin-Tung, Shun ChiaTung, Wang Hsiu-Po, Wu Ming-Shiang. Prevalence and Characteristics of Nonpolypoid Colorectal Neoplasm in an Asymptomatic and Average-Risk Chinese Population. Clinical Gastroenterology and Hepatology 2009;7:463-70.

24. Kim J., Rami P., O'Toole J., Llor X., Carroll R. E., Benya R. V. Prevalence and Size of Flat Neoplasms in a Heterogeneous Population Undergoing Routine Colorectal Cancer Screening. Colorectal Dis 2009;12:471-6.

25. Rondagh E, van der Valk M, Winkens B, de Bruine A, Masclee A, Sanduleanu S. Nonpolypoid (flat and depressed) colorectal neoplasms in women are more likely to contain advanced histology. DDW 2010 (abstract).

26. Winawer S., Fletcher R., Rex D., Bond J., Burt R., Ferrucci J., Ganiats T., Levin T., Woolf S., Johnson D., Kirk L., Litin S., Simmang C. Colorectal cancer screening and surveillance: clinical guidelines and rationale-Update based on new evidence. Gastroenterology 2003;124:544-60.

27. Miller G. E. The assessment of clinical skills/competence/performance. Acad Med 1990;65:S63-7.

28. Muto T, Kamiya J, Sawada T, Konishi F, Sugihara K, Kubota Y, Adachi M, Agawa S, Saito Y, Morioka Y, Tanprayoon T. Small "flat adenoma" of the large bowel with special reference to its clinicopathologic features. Dis Colon Rectum 1985;28:847-51.

29. Kudo S., Tamura S., Hirota S., Sano Y., Yamano H., Serizawa M., Fukuoka T., Mitsuoka H., Nakajima T., Kusaka H. The problem of de novo colorectal carcinoma. Eur J Cancer 1995;31A:1118-20.

30. Tanaka S., Haruma K., Oka S., Takahashi R., Kunihiro M., Kitadai Y., Yoshihara M., Shimamoto F., Chayama K. Clinicopathologic features and endoscopic treatment of superficially spreading colorectal neoplasms larger than 20 mm. Gastrointest Endosc 2001;54:62-6.

31. Leong A. F., Seow-Choen F., Tang C. L. Diminutive cancers of the colon and rectum: comparison between flat and polypoid cancers. Int J Colorectal Dis 1998;13:151-3.

32. The Paris endoscopic classification of superficial neoplastic lesions: esophagus, stomach, and colon: November 30 to December 1, 2002. Gastrointest Endosc 2003;58:S3-43.

33. Strode S. W., Gustke S., Allen A. Technical and clinical progress in telemedicine. Jama 1999;281:1066-8.

34. Rabenstein T., Maiss J., Naegele-Jackson S., Liebl K., Hengstenberg T., Radespiel-Troger M., Holleczek P., Hahn E. G., Sackmann M. Tele-endoscopy: influence of data compression, bandwidth and simulated impairments on the usability of real-time digital video endoscopy transmissions for medical diagnoses. Endoscopy 2002;34:703-10.

35. Kaltenbach T., Muto M., Soetikno R., Dev P., Okamura K., Hahm J., Shimizu S. Teleteaching endoscopy: the feasibility of real-time, uncompressed video transmission by using advanced-network technologies. Gastrointest Endosc 2009;70:1013-7.

36. Haycock A. V., Youd P., Bassett P., Saunders B. P., Tekkis P., Thomas-Gibson S. Simulator training improves practical skills in therapeutic GI endoscopy: results from a randomized, blinded, controlled study. Gastrointest Endosc 2009;70:835-45.

37. Koch A. D., Buzink S. N., Heemskerk J., Botden S. M., Veenendaal R., Jakimowicz J. J., Schoon E. J. Expert and construct validity of the Simbionix GI Mentor II endoscopy simulator for colonoscopy. Surg Endosc 2008;22:158-62

38. Rex Douglas K. Colonoscopic Polypectomy. DVD ASGE Endoscopic Learning Library, 2007.

39. Soetikno Roy M. , Barro Jennifer, Friedland Shai, Matsui Suzanne, Rouse Robert, Fujii Takahiro. Diagnosis of Flat and Depressed Colorectal Neoplasms. DVD ASGE Endoscopic Learning Library, 2006.

40. Kudo S. Endoscopic mucosal resection of flat and depressed types of early colorectal cancer. Endoscopy 1993;25:455-61. 
41. Kaltenbach T., Friedland S., Maheshwari A., Ouyang D., Rouse R. V., Wren S., Soetikno R. Short- and long-term outcomes of standardized EMR of nonpolypoid (flat and depressed) colorectal lesions $>$ or $=$ $1 \mathrm{~cm}$ (with video). Gastrointest Endosc 2007;65:857-65.

42. Kaltenbach T., Soetikno R. Endoscopic mucosal resection of non-polypoid colorectal neoplasm. Gastrointestinal endoscopy clinics of North America 2010;20:503-14.

43. Soetikno R., Kaltenbach T. Dynamic submucosal injection technique. Gastrointestinal endoscopy clinics of North America 2010;20:497-502.

44. Hurlstone D. P., Karajeh M., Cross S. S., McAlindon M. E., Brown S., Hunter M. D., Sanders D. S. The role of high-magnification-chromoscopic colonoscopy in hereditary nonpolyposis colorectal cancer screening: a prospective "back-to-back" endoscopic study. Am J Gastroenterol 2005;100:2167-73.

45. Lynch H. T., Smyrk T., Lanspa S. J., Marcus J. N., Kriegler M., Lynch J. F., Appelman H. D. Flat adenomas in a colon cancer-prone kindred. J Natl Cancer Inst 1988;80:278-82. 


\section{Chapter 3}

\section{Nonpolypoid colorectal neoplasms:}

gender differences in prevalence and malignant potential

Eveline JA Rondagh, Ad AM Masclee, Mirthe E van der Valk, Bjorn Winkens, Adriaan P de Bruïne, Tonya Kaltenbach, Roy M Soetikno, Silvia Sanduleanu Scand J Gastroenterol. 2012;47:80-88 


\section{Abstract}

\section{Objective}

Colonoscopy may fail to prevent colorectal cancer, especially in the proximal colon and in women. Nonpolypoid colorectal neoplasms may potentially explain some of these post-colonoscopy cancers. In the present study, we aimed to examine the prevalence and malignant potential of nonpolypoid colorectal neoplasms in a large population, with special attention to gender and location.

\section{Methods}

We performed a cross-sectional study of all consecutive patients undergoing elective colonoscopy at a single academic medical center. The endoscopists were familiarized on the detection and treatment of nonpolypoid lesions. Advanced histology was defined by the presence of high-grade dysplasia or early cancer.

\section{Results}

We included 2310 patients (53.9\% women, mean age 58.4 years) with 2143 colorectal polyps. Prevalences of colorectal neoplasms and nonpolypoid colorectal neoplasms were lower in women than in men $(20.9 \%$ vs. $33.7 \%, P<0.001$ and $3.0 \%$ vs. $5.5 \%, P=0.002$ ). In women, nonpolypoid colorectal neoplasms were significantly more likely to contain advanced histology than polypoid ones (OR $2.89,95 \% \mathrm{Cl} 1.24-6.74, P=0.01$ ), while this was not the case in men (OR 0.91, 95\% Cl 0.40-2.06, $P=0.83$ ). Proximal neoplasms with advanced histology were more likely to be nonpolypoid than distal ones (OR 4.68, 95\% $\mathrm{Cl} 1.54-14.2, P=0.006$ ).

\section{Conclusion}

Nonpolypoid mechanisms may play an important role in colorectal carcinogenesis, in both women and men. Although women have fewer colorectal neoplasms than men, they have nonpolypoid colorectal neoplasms, which frequently contain advanced histology. 


\section{Introduction}

The effectiveness of conventional colonoscopy has recently been challenged by a number of studies that have reported its limitations to prevent the development of colorectal cancer (CRC), especially in the proximal colon ${ }^{1}$ and in women. ${ }^{2,3}$ Nonpolypoid colorectal neoplasms (NP-CRNs) have been suspected to explain some of the post-colonoscopy cancers, ${ }^{4,5}$ as these lesions are more easily overlooked, ${ }^{6,7}$ their removal requires technical expertise, and some of them are more likely to contain advanced histopathology. ${ }^{8-11}$ Although NP-CRNs were previously described solely in Japan, recent studies have confirmed their existence in the West and other Eastern countries, with prevalences ranging from 4.2 to $34.1 \%{ }^{9,10,12-16}$ These findings together indicate that accurate detection and removal of NP-CRNs are important targets for improving the quality of colonoscopic cancer prevention.

A recent study by Singh et $\mathrm{al}^{2}$ indicated that women may have an increased risk to develop CRC early (within 3 years) after a clearing colonoscopy. Whether gender differences in prevalences and malignant potential of colorectal neoplasms (CRNs) may explain the occurrence of these post-colonoscopy cancers is presently not clear. We therefore hypothesized that women are more likely to develop CRC through nonpolypoid colorectal lesions. ${ }^{17}$ Insights into the potential gender differences in colorectal carcinogenesis may allow tailoring of preventive strategies with regard to age of initiation, endoscopic techniques and surveillance.

In this cross-sectional study, we addressed the prevalence and malignant potential of NP-CRNs, with special attention to the impact of gender and anatomic location.

\section{Methods}

\section{Study design}

We performed a cross-sectional, single center study to investigate the prevalence and clinicopathologic features of NP-CRNs in a large number of patients. Before commencing on this study, all endoscopists at the Division of Gastroenterology and Hepatology of the Maastricht University Medical Center in the Netherlands were trained in order to familiarize them on the detection and management of NP-CRNs. ${ }^{18,19}$ This training consisted of: i) lectures, by an experienced colonoscopist (S.S.), ii) videotraining using accredited programs ${ }^{20,21}$ and iii) feedback and supervision during colonoscopy. We discussed the prevalence of NP-CRNs, how to recognize, classify and remove them and their histopathologic features. ${ }^{5,22}$ Special attention was paid to current targets for quality colonoscopy such as detection of adenomas and cecal intubation rate. ${ }^{23,24}$ 


\section{Study Population}

Between February 2008 and February 2009, all patients referred for routine colonoscopy at our gastrointestinal (GI) endoscopy unit were prospectively included in this study. Indications for colonoscopy were symptoms, surveillance (postpolypectomy or CRC resection) or screening. We excluded patients aged $<18$ years or those with a hereditary CRC syndrome (i.e., Lynch syndrome or known polyposis syndromes). Patients with a positive family history of CRC, but without a known gene mutation, that is, familial CRC patients, were included in the analysis. Familial CRC was defined by the presence of at least threefold increased risk for CRC. ${ }^{25}$

In patients who underwent two colonoscopies during the study period, we evaluated data only from one colonoscopy. For example, index colonoscopy data were used when a second colonoscopy was performed due to onset of new symptoms, polypectomy or control after polypectomy. In cases of poor bowel preparation requiring a second-look colonoscopy, data corresponding to the second colonoscopy were used.

\section{Colonoscopy}

Patients received 3-4 I polyethylene glycol solution for bowel preparation. Colonoscopies were performed by nine gastroenterologists and seven trainees, using high-resolution Pentax endoscopes. The endoscopists were not aware of the main hypotheses of this study. In alignment with previous studies, ${ }^{9-12,26,27}$ we defined NPCRNs as colorectal lesions with a height $<1 / 2$ diameter. This definition combines careful endoscopic examination with objective measurement and is therefore a simple and useful tool in routine practice. According to the Paris-Japanese classification, we further classified nonpolypoid lesions into slightly elevated (0-Ila), completely flat (0-IIb) or slightly depressed (0-IIc) lesions. ${ }^{4,28}$ Selective chromoendoscopy was used, when needed, to clarify the borders of NP-CRNs before endoscopic removal, as illustrated in Figure 3.1. Size of colorectal lesions was estimated visually using a standard biopsy forceps or mini-snare. Colorectal lesions were subdivided according to size into i) diminutive ( $\leq 5 \mathrm{~mm})$, ii) small $(6-9 \mathrm{~mm})$ and iii) large ( $\geq 10 \mathrm{~mm}$ ) and according to location into i) proximal: from cecum to splenic flexure or ii) distal: from descending colon to rectum. Colonoscopic examinations were documented prospectively using a standardized reporting system, including digital photographic documentation. Finally, lesions were removed endoscopically by cold biopsy, snare polypectomy, endoscopic mucosal resection (EMR), or by surgery. ${ }^{29,30}$ The study was approved by the Institutional Review Board of the Maastricht University Medical Center, which waived the need for individual informed consent (MEC 08-4-074). 


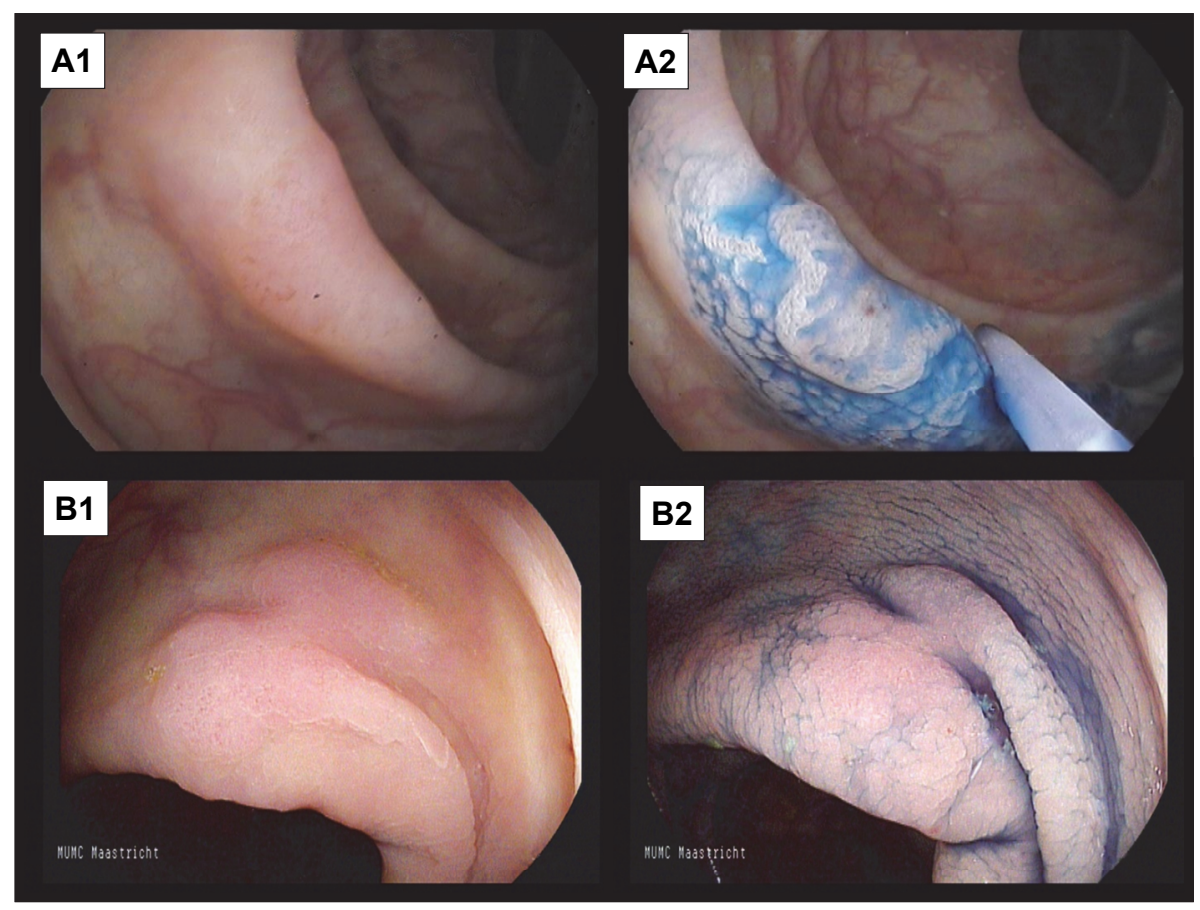

Figure 3.1 Detection and classification of a nonpolypoid adenoma using selective chromoendoscopy. On conventional white light examination, we detected a slightly enlarged fold with discrete erythema (A1 and B1).

After we sprayed $0.4 \%$ indigo-carmine locally, we could visualize a slightly elevated (Paris type 0 -Ila) lesion. Selective chromoendoscopy clarified the borders of the lesion, allowing adequate classification and removal (A2 and B2).

\section{Histopathology}

In this study, CRNs were defined as either adenomas or early carcinomas. The presence of advanced histology, defined as high-grade dysplasia (HGD) or early CRC, was assessed by two experienced GI pathologists using the WHO classification. ${ }^{31}$ Early CRC was defined as CRC limited to the submucosa (T1). Advanced carcinomas, defined as carcinomas invading the muscularis propria, were not included in the present study. In addition, serrated adenomas were not included these analyses, but separately presented, ${ }^{19}$ as these lesions may progress into carcinomas through a different (serrated) pathway. ${ }^{32}$ 


\section{Statistical analysis}

The outcome measure of this study was the presence of $H G D / e a r l y C R C$ in polypoid and NP-CRNs. Multiple logistic regression analyses including age, gender, location, size, and endoscopic appearance were carried out to determine independent risk factors for the presence of HGD/early CRC in CRNs. To examine potential effect modification on the presence of HGD/early CRC in NP-CRNs, separate analyses were performed in men and women. The results were verified using a random intercept model adjusting for potential correlations due to presence of more than one polyp in the same patient, as described elsewhere. ${ }^{33}$ The effect of age on the presence of CRNs with advanced histology in men and women was explored using a multiple logistic regression model, including interaction terms. Linearity assumption was assessed by adding and testing a centered quadratic term.

Differences in dichotomous variables were examined using the chi-square test or Fisher's exact test, when appropriate. Based on previous data, showing HGD/early CRC in $8 \%$ of the polypoid CRNs and $16 \%$ of the NP-CRNs and a prevalence of 0.20 polypoid CRNs and 0.12 NP-CRNs per patient, ${ }^{11}$ a sample size of 2000 patients would give a power of at least $80 \%$ to detect a significant difference between NP-CRNs and polypoid CRNs with regard to presence of HGD/early CRC. All statistical analyses were performed using SPSS 15.0 (SPSS, Chicago, Illinois). Additionally, SAS Proc Glimmix (SAS Institute Inc., North Carolina, USA) was used to construct the random intercept model. All odds ratios $(\mathrm{OR})$ are presented with $95 \%$ confidence intervals $(\mathrm{Cl})$. Two-sided $P$-values $\leq 0.05$ were considered statistically significant.

\section{Results}

\section{Study population}

Between February 2008 and February 2009, a total of 2466 patients were referred for routine colonoscopy at our Gl endoscopy unit. We excluded 7 patients aged $<18$ years and 20 patients having a hereditary CRC syndrome. In addition, 129 patients underwent a second colonoscopy during the study period: 31 due to onset of new symptoms, 23 for polypectomy, 38 for control after polypectomy and 37 because of poor bowel preparation requiring a second-look colonoscopy (men=17; women=20). Finally, we included 2310 consecutive patients (1245 women, mean age 57.1 years; 1065 men, mean age 59.8 years). The demographic and clinicopathologic characteristics of the study population are presented in Table 3.1. The majority (80.5\%) of colonoscopies were performed because of symptoms (e.g. rectal blood loss, abdominal complaints, anemia). The overall cecal intubation rate in this population was $91.2 \%$, namely $90.2 \%$ in symptomatic and $95.3 \%$ in asymptomatic patients. No significant differences were found between gastroenterologists and $\mathrm{Gl}$ trainees regarding the cecal intubation rate: $92.2 \%$ vs. $90.0 \%(P=0.07)$. 
Table 3.1 Characteristics of the study population.

\begin{tabular}{lccc}
\hline & Total population & Women & Men \\
\hline Study population, $\mathrm{n}(\%)$ & 2310 & $1245(53.9)$ & $1065(46.1)$ \\
Mean age, y (SD) & $58.4(16.2)$ & $57.1(17.2)$ & $59.8(14.8)$ \\
Indication for colonoscopy & & & \\
$\quad$ Symptoms, $\mathrm{n}(\%)$ & $1860(80.5)$ & $1040(83.5)$ & $820(77.0)$ \\
Surveillance, $\mathrm{n}(\%)$ & $287(12.4)$ & $119(9.6)$ & $168(15.8)$ \\
Screening, $\mathrm{n}(\%)$ & $163(7.1)$ & $86(6.9)$ & $77(7.2)$ \\
Previous history of CRC, $\mathrm{n}(\%)$ & $78(3.4)$ & $35(2.8)$ & $43(4.0)$ \\
Familial CRC, $\mathrm{n}(\%)$ & $43(1.9)$ & $26(2.1)$ & $17(1.6)$ \\
Inflammatory bowel disease, $\mathrm{n}(\%)$ & $227(9.8)$ & $122(9.8)$ & $105(9.9)$ \\
Previous colon resection, $\mathrm{n}(\%)$ & $159(6.9)$ & $93(7.5)$ & $66(6.2)$ \\
\hline
\end{tabular}

$\mathrm{SD}=$ standard deviation, $\mathrm{CRC}=$ colorectal cancer.

\section{Prevalence of colorectal neoplasms}

Overall, $26.8 \%$ of the patients had at least one CRN, irrespective of endoscopic appearance, and $4.2 \%$ had at least one NP-CRN (Table 3.2). No significant differences were found between gastroenterologists and $\mathrm{Gl}$ trainees regarding prevalences of detected CRNs: $27.4 \%$ vs. $26.0 \%(P=0.44)$ and of detected NP-CRNs: $4.6 \%$ vs. $3.7 \%$, $(P=0.28)$, respectively.

Table 3.2 shows that women have a lower prevalence of both CRNs and NP-CRNs than men. With regard to the prevalence of CRNs harboring HGD/early CRC, no gender significant differences were found. Of note, in patients aged $\geq 50$ years $(n=1682), 28.2 \%$ of women and $40.4 \%$ of men had $\geq 1$ CRN, while $4.2 \%$ of women and $6.6 \%$ of men had $\geq 1$ NP-CRN.

Table 3.2 Prevalences of colorectal neoplasms in women $(n=1245)$ and men $(n=1065)$.

\begin{tabular}{lccccccc}
\hline & $\begin{array}{c}\text { Total } \\
\text { population }\end{array}$ & Women & Men & \multicolumn{3}{c}{ Women vs. Men $^{\text {a }}$} \\
& $\mathrm{n}(\%)$ & $\mathrm{n}(\%)$ & $\mathrm{n}(\%)$ & $\mathrm{OR}$ & $95 \% \mathrm{Cl}$ & $P$-value \\
\hline Patients with $\geq 1$ CRNs & $619(26.8)$ & $260(20.9)$ & $359(33.7)$ & 0.54 & $0.44-0.65$ & $<0.001$ \\
Patients with $\geq 1$ NP-CRNs & $96(4.2)$ & $37(3.0)$ & $59(5.5)$ & 0.55 & $0.36-0.84$ & 0.005 \\
Patients with HGD/early CRC & $97(4.2)$ & $46(3.7)$ & $51(4.8)$ & 0.80 & $0.53-1.21$ & 0.30 \\
\hline
\end{tabular}

${ }^{a}$ Adjusted for age. $\mathrm{OR}=$ odds ratio, $\mathrm{Cl}=$ confidence interval, $\mathrm{CRN}=$ colorectal neoplasm,

$\mathrm{NP}-\mathrm{CRN}=$ nonpolypoid colorectal neoplasm, $\mathrm{HGD}=$ high-grade dysplasia, $\mathrm{CRC}=$ colorectal cancer.

Mean age of women and men having $\geq 1$ CRN was similar ( 65.0 vs. 66.3 years, $P=0.14$ ), while women having $\geq 1$ CRN containing HGD/early CRC were significantly younger than men ( 63.7 vs. 69.2 years, $P=0.02$ ). Figure 3.2 further clarifies the relation between age, gender and prevalence of $\geq 1$ CRN with HGD/early CRC. In women, the prevalence of $\geq 1$ CRN with advanced histology appears to increase at the age of 50 years and to stabilize afterward. In men, by contrast, this prevalence seems to gradually increase after the 
age of 50 years. Multiple logistic regression analysis, including interaction terms, showed that the effect of age (continuous) on the prevalence of CRNs with advanced histology was significantly $(P=0.004)$ different in women vs. men.

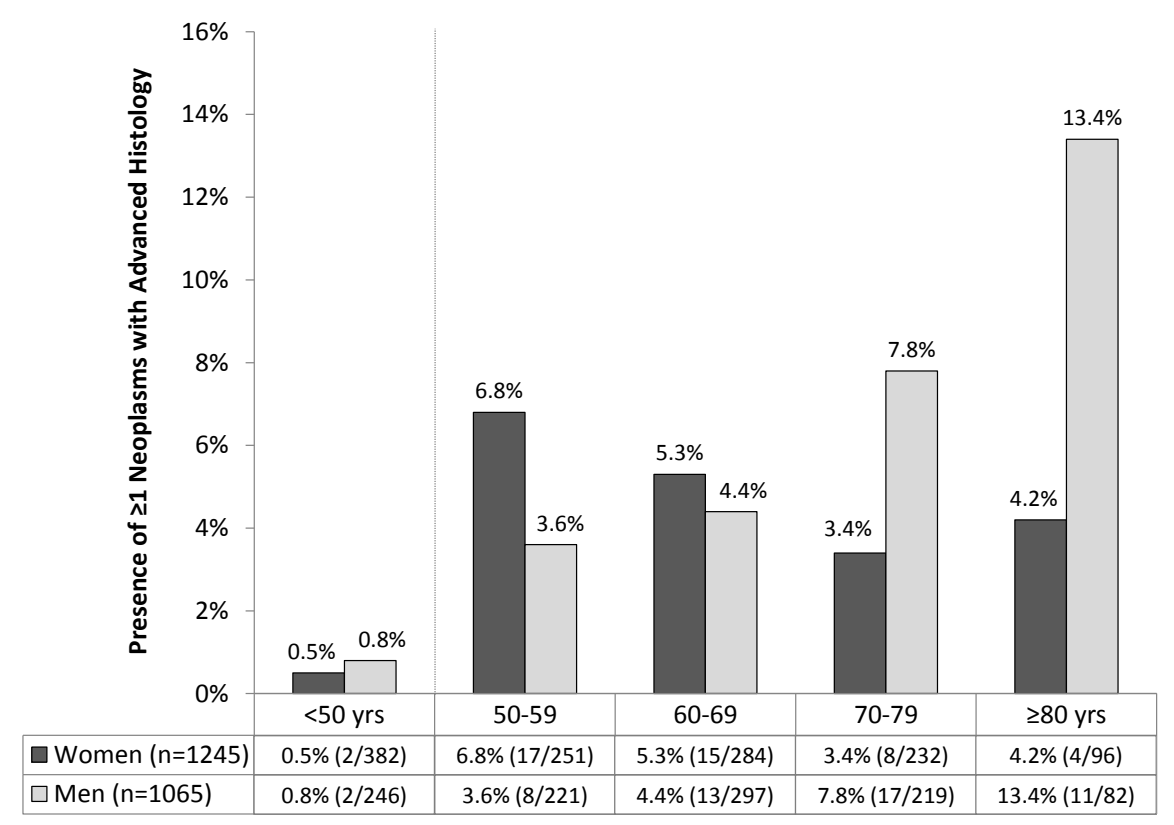

Figure 3.2 Prevalences of colorectal neoplasms with advanced histology in women and men, stratified by age.

In total, 97 patients (46 women and 51 men) had at least one colorectal neoplasm containing advanced histology. In women, the prevalence of $\geq 1$ CRN with advanced histology appears to increase after the age of 50 years and to stabilize afterward. In contrast, in men, this prevalence seems to gradually increase after the age of 50 years. The effect of age on the prevalence of neoplasms containing advanced histology was significantly different in women vs. men $(P=0.004)$.

\section{Predictors of advanced histology in colorectal neoplasms}

In total, 2143 colorectal lesions were detected in 2310 patients (0.93 per patient). Of these, 1167 were CRNs (adenomas and early cancers), of which 431 were found in women (Supplementary Table 3.1). Of all CRNs, 11.1\% (129/1167) had a nonpolypoid appearance. We found 4 slightly depressed (0-IIC) CRNs, of which 3 harbored HGD/early CRC. Overall, NP-CRNs harbored more frequently HGD/early CRC than polypoid CRNs: $15.5 \%$ (20/129) vs. $8.7 \%$ (90/1038), $P=0.01$ (Table 3.3). However, multiple logistic regression analysis (including age, gender, location, size and endoscopic appearance) showed that, overall, size $\geq 10 \mathrm{~mm}$ (OR $6.82,95 \% \mathrm{Cl}$ 4.42-10.52, $P<0.001$ ) and distal location (OR 1.88, 95\% Cl 1.20-2.96, $P=0.006$ ) were 
independent predictors for the presence of HGD/early CRC in CRNs. Nonpolypoid appearance was not independently associated with HGD/early CRC (OR $1.58,95 \% \mathrm{Cl}$ $0.89-2.81, P=0.12)$.

Table 3.3 Presence of advanced histology in colorectal neoplasms, stratified by gender.

\begin{tabular}{cllllll}
\hline & Total & Women & \multicolumn{2}{l}{ Men } & \multicolumn{2}{l}{ Women vs. Men (reference) } \\
& $\mathrm{n}(\%)$ & $\mathrm{n}(\%)$ & $\mathrm{n}(\%)$ & $\mathrm{OR}$ & $95 \% \mathrm{Cl}$ & $P$-value \\
\hline Polypoid CRN & 1038 & 384 & 654 & & & \\
HGD/ early CRC & $90(8.7)$ & $42(10.9)$ & $48(7.3)$ & $1.30^{\mathrm{a}}$ & $0.81-2.06$ & 0.27 \\
Nonpolypoid CRN & 129 & 47 & 82 & & & \\
HGD/ early CRC & $20(15.5)$ & $10(21.3)$ & $10(12.2)$ & $3.26^{\mathrm{a}}$ & $1.08-9.88$ & 0.04 \\
Slightly elevated (0-IIa) & 122 & 43 & 79 & & & \\
HGD/early CRC & $17(13.9)$ & $9(20.9)$ & $8(10.1)$ & & & \\
Flat (0-IIb) & 3 & 2 & 1 & & \\
HGD/early CRC & $0(0)$ & $0(0)$ & $0(0)$ & & & \\
Slightly depressed (0-IIc) & 4 & 2 & 2 & & \\
HGD/early CRC & $3(75)$ & $1(50)$ & $2(100)$ & & & \\
All CRN & 1167 & 431 & 736 & & \\
HGD/early CRC & $110(9.4)$ & $52(12.1)$ & $58(7.9)$ & & & \\
\hline
\end{tabular}

${ }^{a}$ Adjusted for age, size and location. $\mathrm{OR}=$ odds ratio, $\mathrm{Cl}=$ confidence interval, $\mathrm{CRN}=$ colorectal neoplasm, $\mathrm{HGD}=$ high-grade dysplasia, $\mathrm{CRC}=$ colorectal cancer.

Table 3.3 describes the presence of HGD/early CRC in CRNs in men and women. NP-CRNs in women, were more likely to contain advanced histology than those in men (OR 3.26, 95\% Cl 1.08-9.88, $P=0.04$ ). To analyze the association between NP-CRNs and advanced histology, we performed multiple logistic regression analyses, including potential other risk factors (i.e. age, location and size), in women and men separately (Table 3.4). Herewith we found that, in women, NP-CRNs were more likely to contain HGD/early CRC than polypoid CRNs, namely $21.3 \%$ (10/47) vs. $10.9 \%$ (42/384), adjusted $\mathrm{OR} 2.89,95 \% \mathrm{Cl} 1.24-6.74, P=0.01$. In men, by contrast, no significant difference was found between nonpolypoid and polypoid CRNs with regard to the prevalence of HGD/early CRC: $12.2 \%$ (10/82) vs. $7.3 \%$ (48/654), adjusted OR $0.91,95 \%$ $\mathrm{Cl}$ 0.40-2.06, $P=0.83$.

Separate analyses were conducted, showing that indication for colonoscopy, presence of familial CRC or inflammatory bowel disease did not significantly alter the risk for HGD/early CRC in colorectal neoplasms (Supplementary Table S3.2). 
Table 3.4 Multiple logistic regression analyses stratified by gender. Outcome: presence of high-grade dysplasia or early colorectal cancer in colorectal neoplasms.

\begin{tabular}{lcccccc}
\hline & \multicolumn{3}{c}{ Women $(\mathrm{n}=431)$} & \multicolumn{3}{c}{ Men $(\mathrm{n}=736)$} \\
& OR & $95 \% \mathrm{Cl}$ & $P$-value & OR & $95 \% \mathrm{Cl}$ & $P$-value \\
\hline Age (continuous) & 0.98 & $0.95-1.00$ & 0.10 & 1.03 & $1.00-1.07$ & 0.04 \\
Distal location (vs. proximal) & 2.54 & $1.21-5.31$ & 0.01 & 1.59 & $0.88-2.87$ & 0.13 \\
Size $\geq 10 \mathrm{~mm}$ (vs. <10 mm) & 6.05 & $3.13-11.7$ & $<0.001$ & 8.40 & $4.61-15.3$ & $<0.001$ \\
Nonpolypoid appearance (vs. polypoid) & 2.89 & $1.24-6.74$ & 0.01 & 0.91 & $0.40-2.06$ & 0.83 \\
\hline
\end{tabular}

$\mathrm{OR}=$ odds ratio, $\mathrm{Cl}$ = confidence interval.

\section{Nonpolypoid colorectal neoplasms with advanced histology in relation to location}

A total of 581 proximal and 586 distal CRNs were found. Proximal CRNs were more often nonpolypoid than distal ones: $13.3 \%$ vs. $8.9 \%, P=0.02$. Likewise, CRNs with $\mathrm{HGD} /$ early CRC were more often nonpolypoid in the proximal than in the distal colon: $30.6 \%(11 / 36)$ vs. $12.2 \%(9 / 74), P=0.02$. This difference between the proximal and distal colon was especially found in women, in which $41.7 \%(5 / 12)$ of the proximal CRNs with HGD/early CRC vs. only $12.5 \%$ (5/40) of the distal ones were nonpolypoid, $P=0.04$.

Multiple logistic regression analysis (adjusting for age, gender and size) showed that proximal colorectal lesions with HGD/early CRC were more likely to be nonpolypoid than distal ones (OR 4.68, 95\% Cl 1.54-14.20, $P=0.006$ ). Excluding patients with a previous colon resection did not alter this finding (OR 5.76, 95\% $\mathrm{Cl} 1.72-19.3, P=0.005$ ).

\section{Discussion}

The present study indicates that detection of NP-CRNs is important in both men and women for the prevention of CRC. We found gender differences in prevalence and malignant potential of (nonpolypoid) CRNs. That is, although women have fewer CRNs than men, they have NP-CRNs that frequently contain advanced histology.

This observation extends and further substantiates recent data by Singh et al and Bressler et al showing that within 3 years after a (negative) colonoscopy, women have a higher risk for CRC than men. ${ }^{2,3}$ These cancers occurring early after colonoscopy are most likely to arise from missed lesions, in which nonpolypoid mechanisms may play a significant role. A recent meta-analysis by Nguyen et al, ${ }^{34}$ showed that (advanced) CRNs are found more frequently in men, arguing for earlier initiation of CRC prevention in men. At first glance, our data showing that NP-CRNs in women frequently contain advanced histology may imply that physicians should not underestimate the prevention of CRC in women. Second, the current study may shed some light on the adenoma carcinoma paradox in women, that is, even though women have less 
adenomas than men, their life-time risk for CRC is comparable with that of men. Although this discrepancy may simply reflect the increased life expectancy of women, ${ }^{35}$ our study suggests a significant role of nonpolypoid mechanisms in the development of CRC in women. Gender differences in colorectal carcinogenesis may be of relevance, as these may permit fine-tuning of preventive strategies, with regard to age of initiation, endoscopic techniques and surveillance.

The etiology of gender differences in the colorectal carcinogenesis remains unclear. Possible explanations are distinct hormonal and life-style factors, of which the latter might have changed dramatically during the past decades. Hormone replacement therapy in postmenopausal women has been shown to reduce CRC risk. ${ }^{36}$ Stimulation of the estrogen receptor $\beta$, which modulates colonic cell proliferation and apoptosis, as well as influence of estrogen on bile acids and glucose homeostasis, may possibly play a role in this regard. ${ }^{36,37}$ In addition, it has been suggested that susceptibilities for certain risk factors are different among men and women. For example, women might be more susceptible for developing CRC due to smoking, ${ }^{38}$ but less susceptible for CRC due to obesity. ${ }^{39}$ Although only few data are available on environmental risk factors for NP-CRNs, a recent study by Anderson et al showed that smoking was independently associated with (advanced) NP-CRNs. ${ }^{40}$

In the present study, we further explored the relation between age and prevalence of advanced histology in men and women. We found that in both men and women, the prevalence of CRNs containing advanced histology increases after the age of 50 years. In women, however, this prevalence seems to stabilize afterward, while in men it appears to increase gradually. We hypothesize that hormonal changes related to menopause or changes in life-style of women over the past decades may explain this finding.

In agreement with previous data, we found that $4.2 \%$ of the study patients had at least one NP-CRN. In other Western studies prevalences of NP-CRNs ranged from 5.3 to $34.1 \%{ }^{9,10,12-15}$ The study by Soetikno et al found a prevalence of NP-CRNs of $9.3 \%$ in an older, predominantly male population..$^{9}$ In a subgroup analysis of symptomatic patients, the prevalence was $6.0 \%,{ }^{9}$ which is in line with our data, in a predominantly symptomatic population. A recent study addressing the prevalence of NP-CRNs in a large Italian population, found in 5.3\% of the patients NP lesions, either adenomas or hyperplastic polyps. The proportion of CRNs being nonpolypoid was higher (24.5\%) than in our population (11.1\%). ${ }^{14}$ However, this study applied a different definition for NP-CRNs and dealt with larger neoplasms ( $\geq 5 \mathrm{~mm}$ ) only, which makes it difficult to compare these findings with our data. Finally, in a study using pancolonic chromoendoscopy, the prevalence of NP-CRNs was found to be $34.1 \% .{ }^{15}$ It is evident that the relatively wide variation in prevalences of NP-CRNs among different studies may reflect differences in endoscopic definitions or technologies used, differences in demographic features and risk profile (e.g. life-style factors) of study populations, as well as different levels of awareness and training of endoscopists in the detection of these lesions. ${ }^{18}$ 
In the present study, we found that depressed type (0-IIc) lesions are uncommon, yet these lesions frequently contained HGD/early CRC, in agreement with previously published data. ${ }^{4,5}$ In contrast to other studies ${ }^{9-11}$ suggesting that all NP-CRNs may have increased risk to contain HGD/ early cancer, in this study nonpolypoid endoscopic appearance solely was not an independent predictor for advanced histology. It should be noted, however, that nonpolypoid and polypoid CRNs may represent in fact a morphological continuum of which the precise progression mechanisms are still largely unknown. It remains unclear whether the depressed CRNs are truly biologically different entities, and molecular studies are needed in the future to clarify this issue. ${ }^{41,42}$

Recently, Baxter et al reported that colonoscopy reduces deaths from distal CRC (OR 0.33), but not from proximal (OR 0.99) CRC. ${ }^{1}$ In the present study, we found that distal CRNs are more likely to contain advanced histology than proximal CRNs. However, the majority of the distal CRNs with advanced histology (87.8\%) display - an easily recognizable - polypoid shape. On the opposite, proximal CRNs are less likely to contain HGD/early CRC, but a significant proportion of them (30.6\%) display a nonpolypoid shape. This may imply that (advanced) CRNs in the proximal colon are more likely to be missed, thereby partially explaining the predominant proximal location of postcolonoscopy cancers.

Unlike previous Western studies, in which a limited number of trained endoscopists were involved, ${ }^{8-11}$ in our study all 16 endoscopists (faculties and trainees) participated. Prior to commencing on this study, we familiarized the endoscopists on the detection, diagnosis and treatment of the NP-CRNs, with special attention for the current targets for quality of colonoscopy. ${ }^{23,24}$ Prevalence of polypoid and NP-CRNs detected in this study was comparable with data from other Western studies, ${ }^{9,10,12-14}$ implicating that a short systematic training in detection and diagnosis of NP-CRNs is effective, and that it should be widely available in academic and non-academic settings, if quality of colonoscopic cancer prevention is to be optimized. This study, performed at a GI endoscopy unit, which provides secondary and tertiary care for a population of approximately 200,000 inhabitants, provides in fact a survey of the current Dutch endoscopy practice.

Some methodological limitations of this study need to be further addressed. First, we realize that although the study was conducted in a large cohort of patients, the main results are based on a relatively limited number of cases, especially in some of the subset analyses, and that a definite conclusion regarding gender differences in colorectal carcinogenesis cannot be derived. Second, in an attempt to describe our everyday practice, we included all consecutive symptomatic and asymptomatic patients referred for elective colonoscopy. The current findings may therefore not necessarily be applicable to a genuine screening population. Separate analyses were conducted, showing that indication for colonoscopy did not significantly alter the main results and outcome of this study. Nevertheless, the present data need to be further confirmed through large studies in screening populations, before drawing conclusions 
with respect to the relevance for CRC prevention. So far, the current study indicates that nonpolypoid mechanisms may explain some post-colonoscopy cancers in women, early after a (negative) colonoscopy. ${ }^{2}$

In conclusion, in both men and women, detection of NP-CRNs is important for prevention of CRC. Although women have fewer CRNs, CRC prevention in women should not be underestimated, as they have NP-CRNs, which frequently contain HGD/early cancer. Training with regard to detection, diagnosis and treatment of NPCRNs should be offered to all practicing colonoscopists to ultimately improve the effectiveness of colonoscopic cancer prevention.

Supplementary Table S3.1 Histopathology of 2143 colorectal lesions.

\begin{tabular}{lcrrr}
\hline & \multicolumn{2}{c}{ Nonpolypoid lesions } & \multicolumn{2}{c}{ Polypoid lesions } \\
& Women & Men & Women & Men \\
\hline Total number of colorectal lesions, $\mathrm{n}$ & 129 & 168 & 750 & 1096 \\
Early cancers, $\mathrm{n}$ & 1 & 0 & 2 & 6 \\
Tubulo(villous) adenomas, $\mathrm{n}$ & 46 & 82 & 382 & 648 \\
Serrated adenomas, $\mathrm{n}$ & 7 & 1 & 9 & 15 \\
Hyperplastic lesions, $\mathrm{n}$ & 40 & 37 & 198 & 195 \\
Other (normal histology, inflammation, etc.), $\mathrm{n}$ & 35 & 48 & 159 & 232 \\
\hline
\end{tabular}

Supplementary Table S3.2 Multiple logistic regression analyses stratified by gender. Outcome: presence of high-grade dysplasia or early colorectal cancer in colorectal neoplasms

\begin{tabular}{lcccccc}
\hline & \multicolumn{3}{c}{ Women $(\mathrm{n}=431)$} & \multicolumn{3}{c}{ Men $(\mathrm{n}=736)$} \\
& OR & $95 \% \mathrm{Cl}$ & $P$-value & OR & $95 \% \mathrm{Cl}$ & $P$-value \\
\hline Age (continuous) & 0.97 & $0.94-1.00$ & 0.06 & 1.03 & $1.00-1.07$ & 0.03 \\
Distal location (vs. proximal) & 2.44 & $1.16-5.14$ & 0.02 & 1.55 & $0.84-2.83$ & 0.16 \\
Size $\geq 10$ mm (vs. <10 mm) & 5.73 & $2.94-11.2$ & $<0.001$ & 8.51 & $4.58-15.8$ & $<0.001$ \\
Nonpolypoid appearance (vs. polypoid) & 2.99 & $1.26-7.09$ & 0.01 & 0.95 & $0.41-2.17$ & 0.90 \\
Indication for colonoscopy & & & 0.10 & & & 0.75 \\
$\quad$ Screening (vs. symptomatic) & 0.38 & $0.10-1.40$ & 0.15 & 1.49 & $0.43-5.13$ & 0.53 \\
$\quad$ Surveillance (vs. symptomatic) & 0.40 & $0.14-1.14$ & 0.09 & 0.75 & $0.89-1.81$ & 0.45 \\
Familial CRC (vs. absence) & 0.76 & $0.09-6.69$ & 0.80 & 1.64 & $0.17-15.5$ & 0.67 \\
Inflammatory bowel disease (vs. absence) & 2.43 & $0.37-15.8$ & 0.35 & 0.70 & $0.08-6.28$ & 0.75 \\
\hline
\end{tabular}

$\mathrm{OR}=$ odds ratio, $\mathrm{Cl}=$ confidence interval. 


\section{References}

1. Baxter NN, Goldwasser MA, Paszat LF, Saskin R, Urbach DR, Rabeneck L. Association of colonoscopy and death from colorectal cancer. Ann Intern Med 2009;150:1-8.

2. Singh $\mathrm{H}$, Nugent $\mathrm{Z}$, Demers $\mathrm{AA}$, Bernstein $\mathrm{CN}$. Rate and predictors of early/missed colorectal cancers after colonoscopy in manitoba: a population-based study. Am J Gastroenterol 2010;105:2588-96.

3. Bressler B, Paszat LF, Chen Z, Rothwell DM, Vinden C, Rabeneck L. Rates of New or Missed Colorectal Cancers After Colonoscopy and Their Risk Factors: A Population-Based Analysis. Gastroenterology 2007; 132:96-102.

4. Kudo S, Lambert R, Allen JI, Fujii H, Fujii T, Kashida H, Matsuda T, Mori M, Saito H, Shimoda T, Tanaka S, Watanabe H, Sung JJ, Feld AD, Inadomi JM, O'Brien MJ, Lieberman DA, Ransohoff DF, Soetikno RM, Triadafilopoulos G, Zauber A, Teixeira CR, Rey JF, Jaramillo E, Rubio CA, Van Gossum A, Jung M, Vieth $M$, Jass JR, Hurlstone PD. Nonpolypoid neoplastic lesions of the colorectal mucosa. Gastrointest Endosc 2008;68 (Suppl October):S3-47.

5. Soetikno R, Friedland S, Kaltenbach T, Chayama K, Tanaka S. Nonpolypoid (flat and depressed) colorectal neoplasms. Gastroenterology 2006;130:566-576.

6. Church JM, Muto T, Appau K. Flat lesions of the colorectal mucosa: differences in recognition between Japanese and American endoscopists. Dis Colon Rectum 2004;47:1462-1466.

7. Kalidindi V, Kaltenbach TR, Friedland S, Soetikno RM. Endoscopists Trained in the Diagnosis of Nonpolypoid (Flat and Depressed) Colorectal Neoplasms Detect More Adenomatous Lesions. Gastrointestinal endoscopy 2008;67:AB316.

8. Saitoh Y, Waxman I, West AB, Popnikolov NK, Gatalica Z, Watari J, Obara T, Kohgo Y, Pasricha PJ. Prevalence and distinctive biologic features of flat colorectal adenomas in a North American population. Gastroenterology 2001;120:1657-1665.

9. Soetikno RM, Kaltenbach T, Rouse RV, Park W, Maheshwari A, Sato T, Matsui S, Friedland S. Prevalence of nonpolypoid (flat and depressed) colorectal neoplasms in asymptomatic and symptomatic adults. JAMA 2008;299:1027-1035.

10. Tsuda S, Veress B, Toth E, Fork FT. Flat and depressed colorectal tumours in a southern Swedish population: a prospective chromoendoscopic and histopathological study. Gut 2002;51:550-555.

11. Rembacken BJ, Fujii T, Cairns A, Dixon MF, Yoshida S, Chalmers DM, Axon ATR. Flat and depressed colonic neoplasms: a prospective study of 1000 colonoscopies in the UK. The Lancet 2000;355:1211 1214.

12. Jaramillo $E$, Watanabe $M$, Slezak $P$, Rubio $C$. Flat neoplastic lesions of the colon and rectum detected by high-resolution video endoscopy and chromoscopy. Gastrointest Endosc 1995;42:114-122.

13. Kim J, Rami P, O'Toole J, Llor X, Carroll RE, Benya RV. Prevalence and Size of Flat Neoplasms in a Heterogeneous Population Undergoing Routine Colorectal Cancer Screening. Colorectal Dis 2009;12:471-476.

14. Bianco MA, Cipolletta L, Rotondano G, Buffoli F, Gizzi G, Tessari F. Prevalence of nonpolypoid colorectal neoplasia: an Italian multicenter observational study. Endoscopy 2010;42:279-285.

15. Bustamante-Balen M, Bernet L, Cano R, Pertejo V, Ponce J. Prevalence of nonpolypoid colorectal neoplasms in symptomatic patients scheduled for colonoscopy: a study with total colonic chromoscopy. J Clin Gastroenterol 2010;44:280-5.

16. Chiu H-M, Lin J-T, Chen C-C, Lee Y-C, Liao W-C, Liang J-T, Shun C-T, Wang H-P, Wu M-S. Prevalence and Characteristics of Nonpolypoid Colorectal Neoplasm in an Asymptomatic and Average-Risk Chinese Population. Clinical Gastroenterology and Hepatology 2009;7:463-470.

17. Roy HK, Bianchi LK. Differences in colon adenomas and carcinomas among women and men: potential clinical implications. JAMA 2009;302:1696-1697.

18. Sanduleanu S, Rondagh EJ, Masclee AA. Development of expertise in the detection and classification of non-polypoid colorectal neoplasia: Experience-based data at an academic GI unit. Gastrointest Endosc Clin N Am 2010;20:449-460.

19. Rondagh EJ, Masclee AA, Bouwens MW, Winkens B, Riedl RG, de Bruine AP, de Ridder R, Kaltenbach T, Soetikno RM, Sanduleanu S. Endoscopic red flags for the detection of high-risk serrated polyps: an observational study. Endoscopy 2011;43:1052-8. 
20. Soetikno RM, Barro J, Friedland S, Matsui S, Rouse R, Fujii T. Diagnosis of Flat and Depressed Colorectal Neoplasms. ASGE Endoscopic Learning Library 2006; Available at: http://www.asge.org/ell_list.aspx

21. Rex DK. Colonoscopic Polypectomy. ASGE Endoscopic Learning Library 2007; Available at: http://www.asge.org/ell_list.aspx

22. Kudo S, Kashida H, Tamura T, Kogure E, Imai Y, Yamano H, Hart AR. Colonoscopic diagnosis and management of nonpolypoid early colorectal cancer. World J Surg 2000;24:1081-1090.

23. Rex DK, Petrini JL, Baron TH, Chak A, Cohen J, Deal SE, Hoffman B, Jacobson BC, Mergener K, Petersen BT, Safdi MA, Faigel DO, Pike IM. Quality indicators for colonoscopy. Gastrointestinal Endoscopy 2006;63:S16-S28.

24. Kaminski MF, Regula J, Kraszewska E, Polkowski M, Wojciechowska U, Didkowska J, Zwierko M, Rupinski M, Nowacki MP, Butruk E. Quality indicators for colonoscopy and the risk of interval cancer. N Engl J Med 2010;362:1795-803.

25. Kwaliteitsinstituut voor de Gezondheidszorg. CBO richtlijn Erfelijke Darmkanker, 2008.

26. Kil Lee S, II Kim T, Kwan Shin S, Ho Kim W, Kim H, Kyu Kim N. Comparison of the clinicopathologic features between flat and polypoid adenoma. Scand J Gastroenterol 2008;43:1116-1121.

27. Park DH, Kim HS, Kim WH, Kim TI, Kim YH, Park DI, Kim HJ, Yang SK, Byeon JS, Lee MS, Chung IK, Jung SA, Jeen YT, Choi JH, Choi H, Han DS. Clinicopathologic characteristics and malignant potential of colorectal flat neoplasia compared with that of polypoid neoplasia. Dis Colon Rectum 2008;51:43-49.

28. The Paris endoscopic classification of superficial neoplastic lesions: esophagus, stomach, and colon: November 30 to December 1, 2002. Gastrointest Endosc 2003;58 (Suppl December):S3-43.

29. Kudo S, Tamegai Y, Yamano H, Imai Y, Kogure E, Kashida H. Endoscopic mucosal resection of the colon: the Japanese technique. Gastrointest Endosc Clin N Am 2001;11:519-535.

30. Kaltenbach T, Friedland S, Maheshwari A, Ouyang D, Rouse RV, Wren S, Soetikno R. Short- and longterm outcomes of standardized EMR of nonpolypoid (flat and depressed) colorectal lesions $\geq 1 \mathrm{~cm}$ (with video). Gastrointest Endosc 2007;65:857-865.

31. Hamilton S, Aaltonen, LA. WHO Classification of Tumours: Pathology and Genetics: Tumours of the Digestive System IARC Press, 2000.

32. Makinen MJ. Colorectal serrated adenocarcinoma. Histopathology 2007;50:131-150.

33. Snijders T, Bosker R. Multilevel analysis: an introduction to basic and advanced multilevel modeling. SAGE, 1999.

34. Nguyen SP, Bent S, Chen YH, Terdiman JP. Gender as a risk factor for advanced neoplasia and colorectal cancer: a systematic review and meta-analysis. Clin Gastroenterol Hepatol 2009;7:676-681.

35. Brenner H, Hoffmeister M, Arndt V, Haug U. Gender differences in colorectal cancer: implications for age at initiation of screening. Br J Cancer 2007;96:828-31.

36. Chlebowski RT, Wactawski-Wende J, Ritenbaugh C, Hubbell FA, Ascensao J, Rodabough RJ, Rosenberg CA, Taylor VM, Harris R, Chen C, Adams-Campbell LL, White E. Estrogen plus progestin and colorectal cancer in postmenopausal women. N Engl J Med 2004;350:991-1004.

37. Kennelly R, Kavanagh DO, Hogan AM, Winter DC. Oestrogen and the colon: potential mechanisms for cancer prevention. Lancet Oncol 2008;9:385-391.

38. Zisman AL, Nickolov A, Brand RE, Gorchow A, Roy HK. Associations between the age at diagnosis and location of colorectal cancer and the use of alcohol and tobacco: implications for screening. Arch Intern Med 2006;166:629-634.

39. Jacobs ET, Thompson PA, Martinez ME. Diet, gender, and colorectal neoplasia. J Clin Gastroentero 2007;41:731-746.

40. Anderson JC, Stein B, Kahi CJ, Rajapakse R, Walker G, Alpern Z. Association of smoking and flat adenomas: results from an asymptomatic population screened with a high-definition colonoscope. Gastrointest Endosc 2010;71:1234-40.

41. Rex DK. Preventing colorectal cancer and cancer mortality with colonoscopy: what we know and what we don't know. Endoscopy 2010;42:320-3.

42. Yashiro M, Carethers JM, Laghi L, Saito K, Slezak P, Jaramillo E, Rubio C, Koizumi K, Hirakawa K, Boland CR. Genetic pathways in the evolution of morphologically distinct colorectal neoplasms. Cancer Res 2001;61:2676-83. 


\title{
Chapter 4
}

\author{
Endoscopic red flags for the detection of high-risk \\ serrated polyps: \\ an observational study
}

Eveline JA Rondagh, Ad AM Masclee, Mariëlle WE Bouwens, Bjorn Winkens, Robert G Riedl, Adriaan P de Bruïne, Rogier de Ridder, Tonya Kaltenbach, Roy M Soetikno, Silvia Sanduleanu

Endoscopy 2011;43:1052-1058. 


\section{Abstract}

\section{Background and study aims}

In routine practice, colonoscopy may fail to prevent colorectal cancer (CRC), especially in the proximal colon. A better endoscopic recognition of serrated polyps (SPs) is important, as this pathway may explain some of the post-colonoscopy cancers. In this study, we therefore examined the endoscopic characteristics of SPs.

\section{Patients and methods}

We conducted a cross-sectional, single center study of all consecutive patients referred for elective colonoscopy during one year. The endoscopists were familiarized on the detection and treatment of nonpolypoid colorectal lesions. We pragmatically classified SPs into high-risk SPs, defined as dysplastic or large $(\geq 6 \mathrm{~mm})$, proximal non-dysplastic SPs and low-risk SPs, including the remaining non-dysplastic SPs. Advanced colorectal neoplasms were defined as multiple ( $\geq 3), \geq 10 \mathrm{~mm}$ in size, high-grade dysplastic adenomas or CRC.

\section{Results}

We included a total of 2309 patients ( $46.1 \%$ men, mean age 58.4 years), of whom $2.5 \%$ (57) had $\geq 1$ high-risk SP and $13.9 \%$ (322) had $\geq 1$ advanced neoplasm. Overall, SPs were more often nonpolypoid than adenomas: $16.2 \%$ vs. $11.1 \%, P=0.002$. In total, we found 65 high-risk SPs, of which $43.1 \%$ displayed a nonpolypoid endoscopic appearance. Patients with advanced neoplasms were more likely to have synchronous high-risk SPs than patients without advanced neoplasms: OR 3.66 (95\% Cl 2.03-6.61, $P<0.001)$

\section{Conclusion}

High-risk serrated polyps are frequently nonpolypoid and are associated with synchronous advanced colorectal neoplasms. Advanced colorectal neoplasms may therefore be considered red flags for the presence of high-risk serrated polyps. Detection, diagnosis and treatment of high-risk serrated lesions may be important targets to improve the quality of colonoscopic cancer prevention. 


\section{Introduction}

Colonoscopy with removal of adenomatous precursor lesions has been shown to prevent colorectal cancer (CRC) and is therefore sooner or later involved in all CRC prevention programs. Naturally, a legitimate concern was raised when a number of recent studies reported that in the routine endoscopy practice, colonoscopy is limited in its ability to prevent $\mathrm{CRC}^{1-3}$ These post-colonoscopy cancers are frequently characterized by proximal location, CPG island methylator phenotype (CIMP) and microsatellite instability (MSI). ${ }^{1-4}$ As proximal predominance and similar molecular alterations were previously associated with the serrated neoplastic pathway, ${ }^{5-8}$ it is likely that some of the post-colonoscopy CRCs arise via this alternative mechanism.

The serrated neoplastic pathway has been increasingly recognized over the past decade and is suggested to account for up to $15 \%$ of all CRCs. ${ }^{9,10}$ Serrated polyps (SPs) represent a heterogeneous group of lesions, of which a subset harbors significant risk for neoplastic transformation. ${ }^{9-11}$ The majority of SPs are small and distally located non-dysplastic (hyperplastic) polyps, which are most probably harmless, i.e. low-risk SPs. ${ }^{12}$ In contrast, dysplastic SPs as well as large, proximal non-dysplastic SPs, are considered to harbor risk for malignant transformation, ${ }^{12-17}$ i.e. high-risk SPs. In the community practice, endoscopists may easily overlook SPs, which are pale (hypovascular), may have nonpolypoid endoscopic appearance, ${ }^{18}$ and may be covered by mucus. ${ }^{9}$

Li et $\mathrm{al}^{19}$ first described an association between large SPs and advanced colorectal neoplasms. These findings were confirmed by Hiraoka et $\mathrm{al}^{20}$ and Schreiner et $\mathrm{al}^{21}$, who reported that proximal and large SPs are associated with (advanced) colorectal neoplasms during surveillance. However, the endoscopic appearance of high-risk SPs has not been fully addressed in these studies. This information is of practical importance, as it may improve recognition of these lesions. It is known that endoscopists may overlook $30-60 \%$ of the $\mathrm{SPs}^{22,23}$ and endoscopic detection of (proximal) SPs varies widely between endoscopists. ${ }^{24,25}$ Clinical awareness and systematic training may therefore be essential to improve the detection and characterization of high-risk SPs, ${ }^{26}$ and possibly the quality of colonoscopic cancer prevention. In the present study, we first trained our endoscopists on the recognition and treatment of nonpolypoid colorectal lesions, ${ }^{27}$ after which we embarked on a prospective, single-center study to examine the endoscopic characteristics of (highrisk) SPs, with focus on their endoscopic appearance and association with synchronous advanced colorectal neoplasms. 


\section{Patients and methods}

\section{Study design}

Before the start of the study, all endoscopists at the Division of Gastroenterology and Hepatology of the Maastricht University Medical Center were trained in order to familiarize them on the recognition, classification and management of nonpolypoid colorectal lesions, as previously described. ${ }^{27}$ This training consisted of: i) lectures, by an experienced colonoscopist (S.S.), ii) video-training using accredited programs ${ }^{28,29}$ and iii) feedback and supervision during colonoscopy. Between February 2008 and February 2009, we prospectively included all consecutive patients referred for routine colonoscopy at our gastrointestinal endoscopy unit, where both secondary and tertiary care are provided. Exclusion criteria were age $<18$ years or having a hereditary form of CRC, including the serrated polyposis syndrome. ${ }^{10}$ The study was approved by the Institutional Review Board of the Maastricht University Medical Center (MEC 08-4-074), which waived the need for informed consent.

\section{Colonoscopy}

According to routine clinical care, patients received polyethylene glycol solution for bowel preparation. Colonoscopies were performed by 9 gastroenterologists and 7 trainees, using high-resolution Pentax endoscopes (EC-3870FK2; Pentax, Tokyo, Japan). Selective chromoendoscopy was used, when needed, to better visualize the borders of nonpolypoid lesions prior to endoscopic removal. ${ }^{30}$ We used the Paris-Japanese classification to classify the colorectal polyps according to their endoscopic appearance. $^{31}$ Lesions with a height of less than half the diameter were considered to be nonpolypoid. ${ }^{30}$ Nonpolypoid lesions included slightly elevated, flat or slightly depressed lesions. All colorectal polyps, whether adenomas or SPs, were classified according to their size into $<6 \mathrm{~mm}, 6-9 \mathrm{~mm}$ and $>9 \mathrm{~mm}$. Size of colorectal polyps was estimated visually using a standard biopsy forceps or a mini-snare. According to location polyps were categorized into i) proximally-located: from cecum to splenic flexure or ii) distally-located: from descending colon to rectum. Colonoscopic examinations were documented using a standardized reporting system, including digital photographic documentation. Colorectal lesions were removed immediately during colonoscopy using cold biopsy, snare polypectomy or endoscopic mucosal resection; when needed surgical resection was performed. The participating endoscopists were familiar with the detection and treatment of nonpolypoid neoplasms, but were unaware of the scientific hypotheses of the study. 


\section{Histopathological classification of colorectal polyps}

Histopathological classification of colorectal polyps was performed by two experienced gastrointestinal pathologists, who were unaware of the study hypotheses. According to the WHO classification, we diagnosed serrated polyps by the presence of a sawtoothed (serrated) appearance of the glands. ${ }^{32}$ As dysplastic SPs can be accurately distinguished from non-dysplastic SPs, ${ }^{24,33}$ we subdivided SPs into: i) SPs with cytological dysplasia (including traditional serrated adenomas and sessile serrated adenomas/polyps (SSA/P) with dysplasia) and ii) SPs without cytological dysplasia (including hyperplastic polyps and SSA/P without dysplasia).

In addition, we pragmatically classified SPs in two subgroups: i) high-risk SPs, consisting of dysplastic SPs or large ( $\geq 6 \mathrm{~mm}$ ), proximal non-dysplastic SPs and ii) low-risk SPs, including the remaining non-dysplastic SPs. This classification is supported by previously described different histological characteristics, ${ }^{12,34}$ molecular profile ${ }^{6,7}$ and potential risk for malignant transformation ${ }^{13-16}$ between these two subgroups. We used a cut-off of $6 \mathrm{~mm}$ for large SPs, because SPs are usually less than $6 \mathrm{~mm}$ in size and smaller than adenomas. ${ }^{12,16}$ In addition, approximately $30-50 \%$ of the non-dysplastic SPs with architectural abnormalities and increased proliferation (SSA/Ps) are sized 6-9 mm. ${ }^{16,35}$ Presence of an advanced colorectal neoplasm was defined as presence of at least one of the following features: multiple $(\geq 3), \geq 10 \mathrm{~mm}$ in size, high-grade dysplastic adenomas or CRC. ${ }^{36}$ As presence of any villous component is subject to high interobserver variation, ${ }^{37,38}$ we did not include this feature in the primary definition of advanced colorectal neoplasms; however, we conducted additional analyses to examine its potential impact on the study outcome.

\section{Statistical analysis}

The outcome measures of the study were i) endoscopic appearance of (high-risk)SPS and ii) association of advanced colorectal neoplasms with synchronous (high-risk) SPs. Multiple logistic regression analyses were carried out to address the endoscopic appearance of different types of SPs and the association of high-risk SPs with advanced colorectal neoplasms, after adjustment for potential confounders. As data on endoscopic appearance of (high-risk) SPs are scarce, sample size calculation was performed using previously reported prevalences of large SPs and advanced colorectal neoplasms, which are $3 \%$ and $10 \%$, respectively. ${ }^{39}$ At least 1947 patients were needed to achieve $80 \%$ power to detect an association between high-risk SPs and advanced colorectal neoplasms with a significance level of $5 \%$ and assuming a relative risk of at least 2.5.

Differences in dichotomous variables were examined using the chi-squared test or Fisher's exact test, when appropriate. Differences in continuous variables between groups were examined using the independent-samples t-test. All data registration and statistical analyses were performed using SPSS statistical software package 15.0 
(Chicago, Illinois, USA). All odds ratios (ORs) are presented with $95 \%$ confidence intervals (Cls). Two-sided $P$ values $<0.05$ were considered statistically significant.

\section{Results}

In total, 2466 patients were referred for routine colonoscopy between February 2008 and February 2009. We excluded patients aged $<18$ years $(n=7)$ and patients having a hereditary form of CRC $(n=20)$, including hyperplastic polyposis syndrome $(n=1)$. In addition, 129 colonoscopies were second colonoscopies in patients who were already included in the study. Reasons for a second colonoscopy were onset of new symptoms $(n=31)$, polypectomy $(n=23)$ or follow-up colonoscopy after polypectomy $(n=38)$. In case of insufficient bowel preparation requiring a second-look colonoscopy $(n=37)$, data recorded during the second colonoscopy were used.

Finally, we included 2309 consecutive patients ( $46.1 \%$ men, mean age 58.4 years). In $80.5 \%$ of patients, colonoscopy was performed for symptoms (e.g. rectal blood loss, abdominal complaints, anemia), whereas $12.4 \%$ underwent colonoscopy for surveillance (previous polyp or CRC) and 7.1\% for screening indications (Table 4.1). Of all patients, 9.8\% had inflammatory bowel disease. The overall cecal intubation rate was $91.2 \%$. Of all patients, $13.3 \%(n=307)$ had $\geq 1$ SP, $26.8 \%(n=618)$ had $\geq 1$ adenoma, $2.5 \%(n=57)$ had $\geq 1$ high-risk SP and $13.9 \%(n=322)$ had $\geq 1$ advanced colorectal neoplasm. At least one proximal SP was present in $3.8 \%(n=87)$ of the patients. In this study, we did not find significant differences in detection of $\geq 1$ SP or $\geq 1$ high-risk SP between gastroenterologists and gastrointestinal trainees: $13.8 \%(175 / 1271)$ vs. $12.7 \%$ (132/1038), $P=0.46$ and $2.4 \%$ (31/1271) vs. $2.5 \%$ (26/1038), $P=0.92$, respectively. No significant differences were found with regard to age, sex and indication for colonoscopy between patients examined by gastroenterologists versus gastrointestinal trainees (mean age: 57.8 vs. 59.1 years, $P=0.05$; sex: $53.3 \%$ vs. $54.6 \%$ men, $P=0.51$; indication for colonoscopy: $80.7 \%$ vs. $80.3 \%$ symptoms, $P=0.78$ ).

Table 4.1 Demographic data of the study population.

\begin{tabular}{lc}
\hline Study population, no. & 2309 \\
Men, no. (\%) & $1065(46.1)$ \\
Mean age, y (SD) & $58.4(16.2)$ \\
Indication for colonoscopy & \\
Symptoms, no. (\%) & $1859(80.5)$ \\
Surveillance, no. (\%) & $287(12.4)$ \\
Screening, no. (\%) & $163(7.1)$ \\
\hline
\end{tabular}




\section{Endoscopic and histological characteristics of serrated polyps}

A total of 493 SPs were found in 307 patients. Table 4.2 describes the endoscopic appearance of SPs. Overall, we found that SPs were more often nonpolypoid than adenomas, $16.2 \%$ vs. $11.1 \%$ ( $P=0.002)$. Of the proximal SPs, $33.7 \%$ were nonpolypoid vs. $11.7 \%$ of the distal ones $(P<0.001)$. Proximal SPs were also larger $(\geq 6 \mathrm{~mm})$ than distal ones $41.6 \%$ vs. $6.9 \%$ ( $P<0.001)$. Of note, $43.1 \%$ of the high-risk SPs displayed a nonpolypoid endoscopic appearance vs. $12.1 \%$ of the low-risk SPs $(P<0.001)$.

We found a total of 65 high-risk SPs, of which 30 were dysplastic SPs and 35 large, proximal non-dysplastic SPs. Of the dysplastic SPs $(n=30), 3$ were traditional serrated adenomas and 27 SSA/Ps with dysplasia. Of the dysplastic SPs, 7 (23.3\%) were nonpolypoid, including one traditional serrated adenoma and 6 SSA/Ps. Of the large, proximal non-dysplastic SPs ( $n=35), 26$ were hyperplastic polyps and 9 SSA/Ps without dysplasia. Of the large, non-dysplastic SPs, 21 (60.0\%) were nonpolypoid, including 17 hyperplastic polyps and 4 SSA/Ps without dysplasia. Of all small $(<6 \mathrm{~mm})$ SPs $(n=425)$, $3.8 \%(n=16)$ were dysplastic SPs.

Table 4.2 Endoscopic appearance of different types of colorectal polyps.

\begin{tabular}{|c|c|c|c|c|}
\hline \multirow[t]{2}{*}{ Polyp type } & \multicolumn{2}{|c|}{ Nonpolypoid endoscopic appearance } & \multirow[b]{2}{*}{$95 \% \mathrm{Cl}$} & \multirow[b]{2}{*}{$P$ value } \\
\hline & no. (\%) & OR & & \\
\hline Adenoma $(n=1166)$ & $129(11.1)$ & reference & & \\
\hline $\operatorname{SP}(n=493)$ & $80(16.2)$ & 1.63 & $1.20-2.22$ & 0.002 \\
\hline Distal SP (n=392) & $46(11.7)$ & reference & & \\
\hline Proximal SP $(n=101)$ & $34(33.7)$ & 3.90 & $2.32-6.55$ & $<0.001$ \\
\hline SP sized $<6 \mathrm{~mm}(\mathrm{n}=425)$ & $47(11.1)$ & reference & & \\
\hline SP sized $\geq 6 \mathrm{~mm}(n=68)$ & $33(48.5)$ & 7.41 & $4.20-13.1$ & $<0.001$ \\
\hline Low-risk SP (n=428) & $52(12.1)$ & reference & & \\
\hline High-risk SP ( $n=65)$ & $28(43.1)$ & 5.41 & $3.04-9.63$ & $<0.001$ \\
\hline
\end{tabular}

$\mathrm{SP}=$ serrated polyp. ${ }^{\mathrm{a}}$ Prevalence of nonpolypoid endoscopic appearance in relation to the different types of polyps, adjusted for age and sex.

\section{Association of serrated polyps with colorectal neoplasms}

\section{Advanced neoplasms as a risk factor for synchronous high-risk SPS}

High-risk SPs were more often found in patients with advanced colorectal neoplasms than in those without: $7.1 \%(23 / 322)$ vs. $1.7 \%$ (34/1987), $P<0.001$. Multiple logistic regression analysis showed that presence of $\geq 1$ advanced colorectal neoplasm was an independent risk factor for synchronous high-risk SPs, OR 3.66 (95\% Cl 2.03-6.61, $P<0.001$ ) (Table 4.3). Presence of $\geq 1$ low-risk SP was also independently associated with synchronous high-risk SPs, OR 3.54 (95\% Cl 1.97-6.36, $P<0.001$ ). Figure 4.1 illustrates the case of a patient who presented with an advanced colorectal adenoma and a synchronous high-risk SP at the time of colonoscopy. 


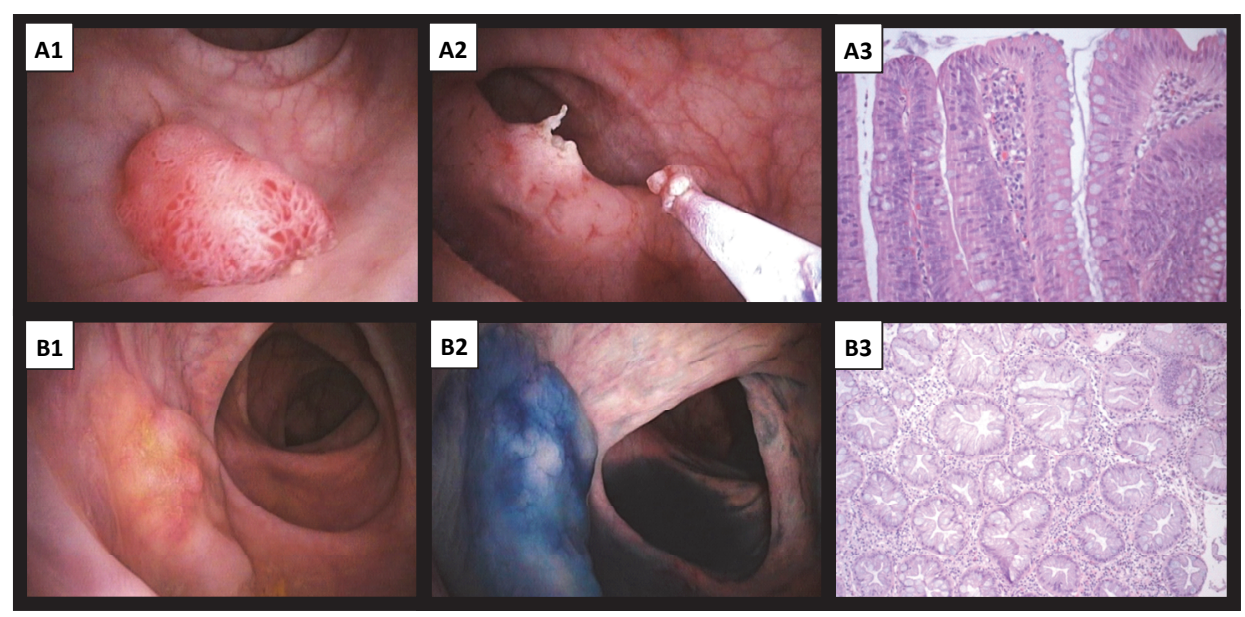

Figure 4.1 In a 54-year old female patient, we detected an easily recognizable large, sessile polyp in the sigmoid colon (A1), which was removed using snare polypectomy (A2). Histologic examination showed a tubulovillous adenoma with low-grade dysplasia (A3). A second large, nonpolypoid lesion with a mucus cap was detected in the ascending colon (B1). Selective chromoendoscopy was applied to better demarcate the lesion, prior to endoscopic removal (B2). Histologic examination showed a non-dysplastic serrated polyp (B3).

Table 4.3 Multiple logistic regression analysis with presence of a high-risk serrated polyp as outcome.

\begin{tabular}{lccccc}
\hline Patient characteristics & $\begin{array}{c}\text { Patients with } \\
\text { high-risk SP } \\
(\mathrm{n}=57)\end{array}$ & $\begin{array}{c}\text { Patients without } \\
\text { high-risk SP } \\
(\mathrm{n}=2252)\end{array}$ & \multicolumn{3}{c}{ Presence of $\geq 1$ high-risk SP } \\
OR & & $95 \% \mathrm{Cl}$ & $P$ value \\
\hline Mean age, y (SD) & $64.6(11)$ & $58.2(16)$ & 1.02 & $1.00-1.04$ & 0.07 \\
Male, no. (\%) & $31(54.4)$ & $1034(45.9)$ & 1.13 & $0.66-1.95$ & 0.65 \\
$\geq 1$ non-advanced adenoma, no. (\%) & $20(35.1)$ & $497(22.1)$ & 0.99 & $0.54-1.79$ & 0.96 \\
$\geq 1$ low-risk SP, no. (\%) & $18(31.6)$ & $249(11.1)$ & 3.54 & $1.97-6.36$ & $<0.001$ \\
$\geq 1$ advanced neoplasm, no. (\%) & $23(40.4)$ & $299(13.3)$ & 3.66 & $2.03-6.61$ & $<0.001$ \\
\hline
\end{tabular}

$\mathrm{SP}=$ serrated polyp. ${ }^{\mathrm{a}}$ Multiple logistic regression analysis including age, sex, presence of a non-advanced adenoma, low-risk SP and advanced neoplasm.

\section{High-risk SPs as a risk factor for synchronous advanced neoplasms}

Advanced colorectal neoplasms were found more often in patients with high-risk SPs than in those without: $40.4 \%(23 / 57)$ vs. $13.3 \%(299 / 2252), P<0.001$. Multiple logistic regression analysis showed that presence of $\geq 1$ high-risk SP was an independent risk factor for synchronous advanced neoplasms (OR 3.84, 95\% Cl 2.11-7.00, $P<0.001)$. This association was also true for large ( $\geq 6 \mathrm{~mm}$ ), proximal non-dysplastic SPs (OR 2.84, 95\% Cl 1.25-6.44, $P=0.01$ ), for dysplastic SPs (OR 3.32, 95\% Cl 1.52-7.28, $P=0.003$ ), for proximal SPs (OR 2.55, 95\% Cl 1.50-4.31, $P<0.001$ ), for SPs sized $\geq 6 \mathrm{~mm}$ (OR 2.69, 95\% 
Cl 1.47-4.94, $P=0.001$ ) as well as for SPs sized $\geq 10 \mathrm{~mm}$ (OR 2.93, 95\% Cl 1.25-6.87, $P=0.01$ ).

Of note, $47.4 \%$ (27/57) of the patients with high-risk SPs did not have any synchronous adenoma or CRC. Of these 27 patients with high-risk SPs only, 10 had a dysplastic SP, 16 had a large, proximal non-dysplastic SP and 1 had both types of high-risk SPs.

Additional analyses were performed to assess whether the definition of advanced colorectal neoplasm may have influenced the outcome of the study. According to the presence of SPs, the study patients were subdivided into 3 subgroups: i) patients without any $S P(n=2002,45.0 \%$ men, mean age 57.8 years), ii) patients with low-risk SPs only ( $\mathrm{n}=250,53.6 \%$ men, mean age 61.4 years) and iii) patients with $\geq 1$ high-risk SP ( $n=57,54.4 \%$ men, mean age 64.6 years). As shown in Figure 4.2, the association between high-risk SPs and (advanced) colorectal neoplasms was found irrespective of the definition of advanced neoplasms. Also, inclusion of villosity in the definition of advanced neoplasm did not alter the association of high-risk SPs with advanced neoplasms (OR $2.47,95 \% \mathrm{Cl} 1.39-4.40, P=0.002$ ). Of note, high-risk SPs were associated with both proximal and distal advanced colorectal neoplasms (OR $2.90,95 \% \mathrm{Cl}$ 1.41-5.98, $P=0.004$ and OR 2.99, $95 \% \mathrm{Cl} 1.57-5.70, P<0.001$, respectively).

\section{Prevalence of different types of colorectal neoplasms}

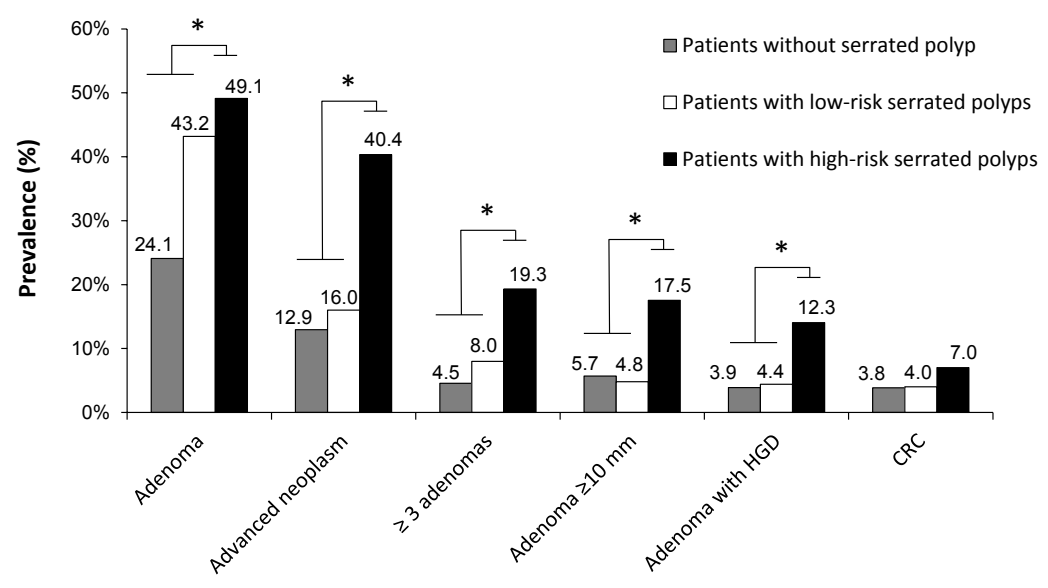

Figure 4.2 Prevalence of colorectal neoplasms in patients without any serrated polyp ( $n=2002$ ), with lowrisk serrated polyps only $(n=250)$ or with at least one high-risk serrated polyp $(n=57)$. High-risk serrated polyps were associated with advanced neoplasms, irrespective of the definition used for advanced colorectal neoplasms.

HGD = high-grade dysplasia, $\mathrm{CRC}=$ colorectal cancer. ${ }^{*}$ Patients with high-risk serrated polyps versus those without, $P \leq 0.002$ 
Separate logistic regression analysis was conducted including indication for colonoscopy (symptoms, surveillance or screening), presence of inflammatory bowel disease and completeness of colonoscopy, which did not alter the association of highrisk SPs with advanced neoplasms (OR 3.72, 95\% Cl 2.04-6.76, $P<0.001$ ).

\section{Discussion}

In the present study, we found that high-risk serrated polyps (dysplastic and large, proximal non-dysplastic SPs) have two important endoscopic features: nearly half of them have a nonpolypoid endoscopic appearance and these lesions are associated with synchronous advanced neoplasms. Advanced colorectal neoplasms may therefore be potential red flags for the inconspicuous high-risk SPs. This study highlights the need for educational programs on the detection of high-risk SPs, including practical tips, such as endoscopic appearance and their association with advanced colorectal neoplasms.

Post-colonoscopy CRCs and the serrated neoplastic pathway share similar characteristics: both are preferentially located in the proximal colon, and frequently display CIMP and MSI. ${ }^{1-4,9}$ It is therefore conceivable that overlooked ${ }^{22,23}$ or incompletely removed high-risk SPs may be at the origin of some post-colonoscopy CRCs. In the present study, we found that nearly half of the high-risk SPs display a nonpolypoid endoscopic appearance. In everyday practice, wide variations were reported among endoscopists with regard to the detection of (proximal) SPs. ${ }^{24,25}$ In contrast to these studies, our study was prospective in design, and preceded by a short systematic training on the recognition of nonpolypoid colorectal lesions, which could possibly explain the similar rates of SPs detection among gastroenterologists and gastrointestinal trainees. Taken together, all these studies, including ours, indicate that educational programs should be targeted to improve the detection and treatment of high-risk SPs, if quality of colonoscopic cancer prevention is to be optimized.

Undeniably, there are biological differences between proximal and distal CRCs. ${ }^{40}$ Previous studies have described histological $1^{12,34}$ and molecular ${ }^{6,7}$ differences between proximal and distal SPs. We found that proximal and distal SPs also differ with regard to their endoscopic appearance. Proximal SPs were larger in size and more often had a nonpolypoid appearance. These data suggest that in addition to technical factors, ${ }^{41}$ biological differences between the proximal and distal colon (i.e. different growth pattern of lesions) may explain the proximal predominance of post-colonoscopy CRCs. In the present study, we found that patients with advanced colorectal neoplasms are more likely to have synchronous high-risk SPs, which is in agreement with previous data. ${ }^{19-21}$ Overall, $2.5 \%$ (1 out of 40 ) of the study patients had a high-risk SP, while of the patients with advanced colorectal neoplasms $7.1 \%$ (1 out of 14) had a high-risk SP. Contrast enhancing endoscopy techniques, namely (virtual) chromoendoscopy, have been shown to improve detection of nonpolypoid colorectal adenomas and serrated 
lesions. ${ }^{42-44}$ The present results support the application of these red flag techniques in endoscopic surveillance of patients with advanced colorectal neoplasms to optimize the detection of synchronous high-risk SPs.

Conversely, in this study, $40.4 \%$ of patients with high-risk SPs harbored synchronous advanced colorectal neoplasms. Of note, this association was found irrespective of the definition used for advanced colorectal neoplasms or for high-risk SPs (e.g. proximal, $\geq 6 \mathrm{~mm}$ or $\geq 10 \mathrm{~mm}$ ). Schreiner et a ${ }^{21}$ showed that patients with proximal and large SPs also have increased risk for colorectal neoplasms during surveillance. Currently, international as well as Dutch guidelines do not yet recommend colonoscopic surveillance of patients with high-risk SPs. ${ }^{45,46}$ In this study, nearly half (47.4\%) of all patients with high-risk SPs did not have any other neoplastic polyps (i.e. synchronous adenomas or $(\mathrm{RC}$ ), and consequently would not routinely receive colonoscopic surveillance. In view of the accumulating evidence and while awaiting longitudinal data, it seems reasonable to provide colonoscopic surveillance to patients with highrisk (dysplastic or large, proximal non-dysplastic) SPs. ${ }^{47}$

The explanation for the association of advanced colorectal neoplasms with high-risk SPs may reside in common environmental risk factors or genetic susceptibility. Although adenomas and SPs progress into cancer via different molecular pathways, some environmental factors may be involved in both pathways. Smoking, alcohol, and high body mass index increase the risk for both types of polyps, while use of aspirin or calcium may protect against them. ${ }^{48-51}$ Future studies are needed to elucidate whether synchronous presence of high-risk SPs and advanced colorectal neoplasms may define a high-risk phenotype, which may need more intensive surveillance.

Some methodological aspects of this study need to be further discussed. As a strength, all endoscopists at our endoscopy department were made familiar with the recognition and treatment of nonpolypoid colorectal lesions. This was essential for the outcome of this study, as nearly half of the high-risk SPs displayed a nonpolypoid endoscopic appearance. ${ }^{26}$ This study was initiated immediately after the training period, and hence the endoscopists may have been early in their learning curve. However, this may only have resulted in an underestimation of the prevalence of nonpolypoid appearance in SPs and therefore would not weaken our main conclusions. The reported prevalences of SPs vary widely among different studies. Kahi et al ${ }^{25}$ reported a $13 \%$ prevalence rate of proximal SPs in their population, while the study by Hetzel et $\mathrm{al}^{24}$ found a lower (3.0-4.4\%) prevalence. In the present study, we found a $3.7 \%$ prevalence rate of proximal SPs, which is in alignment with this latter study. The reasons for these variations are unclear, with differences in the technologies used (high-definition versus high-resolution), as well as geographical differences with regard to life-style habits (e.g. smoking) as possible explanations.

In the present study, we classified SPs into non-dysplastic and dysplastic SPs. So far, accurate histological diagnosis of SSA/Ps, which relies on architectural changes rather than cytological dysplasia, remains challenging and it is likely that many SSA/Ps are misclassified as hyperplastic polyps. ${ }^{24,33,52,53}$ In contrast, dysplastic changes in SPs are 
diagnosed with high interobserver agreement. ${ }^{24,33}$ In an attempt to prevent these reallife diagnostic pitfalls, we pragmatically classified SPs in this study, into high-risk SPS and low-risk SPs. This simple classification which relies on the most relevant endoscopic and histological features, namely location, size of SPs, as well as presence of dysplasia may represent a useful clinical tool to discriminate SPs at different risk for progression. Future longitudinal studies are needed to clarify whether histological differentiation of SSA/Ps from hyperplastic polyps, possibly in conjunction with molecular characterization, may impact on clinical decision making in surveillance of patients with SPs. Moreover, the finding that only $3.8 \%$ of the SPs $<6 \mathrm{~mm}$ in size harbor dysplasia suggests that endoscopic histology, if accurate, in conjunction with a "leave in place" policy could be a possible alternative approach for these diminutive SPs. ${ }^{54}$

To conclude, this study found that high-risk (i.e. dysplastic or large, proximal nondysplastic) SPs are frequently nonpolypoid and are associated with synchronous advanced colorectal neoplasms. Advanced colorectal neoplasms may therefore be considered red flags for the inconspicuous high-risk SPs. Detection, diagnosis and treatment of high-risk serrated lesions may be of relevance if the quality of colonoscopic cancer prevention is to be improved. 


\section{References}

1. Baxter NN, Goldwasser MA, Paszat LF, Saskin R, Urbach DR, Rabeneck L. Association of colonoscopy and death from colorectal cancer. Ann Intern Med 2009;150:1-8.

2. Singh $\mathrm{H}$, Nugent $\mathrm{Z}$, Demers $\mathrm{AA}$, Bernstein $\mathrm{CN}$. Rate and predictors of early/missed colorectal cancers after colonoscopy in manitoba: a population-based study. Am J Gastroenterol 2010;105:2588-96.

3. Brenner H, Hoffmeister M, Arndt V, Stegmaier C, Altenhofen L, Haug U. Protection from right- and leftsided colorectal neoplasms after colonoscopy: population-based study. J Natl Cancer Inst 2010;102: 89-95.

4. Arain MA, Sawhney M, Sheikh S, Anway R, Thyagarajan B, Bond JH, Shaukat A. CIMP status of interval colon cancers: another piece to the puzzle. Am J Gastroenterol 2009;105:1189-95.

5. lino H, Jass JR, Simms LA, Young J, Leggett B, Ajioka Y, Watanabe H. DNA microsatellite instability in hyperplastic polyps, serrated adenomas, and mixed polyps: a mild mutator pathway for colorectal cancer? J Clin Pathol 1999;52:5-9.

6. Yang S, Farraye FA, Mack C, Posnik O, O'Brien MJ. BRAF and KRAS Mutations in hyperplastic polyps and serrated adenomas of the colorectum: relationship to histology and $\mathrm{CpG}$ island methylation status. Am J Surg Pathol 2004;28:1452-9.

7. Kambara T, Simms LA, Whitehall VL, Spring KJ, Wynter CV, Walsh MD, Barker MA, Arnold S, McGivern A, Matsubara N, Tanaka N, Higuchi T, Young J, Jass JR, Leggett BA. BRAF mutation is associated with DNA methylation in serrated polyps and cancers of the colorectum. Gut 2004;53:1137-44.

8. Park SJ, Rashid A, Lee JH, Kim SG, Hamilton SR, Wu TT. Frequent CpG island methylation in serrated adenomas of the colorectum. Am J Pathol 2003;162:815-22.

9. Makinen MJ. Colorectal serrated adenocarcinoma. Histopathology 2007;50:131-50.

10. East JE, Saunders BP, Jass JR. Sporadic and syndromic hyperplastic polyps and serrated adenomas of the colon: classification, molecular genetics, natural history, and clinical management. Gastroenterol Clin North Am 2008;37:25-46.

11. Jass JR. Classification of colorectal cancer based on correlation of clinical, morphological and molecular features. Histopathology 2007;50:113-130.

12. Torlakovic E, Skovlund E, Snover DC, Torlakovic G, Nesland JM. Morphologic reappraisal of serrated colorectal polyps. Am J Surg Pathol 2003;27:65-81.

13. Lash RH, Genta RM, Schuler CM. Sessile serrated adenomas: prevalence of dysplasia and carcinoma in 2139 patients. J Clin Pathol 2010;63:681-6.

14. Goldstein NS. Small colonic microsatellite unstable adenocarcinomas and high-grade epithelia dysplasias in sessile serrated adenoma polypectomy specimens: a study of eight cases. Am J Clin Pathol 2006;125:132-45.

15. Bouwens M, Rondagh E, Winkens B, Driessen A, de Bruine A, P., Masclee A, Sanduleanu S. 600 Are Hyperplastic Polyps Precursors of Colorectal Cancer? A Long-Term, Retrospective Study. Gastroenterology 2009;136:A-97.

16. Lu FI, van Niekerk de W, Owen D, Tha SP, Turbin DA, Webber DL. Longitudinal outcome study of sessile serrated adenomas of the colorectum: an increased risk for subsequent right-sided colorectal carcinoma. Am J Surg Pathol 2010;34:927-34.

17. Hawkins NJ, Ward RL. Sporadic colorectal cancers with microsatellite instability and their possible origin in hyperplastic polyps and serrated adenomas. J Natl Cancer Inst 2001;93:1307-13.

18. Jaramillo $E$, Watanabe $M$, Slezak $\mathrm{P}$, Rubio $\mathrm{C}$. Flat neoplastic lesions of the colon and rectum detected by high-resolution video endoscopy and chromoscopy. Gastrointest Endosc 1995;42:114-22.

19. Li D, Jin C, McCulloch C, Kakar S, Berger BM, Imperiale TF, Terdiman JP. Association of large serrated polyps with synchronous advanced colorectal neoplasia. Am J Gastroenterol 2009;104:695-702

20. Hiraoka S, Kato J, Fujiki S, Kaji E, Morikawa T, Murakami T, Nawa T, Kuriyama M, Uraoka T, Ohara N Yamamoto $\mathrm{K}$. The presence of large serrated polyps increases risk for colorectal cancer. Gastroenterology 2010;139:1503-10.

21. Schreiner MA, Weiss DG, Lieberman DA. Proximal and large hyperplastic and nondysplastic serrated polyps detected by colonoscopy are associated with neoplasia. Gastroenterology 2010;139:1497-502.

22. Harrison $M$, Singh N, Rex DK. Impact of proximal colon retroflexion on adenoma miss rates. Am J Gastroenterol 2004;99:519-22. 
23. Rex DK, Cutler CS, Lemmel GT, Rahmani EY, Clark DW, Helper DJ, Lehman GA, Mark DG. Colonoscopic miss rates of adenomas determined by back-to-back colonoscopies. Gastroenterology 1997;112:24-8.

24. Hetzel JT, Huang CS, Coukos JA, Omstead K, Cerda SR, Yang S, O'Brien MJ, Farraye FA. Variation in the detection of serrated polyps in an average risk colorectal cancer screening cohort. Am J Gastroenterol 2010;105:2656-64.

25. Kahi CJ, Hewett DG, Norton DL, Eckert GJ, Rex DK. Prevalence and variable detection of proximal colon serrated polyps during screening colonoscopy. Clin Gastroenterol Hepatol 2011;9:42-6.

26. Church JM, Muto T, Appau K. Flat lesions of the colorectal mucosa: differences in recognition between Japanese and American endoscopists. Dis Colon Rectum 2004;47:1462-6.

27. Sanduleanu S, Rondagh EJA, Masclee AA. Development of expertise in the detection and classification of non-polypoid colorectal neoplasia: Experience-based data at an academic GI unit. Gastrointest Endosc Clin N Am 2010;20:449-60.

28. Soetikno RM, Barro J, Friedland S, Matsui S, Rouse R, Fujii T. Diagnosis of Flat and Depressed Colorectal Neoplasms. ASGE Endoscopic Learning Library 2006.

29. Rex DK. Colonoscopic Polypectomy. ASGE Endoscopic Learning Library 2007.

30. Soetikno R, Friedland S, Kaltenbach T, Chayama K, Tanaka S. Nonpolypoid (flat and depressed) colorectal neoplasms. Gastroenterology 2006;130:566-76.

31. The Paris endoscopic classification of superficial neoplastic lesions: esophagus, stomach, and colon: November 30 to December 1, 2002. Gastrointest Endosc 2003;58 (Suppl December):S3-43.

32. Bosman FT, Carneiro F, Hruban RH, Theise ND. WHO Classification of Tumours of the Digestive System. IARC Press, 2010.

33. Farris AB, Misdraji J, Srivastava A, Muzikansky A, Deshpande V, Lauwers GY, Mino-Kenudson M. Sessile serrated adenoma: challenging discrimination from other serrated colonic polyps. Am J Surg Pathol 2008;32:30-5.

34. Baker K, Zhang Y, Jin C, Jass JR. Proximal versus distal hyperplastic polyps of the colorectum: different lesions or a biological spectrum? J Clin Pathol 2004;57:1089-93.

35. Spring KJ, Zhao ZZ, Karamatic R, Walsh MD, Whitehall VL, Pike T, Simms LA, Young J, James M, Montgomery GW, Appleyard M, Hewett D, Togashi K, Jass JR, Leggett BA. High prevalence of sessile serrated adenomas with BRAF mutations: a prospective study of patients undergoing colonoscopy. Gastroenterology 2006;131:1400-7.

36. Winawer S, Fletcher R, Rex D, Bond J, Burt R, Ferrucci J, Ganiats T, Levin T, Woolf S, Johnson D, Kirk L, Litin S, Simmang C. Colorectal cancer screening and surveillance: clinical guidelines and rationaleUpdate based on new evidence. Gastroenterology 2003;124:544-60.

37. Costantini M, Sciallero S, Giannini A, Gatteschi B, Rinaldi P, Lanzanova G, Bonelli L, Casetti T, Bertinelli E, Giuliani O, Castiglione G, Mantellini P, Naldoni C, Bruzzi P. Interobserver agreement in the histologic diagnosis of colorectal polyps. the experience of the multicenter adenoma colorectal study (SMAC). J Clin Epidemiol 2003;56:209-14.

38. Terry MB, Neugut AI, Bostick RM, Potter JD, Haile RW, Fenoglio-Preiser CM. Reliability in the classification of advanced colorectal adenomas. Cancer Epidemiol Biomarkers Prev 2002;11:660-3.

39. Li D, Jin C, McCulloch C, Berger BM, Imperiale TF, Terdiman JP. S1114 Association of Large Hyperplastic Polyps with Synchronous Advanced Colorectal Neoplasia. Gastroenterology 2008;134:A-181.

40. lacopetta B. Are there two sides to colorectal cancer? Int J Cancer 2002;101:403-8.

41. Rex DK. Preventing colorectal cancer and cancer mortality with colonoscopy: what we know and what we don't know. Endoscopy 2010;42:320-3.

42. Brooker JC, Saunders BP, Shah SG, Thapar CJ, Thomas HJ, Atkin WS, Cardwell CR, Williams CB. Total colonic dye-spray increases the detection of diminutive adenomas during routine colonoscopy: a randomized controlled trial. Gastrointest Endosc 2002;56:333-8.

43. Le Rhun M, Coron E, Parlier D, Nguyen JM, Canard JM, Alamdari A, Sautereau D, Chaussade S, Galmiche JP. High resolution colonoscopy with chromoscopy versus standard colonoscopy for the detection of colonic neoplasia: a randomized study. Clin Gastroenterol Hepatol 2006;4:349-54.

44. Boparai KS, Mathus-Vliegen EM, Koornstra JJ, Nagengast FM, van Leerdam M, van Noesel CJ, Houben $M$, Cats $A$, van Hest LP, Fockens $P$, Dekker $E$. Increased colorectal cancer risk during follow-up in patients with hyperplastic polyposis syndrome: a multicentre cohort study. Gut 2010;59:1094-100. 
45. Levin B, Lieberman DA, McFarland B, Andrews KS, Brooks D, Bond J, Dash C, Giardiello FM, Glick S, Johnson D, Johnson CD, Levin TR, Pickhardt PJ, Rex DK, Smith RA, Thorson A, Winawer SJ. Screening and surveillance for the early detection of colorectal cancer and adenomatous polyps, 2008: a joint guideline from the American Cancer Society, the US Multi-Society Task Force on Colorectal Cancer, and the American College of Radiology. Gastroenterology 2008;134:1570-95.

46. Nagengast FM, Kaandorp CJ. [Revised CBO guideline 'Follow-up after polypectomy']. Ned Tijdschr Geneeskd 2001;145:2022-5.

47. Terdiman JP, McQuaid KR. Surveillance guidelines should be updated to recognize the importance of serrated polyps. Gastroenterology 2010;139:1444-7.

48. Martinez ME, McPherson RS, Levin B, Glober GA. A case-control study of dietary intake and other lifestyle risk factors for hyperplastic polyps. Gastroenterology 1997;113:423-9.

49. Wallace K, Grau MV, Ahnen D, Snover DC, Robertson DJ, Mahnke D, Gui J, Barry EL, Summers RW, McKeown-Eyssen G, Haile RW, Baron JA. The association of lifestyle and dietary factors with the risk for serrated polyps of the colorectum. Cancer Epidemiol Biomarkers Prev 2009;18:2310-7.

50. Morimoto LM, Newcomb PA, Ulrich CM, Bostick RM, Lais CJ, Potter JD. Risk factors for hyperplastic and adenomatous polyps: evidence for malignant potential? Cancer Epidemiol Biomarkers Prev 2002;11:1012-8.

51. Shrubsole MJ, Wu H, Ness RM, Shyr Y, Smalley WE, Zheng W. Alcohol drinking, cigarette smoking, and risk of colorectal adenomatous and hyperplastic polyps. Am J Epidemiol 2008;167:1050-8.

52. Khalid O, Radaideh S, Cummings OW, O'Brien MJ, Goldblum JR, Rex DK. Reinterpretation of histology of proximal colon polyps called hyperplastic in 2001. World J Gastroenterol 2009;15:3767-70.

53. Glatz K, Pritt B, Glatz D, Hartmann A, O'Brien MJ, Blaszyk H. A multinational, internet-based assessment of observer variability in the diagnosis of serrated colorectal polyps. Am J Clin Pathol 2007;127:938-45.

54. Rex DK, Kahi C, O'Brien M, Levin TR, Pohl H, Rastogi A, Burgart L, Imperiale T, Ladabaum U, Cohen J, Lieberman DA. The American Society for Gastrointestinal Endoscopy PIVI (Preservation and Incorporation of Valuable Endoscopic Innovations) on real-time endoscopic assessment of the histology of diminutive colorectal polyps. Gastrointest Endosc 2011;73:419-22. 
64 
Chapter 5

Endoscopic appearance of proximal colorectal neoplasms and potential implications for colonoscopy in cancer prevention

Eveline JA Rondagh, Mariëlle WE Bouwens, Robert G Riedl, Bjorn Winkens, Rogier de Ridder, Tonya Kaltenbach, Roy M Soetikno, Ad AM Masclee, Silvia Sanduleanu

Gastrointest Endosc 2012;75:1218-1225 


\section{Abstract}

\section{Background}

In everyday practice, the use of colonoscopy for prevention of colorectal cancer (CRC) is less effective in the proximal than the distal colon. A potential explanation for this is that proximal neoplasms have a more subtle endoscopic appearance, making them more likely to be overlooked.

\section{Objective}

To investigate the differences in endoscopic appearance, i.e. diminutive size and nonpolypoid shape, of proximal compared with distal colorectal neoplasms.

\section{Design}

Cross-sectional, single-center study.

\section{Setting}

Endoscopists at the Maastricht University Medical Center in the Netherlands were previously trained in the detection and classification of nonpolypoid colorectal lesions.

\section{Patients}

Consecutive patients undergoing elective colonoscopy.

\section{Main outcome measurements}

Endoscopic appearance, i.e. diminutive size $(<6 \mathrm{~mm})$ or nonpolypoid shape (height less than half of the diameter) of colorectal adenomas and serrated polyps (SPs), with a focus on adenomas with advanced histology, i.e. high-grade dysplasia or early CRC, and SPs with dysplasia or large size.

\section{Results}

We included 3720 consecutive patients with 2106 adenomas and 941 SPs. We found that in both men and women, proximal adenomas with high-grade dysplasia/early CRC $(n=181)$ were more likely to be diminutive or nonpolypoid than distal ones: $76.3 \%$ vs. $26.2 \%$ (OR 9.24, 95\% Cl 4.45-19.2, $P<0.001$ ). Of the proximal adenomas, $84.4 \%$ were diminutive or nonpolypoid vs. $68.0 \%$ of the distal ones (OR $2.66,95 \% \mathrm{Cl}$ 2.14-3.29, $P<0.001)$. Likewise, large/dysplastic SPs in the proximal colon were more often nonpolypoid than distal ones: $66.2 \%$ vs. $27.8 \%$ (OR $5.51,95 \% \mathrm{Cl} 2.79-10.9, P<0.001$ ).

\section{Limitation}

Inclusion of both symptomatic and asymptomatic patients.

\section{Conclusion}

Proximal colorectal neoplasms with advanced histology frequently are small or have a nonpolypoid appearance. These findings support careful inspection of the proximal colon, if quality of cancer prevention with the use of colonoscopy is to be optimized. 


\section{Introduction}

Colonoscopy with polypectomy is considered the most important modality for the prevention of colorectal cancer (CRC). ${ }^{1}$ Unexpectedly, some recent studies raised concerns about the effectiveness of colonoscopy for the prevention of CRC in everyday practice, especially with respect to the proximal colon. ${ }^{2-4}$ Colonoscopy may prevent as many as $85 \%$ of cases of distal CRC, whereas risk reduction for the proximal colon is markedly lower, ranging from $0 \%$ to $55 \% .^{2-5}$

It is currently unclear why colonoscopy is less effective in the prevention of proximal $\mathrm{CRC}^{6}$ A recent study by Kaminski et al showed that a low adenoma detection rate is an important predictor of the development of post-colonoscopy cancers. ${ }^{7}$ Moreover, it has been demonstrated that adenoma detection rates may vary widely among endoscopists. ${ }^{8-10}$ More extensive information is therefore needed to clarify the way in which endoscopist's performance and training may contribute, among other factors, to the limited effectiveness of colonoscopy in the prevention of CRC in the proximal colon.

Colorectal neoplasms with a subtle endoscopic appearance, i.e. diminutive size or nonpolypoid shape, may be more easily overlooked during a routine colonoscopy, ${ }^{11,12}$ especially when co-factors such as low adenoma detection rates or suboptimal bowel preparation are involved. ${ }^{13}$ Previous studies suggested that proximal colorectal neoplasms may be more likely to display a diminutive or nonpolypoid endoscopic appearance, ${ }^{14-16}$ but did not thoroughly examine the relationship between endoscopic appearance and histology and none of them systematically addressed this relationship for all types of colorectal lesions, i.e. conventional adenomas and serrated polyps (SPs).

A preferential distribution of diminutive or nonpolypoid advanced colorectal neoplasms in the proximal colon, could offer a possible explanation for the considerable (3.3-12.4\%) proportion of proximal CRCs diagnosed shortly after a clearing colonoscopy. ${ }^{4,17,18}$ We therefore aimed to investigate the differences in endoscopic appearance of proximal and distal colorectal neoplasms, with a focus on diminutive size and nonpolypoid shape, and their relationship with advanced histology.

\section{Methods}

\section{Study design}

Before beginning this study, all endoscopists at the Division of Gastroenterology and Hepatology of the Maastricht University Medical Center in the Netherlands were trained to familiarize them with the detection, classification and management of nonpolypoid colorectal lesions, as previously described. ${ }^{19,20}$ This training consisted of i) lectures by an experienced colonoscopist (S.S.), ii) video-training by using American 
Society for Gastrointestinal Endoscopy educational programs, ${ }^{21,22}$ and iii) feedback and supervision while performing a colonoscopy. Special attention was paid to quality indicators, i.e. adenoma detection and cecal intubation rates.

From February 2008 to February 2010, we prospectively included all consecutive symptomatic and asymptomatic patients referred for elective colonoscopy at our university hospital. Our endoscopy unit provides colonoscopic examinations for both general practitioner referrals and specialist referrals, serving a population of approximately 300,000 inhabitants. We excluded patients younger than 18 years of age, those having a hereditary CRC syndrome (i.e. Lynch syndrome or known polyposis syndromes, including the hyperplastic polyposis syndrome) or inflammatory bowel disease, those having undergone a previous CRC or colonic resection, or those with inadequate bowel preparation. In patients who underwent two colonoscopies during the study period, we only evaluated colonoscopic data from the first colonoscopy. The study was approved by the Institutional Review Board of the Maastricht University Medical Center (MEC 08-4-074), which waived the need for individual informed consent.

\section{Colonoscopy}

Patients received 2 to $4 \mathrm{I}$ of polyethylene glycol solution for bowel preparation. Colonoscopies were performed by 9 gastroenterologists and 11 trainees, by using highresolution Pentax endoscopes (Pentax B.V.). Colonoscopic examinations were documented prospectively using a standardized reporting system, including digital photographic documentation. Quality of bowel preparation was classified according to the endoscopist's estimation as sufficient (good or fair) or insufficient (poor), as previously described. ${ }^{7,23}$ Colorectal lesions were subdivided according to location into i) proximal: from the cecum to the splenic flexure or ii) distal: from the descending colon to the rectum. The size of the colorectal lesions was estimated visually by using standard biopsy forceps or a mini-snare. We classified the colorectal polyps according to size into $<6 \mathrm{~mm}, 6-9 \mathrm{~mm}$ and $>9 \mathrm{~mm}$. In accord with previous studies, ${ }^{16,24,25}$ we defined nonpolypoid lesions as colorectal lesions with a height less than half of the diameter. Finally, all colorectal lesions were removed endoscopically by cold biopsy, snare polypectomy, endoscopic mucosal resection (EMR), or surgery. ${ }^{26,27}$ Selective chromoendoscopy was used, when needed, to clarify the borders of nonpolypoid lesions before endoscopic removal.

\section{Histopathology and classification of colorectal polyps}

The histopathological diagnosis of all colorectal polyps was performed by experienced GI pathologists, according to the WHO classification. ${ }^{28}$ The pathologists were not aware of the study hypotheses. We defined lesions with advanced histology as adenomas containing high-grade dysplasia (HGD) or early cancer, i.e. limited to the submucosa (T1). SPs were subdivided into: i) dysplastic SPs (including traditional 
serrated adenomas and sessile serrated adenomas/polyps with dysplasia) and ii) nondysplastic SPs (including hyperplastic polyps and sessile serrated adenomas/polyps without dysplasia). We specifically examined the dysplastic SPs and large $(\geq 6 \mathrm{~mm})$ nondysplastic SPs, because these subgroups are considered to harbor a risk of malignant transformation. ${ }^{29-31}$ CRCs invading the muscularis propria or beyond (T2-T4) were not included in the analyses, because these cancers are considered to be advanced cancers and are classified separately. ${ }^{25}$

\section{Statistical analysis}

The primary outcome measure of this study was the endoscopic appearance, i.e. diminutive size or nonpolypoid shape, of adenomas containing HGD/early CRC in relation to colonic location. We secondarily measured the endoscopic appearance of all adenomas and SPs in relation to colonic location.

Based on previous studies showing that diminutive adenomas may represent as many as $27 \%$ and nonpolypoid adenomas as many as $54 \%$ of all adenomas with HGD/early $\mathrm{CRC}^{24,32}$ we estimated that at least 172 adenomas with $\mathrm{HGD} /$ early CRC were needed to detect a difference of more than $20 \%$ between the proximal and distal colon with regard to diminutive size and nonpolypoid appearance, with $80 \%$ power and at a significance level of 0.05 . For this sample size calculation, we assumed that colorectal polyps are equally distributed between the proximal and distal colon. According to previous data ${ }^{24}$ and taking in consideration the defined exclusion criteria for participation into the current study, we expected that an inclusion period of two years (approximately 5000 consecutive colonoscopies) would be sufficient to include at least 172 adenomas with HGD/early CRC.

Multiple logistic regression analyses were used to adjust for age, sex and indication for colonoscopy. The results were verified by using generalized estimating equations, adjusting for potential correlation because of the presence of more than one polyp in the same patient, as previously described. ${ }^{33}$ Differences in dichotomous variables were examined by using the chi-squared test or the Fisher exact test, where appropriate. Differences in continuous variables between groups were examined by using the independent-samples t-test. All statistical analyses were performed by using SPSS statistical software version 15.0 (SPSS Inc, Chicago, Illinois). All odds ratios (ORs) are presented with $95 \%$ confidence intervals $(\mathrm{Cls})$. Two-sided $P$ values $<0.05$ were considered statistically significant. 


\section{Results}

\section{Study population}

From February 2008 to February 2010, a total of 4753 patients underwent 5246 colonoscopies at the Maastricht University Medical Center. We excluded patients younger than 18 years of age $(n=18)$, patients having a hereditary CRC syndrome $(n=43)$ or inflammatory bowel disease $(n=356)$ patients having undergone previous CRC $(n=168)$ or colon resection $(n=80)$ and patients with inadequate bowel preparation $(n=368)$.

Finally, a total of 3720 consecutive patients (mean age 58.9 years, $45.5 \%$ men) were examined (Table 5.1). The majority (82.4\%) of patients underwent colonoscopy because of symptoms (e.g. anemia, change in bowel habits, abdominal pain, and rectal blood loss). In this cohort, the cecal intubation rate was $91.3 \%$. The cecal intubation rate was higher in asymptomatic patients than in symptomatic patients $(95.1 \% \mathrm{vs}$. $90.5 \%, P<0.001)$.

\section{Prevalence of colorectal neoplasms}

Overall, $29.4 \%$ of the patients had at least one adenoma and $14.4 \%$ at least one SP (Table 5.1). As shown in Table 5.1, the prevalence of all types of colorectal neoplasms was significantly higher among patients referred for surveillance after previous polypectomy compared with patients referred for symptoms or screening. The adenoma prevalence rate among gastroenterologists with more than 50 colonoscopies during the study period ranged from 27.1 to $32.7 \%(95 \% \mathrm{Cl}, 20.2-40.3 \%)$, whereas among trainees it ranged from 25.1 to $34.1 \%(95 \% \mathrm{Cl}, 20.9-41.4 \%)$.

Table 5.1 Demographic and clinicopathologic data of the study population.

\begin{tabular}{lcccc}
\hline & & \multicolumn{3}{c}{ Indication for colonoscopy } \\
& All & Symptoms & Screening & Surveillance $^{\text {a }}$ \\
\hline Study population, no. & 3720 & 3065 & 289 & 366 \\
Mean age, y (SD) & $58.9(15.9)$ & $58.5(16.7)$ & $57.0(10.7)$ & $63.8(10.2)$ \\
Men, no. (\%) & $1693(45.5)$ & $1329(43.4)$ & $138(47.8)$ & $226(61.7)$ \\
$\geq 1$ adenoma, no. (\%) & $1095(29.4)$ & $801(26.1)$ & $99(34.3)$ & $195(53.3)$ \\
$\geq 1$ serrated polyp, no. (\%) & $537(14.4)$ & $379(12.4)$ & $57(19.7)$ & $101(27.6)$ \\
$\geq 1$ diminutive adenoma, no. (\%) & $876(23.5)$ & $613(20.0)$ & $88(30.4)$ & $175(47.8)$ \\
$\geq 1$ nonpolypoid adenoma, no. (\%) & $213(5.7)$ & $143(4.7)$ & $13(4.5)$ & $57(15.6)$ \\
\hline
\end{tabular}

SD = standard deviation. ${ }^{\text {a }}$ Significantly more adenomas, serrated polyps, diminutive adenomas and nonpolypoid adenomas in the surveillance group versus symptomatic or screening group $(P<0.001)$. 


\section{Endoscopic appearance of proximal compared with distal (advanced) adenomas}

We detected a total of 2106 adenomas, of which $8.6 \%$ (181) revealed HGD/early CRC. Table 5.2 presents the endoscopic appearance of (advanced) adenomas in the proximal and distal colon. Proximal adenomas with HGD/early CRC were significantly more likely to be diminutive or nonpolypoid than distal ones: $76.3 \%$ vs. $26.2 \%$, adjusted OR 8.54, 95\% Cl 4.01-18.2, $P<0.001$. Advanced histology was present in 3.3\% (50/1500) of the diminutive adenomas and in $13.2 \%$ (37/281) of the nonpolypoid adenomas. Conversely, of the 181 adenomas containing HGD/early CRC, $27.6 \%$ (50) were diminutive and $20.4 \%$ (37) nonpolypoid. Early CRC was diagnosed in 13 colorectal lesions, $30.8 \%$ (4) of them were nonpolypoid (3) or diminutive (1). In general, adenomas with $\mathrm{HGD} /$ early CRC were more likely to be located in the distal than the proximal colon: $67.4 \%$ (122) vs. $32.6 \%(59), P<0.001$.

Of all adenomas, $71.2 \%$ (1500) were diminutive and $13.3 \%$ (281) nonpolypoid. As shown in Table 5.2, proximal adenomas in general were also more likely to be diminutive or nonpolypoid than distal ones: $84.4 \%$ vs. $68.0 \%$, adjusted OR $2.52,95 \% \mathrm{Cl}$ 2.03-3.13, $P<0.001$. Additional analysis, using generalized estimating equations, adjusting for potential correlation because of the presence of more than one polyp in the same patient, showed similar results.

Table 5.3 presents the endoscopic appearance of advanced adenomas in men and women separately. Overall, differences in endoscopic appearance between proximal and distal colorectal neoplasms were found in both men and women.

Table 5.2 Endoscopic appearance of proximal versus distal (advanced) adenomas.

\begin{tabular}{lccccc}
\hline \multirow{2}{*}{ ALL } & All proximal & \multicolumn{2}{c}{ All distal } & \multicolumn{3}{c}{ Proximal vs. Distal (reference) } \\
& adenomas $(\mathrm{n}=1048)$ & adenomas $(\mathrm{n}=1058)$ & OR & $95 \% \mathrm{Cl}$ & $P$-value \\
\hline Diminutive, $\mathrm{n}(\%)$ & $818(78.1)$ & $682(64.5)$ & 1.91 & $1.57-2.34$ & $<0.001$ \\
Nonpolypoid, $\mathrm{n}(\%)$ & $161(15.4)$ & $120(11.3)$ & 1.39 & $1.07-1.80$ & 0.01 \\
Diminutive or & $885(84.4)$ & $719(68.0)$ & 2.52 & $2.03-3.12$ & $<0.001$ \\
Nonpolypoid, $\mathrm{n}(\%)$ & & & & & \\
\hline \multirow{2}{*}{ ADVANCED } & Proximal advanced & Distal advanced & Proximal vs. Distal (reference) & a \\
& adenomas (n=59) & adenomas (n=122) & OR & $95 \% \mathrm{Cl}$ & $P$-value \\
\hline Diminutive, $\mathrm{n}(\%)$ & $27(45.0)$ & $23(18.9)$ & 3.06 & $1.48-6.33$ & 0.003 \\
Nonpolypoid, $\mathrm{n}(\%)$ & $22(37.3)$ & $15(12.3)$ & 4.72 & $2.09-10.7$ & $<0.001$ \\
Diminutive or & $45(76.3)$ & $32(26.2)$ & 8.54 & $4.01-18.2$ & $<0.001$ \\
Nonpolypoid, $\mathrm{n}(\%)$ & & & & & \\
\hline
\end{tabular}

$\mathrm{OR}=$ odds ratio, $\mathrm{Cl}=$ confidence interval. ${ }^{\mathrm{a}}$ Adjusted for age, sex and indication for colonoscopy. 
Table 5.3 Endoscopic appearance of advanced adenomas in men and women.

\begin{tabular}{|c|c|c|c|c|c|}
\hline \multirow{2}{*}{ MEN } & \multirow{2}{*}{$\begin{array}{l}\text { Proximal advanced } \\
\text { adenomas }(n=38)\end{array}$} & \multirow{2}{*}{$\begin{array}{c}\text { Distal advanced } \\
\text { adenomas }(n=67)\end{array}$} & \multicolumn{3}{|c|}{ Proximal vs. Distal (reference) $^{a}$} \\
\hline & & & OR & $95 \% \mathrm{Cl}$ & $\mathrm{p}$-value \\
\hline Diminutive, $\mathrm{n}(\%)$ & $19(50.0)$ & $12(17.9)$ & 4.58 & $1.88-11.2$ & $<0.001$ \\
\hline Nonpolypoid, n (\%) & $11(28.9)$ & 8 (11.9) & 3.02 & $1.09-8.39$ & 0.03 \\
\hline $\begin{array}{l}\text { Diminutive or } \\
\text { Nonpolypoid, } \mathrm{n}(\%)\end{array}$ & $27(71.1)$ & 18 (26.9) & 6.69 & $2.76-16.2$ & $<0.001$ \\
\hline \multirow{2}{*}{ WOMEN } & \multirow{2}{*}{$\begin{array}{l}\text { Proximal advanced } \\
\text { adenomas }(n=21)\end{array}$} & \multirow{2}{*}{$\begin{array}{c}\text { Distal advanced } \\
\text { adenomas }(n=55)\end{array}$} & \multicolumn{3}{|c|}{ Proximal vs. Distal (reference) ${ }^{a}$} \\
\hline & & & OR & $95 \% \mathrm{Cl}$ & $\mathrm{p}$-value \\
\hline Diminutive, $\mathrm{n}(\%)$ & $8(38.1)$ & $11(20.0)$ & 2.46 & $0.82-7.40$ & 0.11 \\
\hline Nonpolypoid, n (\%) & $11(52.4)$ & $7(12.7)$ & 8.02 & $2.43-26.5$ & $<0.001$ \\
\hline $\begin{array}{l}\text { Diminutive or } \\
\text { Nonpolypoid, } \mathrm{n}(\%)\end{array}$ & $18(85.7)$ & $14(25.5)$ & 17.9 & $4.54-70.3$ & $<0.001$ \\
\hline
\end{tabular}

$\mathrm{OR}=$ odds ratio, $\mathrm{Cl}=$ confidence interval. ${ }^{\mathrm{a}}$ Adjusted for age.

\section{Endoscopic appearance of proximal compared with distal serrated polyps}

A total of 941 SPs were found, of which 18.4\% (173) were nonpolypoid. Proximal SPs were more likely to be nonpolypoid than distal SPs: $37.3 \%$ vs. $13.0 \%$, adjusted OR 3.90 , 95\% Cl 2.72-5.57, $P<0.001$ (Table 5.4). In addition, proximal SPs were less often diminutive than distal SPs: $68.4 \%$ (143/209) vs. $90.3 \%$ (661/732), adjusted OR 0.23 , $95 \% \mathrm{Cl} 0.16-0.34, P<0.001$.

Of all SPs, 120 were large, non-dysplastic SPs and 47 dysplastic SPs. As shown in Table 5.4 proximal large or dysplastic SPs were more often nonpolypoid than the distal ones: $66.2 \%$ vs. $27.8 \%$, adjusted OR $5.48,95 \% \mathrm{Cl} 2.75-10.9, P<0.001$. Of the proximal large, non-dysplastic SPs $68.4 \%$ (39/57) were nonpolypoid compared with $33.3 \%$ (21/63) of the distal ones, $P<0.001$. Of the proximal, dysplastic SPs $60.0 \%(12 / 20)$ were nonpolypoid compared with $14.8 \%(4 / 27)$ of the distal ones, $P=0.001$.

Of the 47 dysplastic SPs, $91.5 \%$ (44) were sessile serrated adenomas/polyps with dysplasia, whereas $8.5 \%$ (4) were traditional serrated adenomas. Proximal sessile serrated adenomas/polyps with dysplasia $(n=20)$ were more likely to be nonpolypoid than the distal ones ( $n=23$ ): $60.0 \%$ vs. $8.7 \%, P<0.001$. All traditional serrated adenomas $(n=4)$ were located in the distal colon and two of them were nonpolypoid.

Table 5.4 Nonpolypoid endoscopic appearance of proximal versus distal serrated polyps.

\begin{tabular}{lccccc}
\hline ALL & Proximal SPs & \multicolumn{2}{c}{ Distal SPs } & \multicolumn{3}{c}{ Proximal vs. Distal (reference) ${ }^{\text {a }}$} \\
& $(\mathrm{n}=209)$ & $(\mathrm{n}=732)$ & OR & $95 \% \mathrm{Cl}$ & $P$-value \\
\hline Nonpolypoid, $\mathrm{n}(\%)$ & $78(37.3)$ & $95(13.0)$ & 3.90 & $2.72-5.57$ & $<0.001$ \\
\hline \multirow{3}{*}{ LARGE/DYSPLASTIC } & Proximal large/ & Distal large/ & \multicolumn{2}{c}{ Proximal vs. Distal (reference) $)^{\text {a }}$} \\
& dysplastic SPs & dysplastic SPs & OR & $95 \% \mathrm{Cl}$ & $P$-value \\
& $(\mathrm{n}=77)$ & $(\mathrm{n}=90)$ & & & \\
\hline Nonpolypoid, $\mathrm{n}(\%)$ & $51(66.2)$ & $25(27.8)$ & 5.47 & $2.75-10.9$ & $<0.001$ \\
\hline
\end{tabular}

$\mathrm{SPs}=$ serrated polyps, $\mathrm{OR}=$ odds ratio, $\mathrm{Cl}=$ confidence interval. ${ }^{\mathrm{a}}$ Adjusted for age, sex and indication for colonoscopy. 


\section{Discussion}

This study shows that proximal colorectal neoplasms with advanced histology are more likely to have a diminutive size or nonpolypoid endoscopic appearance than the distal ones. As summarized in Figure 5.1, approximately three fourths of the proximal adenomas with HGD or early cancer were diminutive or nonpolypoid, endoscopic features that have been highly associated with missed lesions during colonoscopy. ${ }^{11,12}$ These findings may offer a possible explanation for the disparity between the proximal and distal colon in the effectiveness of colonoscopy to prevent CRC.

Accurate detection of colorectal neoplasms during colonoscopy is essential for the prevention of CRC. ${ }^{7}$ Nevertheless, in everyday practice, adenoma detection rates vary widely (as high as 37\%) among endoscopists, ${ }^{8-10}$ underscoring the need for educational programs targeted to improve the individual endoscopist's adenoma detection rate. We presume that suboptimal inspection of the colonic mucosa, e.g. by those with a low adenoma detection rate, may particularly affect the detection of diminutive and nonpolypoid lesions, because of their inconspicuous endoscopic appearance (Figure 5.2). The relatively small variations in adenoma prevalence rates among gastroenterologists $(5.6 \%)$ and $\mathrm{Gl}$ trainees $(9.0 \%)$ in this study may reflect the systematic training to recognize nonpolypoid colorectal lesions and moreover suggest that educational programs targeted at optimizing the use of colonoscopy to prevent cancer should include the recognition of nonpolypoid lesions.

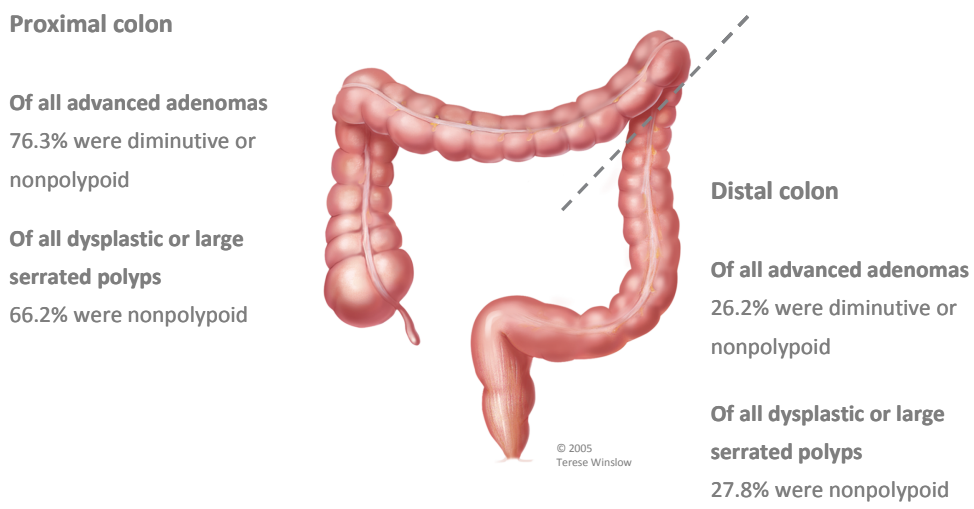

Figure 5.1 Endoscopic appearance of colorectal neoplasms according to location.

Three fourths of the adenomas with high-grade dysplasia or early cancer in the proximal colon were either diminutive or nonpolypoid, while only one fourth of the distal ones. Of the proximal serrated polyps with dysplasia or large size, two thirds were nonpolypoid compared with only one fourth of the distal ones. 
Adenomas with advanced histology in the proximal colon had a three times increased risk of having a diminutive size compared with the distal ones. Although the natural history of diminutive polyps is largely unknown, our data showing a preferred proximal location of advanced adenomas with a diminutive size, similar to the predominant location of post-colonoscopy cancers, may suggest that missed diminutive advanced adenomas are the origin of some of the post-colonoscopy cancers. This hypothesis is in line with other data from our group ${ }^{34}$ and others, ${ }^{35}$ showing that post-colonoscopy cancers frequently have a small macroscopic appearance.

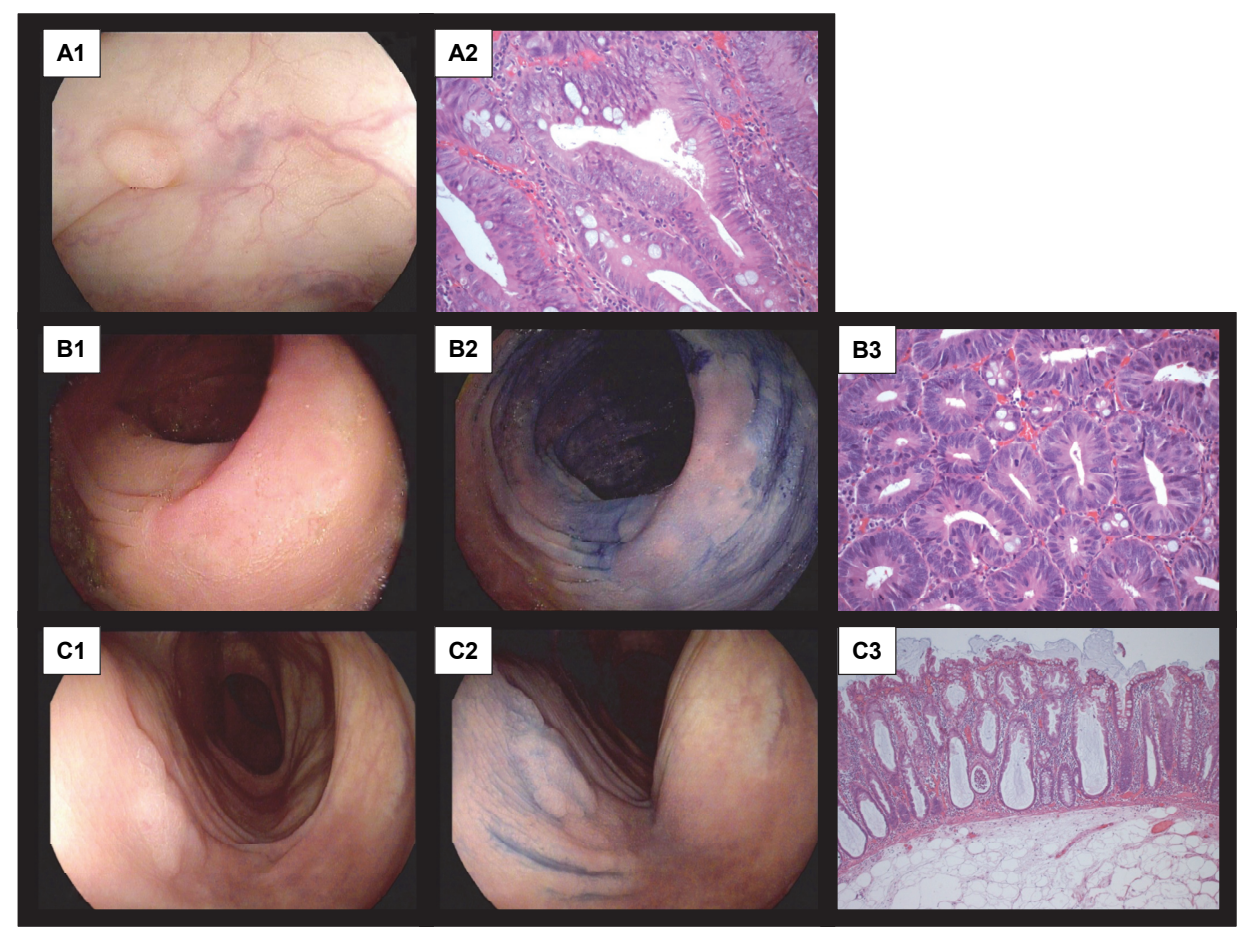

Figure 5.2 Diminutive and nonpolypoid colorectal neoplasms detected during colonoscopic examination. A1 Diminutive polyp located in the proximal colon. A2 Histological examination showed an adenoma containing high-grade dysplasia.

B1 Nonpolypoid (Paris classification Ila) lesion located in the colon transversum with a reddish appearance suggesting an adenomatous lesion. B2 Selective chromoendoscopy clarified the borders of the lesion. B3 Histology showed an adenoma with high-grade dysplasia.

C1 Nonpolypoid (Paris Ila) lesion located at the hepatic flexure, showing a pale and transparent appearance suggesting a serrated lesion. C2 Selective chromoendoscopy clarified the borders of the lesion. C3 Histological examination revealed a sessile serrated adenoma/polyp without dysplasia. 
In the current study, we additionally addressed the endoscopic appearance of the SPs. SPs are a heterogeneous group of lesions, of which the dysplastic as well as the proximal, large non-dysplastic SPs are now generally considered to harbor a significant risk of (abrupt) malignant transformation. ${ }^{29,30}$ In this study, we found that SPs with dysplasia or of a large size in the proximal colon were more often nonpolypoid than distal SPs, which makes them more difficult to visualize during colonoscopy. This, in conjunction with the similarities found between SPs and post-colonoscopy cancers in terms of molecular characteristics, i.e. microsatellite instability and the CpG methylator phenotype, ${ }^{36}$ suggests that overlooked SPs may contribute to the occurrence of some of the post-colonoscopy cancers.

Proximal and distal colorectal neoplasms show distinct epidemiological, clinical and molecular characteristics. ${ }^{37,38}$ Proximal CRCs occur at an older age, predominantly in women and are characterized by diploidy, frequent high levels of microsatellite instability and CpG island methylator phenotype. ${ }^{38}$ In contrast, distal CRCs predominantly occur in males and are characterized by aneuploidy and frequent loss of heterozygosity. ${ }^{38}$ These differences between proximal and distal colorectal neoplasms may be explained by both biological and environmental factors. First, embryologically, the proximal colon originates from the midgut, whereas the distal colon originates in the hindgut. ${ }^{37}$ Second, life-style habits may differentially affect the two colon sides. For example, the consumption of alcohol and red meat are associated with an increased risk for distal, but not proximal CRC. ${ }^{39,40}$ This may explain why CRC predominates in the distal colon in Western countries, whereas in areas with a low-incidence of CRC a proximal location is predominantly found. Finally, differences in luminal processes and exposure to carcinogenics in the proximal versus distal colon may further contribute to the described differences between proximal and distal colorectal neoplasms.

Some methodological aspects of the current study should be discussed. As a strength of this study, before starting, all participating endoscopists were familiarized with the detection and classification of nonpolypoid colorectal lesions. This is, to our knowledge, the first study addressing the endoscopic appearance of colorectal neoplasms according to their location, after training of the endoscopists. Furthermore, we used a standardized endoscopic reporting system, including digital photographic documentation, to ensure the reliability of data registration, with focus on quality metrics.

However, the current study has several limitations. First, the study was conducted in a real-life cohort, including all symptomatic and asymptomatic patients who underwent elective colonoscopy at our endoscopy department. Although these findings may not necessarily be applicable to a real screening population, the current study documenting all examinations performed in our endoscopy department may offer a potential explanation for the substantial (3.3-12.4\%) proportion of proximal CRCs that develop shortly after colonoscopy. ${ }^{4,17,18}$ To minimize potential bias caused by including a heterogeneous study population, we adjusted for the indication for colonoscopy in the logistic regression analyses. 
Second, the cross-sectional study design precluded future risk assessment in the patients with diminutive or nonpolypoid advanced colorectal neoplasms. Whether the described preferred location of diminutive sized and nonpolypoid colorectal neoplasms still holds true during surveillance colonoscopies is unknown and deserves further clarification. Third, in this study, we did not separately record the quality of bowel preparation for the proximal and distal colon. Because bowel preparation has been reported to be worse in the proximal than in the distal colon, ${ }^{41}$ and this will particularly hamper the detection of diminutive and nonpolypoid lesions, localized suboptimal cleansing would have resulted in an underestimation rather than an overestimation of the differences found between the two colon sides. Last, the clinical relevance of diminutive colorectal neoplasms in the prevention of CRC by using colonoscopy remains controversial. The likelihood of diminutive adenomas to contain advanced histology is relatively small. In our study, only $3.3 \%$ of the diminutive adenomas revealed HGD or early CRC, which is in line with other studies reporting a prevalence ranging from 1.1 to $3.5 \% \cdot{ }^{14,42-46}$ However, as the majority of all colorectal adenomas are diminutive, these polyps still represent a significant proportion $(27.3 \%$ in this study) of all adenomas with HGD or early CRC. ${ }^{47}$

In this study, we found that proximal colorectal neoplasms, in particular adenomas with HGD or early CRC, were more likely to have a diminutive size or nonpolypoid appearance than distal ones. Likewise, proximal large or dysplastic SPs were more often nonpolypoid than distal ones. Differences in the endoscopic appearance of colorectal neoplasms may partially explain the disparity between the proximal and the distal colon in CRC prevention by using colonoscopy in everyday practice. Our data advocate careful inspection of the proximal colon during colonoscopic examination to finally optimize the quality of cancer prevention by using colonoscopy. 


\section{References}

1. Jemal A, Bray F, Center MM, Ferlay J, Ward E, Forman D. Global cancer statistics. CA Cancer J Clin 2011;61:69-90.

2. Baxter NN, Goldwasser MA, Paszat LF, Saskin R, Urbach DR, Rabeneck L. Association of colonoscopy and death from colorectal cancer. Ann Intern Med 2009;150:1-8.

3. Singh H, Nugent Z, Mahmud SM, Demers AA, Bernstein CN. Predictors of colorectal cancer after negative colonoscopy: a population-based study. Am J Gastroenterol 2010;105:663-73; quiz 674.

4. Mulder SA, van Soest EM, Dieleman JP, van Rossum LG, Ouwendijk RJ, van Leerdam ME, Kuipers EJ. Exposure to colorectal examinations before a colorectal cancer diagnosis: a case-control study. Eur J Gastroenterol Hepatol 2010;22:437-43.

5. Brenner H, Chang-Claude J, Seiler CM, Rickert A, Hoffmeister M. Protection from colorectal cancer after colonoscopy: a population-based, case-control study. Ann Intern Med 2011;154:22-30.

6. Rex DK. Preventing colorectal cancer and cancer mortality with colonoscopy: what we know and what we don't know. Endoscopy 2010;42:320-3.

7. Kaminski MF, Regula J, Kraszewska E, Polkowski M, Wojciechowska U, Didkowska J, Zwierko M, Rupinski M, Nowacki MP, Butruk E. Quality indicators for colonoscopy and the risk of interval cancer. N Engl J Med 2010;362:1795-803.

8. Imperiale TF, Glowinski EA, Juliar BE, Azzouz F, Ransohoff DF. Variation in polyp detection rates at screening colonoscopy. Gastrointest Endosc 2009;69:1288-95.

9. Hetzel JT, Huang CS, Coukos JA, Omstead K, Cerda SR, Yang S, O'Brien MJ, Farraye FA. Variation in the detection of serrated polyps in an average risk colorectal cancer screening cohort. Am J Gastroenterol 2010;105:2656-64.

10. Kahi CJ, Hewett DG, Norton DL, Eckert GJ, Rex DK. Prevalence and variable detection of proximal colon serrated polyps during screening colonoscopy. Clin Gastroenterol Hepatol 2011;9:42-6.

11. Heresbach D, Barrioz T, Lapalus MG, Coumaros D, Bauret P, Potier P, Sautereau D, Boustiere C, Grimaud JC, Barthelemy C, See J, Serraj I, D'Halluin PN, Branger B, Ponchon T. Miss rate for colorectal neoplastic polyps: a prospective multicenter study of back-to-back video colonoscopies. Endoscopy 2008;40:284-90.

12. van Rijn JC, Reitsma JB, Stoker J, Bossuyt PM, van Deventer SJ, Dekker E. Polyp miss rate determined by tandem colonoscopy: a systematic review. Am J Gastroenterol 2006;101:343-50.

13. Harewood GC, Sharma VK, de Garmo P. Impact of colonoscopy preparation quality on detection of suspected colonic neoplasia. Gastrointest Endosc 2003;58:76-9.

14. Kapsoritakis AN, Potamianos SP, Koukourakis MI, Tzardi M, Mouzas IA, Roussomoustakaki M Alexandrakis G, Kouroumalis EA. Diminutive polyps of large bowel should be an early target for endoscopic treatment. Dig Liver Dis 2002;34:137-40.

15. Konishi K, Fujii T, Boku N, Kato S, Koba I, Ohtsu A, Tajiri H, Ochiai A, Yoshida S. Clinicopathological differences between colonic and rectal carcinomas: are they based on the same mechanism of carcinogenesis? Gut 1999;45:818-21.

16. Jaramillo $E$, Watanabe $M$, Slezak $P$, Rubio $C$. Flat neoplastic lesions of the colon and rectum detected by high-resolution video endoscopy and chromoscopy. Gastrointest Endosc 1995;42:114-22.

17. Baxter NN, Sutradhar R, Forbes SS, Paszat LF, Saskin R, Rabeneck L. Analysis of administrative data finds endoscopist quality measures associated with postcolonoscopy colorectal cancer. Gastroenterology 2011;140:65-72.

18. Singh H, Nugent Z, Demers AA, Bernstein CN. Rate and predictors of early/missed colorectal cancers after colonoscopy in Manitoba: a population-based study. Am J Gastroenterol 2010;105:2588-96.

19. Sanduleanu S, Rondagh EJA, Masclee AA. Development of expertise in the detection and classification of non-polypoid colorectal neoplasia: Experience-based data at an academic GI unit. Gastrointest Endosc Clin N Am 2010;20:449-60.

20. Rondagh EJ, Masclee AA, Bouwens MW, Winkens B, Riedl RG, de Bruine AP, de Ridder R, Kaltenbach T, Soetikno RM, Sanduleanu S. Endoscopic red flags for the detection of high-risk serrated polyps: an observational study. Endoscopy 2011;43:1052-8.

21. Soetikno RM, Barro J, Friedland S, Matsui S, Rouse R, Fujii T. Diagnosis of Flat and Depressed Colorectal Neoplasms. ASGE Endoscopic Learning Library 2006; Available at: http://www.asge.org/ell_list.aspx 
22. Rex DK. Colonoscopic Polypectomy. ASGE Endoscopic Learning Library 2007; Available at: http://www.asge.org/ell_list.aspx

23. Aronchick CA, Lipshutz $\bar{W}$, Wright $\mathrm{SH}$, Dufrayne $\mathrm{F}$, Bergman G. Validation of an instrument to assess colon cleansing [abstract] Am J Gastroenterol 1999;94:2667.

24. Rembacken BJ, Fujii T, Cairns A, Dixon MF, Yoshida S, Chalmers DM, Axon AT. Flat and depressed colonic neoplasms: a prospective study of 1000 colonoscopies in the UK. Lancet 2000;355:1211-4.

25. Soetikno RM, Kaltenbach T, Rouse RV, Park W, Maheshwari A, Sato T, Matsui S, Friedland S. Prevalence of nonpolypoid (flat and depressed) colorectal neoplasms in asymptomatic and symptomatic adults. JAMA 2008;299:1027-35.

26. Kudo S, Tamegai Y, Yamano H, Imai Y, Kogure E, Kashida H. Endoscopic mucosal resection of the colon: the Japanese technique. Gastrointest Endosc Clin N Am 2001;11:519-35.

27. Kaltenbach T, Friedland S, Maheshwari A, Ouyang D, Rouse RV, Wren S, Soetikno R. Short- and longterm outcomes of standardized EMR of nonpolypoid (flat and depressed) colorectal lesions $\geq 1 \mathrm{~cm}$ (with video). Gastrointest Endosc 2007;65:857-65.

28. Bosman F, Carneiro F, Hruban R, Theise N. WHO Classification of Tumours of the Digestive System. IARC Press, 2010

29. Leggett B, Whitehall V. Role of the serrated pathway in colorectal cancer pathogenesis. Gastroenterology 2010;138:2088-100.

30. East JE, Saunders BP, Jass JR. Sporadic and syndromic hyperplastic polyps and serrated adenomas of the colon: classification, molecular genetics, natural history, and clinical management. Gastroenterol Clin North Am 2008;37:25-46.

31. Bouwens M, Rondagh E, Winkens B, Driessen A, de Bruine A, P., Masclee A, Sanduleanu S. 600 Are Hyperplastic Polyps Precursors of Colorectal Cancer? A Long-Term, Retrospective Study. Gastroenterology 2009;136:A-97.

32. Church JM. Clinical significance of small colorectal polyps. Dis Colon Rectum 2004;47:481-5.

33. Zeger SL, Liang KY. Longitudinal data analysis for discrete and continuous outcomes. Biometrics 1986;42:121-30.

34. le Clercq C, Rondagh E, Riedl R, Bosman FT, Beets GL, Hameeteman W, Masclee A, Sanduleanu S. Interval Colorectal Cancers Frequently Have Subtle Macroscopic Appearance: A 10 Year-Experience in an Academic Center. Gastroenterology 2011;140:S112-3.

35. Farrar WD, Sawhney MS, Nelson DB, Lederle FA, Bond JH. Colorectal cancers found after a complete colonoscopy. Clin Gastroenterol Hepatol 2006;4:1259-64.

36. Arain MA, Sawhney M, Sheikh S, Anway R, Thyagarajan B, Bond JH, Shaukat A. CIMP status of interval colon cancers: another piece to the puzzle. Am J Gastroenterol 2010;105:1189-95.

37. Bufill JA. Colorectal cancer: evidence for distinct genetic categories based on proximal or distal tumor location. Ann Intern Med 1990;113:779-88.

38. lacopetta B. Are there two sides to colorectal cancer? Int J Cancer 2002;101:403-8.

39. Chao A, Thun MJ, Connell CJ, McCullough ML, Jacobs EJ, Flanders WD, Rodriguez C, Sinha R, Calle EE. Meat consumption and risk of colorectal cancer. JAMA 2005;293:172-82.

40. Toyomura K, Yamaguchi K, Kawamoto H, Tabata S, Shimizu E, Mineshita M, Ogawa S, Lee KY, Kono S. Relation of cigarette smoking and alcohol use to colorectal adenomas by subsite: the self-defense forces health study. Cancer Sci 2004;95:72-6.

41. Parra-Blanco A, Nicolas-Perez D, Gimeno-Garcia A, Grosso B, Jimenez A, Ortega J, Quintero E. The timing of bowel preparation before colonoscopy determines the quality of cleansing, and is a significant factor contributing to the detection of flat lesions: a randomized study. World J Gastroenterol 2006;12:6161-6.

42. Bretagne JF, Manfredi S, Piette C, Hamonic S, Durand G, Riou F. Yield of high-grade dysplasia based on polyp size detected at colonoscopy: a series of 2295 examinations following a positive fecal occult blood test in a population-based study. Dis Colon Rectum 2010;53:339-45.

43. Butterly LF, Chase MP, Pohl H, Fiarman GS. Prevalence of clinically important histology in small adenomas. Clin Gastroenterol Hepatol 2006;4:343-8.

44. Gschwantler M, Kriwanek S, Langner E, Goritzer B, Schrutka-Kolbl C, Brownstone E, Feichtinger H, Weiss W. High-grade dysplasia and invasive carcinoma in colorectal adenomas: a multivariate analysis of the impact of adenoma and patient characteristics. Eur J Gastroenterol Hepatol 2002;14:183-8. 
45. Aldridge AJ, Simson JN. Histological assessment of colorectal adenomas by size. Are polyps less than 10 $\mathrm{mm}$ in size clinically important? Eur J Surg 2001;167:777-81.

46. Unal H, Selcuk H, Gokcan H, Tore E, Sar A, Korkmaz M, Bilezikci B, Demirhan B, Gur G, Yilmaz U. Malignancy risk of small polyps and related factors. Dig Dis Sci 2007;52:2796-9.

47. Tsai FC, Strum WB. Prevalence of advanced adenomas in small and diminutive colon polyps using direct measurement of size. Dig Dis Sci 2011;56:2384-8. 


\section{Chapter 6}

\section{Nonpolypoid colorectal neoplasms in}

patients with Lynch syndrome:

potential implications for surveillance strategies

Eveline JA Rondagh*, Sanne Gulikers*, Encarna B Gómez-García, Yvan Vanlingen, Yvonne Detisch, Bjorn Winkens, Hans FA Vasen, Ad AM Masclee, Silvia Sanduleanu *Both authors contributed equally to this work

Submitted 


\section{Abstract}

\section{Background \& study aims}

Patients with Lynch syndrome (LS) may develop colorectal cancer (CRC), despite intensive colonoscopic surveillance. Overlooking nonpolypoid colorectal neoplasms may explain some of these cancers. In this casecontrol study, we compared the endoscopic appearance of colorectal neoplasms between LS patients and subjects at average risk for CRC.

\section{Patients and methods}

We familiarized the endoscopists at our academic medical center on the recognition and classification of nonpolypoid lesions. We prospectively included LS patients and patients at average risk for CRC who underwent elective colonoscopy at our institution. We defined nonpolypoid lesions as lesions with a height $<1 / 2$ diameter and advanced histology by the presence of high-grade dysplasia or early cancer.

\section{Results}

A total of 59 LS patients (mean age 48.7 years, $47.5 \%$ men) and 590 matched controls (mean age 50.2 years, $47.5 \%$ men) were included. In patients with LS, adenomas were more likely to be nonpolypoid than in controls: $43.3 \%$ vs. $16.9 \%$, OR $3.77,95 \% \mathrm{Cl} 2.05-6.94, P<0.001$. This was in particular true for proximal adenomas: $58.1 \%$ vs. $16.3 \%$, OR $7.10,95 \% \mathrm{Cl} 3.16-16.0, P<0.001$. Adenomas containing advanced histology were more often nonpolypoid in LS patients than in controls $(4 / 5,80.0 \%$ vs. $5 / 17,29.4 \%, P=0.19)$. Serrated polyps were also more often nonpolypoid in LS patients than in controls: $49.2 \%$ vs. $20.4 \%$, OR $3.78,95 \% \mathrm{CI}$ 2.07-6.91, $P<0.001$.

\section{Conclusions}

In patients with LS, colorectal neoplasms are more likely to have a nonpolypoid shape than those from average-risk subjects, especially in the proximal colon. Our findings suggest that surveillance of this high-risk group should be performed by endoscopists trained on detection of nonpolypoid colorectal lesions. 


\section{Introduction}

The Lynch syndrome (LS) is an autosomal dominant genetic condition, caused by germline mutations in one of the DNA mismatch repair genes. ${ }^{1,2}$ Higher prevalence of colorectal adenomas ${ }^{3}$ in conjunction with a more rapid adenoma to carcinoma progression ${ }^{4}$ explains the increased life-time risk for CRC in patients with LS ranging from 40 to $80 \%,{ }^{1,2}$ and emphasizes the need for intensive colonoscopic surveillance to prevent CRC. Nevertheless, recent cohort studies showed that despite colonoscopic surveillance every 2 to 3 years, LS patients carry approximately $10 \%$ risk of developing CRC during 10 years of follow-up..$^{5-7}$ Shortening these intervals to 1-2 years may reduce this risk to $6 \%{ }^{8}$

Apart from shortening the surveillance intervals, it is of utmost importance to ensure high quality of colonoscopic procedures in LS patients, and especially to improve the adenoma detection, to further downsize the risk of developing CRC during surveillance (i.e. interval CRCs). Nonpolypoid colorectal neoplasms, recently recognized in western countries, ${ }^{9,10}$ are likely to contribute to the occurrence of interval $\mathrm{CRCs}^{10,11}$ as these lesions are more easily overlooked during colonoscopy ${ }^{12}$ and expertise on endoscopic removal techniques is not yet widely available. The contribution of nonpolypoid mechanisms to the colorectal carcinogenesis in patients with LS needs clarification, as this may have clinical implications. It has been shown that detection of nonpolypoid lesions may be improved through training of the endoscopists ${ }^{13-15}$ and by using contrast enhanced endoscopy techniques, such as chromoendoscopy. ${ }^{16}$

Although previous studies found that a substantial proportion of colorectal neoplasms in patients with LS are nonpolypoid, ${ }^{17-22}$ none of them examined the magnitude of the problem in this group compared to an average-risk population. Nowadays, endoscopy programs for colonoscopic examination of LS patients are similar to those for patients at average risk for CRC. A higher proportion of nonpolypoid lesions in LS patients as compared to average-risk subjects could indicate the need for additional expertise and techniques in the colonoscopic surveillance of patients with LS. We therefore conducted a prospective case-control study, in which we familiarized all endoscopists at our university hospital on the detection, classification and treatment of nonpolypoid colorectal lesions. We examined the endoscopic appearance, in particular nonpolypoid shape, of colorectal neoplasms in patients with LS versus average-risk subjects, with special attention for location and histology. 


\section{Methods}

\section{Study Population}

\section{Lynch syndrome group}

We included consecutive patients with Lynch syndrome who attended the multidisciplinary outpatient clinic for hereditary CRC of our institution, between February 2008 and September 2011. This specialized program provides screening and counseling of individuals at high-risk for CRC. Only patients with proven mutation in one of the mismatch repair genes, i.e. MLH1, MSH-2, MSH-6 or PMS-2, and who underwent an index or surveillance colonoscopy between February 2008 and September 2011 were included. Surveillance colonoscopies were provided every 1 to 2 years, according the national guidelines. ${ }^{23}$ We excluded patients aged $<18$ years, those with prior total colectomy, inflammatory bowel disease, as well as those with incomplete colonic visualization due to inadequate preparation or incomplete examination.

\section{Control group}

The control group was derived from a large prospective cohort of consecutive patients who underwent elective index colonoscopy (for symptoms or screening indications) or surveillance colonoscopy (follow-up after polypectomy) at our university hospital between February 2008 and February 2010, as detailed elsewhere. ${ }^{10}$ We excluded patients aged $<18$ years, those with personal or family ${ }^{23}$ history of CRC, colonic resection, inflammatory bowel disease, and those with incomplete colonic visualization due to inadequate preparation or incomplete examination. From this cohort of patients at average-risk for CRC, we randomly selected 10 control patients matched for age, sex and indication for colonoscopy for each LS patient.

\section{Colonoscopy}

Before commencing this study, we trained all endoscopists at our university hospital, as previously described, ${ }^{15}$ with the aim of increasing awareness and developing practical skills on recognition, classification and treatment of nonpolypoid colorectal lesions. This training program comprised lectures by a dedicated colonoscopist (S.S.), video demonstrations using accredited educational programs, ${ }^{9,24}$ and individual feedback. $^{15}$

Patients received 2-4 $\mathrm{L}$ polyethylene glycol solution for bowel preparation and conscious sedation. Colonoscopies were performed by 9 gastroenterologists and $11 \mathrm{GI}$ trainees using high-resolution Pentax endoscopes. We recorded endoscopic data using a standardized reporting system, including photographic documentation. Quality of bowel preparation was classified depending on the endoscopists' estimation as 
sufficient (good or fair) or insufficient (poor), as previously described. ${ }^{25,26}$ We categorized colorectal lesions according to location into i) proximal: from caecum to splenic flexure or ii) distal: from descending colon to rectum. We defined nonpolypoid colorectal neoplasms as lesions with a height $<1 / 2$ of the diameter, in line with previous studies. ${ }^{27,28}$ In case of a suspected nonpolypoid lesion, selective chromoendoscopy was applied using indigo carmine $0.4 \%$, to demarcate the borders before endoscopic resection. Removal of colorectal lesions was performed by cold biopsy, snare polypectomy or endoscopic mucosal resection (EMR).

\section{Histopathology}

Histological diagnosis was performed by experienced pathologists, according to the WHO classification. ${ }^{29}$ We defined advanced histology by the presence of high-grade dysplasia (HGD) or early cancer (limited to the submucosa). We subdivided serrated polyps into dysplastic and non-dysplastic. ${ }^{29}$ CRCs invading the muscularis propria or beyond were not included in the analyses, as these cancers are considered to be advanced cancers and are classified separately.

\section{Outcome Measurement}

The main outcome measure of this study was the proportion of adenomas with nonpolypoid appearance in LS patients versus controls. We paid special attention to location of these adenomas and presence of advanced histology. Secondary outcome was the proportion of serrated polyps with a nonpolypoid endoscopic appearance in LS patients versus controls.

\section{Statistical analysis}

As prevalences of adenomas are likely dependent upon age, ${ }^{30}$ sex $^{30}$ and may differ between index versus surveillance colonoscopy, ${ }^{27}$ we used a matched case-control design, in which every LS case was matched with 10 controls with similar distribution of age, sex and ratio of index versus surveillance indications for colonoscopy. In order to estimate the sample size needed to test whether adenomas in LS patients are more likely to be nonpolypoid than those from average-risk subjects, we made the following assumptions: i) prevalences of adenomas are approximately 1 per patient in LS patients ${ }^{31}$ versus 0.5 per patient in average-risk populations ${ }^{32}$ and ii) nonpolypoid adenomas represent at least $35 \%$ of all adenomas in LS patients ${ }^{17-19}$ and at least $10-15 \%$ of all adenomas in average-risk groups. ${ }^{27,32}$ With these assumptions in mind and in order to detect a difference $>20 \%$ in the proportion of CRNs with nonpolypoid appearance in LS patients versus controls with at least $80 \%$ power, we needed at least $50 \mathrm{LS}$ patients and 500 controls patients.

Differences in dichotomous variables were examined using multiple logistic regression analysis, including the age, sex and index versus surveillance indications for 
colonoscopy to adjust for the matched study design. For differences in continuous variables multiple linear regression analyses were performed, also including age, sex and index versus surveillance colonoscopy. We conducted additional analyses for proximal and distal colorectal neoplasms, separately. Both per patient and per polyp analyses were performed.

All statistical analyses were performed using SPSS statistical software package 15.0 (SPSS, Chicago, Illinois). All odds ratios (OR) are presented with $95 \%$ confidence intervals $(\mathrm{Cl})$. Two-sided $\mathrm{p}$-values $\leq 0.05$ were considered statistically significant.

\section{Results}

\section{Study populations}

Figure 6.1 illustrates the flow chart of the study. A total of 64 LS patients were initially eligible for the study, of whom 5 patients were excluded. Fifty-nine LS patients with a proven MMR gene mutation (11 MLH-1, 6 MSH-2, 30 MSH- 6 and 12 PMS-2 carriers), from 25 pedigrees and who underwent a total of 103 colonoscopies during the study period were examined.

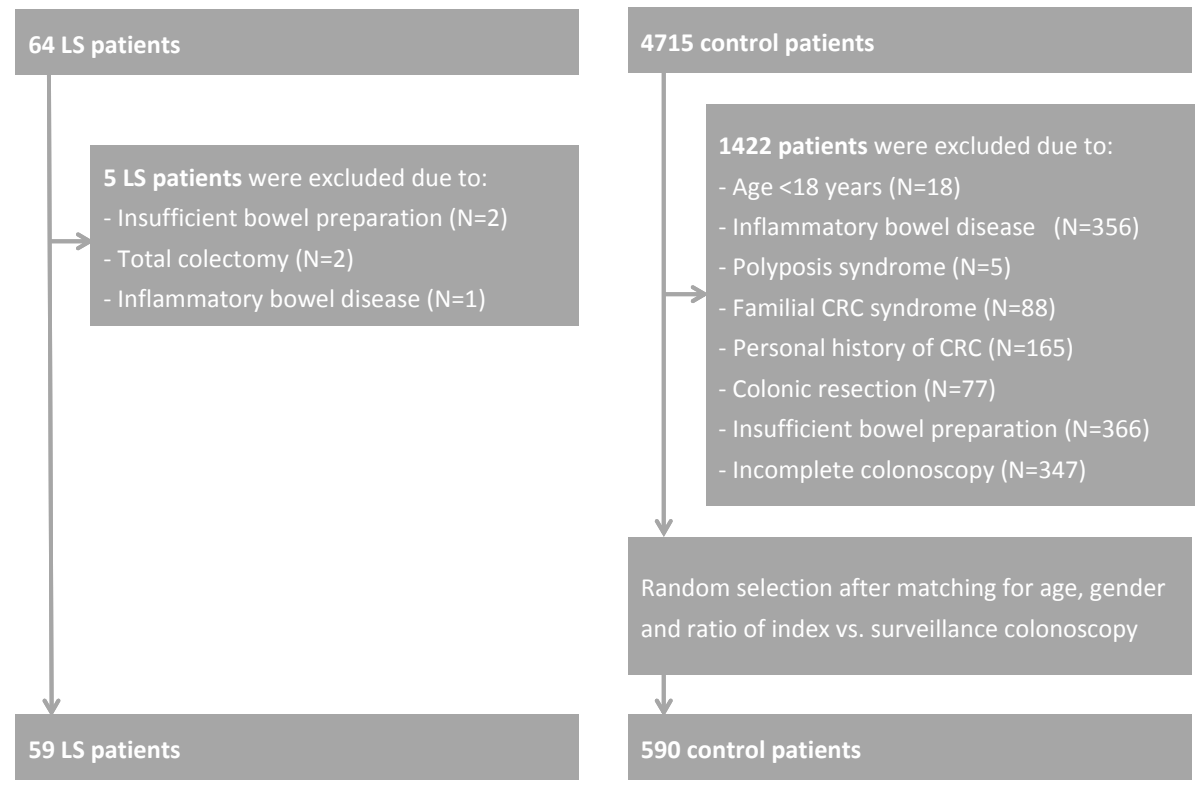

Figure 6.1 Study flow chart. A total of 64 LS patients were initially eligible for inclusion, of whom 5 were excluded. In the control group, a total of $\mathbf{4 7 1 5}$ patients were initially eligible for inclusion, of whom 1422 were excluded. Of the remaining patients, we randomly selected 590 controls, with similar distribution of age, sex and ratio between index and surveillance indications. 
A total of 4715 control subjects were initially eligible for the study, of whom 1422 were excluded according to the exclusion criteria (Figure 6.1). Of the remaining 3293 patients, we randomly selected 590 control patients (620 colonoscopies) with similar distribution of age, sex and ratio of index versus surveillance indications for colonoscopy (Table 6.1). Of the control patients who underwent an index colonoscopy (335), 92.2\% were referred for symptoms (e.g. abdominal pain, aspecific abdominal complaints) and $7.8 \%$ for screening indications.

Table 6.1 Demographic and clinicopathologic data of the study populations.

\begin{tabular}{lccc}
\hline & LS group & Control group & $P$-value \\
\hline Study population, $\mathrm{n}$ & 59 & 590 & \\
Mean age, y (SD) & $48.7(12.6)$ & $50.2(14.8)$ & 0.29 \\
Men, $\mathrm{n}(\%)$ & $28(47.5)$ & $280(47.5)$ & 0.76 \\
Index (vs. surveillance) colonoscopy, $\mathrm{n}(\%)$ & $33(55.9)$ & $335(56.8)$ & 0.40 \\
Patients with $\geq 1$ adenoma, $\mathrm{n}(\%)$ & $28(47.5)$ & $181(30.7)$ & 0.001 \\
Patients with $\geq 1$ serrated polyp, $\mathrm{n}(\%)$ & $26(44.1)$ & $112(19.0)$ & $<0.001$ \\
Patients with colorectal cancer, $\mathrm{n}(\%)$ & $3(5.1)$ & $3(0.5)$ & 0.004 \\
\hline
\end{tabular}

LS = Lynch syndrome, $\mathrm{SD}=$ standard deviation

\section{Prevalence and histopathologic characteristics of adenomas}

Overall, we found that the prevalence of adenomas was higher in patients with LS than controls (47.5\% vs. 30.7\%, $P=0.001$ ) (Table 6.1). A total of 53 adenomas were found in the LS group (13 adenomas in MLH-1, 6 in MSH-2, 26 in MSH-6 and 8 in PMS-2 mutation carriers) vs. 349 adenomas in the control group. Of the adenomas found in LS patients, 9.4\% (5/53) contained advanced histology vs. $4.9 \%(17 / 349)$ of those from control patients, $P=0.40$.

Three LS patients were diagnosed with CRC during the study period (Table 6.1), of whom one at the index-colonoscopy, while the other two during surveillance, at 9 and 31 months respectively after the last colonoscopic examination. The two CRCs diagnosed during surveillance were both found in MLH1 mutation carriers and were proximally located and had a nonpolypoid endoscopic appearance.

\section{Colorectal adenomas with nonpolypoid appearance in LS patients versus controls}

Colorectal adenomas from LS patients were significantly more likely to have a nonpolypoid endoscopic appearance than those from controls: $43.4 \%$ (23/53) vs. $16.9 \%$ (53/349), OR 3.60, 95\% Cl 1.90-6.83, $P<0.001$ (Table 6.2). This was especially true for proximally located adenomas, of which $58.1 \%(18 / 31)$ in the LS group and $16.3 \%(31 / 190)$ in the control group were nonpolypoid (OR 6.93, 95\% Cl 2.92-16.4, $P<0.001)$. 
Table 6.2 The endoscopic appearance of proximal versus distal adenomas in LS patients versus control subjects.

\begin{tabular}{lccccc}
\hline & LS & Control & \multicolumn{3}{c}{ LS patients vs. control subjects $^{\text {a }}$} \\
& patients & subjects & OR & $95 \% \mathrm{Cl}$ & $P$-value \\
\hline $\begin{array}{l}\text { All adenomas, } \\
\% \text { nonpolypoid }\end{array}$ & $43.4 \%(23 / 53)$ & $16.9 \%(59 / 349)$ & 3.60 & $1.90-6.83$ & $<0.001$ \\
$\begin{array}{l}\text { Proximal adenomas, } \\
\% \text { nonpolypoid }\end{array}$ & $58.1 \%(18 / 31)$ & $16.3 \%(31 / 190)$ & 6.93 & $2.92-16.4$ & $<0.001$ \\
$\begin{array}{l}\text { Distal adenomas, } \\
\% \text { nonpolypoid }\end{array}$ & $22.7 \%(5 / 22)$ & $17.6 \%(28 / 159)$ & 1.09 & $0.35-3.44$ & 0.88 \\
\hline
\end{tabular}

$\mathrm{LS}=$ Lynch syndrome, $\mathrm{OR}=$ odds ratio, $\mathrm{Cl}=$ Confidence interval. ${ }^{\mathrm{a}}$ Adjusted for age, sex and index versus surveillance colonoscopy.

Adenomas containing HGD/early CRC had more often a nonpolypoid appearance in LS patients than in controls, although this difference was not statistically significant $(4 / 5$, $80.0 \%$ vs. $5 / 17,29.4 \%, P=0.19)$. Of the 4 nonpolypoid adenomas with HGD/early CRC in LS patients, 2 were located in the proximal colon en 2 in the distal colon.

The proportions of adenomas with a nonpolypoid shape were 53.8\%, 83.3\%, 26.9\% and $50.0 \%$ for MLH1, MSH2, MSH6 and PMS2 mutation carriers, respectively $(P>0.05)$. In both LS and control patients, we found no significant differences with regard to the endoscopic appearance of adenomas found during the index or surveillance colonoscopy: $41.2 \%(7 / 17)$ vs. $44.4 \%$ (16/36), $P=0.99$ and $16.0 \%(15 / 94)$ vs. 17.3 (44/255), $P=0.52$.

\section{Prevalence and histopathologic characteristics of serrated polyps}

Prevalence of serrated polyps was higher in patients with LS than controls $(44.1 \% \mathrm{vs}$. $19.0 \%, P<0.001$ ). A total of 63 serrated polyps were found in the LS group ( 6 in MLH-1, 2 in MSH-2, 34 in MSH-6 and 21 in PMS-2 mutation carriers) vs. 196 in the control group. Only $1.6 \%(1 / 63)$ of the serrated polyps in LS patients contained dysplasia (PMS2 mutation carrier) vs. $3.1 \%(6 / 196)$ of those from controls, $P=0.71$.

\section{Serrated polyps with nonpolypoid appearance in LS patients versus controls}

Serrated polyps from LS patients had significantly more often a nonpolypoid endoscopic appearance than those from controls $49.2 \%$ (31/63) vs. $20.4 \%$ (40/196), OR $3.57,95 \% \mathrm{Cl} 1.91-6.68, P<0.001$. In the proximal colon, $70.0 \%(7 / 10)$ of the serrated polyps from LS patients were nonpolypoid vs. $37.1 \%$ (25/57) of the serrated polyps from controls, $P=0.10$. In the distal colon, $45.3 \%(24 / 53)$ of the serrated polyps from LS patients were nonpolypoid vs. $12.1 \%(15 / 139)$ of those from controls, $P<0.001$. 


\section{Discussion}

In the present study, we found that colorectal neoplasms in patients with LS are more likely to have a nonpolypoid endoscopic appearance than those from subjects at average risk for CRC. This finding concerned adenomas, adenomas with advanced histology as well as serrated polyps, and underscores the importance of accurate detection and removal of nonpolypoid lesions during colonoscopic surveillance of patients with LS.

Current surveillance guidelines for LS patients do not contain special recommendations in terms of endoscopist's proficiency on detection and treatment of nonpolypoid colorectal neoplasms or type of colonoscopic examination (i.e. use of chromoendoscopy). It is known that accurate detection of nonpolypoid colorectal neoplasms may require optimal endoscopic circumstances, as these lesions are easily overlooked due to their subtle appearance (Figure 6.2). ${ }^{12}$ Endoscopists with expertise on the recognition of nonpolypoid lesions have been shown to detect more nonpolypoid as well as polypoid adenomas. ${ }^{13,14,33}$ Moreover, a recent study in LS patients showed that intensive (at least 20 minutes) inspection of the colonic mucosa, as well as pan-chromoendoscopy, increases the detection of in particular nonpolypoid neoplasms. ${ }^{19}$ Our finding that adenomas in LS patients are more often nonpolypoid than in controls indicates that colonoscopic surveillance in this high-risk group should be performed by experienced endoscopists using additional techniques (i.e. intensive inspection, chromoendoscopy) targeted on the detection of these lesions.

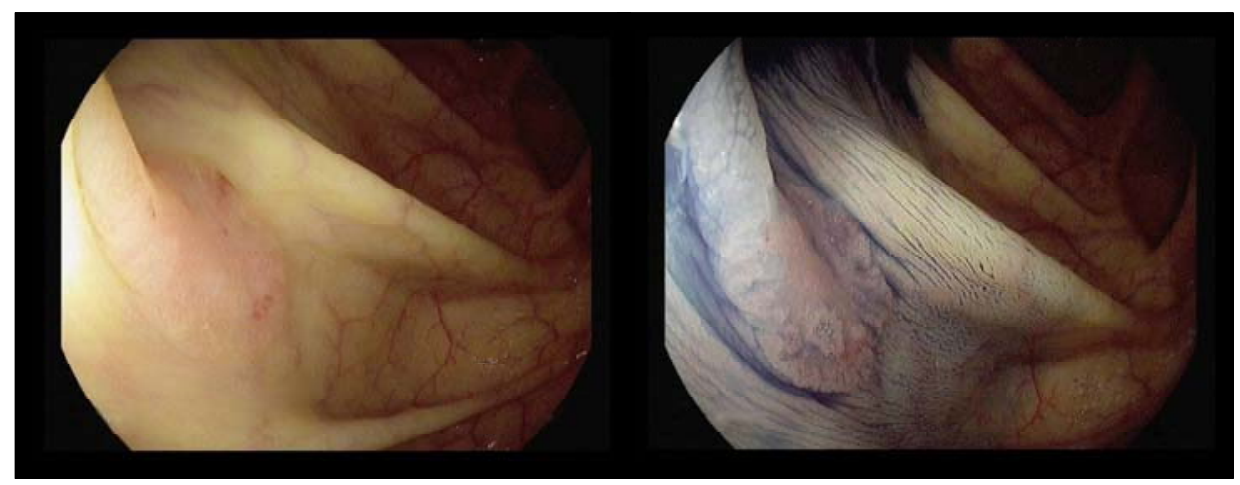

Figure 6.2 Nonpolypoid colorectal lesion found in a Lynch syndrome patient.

This MLH1 mutation carrier underwent surveillance colonoscopy, which showed a nonpolypoid colorectal neoplasm (Paris type Ila) located in the ascending colon. Selective chromoendoscopy using indigo carmine $0.4 \%$ allowed better delineation of borders prior to endoscopic removal. 
Notably, in our study we found a high proportion of nonpolypoid adenomas in the proximal colon of LS patients (58\%) as compared to controls (16\%) (Figure 6.3). In a recent Dutch study, 33 of the 745 patients with LS developed CRC during surveillance, $62 \%$ of these cancers were found in the proximal colon. ${ }^{8}$ Rijcken et al showed that proximal adenomas in LS patients are more likely to contain HGD than distal ones suggesting that these proximal adenomas have a higher malignant potential. ${ }^{34}$ These findings, together with the predominant proximal location of nonpolypoid adenomas, underscore the importance of meticulous inspection, possibly in conjunction with panchromoendoscopy, ${ }^{16}$ in the proximal colon.

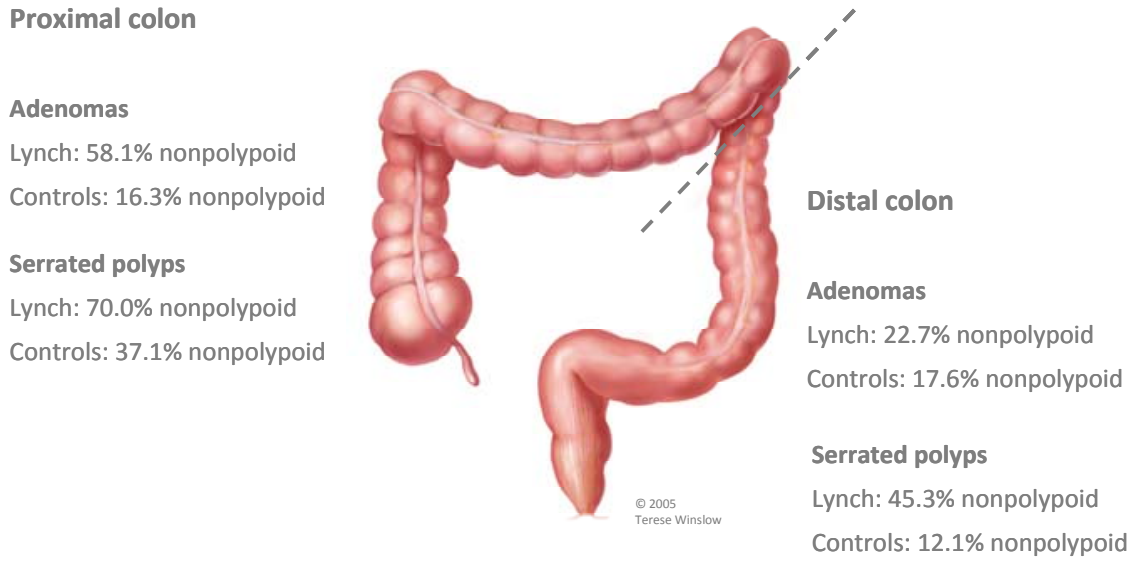

Figure 6.3 Nonpolypoid endoscopic appearance of colorectal neoplasms according to location. In patients with Lynch syndrome, a high proportion of the colorectal neoplasms in the proximal colon have a nonpolypoid endoscopic appearance.

Previous studies in populations at average risk for CRC suggested that a subset of the nonpolypoid neoplasms, especially the Paris type II-c lesions, are more likely to contain advanced histology. ${ }^{27,35}$ Although the present study was not powered to address the malignant potential of nonpolypoid adenomas in patients with LS, we found that $80 \%$ (4/5) of adenomas with advanced histology had a nonpolypoid appearance. The malignant potential of nonpolypoid colorectal neoplasms in patients with LS is presently unclear and needs further investigation in larger, multi-center studies. Nevertheless, detection of all adenomas is important in patients with LS, as their adenomas are more prone to malignant transformation ${ }^{3}$ and have a short polyp dwell time. $^{4}$

Clinical and molecular studies suggest that the serrated neoplastic pathway is not involved in the LS, as prevalences of traditional serrated adenomas ${ }^{3}$ and sessile serrated polyps/adenomas ${ }^{36}$ are low, and BRAF mutations and CpG island methylator 
phenotype are uncommon in these patients. ${ }^{37}$ In our study, we found a high frequency of serrated polyps in patients with LS, especially in MSH-6 and PMS-2 mutation carriers. Whether a relation exists between mismatch repair deficiency and the serrated neoplastic pathway in MSH-6 and PMS-2 mutation carriers is presently unclear and should be examined in future studies.

All endoscopists participating in this study were trained on the recognition and classification of nonpolypoid lesions, after which both study groups were simultaneously included, which can be regarded as a strength of this study. Additionally, inclusion through a specialized outpatient program for patients with hereditary forms of CRC and use of standardized endoscopy reports ensured accurate documentation of genetic diagnoses and endoscopic findings. Nevertheless, some potential limitations of the present study should be discussed as well. First, it has been shown that pan-chromoendoscopy increases the detection of nonpolypoid colorectal lesions, ${ }^{16}$ while in the present study we used selective chromoendoscopy. Although our findings that $43 \%$ of the adenomas in LS are nonpolypoid are in line with previous studies, ${ }^{17-19}$ we realize this might be an underestimation. However, a higher prevalence of nonpolypoid adenomas in LS patients would only strengthen the main conclusions of this study. Second, as the number of adenomas with advanced histology in LS patients was relatively low, we cannot draw any conclusions regarding the endoscopic appearance of these lesions. So far, our data indicate that the frequent nonpolypoid endoscopic appearance also holds true for adenomas with advanced histology, emphasizing the need for accurate detection and complete removal. Third, the control group, which was recruited simultaneously with the Lynch population, consisted of predominantly symptomatic patients, in whom the prevalence of colorectal neoplasms might have been higher than in screening patients. Inclusion of a genuine screening population could therefore have resulted in even more evident difference in the prevalence of colorectal neoplasms.

In conclusion, this study indicates that nonpolypoid mechanisms may play an important role in colorectal carcinogenesis in patients with LS, especially in the proximal colon. We therefore recommend that surveillance of patients with LS should be performed by endoscopists experienced on detection and treatment of nonpolypoid lesions, to optimize the quality of colonoscopic cancer prevention in this population at high-risk for CRC. 


\section{References}

1. Vasen HF. Review article: The Lynch syndrome (hereditary nonpolyposis colorectal cancer). Aliment Pharmacol Ther 2007;26 Suppl 2:113-26.

2. Lindor NM, Petersen GM, Hadley DW, Kinney AY, Miesfeldt S, Lu KH, Lynch P, Burke W, Press N. Recommendations for the care of individuals with an inherited predisposition to Lynch syndrome: a systematic review. JAMA 2006;296:1507-17.

3. De Jong AE, Morreau H, Van Puijenbroek M, Eilers PH, Wijnen J, Nagengast FM, Griffioen $G$, Cats $A$ Menko FH, Kleibeuker JH, Vasen HF. The role of mismatch repair gene defects in the development of adenomas in patients with HNPCC. Gastroenterology 2004;126:42-8.

4. Edelstein DL, Axilbund J, Baxter M, Hylind LM, Romans K, Griffin CA, Cruz-Correa M, Giardiello FM. Rapid Development of Colorectal Neoplasia in Patients With Lynch Syndrome. Clin Gastroentero Hepatol 2010.

5. de Vos tot Nederveen Cappel WH, Nagengast FM, Griffioen G, Menko FH, Taal BG, Kleibeuker JH, Vasen HF. Surveillance for hereditary nonpolyposis colorectal cancer: a long-term study on 114 families. Dis Colon Rectum 2002;45:1588-94.

6. Jarvinen HJ, Renkonen-Sinisalo L, Aktan-Collan K, Peltomaki P, Aaltonen LA, Mecklin JP. Ten years after mutation testing for Lynch syndrome: cancer incidence and outcome in mutation-positive and mutation-negative family members. J Clin Oncol 2009;27:4793-7.

7. Mecklin JP, Aarnio M, Laara E, Kairaluoma MV, Pylvanainen K, Peltomaki P, Aaltonen LA, Jarvinen HJ. Development of colorectal tumors in colonoscopic surveillance in Lynch syndrome. Gastroenterology 2007;133:1093-8

8. Vasen HF, Abdirahman M, Brohet R, Langers AM, Kleibeuker JH, van Kouwen M, Koornstra JJ, Boot $\mathrm{H}_{2}$ Cats A, Dekker E, Sanduleanu S, Poley JW, Hardwick JC, de Vos Tot Nederveen Cappel WH, van der Meulen-de Jong AE, Tan TG, Jacobs MA, Mohamed FL, de Boer SY, van de Meeberg PC, Verhulst ML, Salemans JM, van Bentem N, Westerveld BD, Vecht J, Nagengast FM. One to 2-year surveillance intervals reduce risk of colorectal cancer in families with Lynch syndrome. Gastroenterology 2010;138:2300-6.

9. Soetikno RM, Barro J, Friedland S, Matsui S, Rouse R, Fujii T. Diagnosis of Flat and Depressed Colorectal Neoplasms. ASGE Endoscopic Learning Library 2006; Available at: http://www.asge.org/ell_list.aspx

10. Rondagh EJ, Bouwens MW, RiedI RG, de Ridder R, Kaltenbach T, Soetikno R, Masclee AA, Sanduleanu S Endoscopic appearance of proximal colorectal neoplasms and potential implications for colonoscopic cancer prevention. Gastrointest Endosc In press.

11. Rondagh EJ, Masclee AA, Bouwens MW, Winkens B, RiedI RG, de Bruine AP, de Ridder R, Kaltenbach T, Soetikno RM, Sanduleanu S. Endoscopic red flags for the detection of high-risk serrated polyps: an observational study. Endoscopy 2012;43:1052-8.

12. Heresbach D, Barrioz T, Lapalus MG, Coumaros D, Bauret P, Potier P, Sautereau D, Boustiere C, Grimaud JC, Barthelemy C, See J, Serraj I, D'Halluin PN, Branger B, Ponchon T. Miss rate for colorectal neoplastic polyps: a prospective multicenter study of back-to-back video colonoscopies. Endoscopy 2008;40:284-90

13. Church JM, Muto T, Appau K. Flat lesions of the colorectal mucosa: differences in recognition between Japanese and American endoscopists. Dis Colon Rectum 2004:47:1462-1466.

14. Kaltenbach T, McGill SK, Kalidindi V, Friedland S, Soetikno R. Proficiency in the Diagnosis of Nonpolypoid Colorectal Neoplasm Yields High Adenoma Detection Rates. Dig Dis Sci 2011.

15. Sanduleanu S, Rondagh EJA, Masclee AA. Development of expertise in the detection and classification of non-polypoid colorectal neoplasia: Experience-based data at an academic Gl unit. Gastrointest Endosc Clin N Am 2010;20:449-460.

16. Le Rhun M, Coron E, Parlier D, Nguyen JM, Canard JM, Alamdari A, Sautereau D, Chaussade S, Galmiche JP. High resolution colonoscopy with chromoscopy versus standard colonoscopy for the detection of colonic neoplasia: a randomized study. Clin Gastroenterol Hepatol 2006;4:349-54.

17. Huneburg R, Lammert F, Rabe C, Rahner N, Kahl P, Buttner R, Propping P, Sauerbruch T, Lamberti C. Chromocolonoscopy detects more adenomas than white light colonoscopy or narrow band imaging colonoscopy in hereditary nonpolyposis colorectal cancer screening. Endoscopy 2009;41:316-22. 
18. Hurlstone DP, Karajeh M, Cross SS, McAlindon ME, Brown S, Hunter MD, Sanders DS. The role of highmagnification-chromoscopic colonoscopy in hereditary nonpolyposis colorectal cancer screening: a prospective "back-to-back" endoscopic study. Am J Gastroenterol 2005;100:2167-73.

19. Stoffel EM, Turgeon DK, Stockwell DH, Zhao L, Normolle DP, Tuck MK, Bresalier RS, Marcon NE, Baron JA, Ruffin MT, Brenner DE, Syngal S. Missed adenomas during colonoscopic surveillance in individuals with Lynch Syndrome (hereditary nonpolyposis colorectal cancer). Cancer Prev Res (Phila Pa) 2008;1:470-5

20. East JE, Suzuki N, Stavrinidis M, Guenther T, Thomas HJ, Saunders BP. Narrow band imaging for colonoscopic surveillance in hereditary non-polyposis colorectal cancer. Gut 2008;57:65-70.

21. Ramsoekh D, Haringsma J, Poley JW, van Putten P, van Dekken H, Steyerberg EW, van Leerdam ME, Kuipers EJ. A back-to-back comparison of white light video endoscopy with autofluorescence endoscopy for adenoma detection in high-risk subjects. Gut 2010;59:785-93.

22. Watanabe T, Muto T, Sawada T, Miyaki M. Flat adenoma as a precursor of colorectal carcinoma in hereditary nonpolyposis colorectal carcinoma. Cancer 1996;77:627-34.

23. (2008). "Kwaliteitsinstituut voor de Gezondheidszorg. CBO richtlijn Erfelijke Darmkanker." Retrieved 19 August 2010, from http://www.cbo.nl/Downloads/257/rl_erf_darm_08.pdf.

24. Rex DK. Colonoscopic Polypectomy. ASGE Endoscopic Learning Library 2007; Available at: http://www.asge.org/ell_list.aspx

25. Aronchick CA, Lipshutz $\bar{W}$ H, Wright SH, Dufrayne F, Bergman G. Validation of an instrument to assess colon cleansing [abstract] Am J Gastroenterol 1999;94:2667.

26. Kaminski MF, Regula J, Kraszewska E, Polkowski M, Wojciechowska U, Didkowska J, Zwierko M, Rupinski M, Nowacki MP, Butruk E. Quality indicators for colonoscopy and the risk of interval cancer. N Engl J Med 2010;362:1795-803.

27. Soetikno RM, Kaltenbach T, Rouse RV, Park W, Maheshwari A, Sato T, Matsui S, Friedland S. Prevalence of nonpolypoid (flat and depressed) colorectal neoplasms in asymptomatic and symptomatic adults. JAMA 2008;299:1027-1035.

28. Park DH, Kim HS, Kim WH, Kim TI, Kim YH, Park DI, Kim HJ, Yang SK, Byeon JS, Lee MS, Chung IK, Jung SA, Jeen YT, Choi JH, Choi H, Han DS. Clinicopathologic characteristics and malignant potential of colorectal flat neoplasia compared with that of polypoid neoplasia. Dis Colon Rectum 2008;51:43-49.

29. Bosman F, Carneiro F, Hruban R, Theise N. WHO Classification of Tumours of the Digestive System. IARC Press, 2010

30. Nguyen SP, Bent S, Chen YH, Terdiman JP. Gender as a risk factor for advanced neoplasia and colorectal cancer: a systematic review and meta-analysis. Clin Gastroenterol Hepatol 2009;7:676-681.

31. Sanduleanu S, Driessen A, Gomez-Garcia E, Hameeteman W, de Bruine A, Masclee A. In vivo diagnosis and classification of colorectal neoplasia by chromoendoscopy-guided confocal laser endomicroscopy. Clin Gastroenterol Hepatol 2009;8:371-8.

32. Rondagh EJ, Masclee AA, van der Valk ME, Winkens $B$, de Bruine AP, Kaltenbach T, Soetikno RM, Sanduleanu S. Nonpolypoid colorectal neoplasms: gender differences in prevalence and malignant potential. Scand J Gastroenterol 2011;47:80-8.

33. Saitoh Y, Waxman I, West AB, Popnikolov NK, Gatalica Z, Watari J, Obara T, Kohgo Y, Pasricha PJ. Prevalence and distinctive biologic features of flat colorectal adenomas in a North American population. Gastroenterology 2001;120:1657-1665.

34. Rijcken FE, Hollema H, Kleibeuker JH. Proximal adenomas in hereditary non-polyposis colorectal cancer are prone to rapid malignant transformation. Gut 2002;50:382-6.

35. Kudo S, Lambert R, Allen JI, Fujii H, Fujii T, Kashida H, Matsuda T, Mori M, Saito H, Shimoda T, Tanaka S, Watanabe H, Sung JJ, Feld AD, Inadomi JM, O'Brien MJ, Lieberman DA, Ransohoff DF, Soetikno RM, Triadafilopoulos G, Zauber A, Teixeira CR, Rey JF, Jaramillo E, Rubio CA, Van Gossum A, Jung M, Vieth $M$, Jass JR, Hurlstone PD. Nonpolypoid neoplastic lesions of the colorectal mucosa. Gastrointest Endosc 2008;68 (Suppl October):S3-47.

36. Andersen SH, Lykke E, Folker MB, Bernstein I, Holck S. Sessile serrated polyps of the colorectum are rare in patients with Lynch syndrome and in familial colorectal cancer families. Fam Cancer 2008;7:157-62.

37. Kambara T, Simms LA, Whitehall VL, Spring KJ, Wynter CV, Walsh MD, Barker MA, Arnold S, McGivern A, Matsubara N, Tanaka N, Higuchi T, Young J, Jass JR, Leggett BA. BRAF mutation is associated with DNA methylation in serrated polyps and cancers of the colorectum. Gut 2004;53:1137-44. 
94 


\section{Chapter 7}

\section{Diverticulosis and colorectal polyps at younger age:}

a possible link?

Eveline JA Rondagh, Silvia Sanduleanu, Chantal MC le Clercq, Bjorn Winkens, Ad AM Masclee

Eur J Gastroenterol Hepatol. 2011;23:1050-1055 


\section{Abstract}

\section{Objective}

An association between diverticulosis and colorectal neoplasms may have implications for colonoscopic prevention of colorectal cancer. We aimed to examine the association between diverticulosis and colorectal polyps with special attention to the age at diagnosis, the anatomical location and the histological subtype of colorectal polyps.

\section{Methods}

We included all consecutive patients referred for routine colonoscopy between February 2008 and February 2009. We recorded the presence of diverticulosis (defined as at least two diverticula) and colorectal polyps (adenomas and serrated polyps).

\section{Results}

We included 2310 patients ( $46.1 \%$ men, mean age 58.4 years), of which $37.0 \%$ had diverticulosis and $34.2 \%$ had one or more colorectal polyps. Multiple logistic regression analysis, including age, sex and interaction terms with diverticulosis, showed that the association between diverticulosis and colorectal polyps was significantly influenced by age $(P=0.009)$. In patients aged below 60 years, prevalence of colorectal polyps was significantly higher in those with diverticulosis compared with those without diverticulosis: $39.1 \%$ (79 of 202 patients) vs. 19.6\% (176/898), adjusted odds ratio (OR) 1.87, 95\% confidence interval (Cl) $1.26-2.78$ $P=0.002$. This association was found for both proximal and distal polyps and for all histological subtypes, namely adenomas (adjusted OR $1.60,95 \% \mathrm{Cl} 1.02-2.49, P=0.04$ ), serrated polyps (adjusted OR $1.73,95 \% \mathrm{Cl}$ 1.03-2.91, $P=0.04$ ) and advanced neoplasms (adjusted OR 2.32, 95\% Cl 1.31-4.12, $P=0.004$ ).

\section{Conclusions}

Presence of diverticulosis in patients aged below 60 years may be considered a 'red flag' for synchronous adenomas, serrated polyps, and advanced neoplasms. Diverticulosis may represent an indication for earlier initiation of colorectal cancer prevention programs. 


\section{Introduction}

Diverticulosis and colorectal neoplasms are common findings during colonoscopic examination, with nearly half of the Western population aged above 60 years having diverticulosis and $30-60 \%$ having colorectal neoplasms. ${ }^{1-3}$ A possible association between both conditions has been addressed in several studies, yielding controversial results so far. ${ }^{4}$ Some studies reported a positive association, ${ }^{5-9}$ whereas others could not confirm this. ${ }^{10-12}$

A positive association between diverticulosis and colorectal neoplasms, if present, may be of clinical relevance, as it may highlight a subgroup of patients at increased risk for CRC. These patients may be potential candidates for earlier initiation of colorectal cancer (CRC) prevention programs, preferably colonoscopic screening and perhaps a more intensive surveillance. A recent study by Bressler et al, showed that diverticulosis was an independent risk factor for subsequent development of CRC within 3 years after a colonoscopy. ${ }^{13}$ It is possible that an increased a priori risk for CRC in conjunction with potential technical difficulties of the colonoscopic procedure increasing the likelihood of missing polyps or ineffectively treating them may explain some of these post-colonoscopy cancers.

Although several studies have been reported on the association between diverticulosis and colorectal neoplasms, ${ }^{4}$ only a few adjusted this correctly for the age at diagnosis and presented the histological subtype of colorectal polyps, including adenomas and the recently described serrated neoplastic lesions. This information is of importance as it may increase the awareness of the clinician with regard to the risk for CRC of these patients and possibly affect the colonoscopic preventive measures in terms of age of initiation, tools and surveillance intervals.

In this large, cross-sectional study, we aimed to address the possible association between diverticulosis and colorectal polyps, with special attention to the age at diagnosis, the anatomical location and the histological subtype of colorectal polyps. We hypothesized that the presence of diverticulosis is associated with an increased risk for synchronous presence of (advanced) colorectal neoplasms.

\section{Methods}

\section{Study design and population}

All patients referred for elective colonoscopy at the endoscopy unit of our academic center between February 2008 and February 2009 were included. Indications for colonoscopy were symptoms, surveillance (post-polypectomy or CRC resection) or screening. We excluded patients aged below 18 years or with hereditary CRC syndromes (i.e. Lynch syndrome or known polyposis syndromes). 
Patients with a family history of CRC, but without gene mutation, also known as familial CRC, were included in the analysis. According to the Dutch guidelines, familial CRC is defined as patients with at least three-fold increased risk for CRC, namely those with i) one or more first degree relatives with CRC diagnosed below 50 years of age or ii) two or more first degree relatives with CRC diagnosed between 50 and 70 years of age or iii) one first degree and one second degree relative with CRC diagnosed at less than 70 years of age.

\section{Colonoscopy and histopathology}

Patients received a polyethylene glycol solution for bowel preparation. Colonoscopies were performed by a team of nine gastroenterologists and seven gastrointestinal trainees, using high-resolution Pentax endoscopes. Endoscopists were not aware of the study hypothesis. Colonoscopy findings were documented using a standardized colonoscopy reporting system, which includes digital photographic documentation. We defined diverticulosis as the presence of at least two diverticula. We classified colorectal polyps according to size into i) diminutive $(\leq 5 \mathrm{~mm})$, ii) small $(6-9 \mathrm{~mm})$ and iii) large $(\geq 10 \mathrm{~mm})$. Both diverticulosis and colorectal polyps were classified according to location into proximal (from cecum to splenic flexure) or distal (from descending colon to rectum). The histopathology of colorectal polyps was assessed using the World Health Organization classification, ${ }^{14,15}$ by two experienced gastrointestinal pathologists, who were unaware of the study hypothesis. Colorectal polyps were categorized into i) adenomas or ii) serrated colorectal polyps, which included both hyperplastic polyps and serrated adenomas. The presence of an advanced colorectal neoplasm was defined as having at least one of the following features: multiple ( $\geq 3)$, large ( $\geq 10 \mathrm{~mm})$, high-grade dysplastic adenomas or CRC. ${ }^{16}$

\section{Statistical analysis}

The outcome measures of this study were i) the presence of diverticulosis and ii) the presence of colorectal polyps (adenomas or serrated polyps). Special attention was paid to the age of patient at diagnosis, the location and the histological subtype of polyps. Multiple logistic regression analysis including age, sex and interaction terms with diverticulosis were carried out to investigate the association between diverticulosis and colorectal polyps. The interaction terms were assessed using the likelihood ratio test. The linearity assumption was assessed by adding and testing a centered quadratic term. To illustrate the influence of age on the association between diverticulosis and colorectal neoplasms, the odds ratios (OR) and corresponding $95 \%$ confidence intervals $(\mathrm{Cl})$ were plotted against age on a line chart. CRC prevention programs in Western countries are currently targeted toward patients above 50 years of age and certainly toward all those aged above 60 years. We used this latter cut-off value to present the association between diverticulosis and subtypes of colorectal polyps. We conducted an additional analysis with exclusion of patients with 
inflammatory bowel disease or incomplete colonoscopy to examine the effect of potential confounding.

On the basis of previous data, showing diverticulosis in $27 \%$ of the patients and colorectal polyps in $17 \%$ of the patients without diverticulosis, ${ }^{10}$ a sample size of 892 patients was required to achieve at least $80 \%$ power to detect a significant association with a relative risk of 1.5 and a significance level of 0.05 . Differences in dichotomous variables were examined using the chi-squared test or Fisher's exact test where appropriate. Differences in continuous variables between groups were examined using the independent-samples $t$-test. All statistical analyses were performed using SPSS statistical software package 15.0 (SPSS, Chicago, Illinois). All ORs are presented with 95\% Cl. Two-sided $P$-values less than 0.05 were considered to be statistically significant.

This study was approved by the Institutional Review Board of the Maastricht University Medical Center+ (MEC 08-4-074).

\section{Results}

A total of 2466 consecutive patients were referred for routine colonoscopy at our gastrointestinal endoscopy unit. We excluded patients aged below 18 years $(n=7)$ or with hereditary CRC syndromes $(n=20)$. A total of 129 patients underwent two colonoscopies during the study period, because of the onset of new symptoms $(n=31)$, polypectomy $(n=23)$, control after polypectomy $(n=38)$, or poor bowel preparation $(n=37)$. Finally, this has resulted in a study population of 2310 patients (mean age 58.4 years, $46.1 \%$ males), of which $80.5 \%$ were referred because of symptoms and $19.5 \%$ for screening or surveillance indications. Table 7.1 depicts the clinical and endoscopic characteristics of the study population. The overall cecal intubation rate was $90.2 \%$ in symptomatic and $95.3 \%$ in asymptomatic patients.

Table 7.1 Clinical and endoscopic characteristics of the study population

\begin{tabular}{|c|c|c|c|c|}
\hline & $\begin{array}{c}\text { Total } \\
\text { population }\end{array}$ & $\begin{array}{l}\text { Patients with } \\
\text { diverticulosis }\end{array}$ & $\begin{array}{c}\text { Patients without } \\
\text { diverticulosis }\end{array}$ & $P$ value $^{\mathrm{a}}$ \\
\hline Study population, n (\%) & 2310 & $855(37.0)$ & $1455(63.0)$ & \\
\hline Males, n (\%) & $1065(46.1)$ & $413(48.3)$ & $652(44.8)$ & 0.10 \\
\hline Mean age, years (SD) & $58.4(16.2)$ & $67.6(11.4)$ & $52.9(16.1)$ & $<0.001$ \\
\hline \multicolumn{5}{|l|}{ Indication for colonoscopy } \\
\hline Symptoms, n (\%) & $1860(80.5)$ & $686(80.2)$ & $1174(80.7)$ & 0.79 \\
\hline Surveillance/screening, n (\%) & $450(19.5)$ & 169 (19.8) & $281(19.3)$ & \\
\hline Familial colorectal cancer, $\mathrm{n}(\%)$ & 43 (1.9) & $9(1.1)$ & $34(2.3)$ & 0.03 \\
\hline Presence of $\geq 1$ polyp, ${ }^{b} \mathrm{n}(\%)$ & $790(34.2)$ & $370(43.3)$ & $420(28.9)$ & $<0.001$ \\
\hline Presence of $\geq 1$ adenoma, $\mathrm{n}(\%)$ & $619(26.8)$ & $289(33.8)$ & $330(22.7)$ & $<0.001$ \\
\hline Presence of $\geq 1$ serrated polyp, $n(\%)$ & $308(13.3)$ & $142(16.6)$ & $166(11.4)$ & $<0.001$ \\
\hline Presence of $\geq 1$ advanced neoplasm, $n(\%)$ & $322(13.9)$ & $160(18.7)$ & $162(11.1)$ & $<0.001$ \\
\hline
\end{tabular}

SD = standard deviation. ${ }^{a}$ Unadjusted; ${ }^{b}$ Adenoma or serrated polyp. 
Thirty-seven percent of patients $(n=855)$ presented with diverticulosis and $34.2 \%(790)$ had at least one polyp (Table 7.1). Prevalences of both diverticulosis and colorectal polyps increased with age (Figure 7.1). Of the patients presenting with diverticulosis, $77.0 \%(n=658)$ had left-sided diverticulosis only, 1.9\% ( $n=16)$ had right-sided diverticulosis only and $21.2 \%(n=181)$ had generalized diverticulosis. Endoscopic signs of (mildly) inflamed mucosa around diverticula (i.e. erythema, edema) were present in $9.0 \%(n=77)$ of the patients having diverticulosis.

In total, 1669 colorectal polyps were found, of which $41.3 \%$ (689) were located in the proximal colon and $58.7 \%(980)$ in the distal colon. Moreover, $77.0 \%$ (1285) were diminutive, $10.1 \%$ (169) small and $12.9 \%$ (215) large.

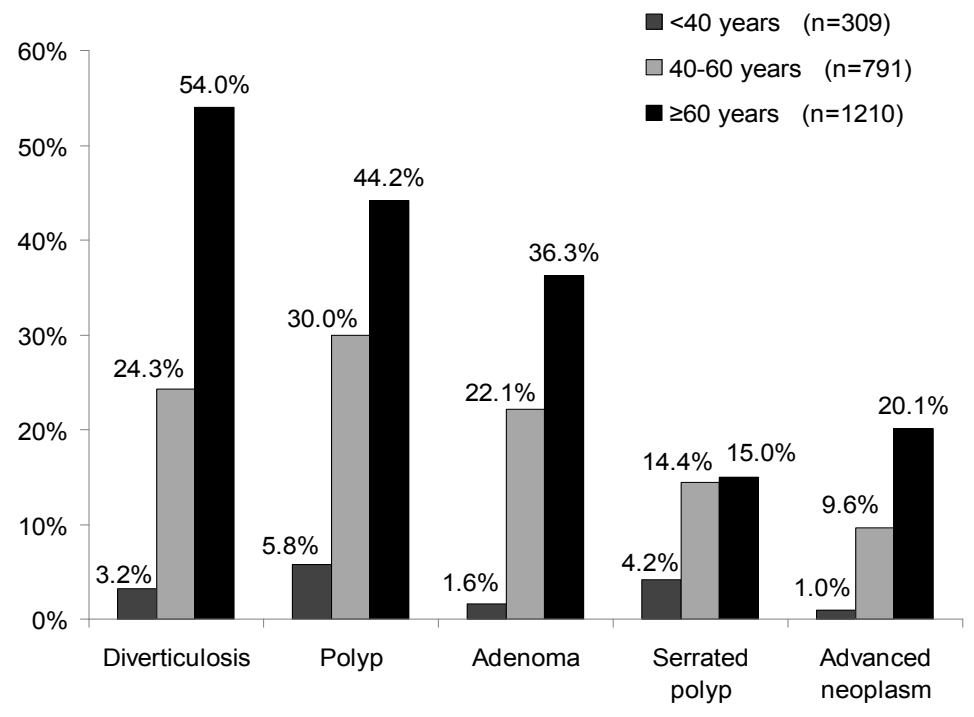

Figure 7.1 Prevalences of diverticulosis and colorectal polyps in patients of different age groups.

\section{Diverticulosis and colorectal polyps in relation to age, location and histological subtype}

Table 7.1 shows that patients with diverticulosis are significantly more likely to have at least one synchronous colorectal polyp, adenoma, serrated polyp or advanced colorectal neoplasm than patients without diverticulosis. Multiple logistic regression analysis, including age, sex and interaction terms with diverticulosis, showed that the association between diverticulosis and colorectal polyps was significantly influenced by age, $P=0.009$, but not by sex, $P=0.39$. Figure 7.2 illustrates the strength of the association between diverticulosis and colorectal polyps according to age at diagnosis, showing an increase with younger age. Patients aged below 60 years with diverticulosis were more likely to have at least one colorectal polyp than those without diverticulosis: $39.1 \%$ (79 of 202 patients) vs. 19.6\% (176 of 898 patients), adjusted OR 1.87, $95 \% \mathrm{Cl} 1.26-2.78, P=0.002$. This association was found for both proximal and 
distal colorectal polyps, and for all histological subtypes (Table 7.2). Of note, $4.0 \%$ (eight of 202 patients) of the patients aged below 60 years with diverticulosis had CRC compared with $0.6 \%$ (five of 898 patients) of those without diverticulosis, $P<0.001$. In patients aged 60 years or above, the presence of diverticulosis was not associated with an increased risk of colorectal polyps: $44.6 \%$ (291 of 653 patients) vs. $43.8 \%$ (244 of 557 patients), adjusted $P=0.97$.

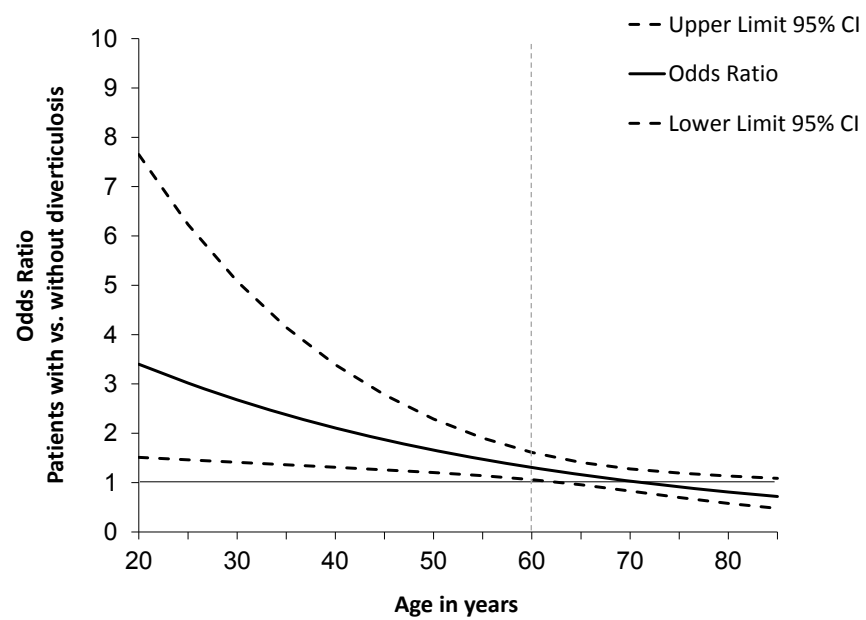

Figure 7.2 Association between diverticulosis and colorectal polyps according to patients' age. Diverticulosis and colorectal polyps are significantly associated in patients younger than 60 years, whereas no significant association was found in patients older than 60 years. $\mathrm{Cl}$, confidence interval

Table 7.2 Association between diverticulosis and colorectal polyps in patients younger or older than 60 years.

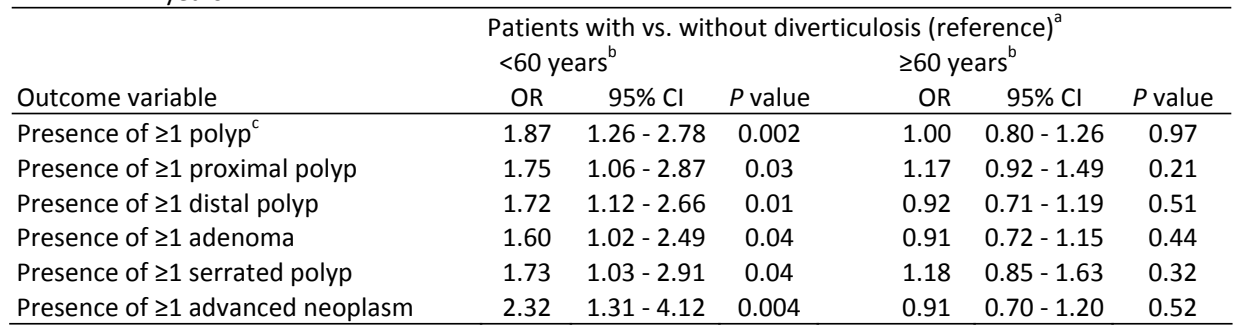

$\mathrm{OR}=$ odds ratio, $\mathrm{Cl}=$ confidence interval. ${ }^{\mathrm{a}}$ Results obtained from multiple logistic regression analysis including age, sex and interaction of age with diverticulosis. ${ }^{b}$ OR at mean age of patients below 60 years (45 years) and mean age of patients 60 years or above (71 years). 'Adenoma or serrated polyp

With regard to the location of diverticulosis, we found no significant differences in the prevalence of colorectal polyps between patients aged below 60 years with distal and those with proximal or generalized diverticulosis: $38.0 \%$ (60 of 158 patients) vs. $43.2 \%$ 
(19 of 44 patients), $P=0.53$. Furthermore, in patients aged below 60 years having diverticulosis, the prevalence of colorectal polyps was comparable between those with and those without endoscopic signs of diverticular inflammation: $40.9 \%$ (nine of 22 patients) vs. $38.9 \%$ (70 of 180 patients), $P=0.86$.

To exclude a potential bias, we conducted a separate analysis after exclusion of patients with previous polypectomy, colon resection, inflammatory bowel disease or incomplete colonoscopy, which showed similar results: 39.9\% (55 of 138 patients) of the patients aged younger than 60 years having diverticulosis had colorectal polyps, as against only $21.7 \%$ (131 of 605 patients) of those without diverticulosis $(P<0.001)$.

\section{Discussion}

In this study, we found that in patients younger than 60 years, diverticulosis is independently associated with an increased risk of synchronous colorectal neoplasms, namely adenomas, serrated polyps, and advanced neoplasms. To our knowledge, this is the first study to report an age-dependent association between diverticulosis and colorectal polyps. In our study, approximately 1 out of 5 patients aged below 60 years had diverticulosis. In this younger subgroup, the prevalence of colorectal polyps was two times higher (40\%) than that in patients without diverticulosis (20\%). Our findings indicate that diverticulosis in younger patients undergoing routine colonoscopy may be considered as a 'red flag' for the simultaneous presence of colorectal neoplasms. These data may suggest that young patients diagnosed with diverticulosis are potential candidates for earlier initiation of CRC prevention programs. Longitudinal studies are needed to evaluate whether risk assessment on the basis of the presence of diverticulosis, possibly in conjunction with other known risk factors, may play a role in fine-tuning of CRC prevention strategies.

A number of hypotheses may explain the association between diverticulosis and colorectal polyps. First, it has been suggested that common environmental risk factors could explain their co-existence. ${ }^{17}$ Following a significant change in dietary habits during the $20^{\text {th }}$ century, prevalences of both conditions have increased considerably in the Western countries. ${ }^{17,18}$ Several factors were considered to account for this, among them the decrease in fiber intake. Low fiber intake may increase the risk for both diverticulosis and colorectal neoplasms. ${ }^{19-21}$ Lack of dietary fibers results in a prolonged fecal transit time, which allows more water absorption, leading to a smaller, more viscous fecal bulk. ${ }^{18,22}$ As a result, colonic segmentation and intraluminal pressure may increase, favoring the development of colonic diverticular. ${ }^{18,22}$ Furthermore, fiber intake may decrease CRC risk by reducing colonic exposure to carcinogenic products because of an accelerated transit time as well as by dilution and binding of carcinogenic products. ${ }^{23,24}$

In this study, we found an age-dependent association between diverticulosis and presence of synchronous colorectal neoplasms. It is possible that common 
environmental risk factors, such as low-fiber dietary habits, predispose one to both conditions at a younger age. In older patients, the impact of age most probably prevails upon lifestyle factors, possibly confounding this association.

A second potential explanation for the association between diverticulosis and colorectal neoplasms is that (microscopic) inflammation of the diverticular colonic mucosa predisposes one to colorectal neoplasms. Current evidence strongly supports the etiological role of chronic inflammation in colorectal carcinogenesis. ${ }^{25}$ Histopathologic studies showed an increased inflammatory cell density and proliferation index in the colonic mucosa of patients with diverticulosis as compared with healthy controls. ${ }^{26,27}$ In addition, others showed that diverticulosis, which predominantly affects the distal colon, increases risk for merely distal colorectal neoplasms. ${ }^{5-7}$ However, this hypothesis could not be confirmed by other studies failing to show an association between diverticular inflammation and colorectal neoplasms. ${ }^{11,12}$ Interestingly, our study does not support an association between diverticulosis and the presence of colorectal polyps in the same colonic segment, as patients with diverticula had an increased risk for both proximal and distal colorectal polyps. We assume that patients with symptomatic diverticular inflammation may also be protected against CRC, as they are more likely to undergo colonoscopy with potential removal of colorectal polyps.

The disparity of data regarding a possible association between diverticulosis and colorectal neoplasms $\mathrm{s}^{5-12}$ most probably reflects the high heterogeneity with regard to the study populations, methodology and outcomes. Of note, some studies did not adjust the relation of diverticulosis with colorectal neoplasms for the age at diagnosis. A large Dutch cross-sectional study found that patients with diverticula were more likely to have synchronous colorectal polyps compared with controls, whereas they found a lower incidence of (distal) CRC. ${ }^{10}$ However, patients with diverticula in this study were two decades older than the controls, which could affect their findings. Considering the high prevalence of diverticulosis and colorectal neoplasms in patients above 60 years of age, and the fact that CRC screening programs are already targeted toward this age group, relation with age at diagnosis is essential when addressing diverticulosis as a potential risk marker for colorectal neoplasms.

This study has some methodological limitations. First, this study is cross-sectional in design, precluding us to assess the future risk for developing colorectal neoplasms in patients with diverticulosis. However, the presence of an advanced colorectal neoplasm is considered to be a valid intermediate marker for future risk of colorectal neoplasms. ${ }^{16}$ In this study, we found that diverticulosis is independently associated with advanced colorectal neoplasms in young patients, which supports the potential risk for future colorectal neoplasms. A second possible limitation is that the presence of colorectal neoplasms may have resulted in underreporting of the diverticula, as debated in previous studies. In our study, colonoscopy findings were documented prospectively using a standardized colonoscopy reporting system, including digital photographic documentation, which ensured adequate quality of data registration. In 
addition, if underreporting would have been the case, the association of diverticulosis with colorectal neoplasms would have been even stronger. Thus the main results and conclusion of this study would not have been significantly affected by this limitation. A third possible limitation of this study is that neither the extent of diverticulosis nor the severity of inflammation was systematically recorded in this study, as validated scales in this regard are not available currently. Our approach comparing patients with 'at least 2 diverticula' against those without and patients with inflammation against those without could therefore have biased some analyses. Clinically meaningful endoscopic classifications of diverticulosis need to be validated in future studies dealing with this issue. Fourth, the presence of diverticulosis will remain unnoticed in asymptomatic individuals. Therefore, the use of diverticulosis as a risk marker for colorectal neoplasms will be applicable only for patients who have already undergone sigmoidoscopy or colonoscopy.

In this large cohort of patients undergoing diagnostic colonoscopy, we found that those aged below 60 years and having diverticulosis are at an increased risk for synchronous adenomas, serrated polyps, and advanced colorectal neoplasms. The presence of diverticulosis at a younger age may therefore be considered as a 'red flag' for the synchronous presence of colorectal neoplasms. Future studies are needed to clarify whether the presence of diverticulosis at a young age may be an indication for earlier initiation of CRC prevention programs. 


\section{References}

1. Hughes LE. Postmortem survey of diverticular disease of the colon. I. Diverticulosis and diverticulitis. Gut 1969;10:336-344.

2. Jass JR, Young PJ, Robinson EM. Predictors of presence, multiplicity, size and dysplasia of colorectal adenomas. A necropsy study in New Zealand. Gut 1992;33:1508-1514.

3. Rex DK, Helbig CC. High yields of small and flat adenomas with high-definition colonoscopes using either white light or narrow band imaging. Gastroenterology 2007;133:42-7.

4. Morini S, Zullo A, Hassan C, Tomao S, Campo SM. Diverticulosis and colorectal cancer: between lights and shadows. J Clin Gastroenterol 2008;42:763-770.

5. Stefansson T, Ekbom A, Sparen P, Pahlman L. Increased risk of left sided colon cancer in patients with diverticular disease. Gut 1993;34:499-502.

6. Morini S, Hassan C, Zullo A, De Francesco V, Festa V, Barberani F, Faleo D, Stroffolini T. Diverticular disease as a risk factor for sigmoid colon adenomas. Dig Liver Dis 2002;34:635-639.

7. Kieff BJ, Eckert GJ, Imperiale TF. Is diverticulosis associated with colorectal neoplasia? A cross-sectional colonoscopic study. Am J Gastroenterol 2004;99:2007-2011.

8. Rajendra S, Ho JJ. Colonic diverticular disease in a multiracial Asian patient population has an ethnic predilection. Eur J Gastroenterol Hepatol 2005;17:871-875.

9. Hirata $\mathrm{T}$, Kawakami Y, Kinjo N, Arakaki S, Arakaki T, Hokama A, Kinjo F, Fujita J. Association between colonic polyps and diverticular disease. World J Gastroenterol 2008;14:2411-2413.

10. Loffeld RJ, Van Der Putten AB. Diverticular disease of the colon and concomitant abnormalities in patients undergoing endoscopic evaluation of the large bowel. Colorectal Dis 2002;4:189-192.

11. Krones CJ, Klinge U, Butz N, Junge K, Stumpf M, Rosch R, Hermanns B, Heussen N, Schumpelick V. The rare epidemiologic coincidence of diverticular disease and advanced colonic neoplasia. Int J Colorectal Dis 2006;21:18-24.

12. Meurs-Szojda MM, Terhaar sive Droste JS, Kuik DJ, Mulder CJ, Felt-Bersma RJ. Diverticulosis and diverticulitis form no risk for polyps and colorectal neoplasia in 4,241 colonoscopies. Int J Colorectal Dis 2008;23:979-984.

13. Bressler B, Paszat LF, Chen Z, Rothwell DM, Vinden C, Rabeneck L. Rates of New or Missed Colorectal Cancers After Colonoscopy and Their Risk Factors: A Population-Based Analysis. Gastroenterology 2007;132:96-102.

14. Hamilton S, Aaltonen, L. WHO Classification of Tumours. Pathology and Genetics of Tumours of the Digestive System. IARC Press, 2000.

15. Bosman FT, Carneiro F, Hruban RH, Theise ND. WHO Classification of Tumours of the Digestive System. IARC Press, 2010.

16. Winawer SJ, Zauber AG, Fletcher RH, Stillman JS, O'Brien MJ, Levin B, Smith RA, Lieberman DA, Burt RW, Levin TR, Bond JH, Brooks D, Byers T, Hyman N, Kirk L, Thorson A, Simmang C, Johnson D, Rex DK. Guidelines for colonoscopy surveillance after polypectomy: a consensus update by the US MultiSociety Task Force on Colorectal Cancer and the American Cancer Society. Gastroenterology 2006;130:1872-1885.

17. Burkitt DP. Epidemiology of cancer of the colon and rectum. Cancer 1971;28:3-13.

18. Painter NS, Burkitt DP. Diverticular disease of the colon, a 20th century problem. Clin Gastroenterol $1975 ; 4: 3-21$.

19. Aldoori WH, Giovannucci EL, Rockett HR, Sampson L, Rimm EB, Willett WC. A prospective study of dietary fiber types and symptomatic diverticular disease in men. J Nutr 1998;128:714-719.

20. Fisher N, Berry CS, Fearn T, Gregory JA, Hardy J. Cereal dietary fiber consumption and diverticular disease: a lifespan study in rats. Am J Clin Nutr 1985;42:788-804.

21. Dahm CC, Keogh RH, Spencer EA, Greenwood DC, Key TJ, Fentiman IS, Shipley MJ, Brunner EJ, Cade JE, Burley VJ, Mishra G, Stephen AM, Kuh D, White IR, Luben R, Lentjes MA, Khaw KT, Rodwell Bingham SA. Dietary fiber and colorectal cancer risk: a nested case-control study using food diaries. J Natl Cancer Inst 2010;102:614-626.

22. Stollman N, Raskin JB. Diverticular disease of the colon. Lancet 2004;363:631-639.

23. Young GP, Hu Y, Le Leu RK, Nyskohus L. Dietary fibre and colorectal cancer: a model for environment-gene interactions. Mol Nutr Food Res 2005;49:571-584. 
24. Norat $T$, Bingham S, Ferrari $P$, Slimani N, Jenab M, Mazuir M, Overvad K, Olsen A, Tjonneland A, Clavel F, Boutron-Ruault MC, Kesse E, Boeing H, Bergmann MM, Nieters A, Linseisen J, Trichopoulou A, Trichopoulos D, Tountas Y, Berrino F, Palli D, Panico S, Tumino R, Vineis P, Bueno-de-Mesquita HB, Peeters PH, Engeset D, Lund E, Skeie G, Ardanaz E, Gonzalez C, Navarro C, Quiros JR, Sanchez MJ, Berglund G, Mattisson I, Hallmans G, Palmqvist R, Day NE, Khaw KT, Key TJ, San Joaquin M, Hemon B, Saracci R, Kaaks R, Riboli E. Meat, fish, and colorectal cancer risk: the European Prospective Investigation into cancer and nutrition. J Natl Cancer Inst 2005;97:906-916.

25. Itzkowitz SH, Yio X. Inflammation and cancer IV. Colorectal cancer in inflammatory bowel disease: the role of inflammation. Am J Physiol Gastrointest Liver Physiol 2004;287:G7-17.

26. Tursi A, Brandimarte G, Elisei W, Inchingolo CD, Aiello F. Epithelial cell proliferation of the colonic mucosa in different degrees of colonic diverticular disease. J Clin Gastroenterol 2006;40:306-311.

27. Morini S, Hassan C, Zullo A, De Francesco V, Burattini O, Margiotta M, Panella C, lerardi E. Epithelia cell proliferation of the colonic mucosa in diverticular disease: a case-control study. Aliment Pharmacol Ther 2005;21:1385-1390. 


\section{Chapter 8}

\section{Tracking the molecular features of nonpolypoid colorectal neoplasms:}

a systematic review and meta-analysis

Quirinus JM Voorham*, Eveline JA Rondagh*, Dirk L Knol, Manon van Engeland, Beatriz Carvalho, Gerrit A Meijer, Silvia Sanduleanu

*Both authors contributed equally to this work

Submitted 


\section{Abstract}

\section{Background}

Although nonpolypoid colorectal neoplasms (NP-CRNs) are currently recognized worldwide, little is known about their genotype. We therefore conducted a systematic review and meta-analysis of the evidence on molecular characteristics of NP-CRNs.

\section{Methods}

PubMed and EMBASE were searched systematically for studies examining molecular characteristics of NPCRNs from 1986 until December 2011. A meta-analysis was performed on the KRAS mutation data and summary odd ratios (ORs) were estimated using random effects models. $I^{2}$ was used as measurement of the heterogeneity among the different studies.

\section{Results}

Fifty-three studies on KRAS, APC or BRAF mutations, microsatellite status or promoter hypermethylation were included. We found that depressed (Paris type 0 -IIC) CRNs were less likely to contain KRAS mutations (summary OR $0.12,95 \% \mathrm{Cl} 0.05-0.29, \mathrm{I}^{2}=0 \%$ ) than polypoid CRNs. Lateral spreading lesions of non-granular type (LST-NG) showed also less KRAS mutations (summary OR $0.61,95 \% \mathrm{Cl} 0.37-0.99, \mathrm{I}^{2}=0 \%$ ) than polypoid CRNs. Likewise, early nonpolypoid carcinomas showed less KRAS mutations than polypoid ones (summary OR $0.10,95 \% \mathrm{Cl} 0.06-0.19, I^{2}=0.0 \%$ ). With regard to $A P C, B R A F$ mutations, microsatellite instability and promoter hypermethylation, limited and often inconsistent results are described, precluding meaningful conclusions.

\section{Conclusion}

This meta-analysis provides indications that some subtypes of NP-CRNs, in particular depressed and LST-NG, may share similar molecular features, which are distinct from those found in polypoid CRNs. Prospective, multicenter studies are needed to clarify the molecular pathways underlying nonpolypoid colorectal carcinogenesis. 


\section{Introduction}

Already in 1985 Muto et al described a distinct phenotype of colorectal lesions, termed 'small flat adenoma'. ${ }^{1}$ For a long while, these flat adenomas were considered to be uncommon in Western countries, in contrast to Japan where nonpolypoid (flat or depressed) colorectal neoplasms (NP-CRNs) have been reported to represent up to $40 \%$ of all colorectal neoplasms. ${ }^{2,3}$ Recent studies in Western populations, however, have reported similar prevalences of NP-CRNs ranging from 7 to $40 \%{ }^{4-10}$

Awareness of the importance of NP-CRNs has recently been increased by several studies reporting limited effectiveness of colonoscopic cancer prevention in the proximal colon. ${ }^{11}$ As NP-CRNs are predominantly located in the proximal colon, ${ }^{10}$ more easily overlooked, and more challenging to remove endoscopically, these lesions were suspected to be an important cause of post-colonoscopy (i.e. interval) colorectal cancers. ${ }^{8,12}$ With this rationale in mind, the practical issue is: Are NP-CRNs a distinct phenotype of lesions only or do they also have different biologic features? In the first case, the problem could be solved by updating education and training of practicing endoscopists. However, if apart from a distinct phenotype, nonpolypoid lesions also have biologic characteristics associated with more rapid progression to cancer than their polypoid counterparts, ${ }^{6,8,13}$ this approach may not be sufficient to contain the problem. In a study conducted in an older population of American veterans, Soetikno et al found that in general, NP-CRNs are 10-times more likely to contain advanced histology (high-grade dysplasia or early cancer) than polypoid lesions. ${ }^{8}$ Several other studies reported that especially the depressed (Paris type 0 -IIc) subtype of NP-CRNs have an increased risk to contain advanced histology. $3,4,10,14$

Whether NP-CRNs have a different biologic behavior than polypoid lesions is presently unclear. Insight into the molecular characteristics of NP-CRNs could provide the basis for the most appropriate endoscopic versus surgical treatment and eventually allow us to customize surveillance programs of these patients, with regard to type and frequency of the procedure. The molecular characteristics of NP-CRNs have been extensively studied over the past years. ${ }^{15-22}$ Early studies suggested a lower incidence of KRAS mutations in nonpolypoid adenomas (15\%) versus polypoid adenomas $(52 \%),{ }^{16}$ in particular with regard to the depressed type lesions (0\% versus $31 \%)$, ${ }^{18}$ while more recent studies contradict these findings. ${ }^{20-22}$ Similar contradicting results have been described for other events, such as BRAF mutation. ${ }^{19,22}$ It is unclear whether the paradoxical results may be explained by variation in methodological aspects, including heterogeneous definition of NP-CRNs, low statistical power, population characteristics or the predominant performance of studies in an expert setting, implying potential selection bias. Consequently, little is known so far about the molecular events in NPCRNs.

Here, we present a systematic review on molecular characteristics of NP-CRNs, focusing on KRAS, BRAF, APC mutation, microsatellite instability (MSI) and promoter hypermethylation of several genes, aiming to clarify the major molecular events 
underlying the pathogenesis of these lesions and define recommendations for future research in this area.

\section{Methods}

\section{Search strategy and study selection}

We followed standard criteria for conducting and reporting a systematic review and meta-analysis. ${ }^{23}$ We conducted an electronic search on PUBMED at the $30^{\text {th }}$ of December 2011 using the following keywords and medical subjects heading (MeSH) terms: (flat OR non-polypoid OR NPN OR nonpolypoid OR superficial*) AND (adenoma OR carcinoma OR adenocarcinoma OR neoplasia OR cancer) AND (KRAS OR K-RAS OR RAS OR Ki-ras OR BRAF OR B-raf OR APC OR methylation OR CpG-island OR microsatellite) AND (colon OR colorectal OR CRC OR "colorectal neoplasms"[Mesh]). On EMBASE, we performed a similar search using the same keywords. A manual search of the reference lists was performed.

Two reviewers (Q.V. and E.R.) first screened all abstracts and excluded review articles, case reports, studies investigating non-colorectal or non-human tissues and studies investigating patients with hereditary forms of colorectal cancer. Of the remaining articles, full text was evaluated by the two reviewers who excluded studies that did not investigate NP-CRNs, performed immunohistochemistry only, investigated colitis associated neoplasms, mucinous cancers or serrated adenomas only or provided unclear data. In case of disagreement among the reviewers, revision was performed and consensus on inclusion was achieved.

\section{Data extraction}

We retrieved the following data from each study: first author's last name, publication year, country where study was conducted, definition used for NP-CRNs, number of samples, type of neoplasm, methods and results (including $\mathrm{p}$-values, if calculated). We recorded the examined codons for KRAS mutations, the examined exons for BRAF and $A P C$ gene mutations, the markers used to define MSI and in case of promoter hypermethylation, the examined regions and technique used.

Retrospective or prospective design and consecutive or non-consecutive nature of data collection was recorded as well. However, in case no indication was provided, we assumed that these studies were retrospective. Also with regard to collection of data, when no indication was provided these studies were assumed to be non-consecutive. As the majority of studies were performed in Japan, different histological grading was used compared with Western studies. ${ }^{24}$ For the purpose of this review, we defined both intramucosal carcinoma and carcinoma in situ, as high-grade dysplasia. We performed subgroup analyses of studies examining adenomas only (including 
adenomas with high-grade dysplasia and advanced adenomas, definition provided with footnotes), carcinomas only (including stage T1 (submucosal) carcinomas or a mixture of T2-T4 carcinomas) and studies investigating a mixture of adenomas and carcinomas (without indicating separate results for both histological types). Studies investigating adenomas as well as carcinomas were included as two separate studies. Similarly, studies investigating $\mathrm{T} 1$ as well as T2-T4 carcinomas were also included as two separate studies.

In the present study, we did not specifically assessed quality of the studies using a scoring system, but evaluated whether study characteristics, such as retro- versus prospective studies or non-consecutive versus consecutive inclusion of tissues, which are indicators of the quality of the study, had any influence on the results. Moreover, we evaluated whether the definition used for NP-CRN, the morphologic subtype (e.g. depressed type, lateral spreading tumors), the histologic type (e.g. adenoma or carcinoma) or the method used to detect the molecular alteration, influenced the results.

\section{Statistical methods}

Random effect models were used to calculate summary odds ratios (ORs) and $95 \%$ confidence intervals $(95 \% \mathrm{Cl}) .{ }^{25}$ Heterogeneity among the studies was expressed using $I^{2}$ statistics. ${ }^{26} \mathrm{I}^{2}$ close to $0 \%$ is an indicator of low heterogeneity (large homogeneity) between the studies, and $\mathrm{I}^{2}$ close to $100 \%$ is an indication of large heterogeneity. To assess potential sources of heterogeneity, we performed subgroup analyses and metaanalyses of data with regard to KRAS and MSI. Statistical analyses were performed using Stata version 11.2 and data of the meta-analyses were presented in forest plots.

\section{Results}

\section{General}

The search strategy and selection of articles is outlined in Figure 8.1a. An electronic search on PubMed resulted in 166 hits. A similar search on Embase showed 145 hits, revealing 17 additional articles after removing duplicates. A further 2 articles were identified after reviewing the reference lists, resulting in a total of 185 records identified. Articles were excluded after abstract screening $(n=87)$ or full text evaluation $(n=45)$ by the two reviewers. In 4 cases $(2.2 \%)$ there was disagreement among the reviewers, after which consensus was reached. 


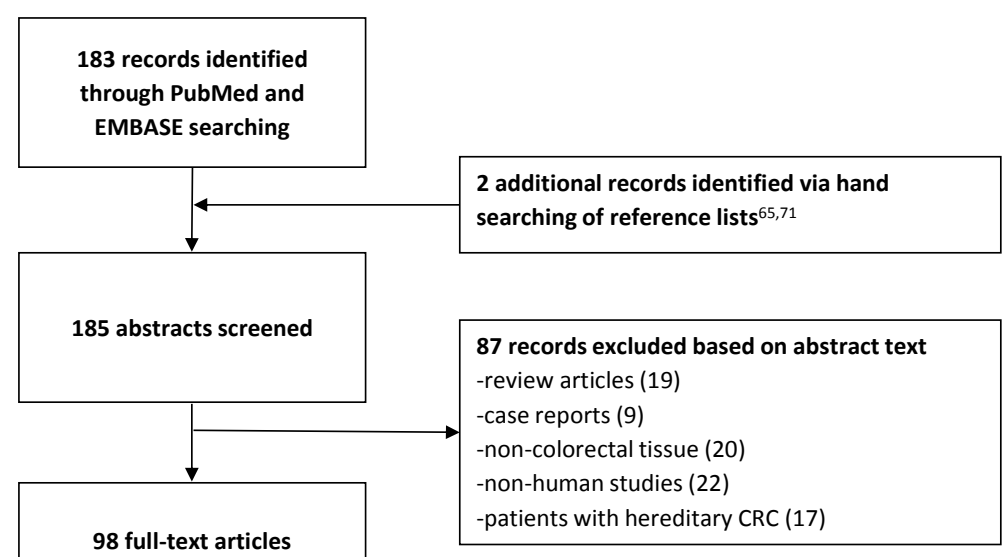

assessed for eligibility

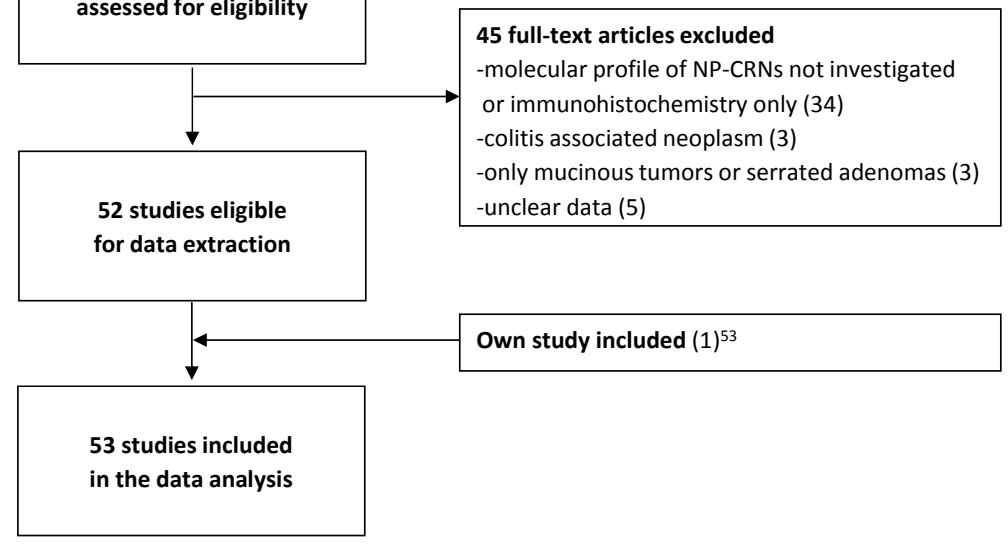

Figure 8.1a Flow chart of the search strategy and selection of studies eligible for data analysis. $\mathrm{CRC}=$ Colorectal cancer; NP-CRNs = nonpolypoid colorectal neoplasms.

In total, 53 studies $^{16-22,27-72}$ were included in this systematic review of which 44 investigated KRAS mutation, ${ }^{16-22,27-63} 8$ APC mutation, ${ }^{18,53,59-64} 5$ BRAF mutation, $^{19,22,41,42,53} 13 \mathrm{MSI}$ status ${ }^{16,21,42,53,59,60,62,65-70}$ and 7 promoter hypermethylation of several genes ${ }^{20-22,36,40,71,72}$ (Figure 8.1b). Data pertaining to other gene mutations, mRNA expression, loss of heterozygosity, chromosomal instability were scarce (each investigated in less than three studies) ${ }^{65,73,74}$ and we therefore refrained from presenting them in this review. Forty-seven studies used Japanese samples only, ${ }^{17-22,27-}$ 29,31-52,54-60,63-72 5 studies used samples from Europe, ${ }^{16,30,53,61,62}$ while 1 study used samples collected in North America. ${ }^{70}$ 


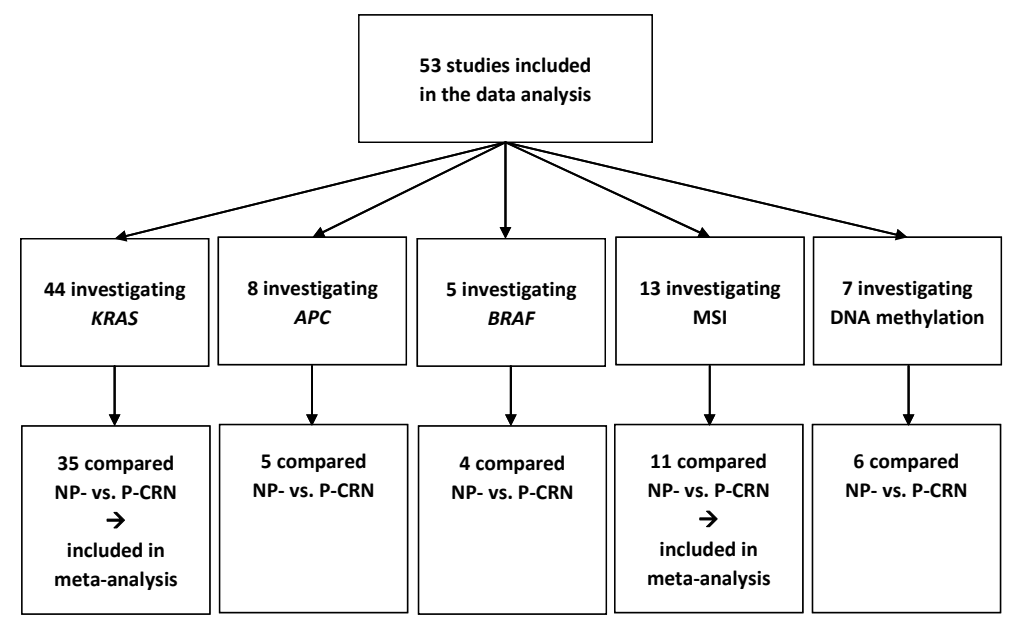

Figure 8.1b Studies included in the data analysis and meta-analysis.

$\mathrm{CRC}=$ Colorectal cancer $; \mathrm{NP}-\mathrm{CRNs}=$ nonpolypoid colorectal neoplasms; $\mathrm{P}-\mathrm{CRNs}=$ polypoid colorectal neoplasms.

\section{Definitions and study designs}

Large variation was found between studies with regard to definitions used for NPCRNs, in particular endoscopic versus histological definitions. Table $8.1^{7,75-79}$ summarizes the definitions used in the 53 studies analyzed in this review. The most frequently applied definition was the histological definition defining nonpolypoid lesions as lesions with a height less than two times the mucosa thickness. Sixteen studies used less frequent definitions, and were grouped in the category "other definitions". The currently recommended Paris-Japanese classification ${ }^{3,80}$ was used in 9 studies $^{17,18,49-54,59,64}$ to further subdivide NP-CRNs into slightly elevated (0-Ila), completely flat (0-IIb) or depressed (0-IIc). Eight studies ${ }^{20,22,53-58}$ provided separate information on subtypes lateral spreading granular (LST-G) versus lateral spreading non-granular (LST-NG). ${ }^{81}$

Ten studies were prospective, ${ }^{19,20,37-39,57,58,61,70,71}$ whereas forty-three were retrospective in design. Twenty-eight studies used consecutively collected samples, ${ }^{18-20,30-44,51,57-61,69-71}$ whereas in twenty-five studies the samples were most probably not consecutively collected. 
Table 8.1 Definitions used for nonpolypoid neoplasms, classified into 7 categories.

\begin{tabular}{|c|c|c|c|c|}
\hline Code & Definition & $\begin{array}{l}\text { Definition } \\
\text { based on } \\
\text { publication by }\end{array}$ & $\begin{array}{l}\text { Microscopic/ } \\
\text { macroscopic }\end{array}$ & Studies \\
\hline 1 & Lesions $<2 \mathrm{x}$ mucosa thickness & Wolber, $1991^{76}$ & Microscopic & $\begin{array}{l}\text { Fujii, Fujimori, Hasegawa, Hiraoka, } \\
\text { Minamoto, Noda, Noro, Okamoto, } \\
\text { Orita, Sakamoto, Sakashita, } \\
\text { Umetani, Yamagata 1994, Yashiro } \\
\text { (adenoma) }\end{array}$ \\
\hline 2 & $\begin{array}{l}\text { According to the Japanese } \\
\text { research society for cancer of } \\
\text { the colon and rectum (JRSCCR) }\end{array}$ & JRSCCR , $1983^{77}$ & Macroscopic & $\begin{array}{l}\text { Akiyama, Kaneko 2000, Komura, } \\
\text { Ohmura, Yagi }\end{array}$ \\
\hline 3 & Height $<2-3 \mathrm{~mm}$ & Saitoh, $2001^{78}$ & Macroscopic & $\begin{array}{l}\text { Kobayashi, Kojima, Mikami, Nosho } \\
\text { 2007, Nosho 2008, Takahashi, } \\
\text { Voorham, }\end{array}$ \\
\hline 4 & Lesion height $<1 / 2$ diameter & $\begin{array}{l}\text { Jaramillo, } \\
1995^{79}\end{array}$ & Macroscopic & Kinney, Konishi, Van Wyk \\
\hline 5 & $\begin{array}{l}\text { Margins are covered with non- } \\
\text { cancerous mucosa }\end{array}$ & Kudo, $1996^{80}$ & Microscopic & $\begin{array}{l}\text { Kaneko 1998, Kaneko 2004, } \\
\text { Kurahashi }\end{array}$ \\
\hline 6 & $\begin{array}{l}\text { Lesion without (intramucosal) } \\
\text { protuberant growth }\end{array}$ & $\begin{array}{l}\text { Shimoda, } \\
1989^{81}\end{array}$ & Macroscopic & $\begin{array}{l}\text { Mukai, Ogawa, Okawa, Saito 1999, } \\
\text { Yamagata } 1995\end{array}$ \\
\hline 7 & Others & & both & $\begin{array}{l}\text { Aoki, George, Hirata, Harada, } \\
\text { Ishihara, Kusaka, Morita, Mukawa, } \\
\text { Olschwang, Sada, Saito 2000, Soh, } \\
\text { Sugimoto, Watari, Yashiro } \\
\text { (carcinoma), Yokoyama, Yoshida }\end{array}$ \\
\hline
\end{tabular}

\section{KRAS}

In total 44 studies investigated KRAS mutations (Table 8.2), which was thereby the most frequently investigated molecular characteristic of NP-CRNs. Overall, large variations were observed between studies with regard to sample sizes, methods and outcomes. Fourteen studies included a limited $(<25)$ number of NP-CRNs. ${ }^{28-32,39,43-}$ $46,59,60,62,63$ In total, seven different detection methods were used across the studies to investigate KRAS mutation status. In 20 studies codon 12 only was investigated.

Of all studies investigating KRAS status, 35 studies compared nonpolypoid with polypoid neoplasms (adenomas and carcinomas) and these were included in the metaanalyses (Supplementary Figure S8.1). In an attempt to outweigh the high heterogeneity among studies $\left(I^{2}=78 \%\right)$, we conducted separate analyses for adenomas and carcinomas. In case of unclear separation of adenomas and carcinomas (defined as "mixed" in Supplementary Figure S8.1), studies were excluded from the analyses. 


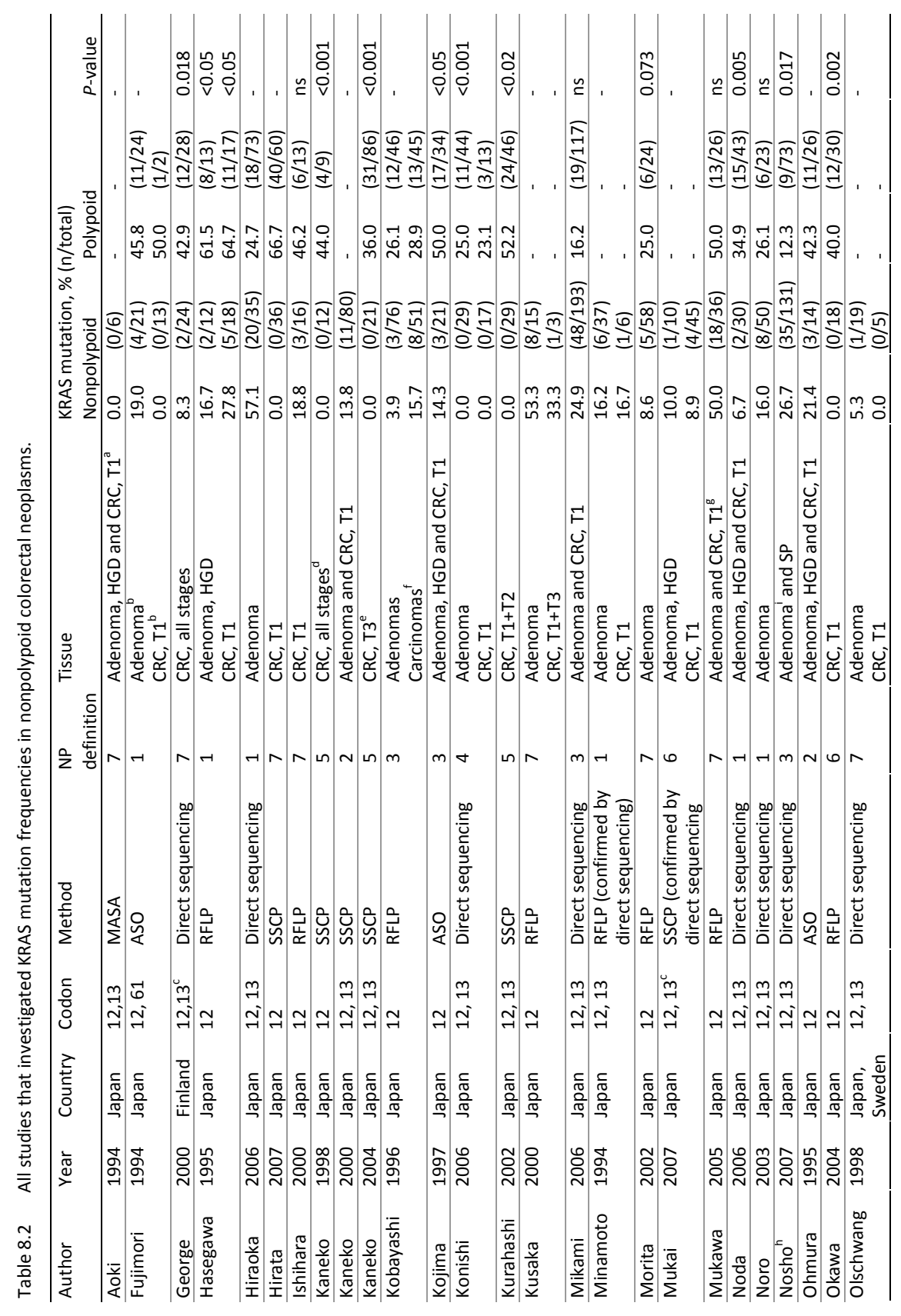




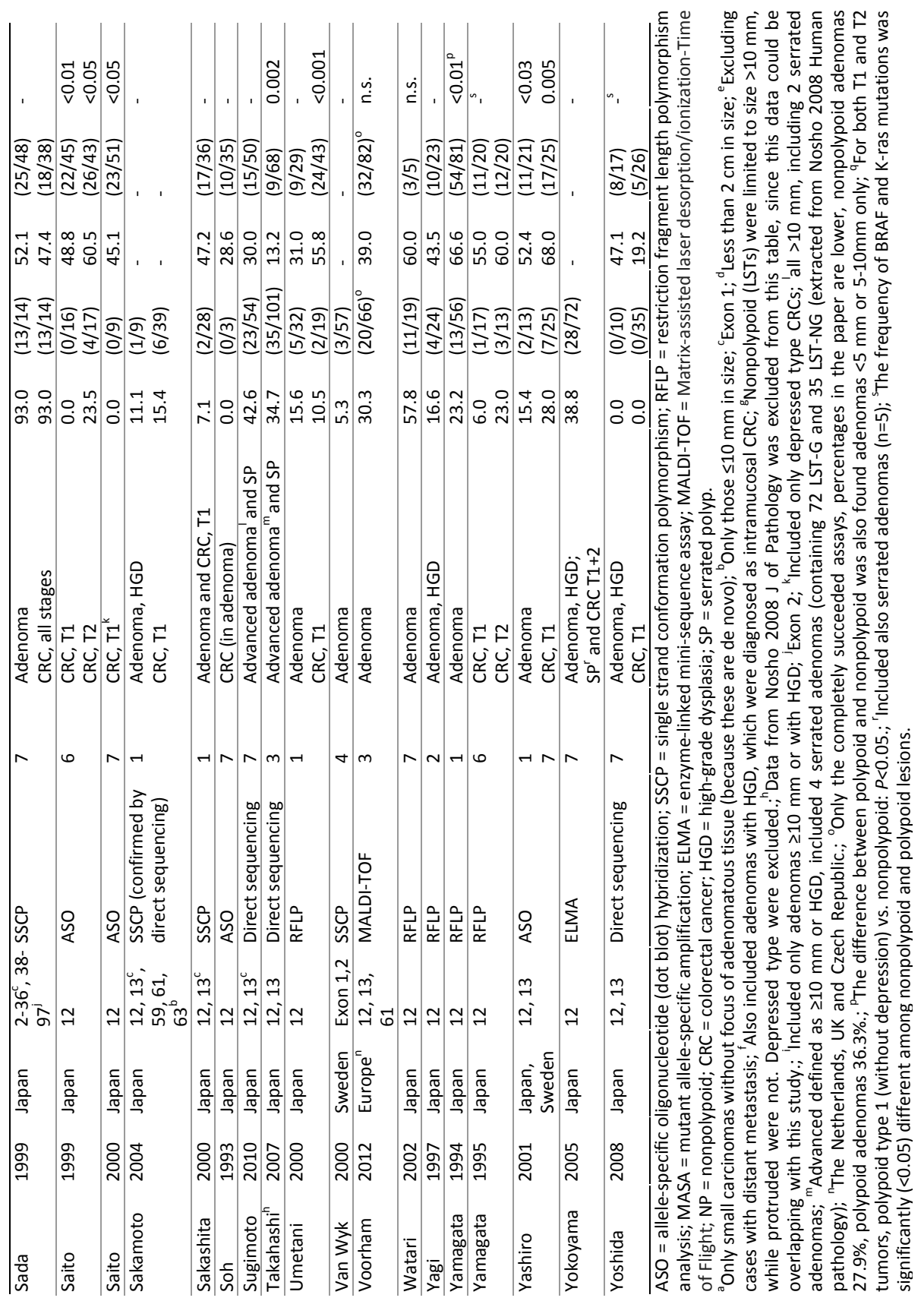


In total, we found 21 studies investigating 1118 carcinomas (423 nonpolypoid and 695 polypoid). The meta-analysis indicated that KRAS mutations are less frequently observed in nonpolypoid than polypoid carcinomas (of all stages), with a summary OR of $0.14(95 \% \mathrm{Cl} 0.08-0.25)$ and moderate heterogeneity $\left(I^{2}=45 \%\right)$ (Figure $\left.8.2 \mathrm{a}\right)$. One study $^{38}$ showed opposite results: summary OR 14.4 (95\% Cl 1.71-121.7). Of note, two studies were included twice, since a separation was made between T1 carcinomas and other stages. ${ }^{47,48}$ Separate analysis of early (T1) cancers reduced the heterogeneity $\left(I^{2}=0 \%\right)$ and again showed less KRAS mutation in nonpolypoid compared with polypoid cancers (summary OR $0.10,95 \% \mathrm{Cl} 0.06-0.19, \mathrm{I}^{2}=0.0 \%$ ) (Figure $8.2 \mathrm{~b}$ ).

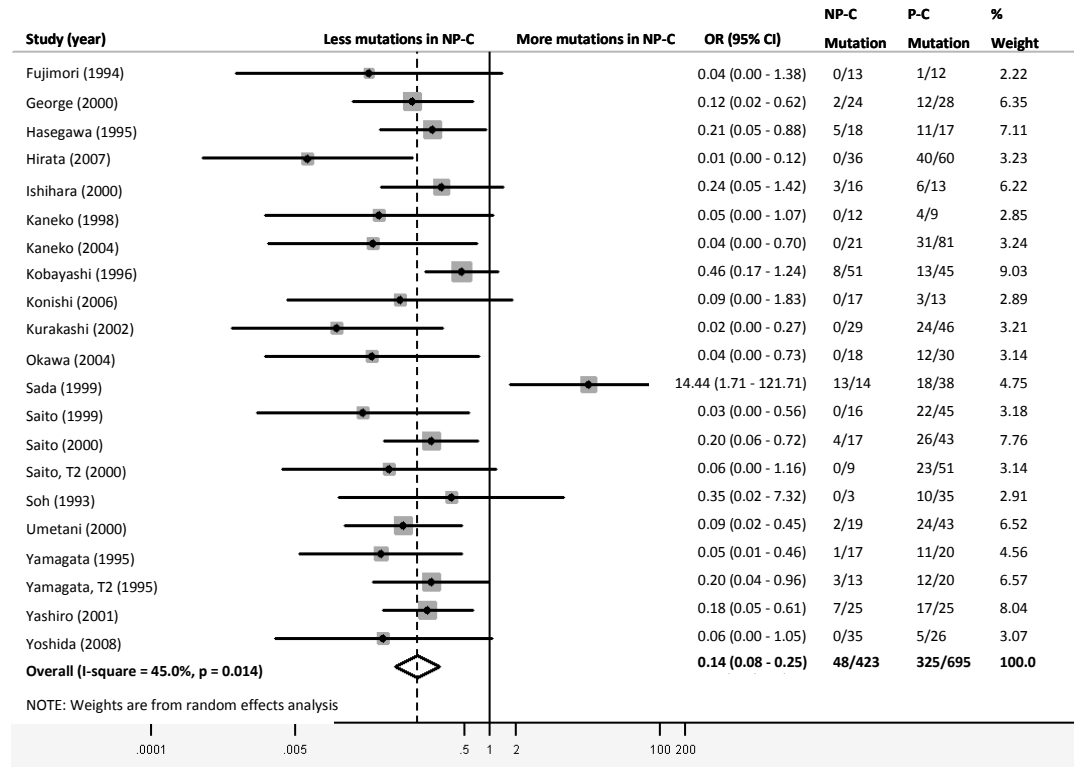

OR, Odds ratio; $95 \% \mathrm{Cl}$, 95\% confidence interval; NP-C, Nonpolypoid carcinoma; PC, Polypoid carcinoma.

Figure $8.2 a$

Meta-analysis of studies investigating the frequency of KRAS mutation in nonpolypoid versus polypoid carcinomas (of all stages). Random effect meta-analysis showed less KRAS mutations in nonpolypoid carcinomas compared with polypoid carcinomas with a summary OR of $0.14,95 \% \mathrm{Cl} 0.08-0.25, \mathrm{I}^{2}=45.0 \%$.

We performed subgroup analyses of studies using similar definition of nonpolypoid lesions or using similar methods for mutation, which did not alter the study heterogeneity (data not shown). Moreover, the study heterogeneity did not improve when including prospective or consecutive studies only.

With regard to adenomas, 18 studies investigated a total of 1652 adenomas (809 nonpolypoid adenomas and 743 polypoid adenomas), showing greater heterogeneity than studies on carcinomas $\left(I^{2}=83 \%\right)$. Figure 8.3 visualizes the large differences in the outcomes of these studies, with a summary OR of 0.54 (95\% Cl 0.27-1.04). Again, we 
conducted subanalyses of data from studies using similar definitions, methodology and inclusion criteria (all types of adenomas or advanced adenomas only); however this resulted in small subgroups, precluding meaningful statistical summaries of effect size (data not shown). In addition, we conducted separate analyses of studies after excluding studies investigating codon 12 of the KRAS gene only $(n=20)$, which did not alter the study heterogeneity (summery OR $0.49,95 \% \mathrm{Cl} 0.24-0.99, \mathrm{I}^{2}=83 \%$ ).

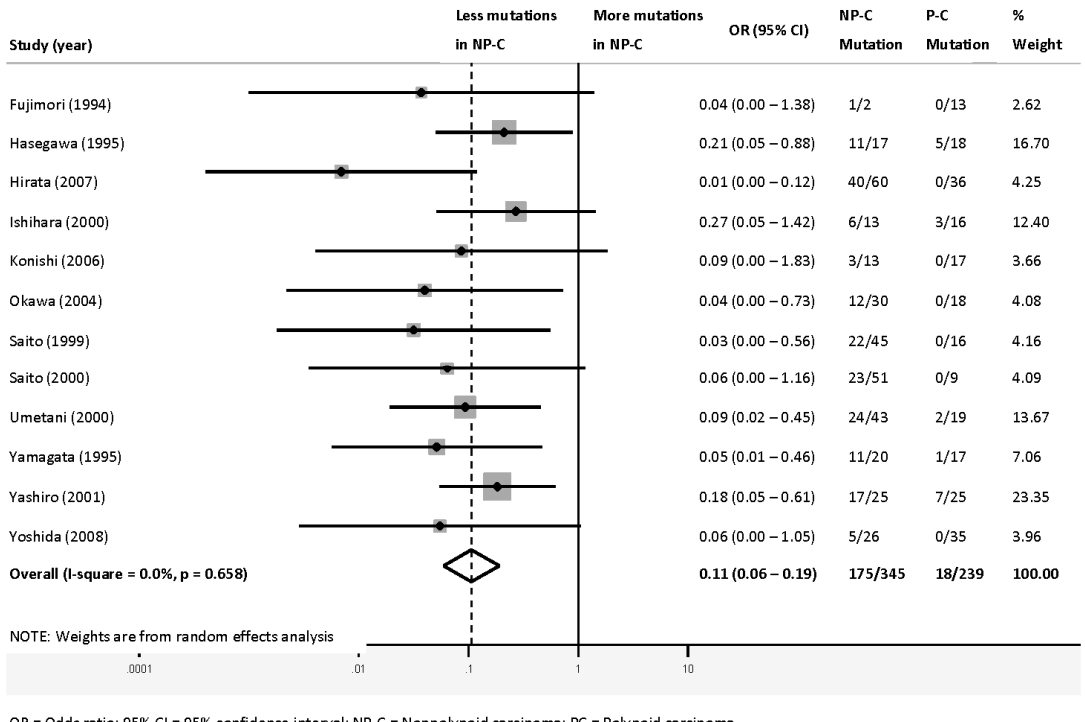

Figure 8.2b Meta-analysis of studies investigating the frequency of KRAS mutation in early nonpolypoid carcinomas versus early polypoid carcinomas. Random effect meta-analysis showed less KRAS mutations in early nonpolypoid carcinomas (T1) compared with early polypoid carcinomas (T1) with a summary OR of $0.11,95 \% \mathrm{Cl} 0.06-0.19, I^{2}=0.0 \%$.

\section{KRAS mutation in subtypes of nonpolypoid colorectal neoplasms}

In total 9 studies classified NP-CRNs according to Paris classification into the subtypes slightly elevated (0-IIa), completely flat (0-IIb) and depressed (0-IIc) (Table 8.3). The forest plots visualizing KRAS mutation status in the subtypes 0-Ila and 0-Ilc are shown in Supplementary Figure S8.2 and Figure 8.4. With regard to the depressed neoplasms (0-IIc), all studies consistently showed less KRAS mutations than in the polypoid neoplasms (summary OR $0.12,95 \% \mathrm{Cl} 0.05-0.29, \mathrm{I}^{2}=0 \%$ ). With regard to the slightly elevated neoplasms $(0-11 \mathrm{a})$, a large heterogeneity $\left(I^{2}=68 \%\right)$ was found among studies, precluding meaningful statistical summaries. 


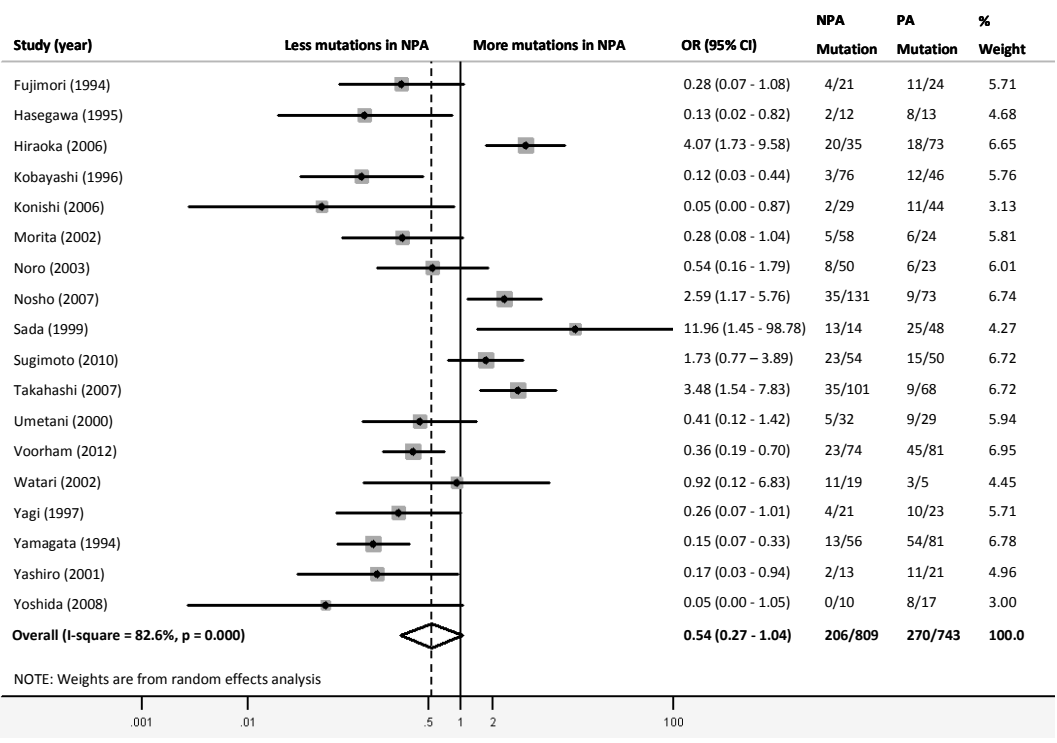

OR, Odds ratio; Cl, confidence interval; NPA, Nonpolypoid adenoma; PA Polypoid adenoma

Figure 8.3 Meta-analysis of studies investigating the frequency of KRAS mutation in nonpolypoid adenomas versus polypoid adenomas. Random effect meta-analysis showed large heterogeneity among the studies, $I^{2}=82.6 \%$.

A total of 8 studies investigated LSTs separately, of which 6 compared their KRAS status with that of polypoid neoplasms (Table 8.4). Although the total number of samples was relatively small, forest plots were constructed (Figure 8.5 and Supplementary Figure 58.3 ). In the LST non-granular type neoplasms, we found less KRAS mutations than in polypoid neoplasms, with a low heterogeneity $\left(I^{2}=0 \%\right)$ and a summary OR of 0.61 ( $95 \% \mathrm{Cl} 0.37-0.99)$, (Figure 8.5). In the LST-G type neoplasms, on the opposite, we found a trend toward more KRAS mutations than in polypoid neoplasms, albeit greater heterogeneity was observed among studies (summary OR 2.30, $95 \% \mathrm{Cl} 0.82-6.45, \mathrm{I}^{2}=81 \%$ ) (Supplementary Figure $\mathrm{S} 8.3$ ). 


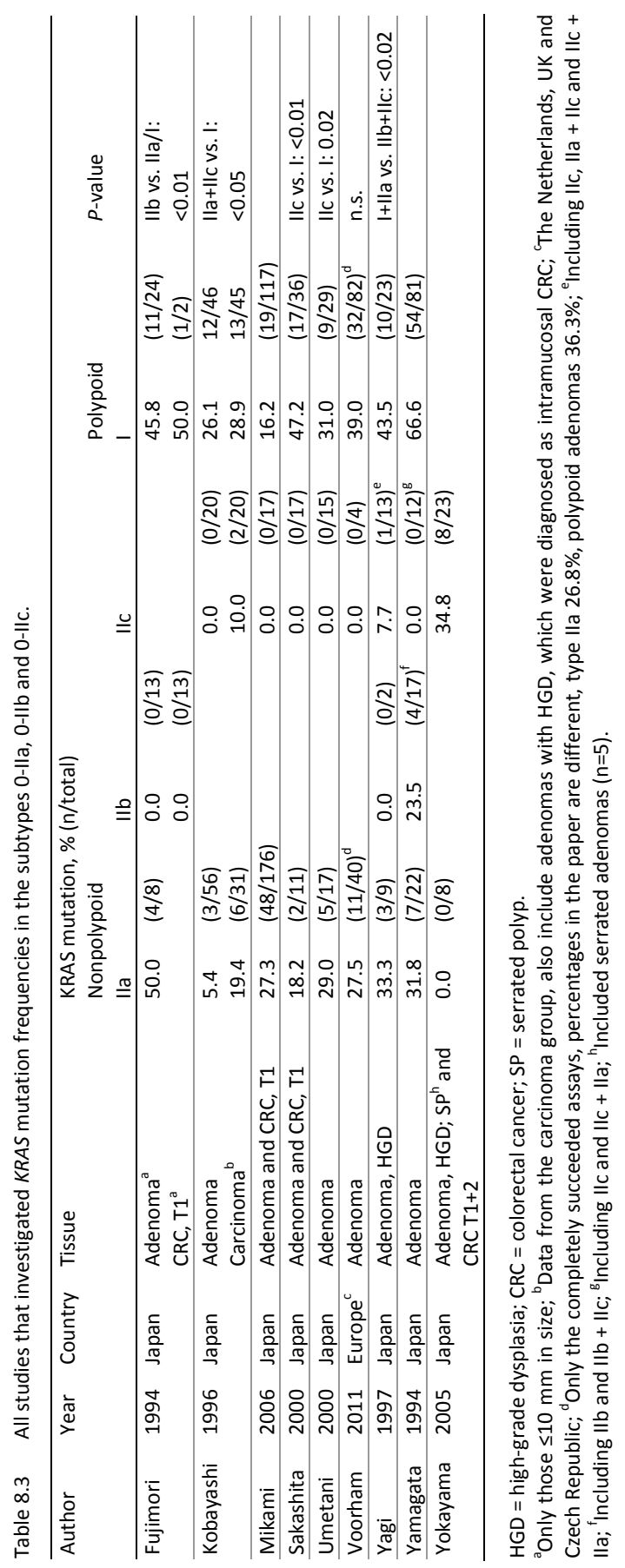


Tracking the molecular features of nonpolypoid colorectal neoplasms

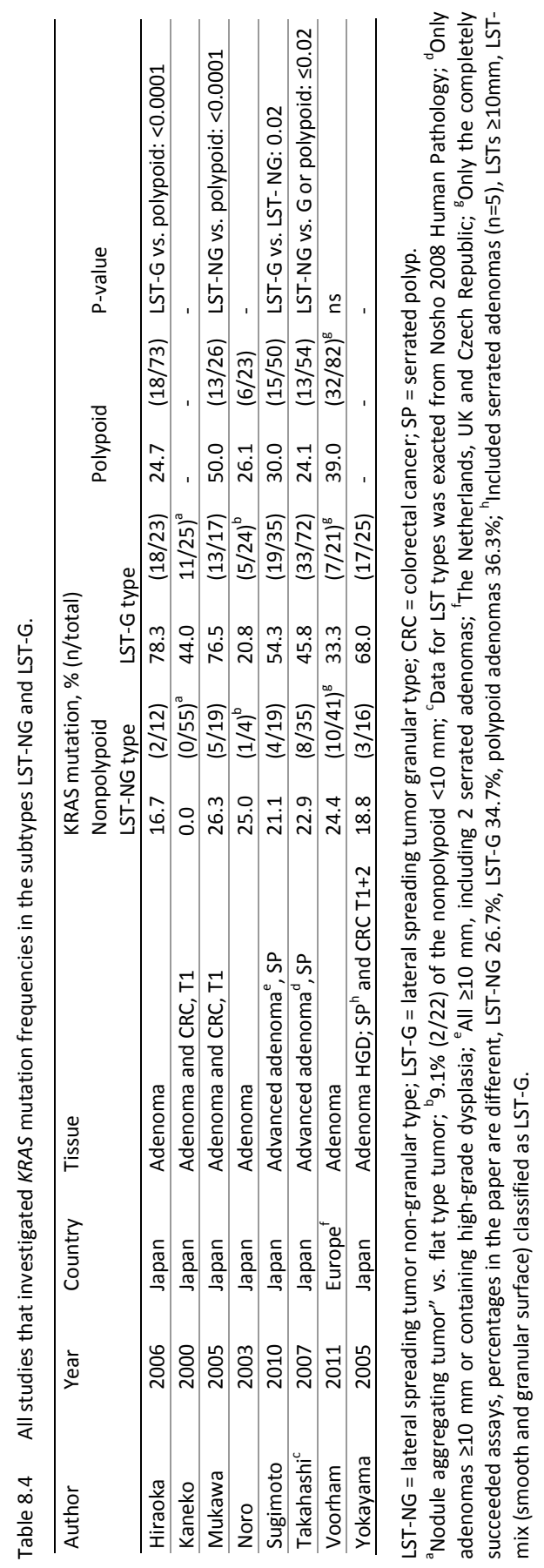




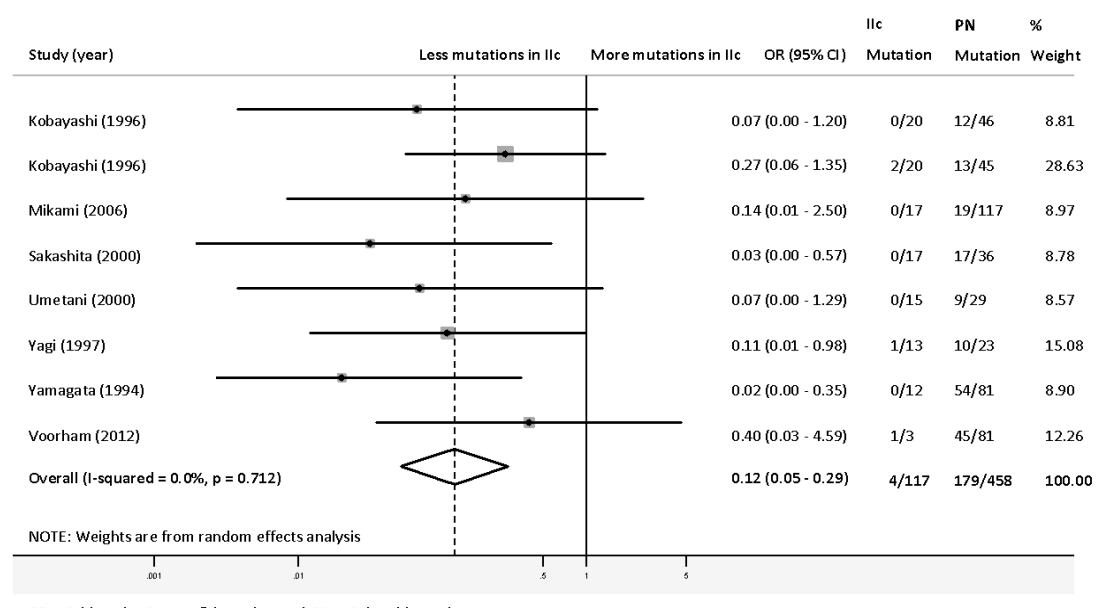

$\mathrm{OR}=$ Odds ratio; $\mathrm{Cl}=$ confidence interval; $\mathrm{PN}$ = Polypoid neoplasm

Figure 8.4 Meta-analysis of studies investigating the frequency of KRAS mutation in depressed type (IIc) neoplasms versus polypoid neoplasms. Random effect meta-analysis showed less KRAS mutations in depressed type neoplasms compared with polypoid neoplasms with a summary OR of $0.12,95 \% \mathrm{Cl} 0.05-0.29, \mathrm{I}^{2}=0.0 \%$.

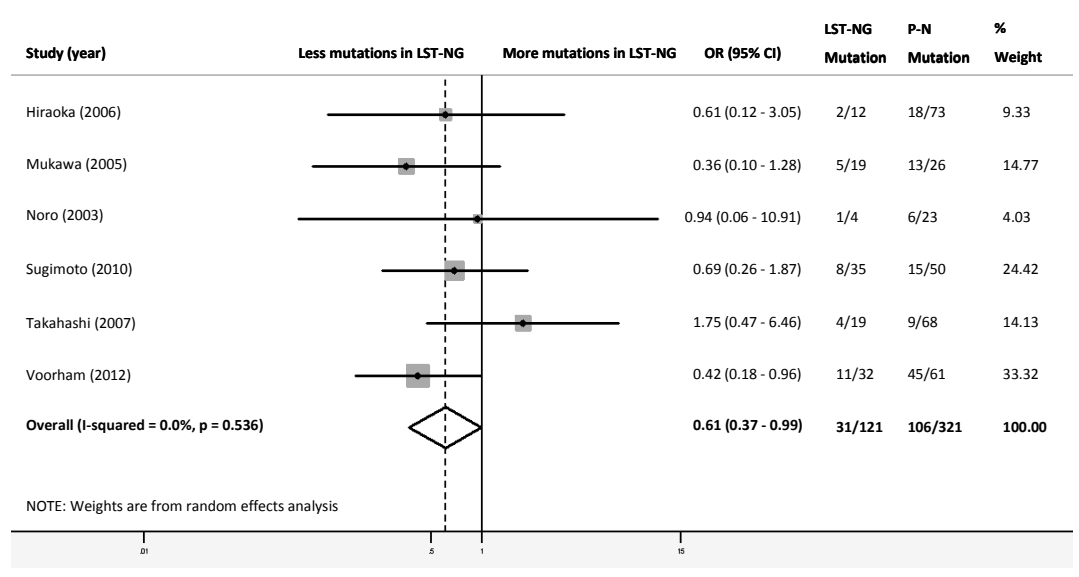

OR, Odds ratio; Cl, confidence interval; LST-NG, Non-granular type lateral spreading tumor; PN, Polypoid neoplasm.

Figure 8.5 Meta-analysis of studies investigating the frequency of KRAS mutation in LST-NG type neoplasms versus polypoid neoplasms. Random effect meta-analysis showed less KRAS mutations in LST-NG type neoplasms than in polypoid neoplasms with a summary OR of 0.61 , $95 \% \mathrm{Cl} 0.37-0.99, \mathrm{I}^{2}=0.0 \%$.

\section{APC}

A total of 8 studies investigated APC mutations in NP-CRNs, and all examined at least the mutation cluster region (MCR) of APC (Table 8.5). In total 504 neoplasms were 
examined, of which 219 carcinomas (65 nonpolypoid carcinomas and 154 polypoid carcinomas), 279 adenomas (147 nonpolypoid adenomas and 132 polypoid adenomas) and 6 unspecified adenomas and early cancers (all 6 nonpolypoid). Large variation existed with respect to sample sizes, ranging from 6 to 60 nonpolypoid neoplasms. Five studies compared nonpolypoid neoplasms with polypoid neoplasms, providing insufficient data for meta-analysis. All five studies observed a lower frequency of $A P C$ mutation in nonpolypoid neoplasms than polypoid neoplasms, of which two found statistically significant differences, one in slightly elevated lesions ${ }^{53}$ and the other one in depressed lesions. ${ }^{18}$

\section{BRAF}

Table 8.6 presents the five studies that investigated the BRAF mutation frequency in nonpolypoid neoplasms. In total, 473 adenomas ( 251 nonpolypoid adenomas and 222 polypoid adenomas) and 136 carcinomas ( 97 nonpolypoid carcinomas and 39 polypoid carcinomas) were examined. Four studies compared mutation frequency in nonpolypoid versus polypoid neoplasms, all of them reporting low BRAF mutation frequencies in both types of lesions (range $0-14.3 \%$ for nonpolypoid neoplasms and 0 $2.9 \%$ for polypoid neoplasms), without statistically significant differences.

\section{$\mathrm{MSI}$}

Thirteen studies investigated the MSI status of NP-CRNs (Table 8.7), examining a total of 972 neoplasms: 371 carcinomas (174 nonpolypoid carcinomas and 197 polypoid carcinomas), 508 adenomas ( 270 nonpolypoid adenomas and 238 polypoid adenomas) and 93 unspecified adenomas and carcinomas (65 nonpolypoid and 28 polypoid neoplasms). Large variation was noted among these studies with regard to methodology used to determine the MSI status. In seven studies the National Cancer Institute $(\mathrm{NCl})$ marker panel ${ }^{82}$ was used. Five of these studies compared nonpolypoid with polypoid neoplasms, and data from these studies were used to construct a forest plot (Supplementary Figure S8.4), showing a summary OR of 0.95 (95\% Cl 0.14-6.47), $\mathrm{I}^{2}=53 \%$. One study ${ }^{21}$ could not be included in the meta-analysis, as none of the samples in this study showed MSI. We could still take into consideration these data using Bayesian intervals, which did not influence the outcome of the meta-analysis (data not shown). We found comparable results by including all studies, irrespective of the panel used (summary OR 0.99, 95\% $\mathrm{Cl} 0.21-4.71, \mathrm{I}^{2}=70 \%$ ).

\section{DNA Promoter Hypermethylation}

Promoter hypermethylation in NP-CRNs was investigated in 7 studies. Of them, 6 provided separate data on nonpolypoid and polypoid neoplasms (thereby excluding Ogawa et $\mathrm{al}^{67}$ ). As shown in Table 8.8 , a total of 334 nonpolypoid and 322 polypoid colorectal neoplasms were analyzed. 


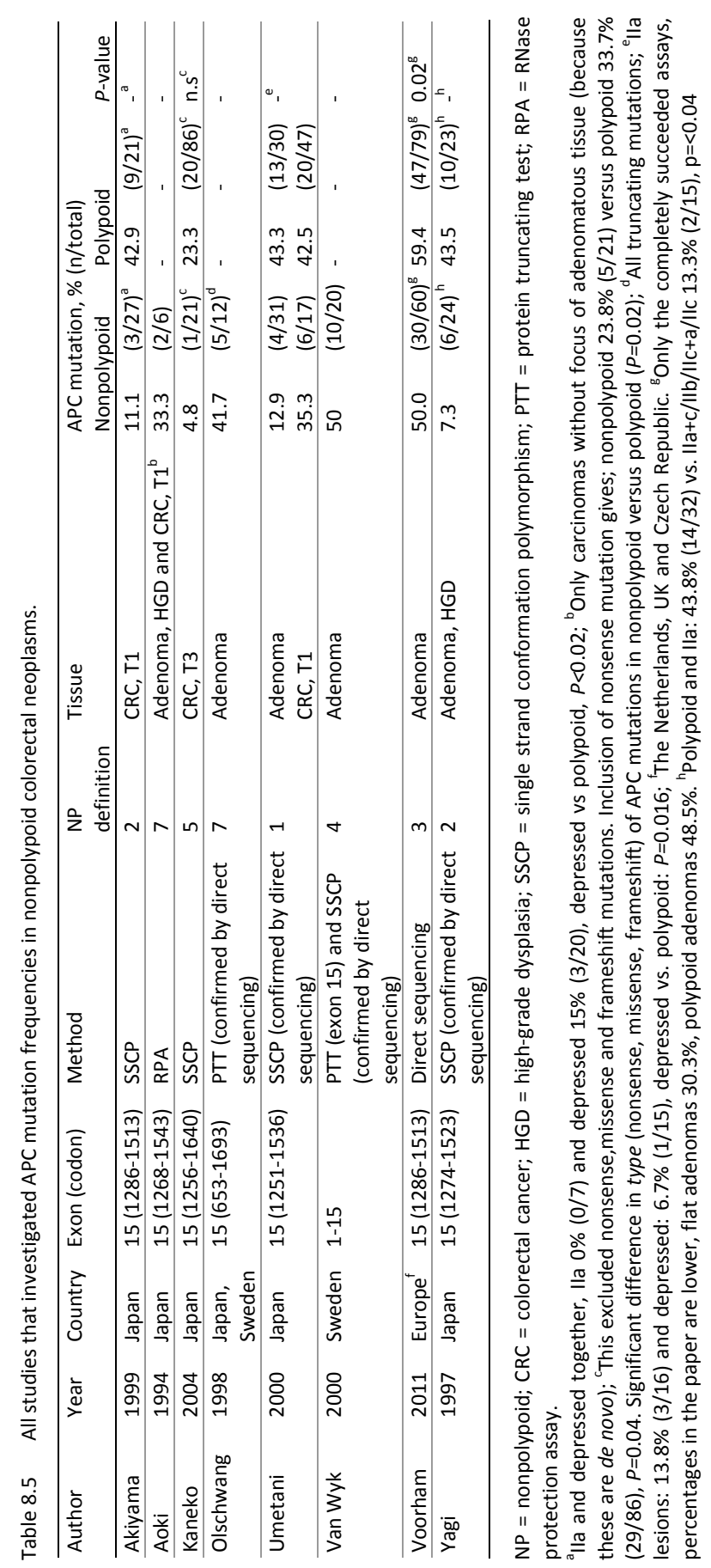


Tracking the molecular features of nonpolypoid colorectal neoplasms

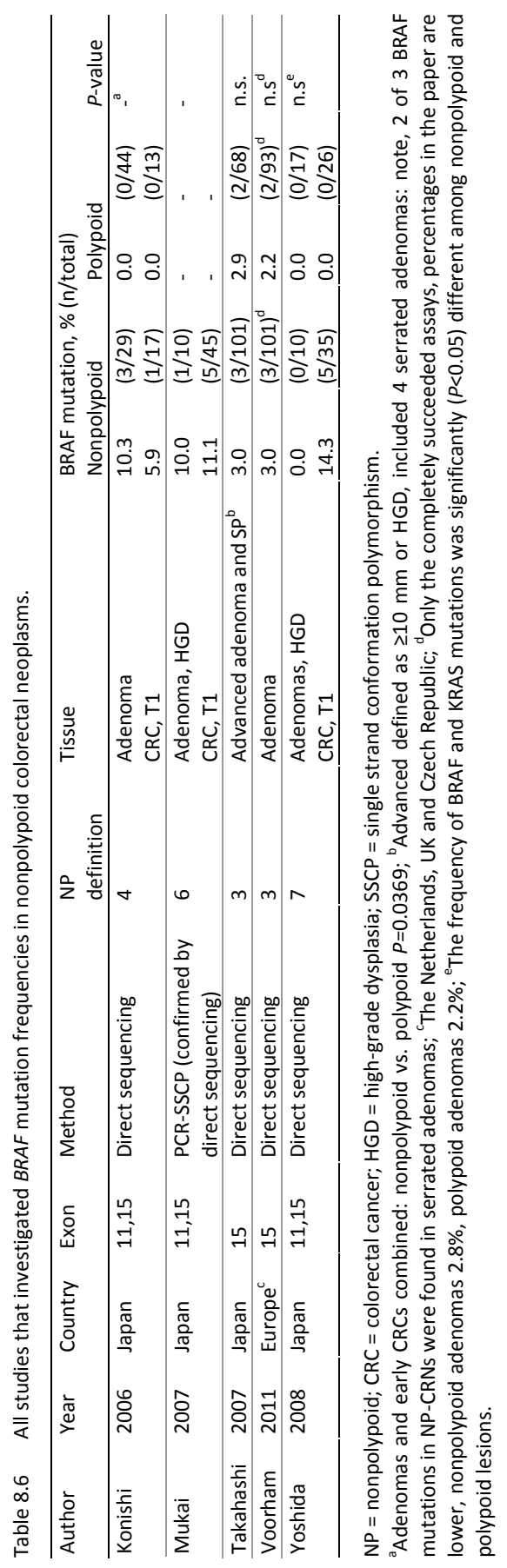




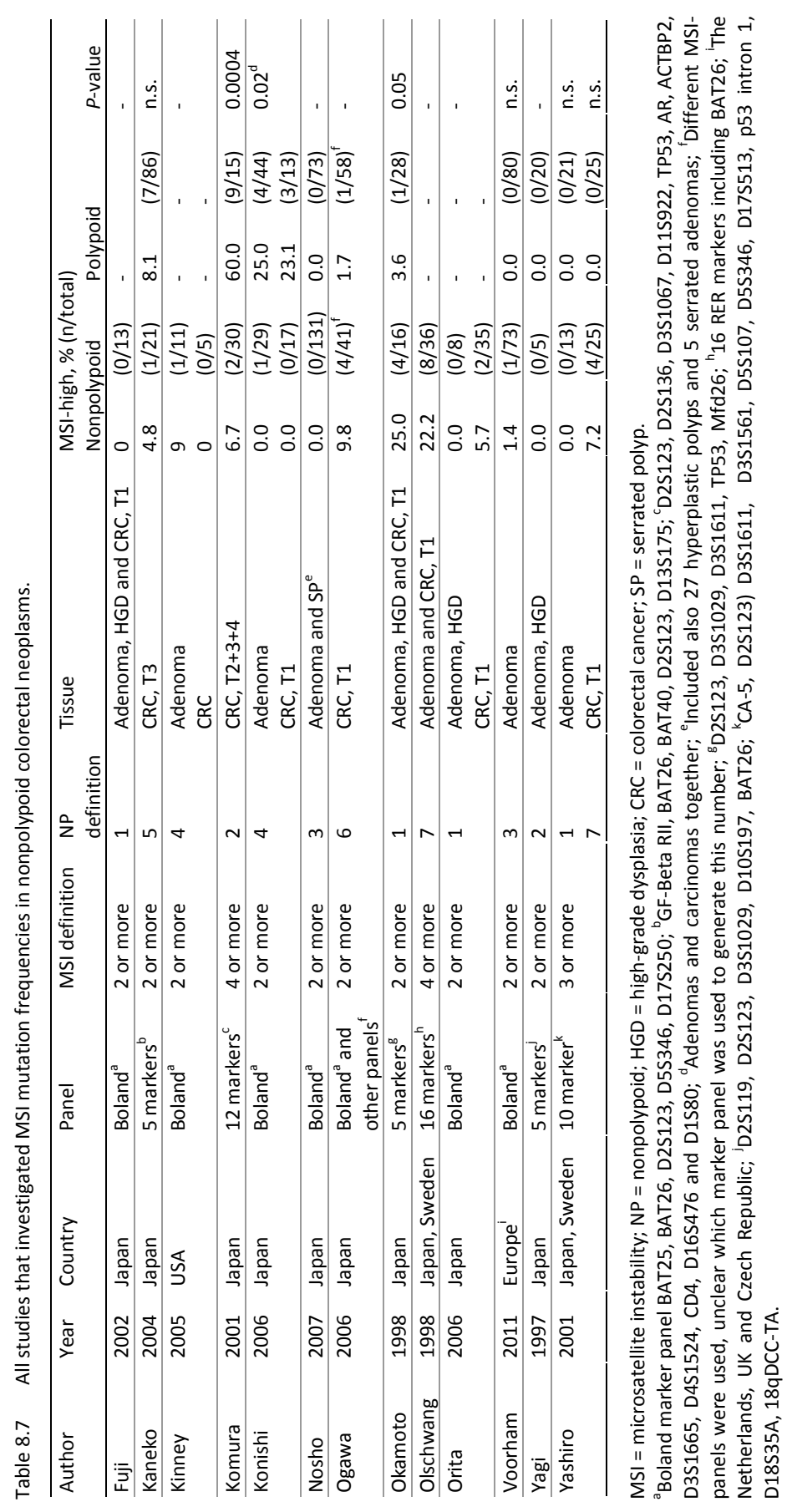




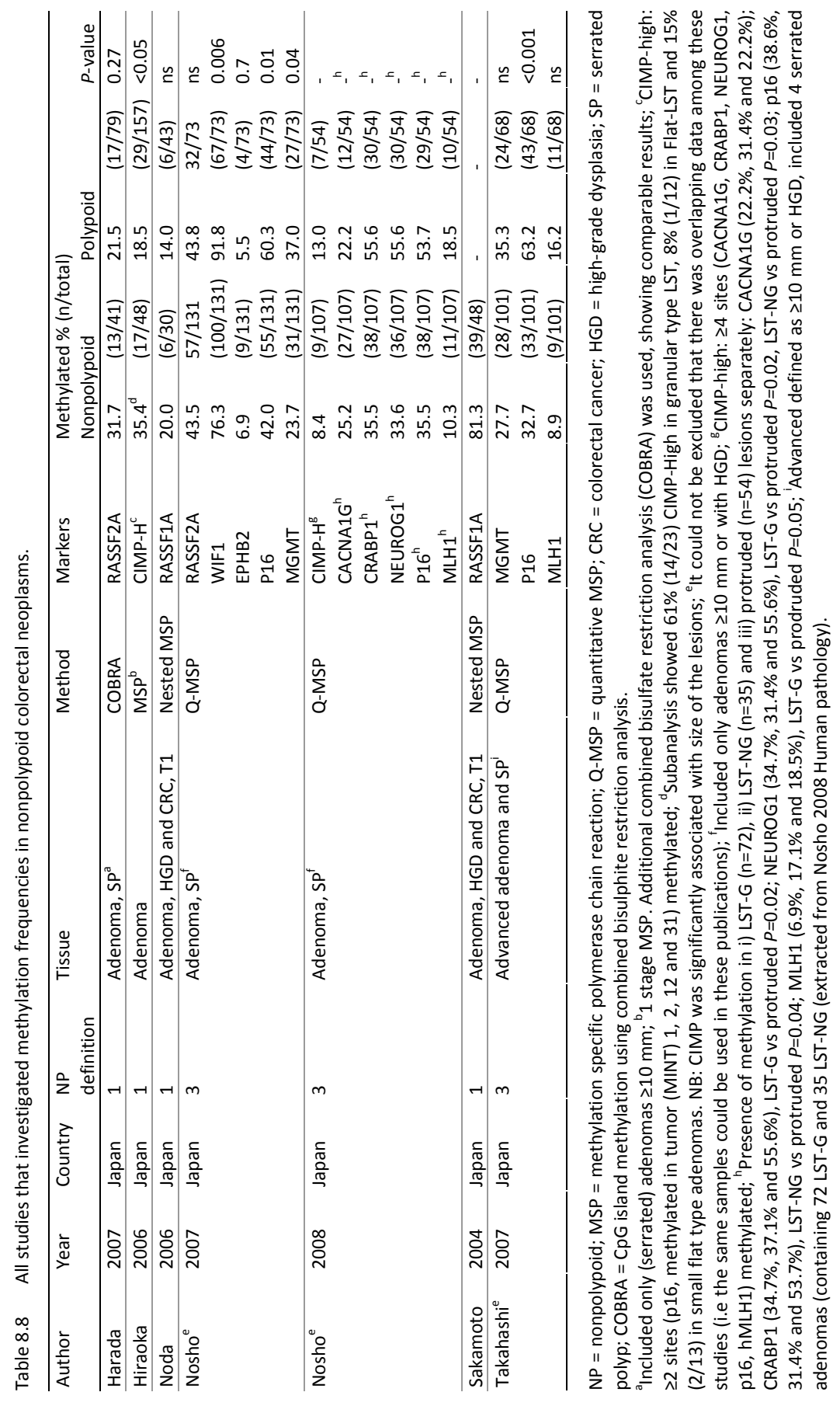


Different genes were analyzed and only the genes $\mathrm{p} 16, \mathrm{MLH} 1$ and RASSF2 were analyzed in two studies, showing similar results; MLH1 and RASSF2 showed no difference between nonpolypoid and polypoid neoplasms, whereas $p 16$ was less frequently methylated in nonpolypoid compared with polypoid neoplasms. Hiraoka et $a l^{20}$ found that nonpolypoid adenomas, in particular proximally located LST-G type ones, were more likely to have a $\mathrm{CpG}$ island methylator phenotype (CIMP) than polypoid adenomas. In contrast, the study by Nosho et $a l^{72}$ showed no significant differences between nonpolypoid and polypoid neoplasms with regard to CIMP status.

\section{Discussion}

In this systematic review, we found that some subtypes of NP-CRNs, that is, depressed (Paris type 0-IIc) and LST-NG type neoplasms, as well as early (T1) nonpolypoid carcinomas are consistently associated with less KRAS mutations compared with their polypoid counterparts. These findings may argue for a distinct, potentially shared molecular pathway. Although a large gap still exists in our knowledge on the molecular make-up of NP-CRNs, these findings may provide the basis for future studies aiming to clarify the biologic characteristics, malignant potential and clinical significance of nonpolypoid neoplasms.

NP-CRNs represent a morphologically heterogeneous group of lesions, which may unequivocally give rise to post-colonoscopy (i.e. interval) colorectal cancers. ${ }^{8,12}$ It is presently unknown, however, whether this association is solely explained by their phenotype, i.e. subtle endoscopic appearance rendering them more easily to be overlooked, or if biologic features associated with a more rapid growth may play an additional role. This issue is of practical importance as the former scenario may be amenable for corrective measures, i.e. training on detection and endoscopic removal of nonpolypoid lesions, while the latter may additionally require customized surveillance, in terms of type of procedure recommended (i.e. chromoendoscopy) and frequency of intervals. We therefore aimed to thoroughly examine the current knowledge on major molecular events underlying the nonpolypoid carcinogenesis.

\section{KRAS}

Mutation in the KRAS gene was by far the most frequently investigated molecular event in NP-CRNs. We found that early nonpolypoid carcinomas were less likely to contain KRAS mutations than polypoid ones. In contrast to nonpolypoid carcinomas, the frequency of KRAS mutations in colorectal adenomas remains controversial. Some studies reported a lower incidence of KRAS mutations in nonpolypoid than polypoid adenomas, while others did not find any difference or found opposite results. This large heterogeneity of study outcomes is probably not unexpectedly, as the phenotype of adenomas (e.g. size, endoscopic shape and histological type) as well as their 
molecular make-up may vary widely. Subgroup analyses aiming to downsize the effect of heterogeneity resulted into very small groups, thereby precluding us from drawing sound conclusion.

In this review we paid special attention to potential differences in the molecular profile of endoscopic subtypes of NP-CRNs. We found that, in spite of relatively limited statistical power, current data support a significantly lower frequency of KRAS mutations in depressed type (Paris type 0-IIc) than in polypoid neoplasms. Several studies showed that, although uncommon (1:100-1:500 colonoscopies in Western Countries), ${ }^{8,83}$ depressed lesions are associated with a more aggressive biologic behavior, with approximately $55 \%$ of them containing high-grade dysplasia or invasive cancer at the time of diagnosis. ${ }^{3,84}$ In contrast, data pertaining to the more frequently detected slightly elevated (Paris type 0 -Ila) neoplasms are largely controversial, due to great heterogeneity among the studies, possibly reflecting differences of the used definitions, methodology and inclusion criteria.

An interesting observation of our meta-analysis is a potential difference in molecular make-up of granular versus non-granular type of LSTs. While LSTs-NG appear to contain less KRAS mutations than polypoid neoplasms, LSTs-G may show opposite features, with a trend toward more KRAS mutation than their polypoid counterparts. Studies investigating the clinicopathologic features of LSTs suggested that LSTs-NG, ${ }^{85}$ and in particular those with pseudodepression, ${ }^{3,86,87}$ are associated with advanced histological features.

Taken together, these findings and the current meta-analysis may suggest that the depressed type lesions as well as the non-granular type LSTs may share a common molecular pathway, with less KRAS mutation as a key-feature. Intriguingly, as this feature is also frequently found in early nonpolypoid carcinomas, one may speculate that depressed and/or LST-NG type lesions can be potential precursors of nonpolypoid carcinomas.

\section{APC}

Only a few studies investigated APC mutations, and most of them focused on the MCR region of this gene, showing no differences between NP and polypoid CRNs. Only one study conducted in an international (Western-Japanese) sample-set found a difference in $A P C$ mutations between nonpolypoid and polypoid adenomas, ${ }^{53}$ and therefore, the contribution of $A P C$ mutations to the nonpolypoid carcinogenesis remains largely unclear.

\section{BRAF}

BRAF mutations are considered to be an alternative mechanism to KRAS mutations for activation of the RAS-RAF-MAPK signal in colorectal tumorigenesis and consequently these genetic alterations have been shown to be mutually exclusive. ${ }^{88}$ Mutations in $B R A F$ could be an alternative for the lower frequency of KRAS mutation that has been 
observed in NP-CRNs in the past. ${ }^{19}$ In the present analysis, however, BRAF mutation frequency did not appear to differ between nonpolypoid and polypoid neoplasms, albeit again, only a few studies investigated this issue.

\section{$\mathrm{MSI}$}

Although widely examined in routine practice, MSI status of NP-CRNs received, so far, limited consideration. Furthermore, a large variety exists among studies with regard to the panel of markers used. Separate examination of studies using the $\mathrm{NCl}$ marker panel showed, however, inconsistent results, probably because of the overall low prevalence of MSI in precancerous lesions. ${ }^{89}$

\section{DNA Promoter hypermethylation}

Data on DNA promoter hypermethylation in NP-CRNs are conflicting. Hiraoka et al ${ }^{20}$ found that nonpolypoid adenomas, in particular proximally located LST-G type were more likely to have a CIMP-high phenotype than polypoid adenomas, while Nosho et $\mathrm{al}^{72}$ could not confirm these results. However, Hiraoka et al ${ }^{20}$ combined conventional and serrated adenomas in their analysis, which may be an important confounder as these two histological subtypes may evolve to cancer via molecularly different routes. ${ }^{89}$ Different methodologies, i.e. different types of tissues examined, techniques (MSP versus Q-MSP) as well as definitions for CIMP-high, could contribute to the observed disparities between these studies, and make it again premature to draw any conclusions with regard to the role of promoter methylation in NP-CRNs at this moment.

To our knowledge, this is the first meta-analysis which exploring the major molecular events in NP-CRNs. Our review provides orientation hints on potentially distinct molecular features of some subtypes of NP-CRNs, which may form the basis for future prospective research in this area.

Some methodological limitations need, however, to be further discussed. First, nearly all studies investigating the molecular characteristics of NP-CRN were performed in Japan. Mutational differences have been reported between Asian and Western populations. ${ }^{90,91}$ Geographic differences in molecular features of NP-CRNs could not be investigated in this meta-analysis, as only six studies (partially) examined non-Japanese samples. So far, the molecular profile of NP-CRNs in Western populations is largely unknown and needs further clarification. Second, a great heterogeneity was found between studies concerning definitions used. We therefore conducted separate analyses of studies using similar definitions, which unfortunately did not reduce the study heterogeneity. Third, the majority of studies included were performed in an expert setting, implying potential selection bias. Awaiting data reflecting everyday practice, we assume that the current meta-analysis may already provide an estimate of the most frequent molecular events. Finally, as many of the studies were retrospective and did not consecutively include colorectal neoplasms, had insufficient statistical 
power to detect moderate associations, and importantly, none of them specifically addressed this in relation with size and location of CRNs, which may have impact on the outcomes, we realize that caution should be exercised when interpreting the outcome of this review.

\section{Where to go from here?}

This systematic review, which spans the past 2 decades of molecular research on NPCRNs underscores that although NP-CRNs have been extensively studied, our knowledge about their underlying molecular mechanisms is unfortunately limited and mostly restricted to KRAS mutation status. One of the major issues that stands out from this work is the need for multicenter, prospective studies, combining Western and Eastern expertise in this field, using simple and reproducible definitions, and rigorous data collection, with photographic documentation of endoscopic features of colorectal neoplasms, especially shape, size and location. This approach may help us to clarify the way nonpolypoid CRNs may contribute to the limited effectiveness of colonoscopy in the proximal colon. ${ }^{11,92,93}$ In addition, use of international histological classifications of CRNs is key-factor to allow comparisons among studies. ${ }^{24,94}$

With these premises in mind, the next step would be to define most important targets for molecular research. While some data already exist concerning KRAS mutation status, other major molecular events, such as BRAF, APC and TP53 mutations as well as for promoter hypermethylation received only limited attention. In line with current evidence suggesting a pivotal role of chromosomal instability in colorectal carcinogenesis, $^{95,96}$ we suggest that future studies should explore its potential contribution to nonpolypoid colorectal carcinogenesis. Upcoming techniques (such as massive parallel sequencing) might provide important insights in the near future. ${ }^{97}$ However, even with these technologies or especially with them, the need for well classified and carefully collected samples remains of high priority.

In conclusion, with this meta-analysis we set out a first attempt to clarify the molecular biology of NP-CRNs. We found that some subtypes of NP-CRNs, in particular depressed (Paris type 0-IIC) and LSTs-NG type neoplasms appear to contain less KRAS mutations than polypoid neoplasms, suggesting a potentially distinct molecular pathway. In view of the high heterogeneity among the existing studies, we recommend prospective multicenter initiatives to elucidate the biology and potential clinical significance of nonpolypoid colorectal neoplasms. 


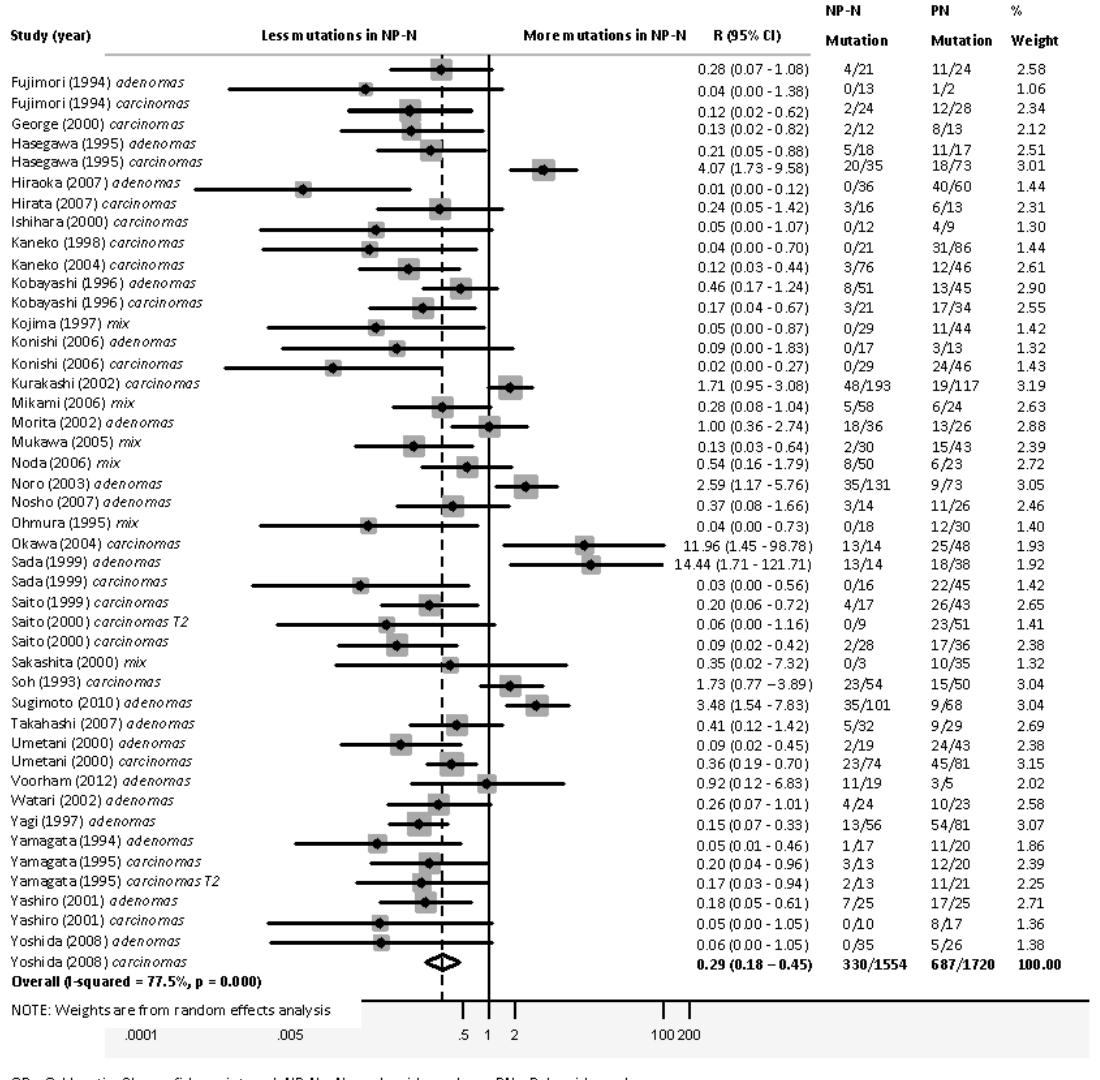

$\mathrm{OR}=0$ dds r atio; $\mathrm{Cl}=$ confidence interval; $\mathrm{NP}-\mathrm{N}=$ Nonpolypoid neoplasm; $\mathrm{PN}=$ Polypoid neoplasm.

Figure S8.1 Meta-analysis of studies investigating the frequency of KRAS mutation in nonpolypoid versus polypoid neoplasms. Random effect meta-analysis showed large heterogeneity among the studies, $I^{2}=77.5 \%$. 


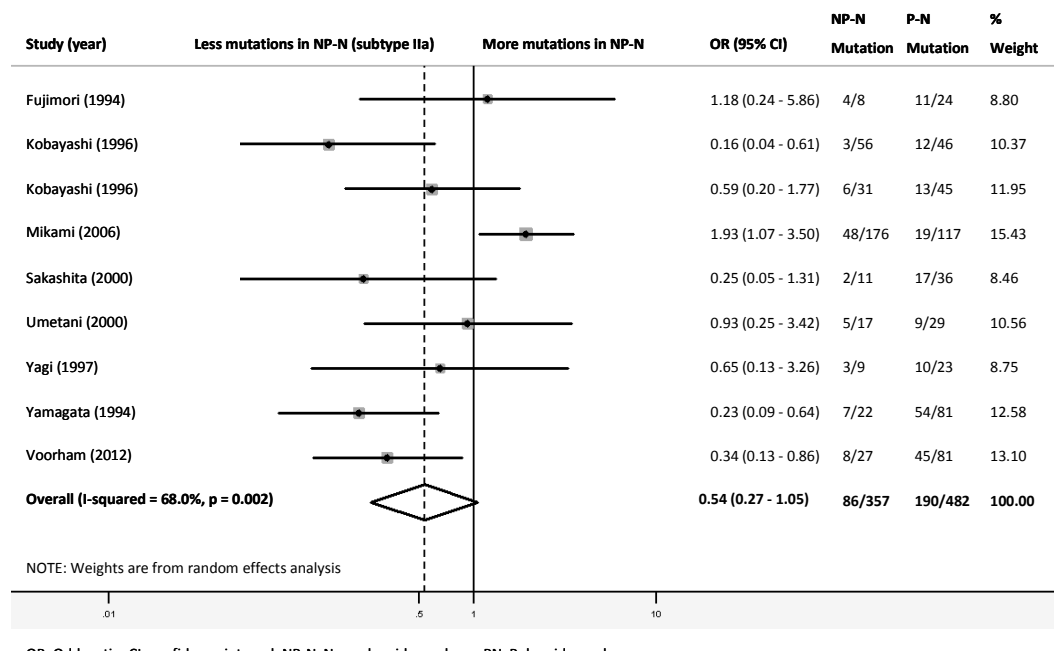

Figure S8.2 Meta-analysis of studies investigating the frequency of KRAS mutation in nonpolypoid neoplasms subtype lla versus polypoid neoplasms. Random effect meta-analysis showed large heterogeneity among the studies, $I^{2}=68.0 \%$.

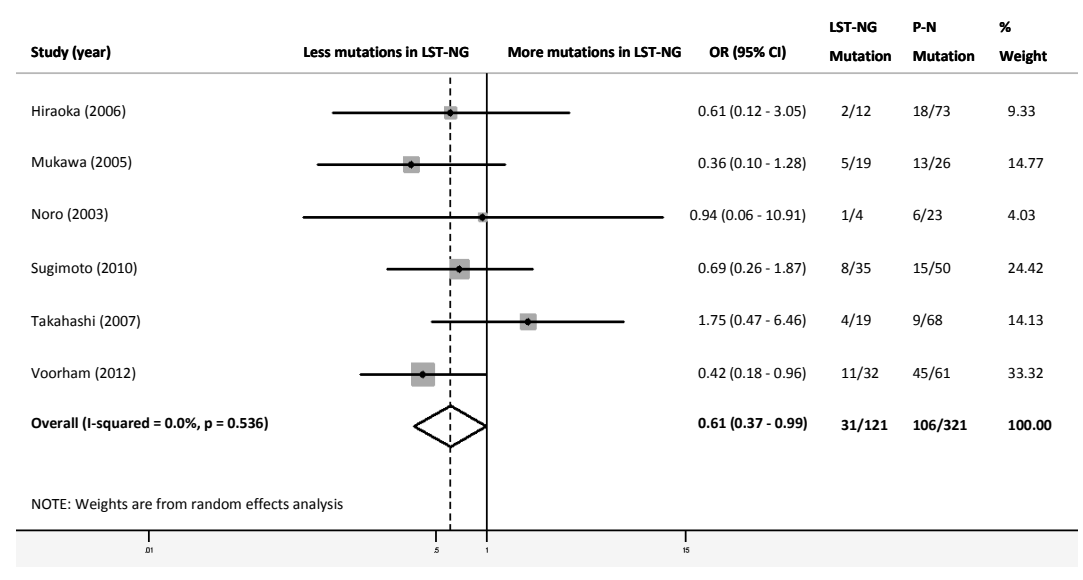

OR, Odds ratio; Cl, confidence interval; LST-NG, Non-granular type lateral spreading tumor; PN, Polypoid neoplasm.

Figure S8.3 Meta-analysis of studies investigating the frequency of KRAS mutation in LST-G type neoplasms versus polypoid neoplasms. Random effect meta-analysis showed large heterogeneity among the studies, $12=80.5 \%$. 


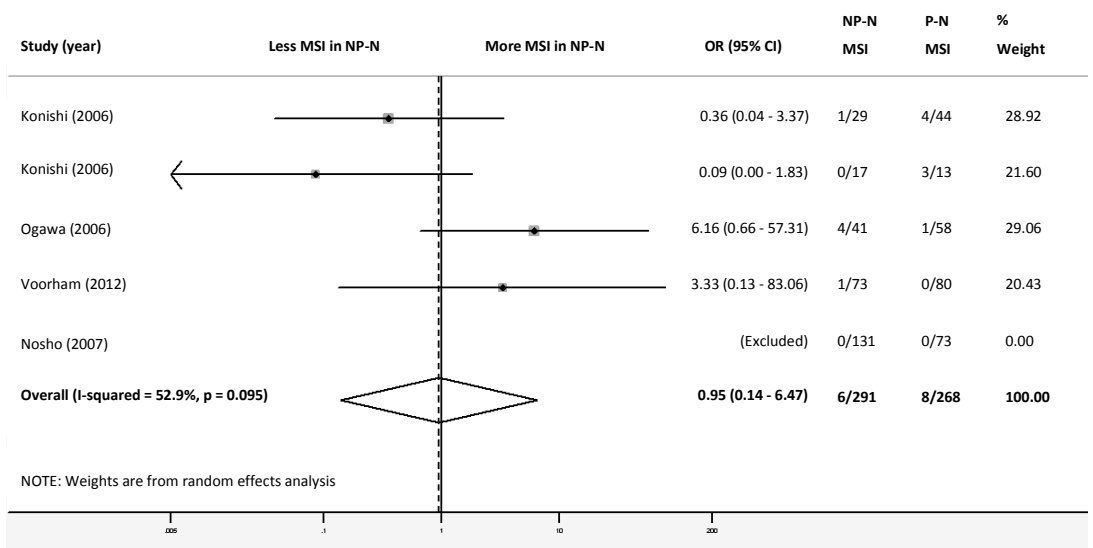

OR, Odds ratio; Cl, confidence interval; NP-N, Nonpolypoid neoplasm; PN, Polypoid neoplasm.

Figure S8.4 Meta-analysis of studies using the BOLAND panel to investigate the frequency of MSI in nonpolypoid neoplasms versus polypoid neoplasms. Random effect meta-analysis showed moderate heterogeneity among the studies, $\mathrm{I}^{2}=52.9 \%$ and no significant differences between nonpolypoid and polypoid neoplasms, summary OR 0.95, 95\% $\mathrm{Cl}$ 0.14-6.47. 


\section{References}

1. Muto T, Kamiya J, Sawada T, Konishi F, Sugihara K, Kubota Y, Adachi M, Agawa S, Saito Y, Morioka Y, Tanprayoon T. Small "flat adenoma" of the large bowel with special reference to its clinicopathologic features. Dis Colon Rectum 1985;28:847-51.

2. Kudo S., Tamura S., Hirota S., Sano Y., Yamano H., Serizawa M., Fukuoka T., Mitsuoka H., Nakajima T., Kusaka H. The problem of de novo colorectal carcinoma. European journal of cancer 1995;31A:1118 20.

3. Kudo S., Lambert R., Allen J. I., Fujii H., Fujii T., Kashida H., Matsuda T., Mori M., Saito H., Shimoda T., Tanaka S., Watanabe H., Sung J. J., Feld A. D., Inadomi J. M., O'Brien M. J., Lieberman D. A., Ransohoff D. F., Soetikno R. M., Triadafilopoulos G., Zauber A., Teixeira C. R., Rey J. F., Jaramillo E., Rubio C. A., Van Gossum A., Jung M., Vieth M., Jass J. R., Hurlstone P. D. Nonpolypoid neoplastic lesions of the colorectal mucosa. Gastrointestinal endoscopy 2008;68:S3-47.

4. Bianco M. A., Cipolletta L., Rotondano G., Buffoli F., Gizzi G., Tessari F. Prevalence of nonpolypoid colorectal neoplasia: an Italian multicenter observational study. Endoscopy 2010;42:279-285.

5. Diebold Marie-Danile, Samalin Emmanuelle, Merle Corinne, Bouche Olivier, Higuero Thierry, Jolly Damien, Ramaholimihaso Fidy, Renard Pascal, Yaziji Nahla, Thiefin Grard, Cadiot Guillaume. Colonic Flat Neoplasia: Frequency and Concordance Between Endoscopic Appearance and Histological Diagnosis in a French Prospective Series. Am J Gastroenterol 2004;99:1795-1800.

6. Rembacken B. J., Fujii T., Cairns A., Dixon M. F., Yoshida S., Chalmers D. M., Axon A. T. R. Flat and depressed colonic neoplasms: a prospective study of 1000 colonoscopies in the UK. The Lancet 2000;355:1211-1214.

7. Saitoh Y., Waxman I., West A. B., Popnikolov N. K., Gatalica Z., Watari J., Obara T., Kohgo Y., Pasricha P. J. Prevalence and distinctive biologic features of flat colorectal adenomas in a North American population. Gastroenterology 2001;120:1657-1665.

8. Soetikno R. M., Kaltenbach T., Rouse R. V., Park W., Maheshwari A., Sato T., Matsui S., Friedland S. Prevalence of nonpolypoid (flat and depressed) colorectal neoplasms in asymptomatic and symptomatic adults. JAMA 2008;299:1027-1035.

9. Tsuda S., Veress B., Toth E., Fork F. T. Flat and depressed colorectal tumours in a southern Swedish population: a prospective chromoendoscopic and histopathological study. Gut 2002;51:550-555.

10. Rondagh E. J., Bouwens M. W., Riedl R. G., Winkens B., de Ridder R., Kaltenbach T., Soetikno R. M., Masclee A. A., Sanduleanu S. Endoscopic appearance of proximal colorectal neoplasms and potential implications for colonoscopy in cancer prevention. Gastrointestinal endoscopy 2012.

11. Baxter N. N., Goldwasser M. A., Paszat L. F., Saskin R., Urbach D. R., Rabeneck L. Association of colonoscopy and death from colorectal cancer. Ann Intern Med 2009;150:1-8.

12. Rex D. K. Preventing colorectal cancer and cancer mortality with colonoscopy: what we know and what we don't know. Endoscopy 2010;42:320-3.

13. Hurlstone David P., Cross Simon S., Adam Ian, Shorthouse Andrew J., Brown Steven, Sanders David S., Lobo Alan J. A prospective clinicopathological and endoscopic evaluation of flat and depressed colorectal lesions in the United Kingdom. Am J Gastroenterol 2003;98:2543-2549.

14. Chiu Han-Mo, Lin Jaw-Town, Chen Chien-Chuan, Lee Yi-Chia, Liao Wei-Chih, Liang Jin-Tung, Shun ChiaTung, Wang Hsiu-Po, Wu Ming-Shiang. Prevalence and Characteristics of Nonpolypoid Colorectal Neoplasm in an Asymptomatic and Average-Risk Chinese Population. Clinical Gastroenterology and Hepatology 2009; 7:463-470.

15. Watanabe T., Muto T. Colorectal carcinogenesis based on molecular biology of early colorectal cancer, with special reference to nonpolypoid (superficial) lesions. World J Surg 2000;24:1091-7.

16. Yashiro M., Carethers J. M., Laghi L., Saito K., Slezak P., Jaramillo E., Rubio C., Koizumi K., Hirakawa K., Boland C. R. Genetic pathways in the evolution of morphologically distinct colorectal neoplasms. Cancer Res 2001;61:2676-83.

17. Mikami M., Nosho K., Yamamoto H., Takahashi T., Maehata T., Taniguchi H., Adachi Y., Imamura A. Fujita M., Hosokawa M., Itoh F., Imai K., Shinomura Y. Mutational analysis of beta-catenin and the RASRAF signalling pathway in early flat-type colorectal tumours. Eur J Cancer 2006;42:3065-72.

18. Umetani N., Sasaki S., Masaki T., Watanabe T., Matsuda K., Muto T. Involvement of APC and K-ras mutation in non-polypoid colorectal tumorigenesis. Br J Cancer 2000;82:9-15. 
19. Yoshida S., Ikehara N., Aoyama N., Shirasaka D., Sakashita M., Semba S., Hasuo T., Miki I., Morita Y., Tamura T., Azuma T., Yokozaki H., Kasuga M. Relationship of BRAF mutation, morphology, and apoptosis in early colorectal cancer. Int J Colorectal Dis 2008;23:7-13.

20. Hiraoka S., Kato J., Tatsukawa M., Harada K., Fujita H., Morikawa T., Shiraha H., Shiratori Y. Laterally spreading type of colorectal adenoma exhibits a unique methylation phenotype and K-ras mutations. Gastroenterology 2006;131:379-89.

21. Nosho K., Yamamoto H., Takahashi T., Mikami M., Taniguchi H., Miyamoto N., Adachi Y., Arimura Y., Itoh F., Imai K., Shinomura Y. Genetic and epigenetic profiling in early colorectal tumors and prediction of invasive potential in pT1 (early invasive) colorectal cancers. Carcinogenesis 2007;28:1364-70.

22. Takahashi T., Nosho K., Yamamoto H., Mikami M., Taniguchi H., Miyamoto N., Adachi Y., Itoh F., Imai K., Shinomura Y. Flat-type colorectal advanced adenomas (laterally spreading tumors) have different genetic and epigenetic alterations from protruded-type advanced adenomas. Mod Pathol 2007;20:139-47.

23. Moher D., Liberati A., Tetzlaff J., Altman D. G. Preferred reporting items for systematic reviews and meta-analyses: the PRISMA statement. Journal of clinical epidemiology 2009;62:1006-12.

24. Schlemper R. J., Riddell R. H., Kato Y., Borchard F., Cooper H. S., Dawsey S. M., Dixon M. F., FenoglioPreiser C. M., Flejou J. F., Geboes K., Hattori T., Hirota T., Itabashi M., Iwafuchi M., Iwashita A., Kim Y. I., Kirchner T., Klimpfinger M., Koike M., Lauwers G. Y., Lewin K. J., Oberhuber G., Offner F., Price A. B., Rubio C. A., Shimizu M., Shimoda T., Sipponen P., Solcia E., Stolte M., Watanabe H., Yamabe H. The Vienna classification of gastrointestinal epithelial neoplasia. Gut 2000;47:251-5.

25. DerSimonian R., Laird N. Meta-analysis in clinical trials. Controlled clinical trials 1986;7:177-88.

26. Higgins J. P., Thompson S. G. Quantifying heterogeneity in a meta-analysis. Statistics in medicine 2002;21:1539-58.

27. Hirata I., Wang F. Y., Murano M., Inoue T., Toshina K., Nishikawa T., Maemura K. Histopathological and genetic differences between polypoid and non-polypoid submucosal colorectal carcinoma. World J Gastroenterol 2007;13:2048-52.

28. Kojima M., Konishi F., Tsukamoto T., Yamashita K., Kanazawa K. Ki-ras point mutation in different types of colorectal carcinomas in early stages. Dis Colon Rectum 1997;40:161-7.

29. Kusaka T., Fukui H., Sano Y., Ueda Y., Chiba T., Fujimori T. Analysis of K-ras codon 12 mutations and p53 overexpression in colorectal nodule-aggregating tumors. J Gastroenterol Hepatol 2000;15:1151-7.

30. George S. M., Makinen M. J., Jernvall P., Makela J., Vihko P., Karttunen T. J. Classification of advanced colorectal carcinomas by tumor edge morphology: evidence for different pathogenesis and significance of polypoid and nonpolypoid tumors. Cancer 2000;89:1901-9.

31. Ishihara S., Watanabe T., Umetani N., Yamagata S., Masaki T., Nagawa H., Muto T. Small advanced colorectal cancers: clinicopathological characteristics and pathogenetic origin. Jpn J Clin Oncol 2000;30:504-9.

32. Kaneko K., Fujii T., Kato S., Boku N., Oda Y., Koba I., Ohtsu A., Hosokawa K., Ono M., Shimoda T., Yoshida S. Growth patterns and genetic changes of colorectal carcinoma. Jpn J Clin Oncol 1998;28:196201.

33. Kurahashi T., Kaneko K., Makino R., Mitamura K. Colorectal carcinoma with special reference to growth pattern classifications: clinicopathologic characteristics and genetic changes. J Gastroenterol 2002;37:354-62.

34. Minamoto T., Sawaguchi K., Mai M., Yamashita N., Sugimura T., Esumi H. Infrequent K-ras activation in superficial-type (flat) colorectal adenomas and adenocarcinomas. Cancer Res 1994;54:2841-4.

35. Morita T., Tomita N., Ohue M., Sekimoto M., Yamamoto H., Ohnishi T., Tada M., Ikenaga M., Miyake Y. Sakita I., Tamaki Y., Matsuura N., Ito M., Monden M. Molecular analysis of diminutive, flat, depressed colorectal lesions: are they precursors of polypoid adenoma or early stage carcinoma? Gastrointest Endosc 2002; 56:663-71.

36. Noda H., Kato Y., Yoshikawa H., Arai M., Togashi K., Nagai H., Konishi F., Miki Y. Frequent involvement of ras-signalling pathways in both polypoid-type and flat-type early-stage colorectal cancers. J Exp Clin Cancer Res 2006;25:235-42.

37. Hasegawa H., Ueda M., Watanabe M., Teramoto T., Mukai M., Kitajima M. K-ras gene mutations in early colorectal cancer ... flat elevated vs polyp-forming cancer. Oncogene 1995;10:1413-6. 
38. Sada M., Mitomi H., Igarashi M., Katsumata T., Saigenji K., Okayasu I. Cell kinetics, p53 and bcl-2 expression, and c-Ki-ras mutations in flat-elevated tubulovillous adenomas and adenocarcinomas of the colorectum: comparison with polypoid lesions. Scand J Gastroenterol 1999;34:798-807.

39. Watari J., Saitoh Y., Obara T., Fujiya M., Maemoto A., Ayabe T., Ashida T., Yokota K., Orii Y., Kohgo Y. Natural history of colorectal nonpolypoid adenomas: a prospective colonoscopic study and relation with cell kinetics and K-ras mutations. Am J Gastroenterol 2002;97:2109-15.

40. Sakamoto N., Terai T., Ajioka Y., Abe S., Kobayasi O., Hirai S., Hino O., Watanabe H., Sato N., Shimoda T., Fujii $\mathrm{H}$. Frequent hypermethylation of RASSF1A in early flat-type colorectal tumors. Oncogene 2004;23:8900-7.

41. Mukai S., Hiyama T., Tanaka S., Yoshihara M., Arihiro K., Chayama K. Involvement of Kruppel-like factor 6 (KLF6) mutation in the development of nonpolypoid colorectal carcinoma. World J Gastroenterol 2007;13:3932-8

42. Konishi K., Takimoto M., Kaneko K., Makino R., Hirayama Y., Nozawa H., Kurahashi T., Kumekawa Y., Yamamoto T., Ito H., Yoshikawa N., Kusano M., Nakayama K., Rembacken B. J., Ota H., Imawari M. BRAF mutations and phosphorylation status of mitogen-activated protein kinases in the development of flat and depressed-type colorectal neoplasias. Br J Cancer 2006;94:311-7.

43. Ohmura M., Hattori T. A possible multiclonal development in human colonic carcinomas. J Cancer Res Clin Oncol 1995;121:321-6.

44. Okawa T., Yoshinaga K., Uetake H., Sato T., Higuchi T., Nemoto T., Sugihara K. Cyclooxygenase-2 overexpression is related to polypoid growth and K-ras gene mutation in T1 colorectal carcinomas. Dis Colon Rectum 2004;47:1915-21.

45. Soh K., Yanagisawa A., Hiratsuka H., Sugano H., Kato Y. Variation in K-ras codon 12 point mutation rate with histological atypia within individual colorectal tumors. Jpn J Cancer Res 1993;84:388-93.

46. Saito K., Arai K., Mori M. p53 overexpression and K-ras codon 12 mutations in submucosal invasive depressed-type colorectal cancer. Oncology Reports 2000;7:741-744.

47. Yamagata S., Muto T., Uchida Y., Masaki T., Higuchi Y., Sawada T., Hirooka T. Polypoid growth and Kras codon 12 mutation in colorectal cancer. Cancer 1995;75:953-7.

48. Saito Kenichi, Ogawa Akira, Ohki Ichiro, Mori Masatomo. K-ras Codon 12 Mutation and Horizontal Growth of Colorectal Cancer. Digestive Endoscopy 1999;11:125-131.

49. Fujimori T., Satonaka K., Yamamura-Idei Y., Nagasako K., Maeda S. Non-involvement of ras mutations in flat colorectal adenomas and carcinomas. Int J Cancer 1994;57:51-5.

50. Kobayashi M., Watanabe H., Ajioka Y., Honma T., Asakura H. Effect of K-ras mutation on morphogenesis of colorectal adenomas and early cancers: relationship to distribution of proliferating cells. Hum Pathol 1996;27:1042-9.

51. Sakashita M., Aoyama N., Maekawa S., Kuroda K., Shirasaka D., Ichihara T., Kuroda Y., Minami R., Maeda S., Kasuga M. Flat-elevated and depressed, subtypes of flat early colorectal cancers, should be distinguished by their pathological features. Int J Colorectal Dis 2000;15:275-81.

52. Yamagata S., Muto T., Uchida Y., Masaki T., Sawada T., Tsuno N., Hirooka T. Lower incidence of K-ras codon 12 mutation in flat colorectal adenomas than in polypoid adenomas. Jpn J Cancer Res 1994;85:147-51.

53. Voorham Q. J., Carvalho B., Spiertz A. J., van Grieken N. C. , Mongera S., Rondagh E. J., van de Wiel M. A., Jordanova E. S., Ylstra B., Kliment M., Grabsch H., Rembacken B. J., Arai T., de Bruine A. P., Sanduleanu S., Quirke P., Mulder C. J., van Engeland M., Meijer G. A. Abstract PP15: Chromosome 5q loss in colorectal flat adenomas. Cell Oncol 2012;35 (Suppl 1):S22.

54. Yokoyama Yuichi, Tamura Satoru, Onishi Saburo. Frequent K-RAS mutations among laterally spreading tumors with granular components and their significance for rectal carcinomas. Digestive Endoscopy 2005;17:69-72.

55. Mukawa K., Fujii S., Takeda J., Kitajima K., Tominaga K., Chibana Y., Fujita M., Ichikawa K., Tomita S. Ono Y., Imura J., Kawamata H., Chiba T., Hiraishi H., Terano A., Fujimori T. Analysis of K-ras mutations and expression of cyclooxygenase- 2 and gastrin protein in laterally spreading tumors. J Gastroenterol Hepatol 2005;20:1584-90.

56. Noro A., Sugai T., Habano W., Nakamura S. Analysis of Ki-ras and p53 gene mutations in laterally spreading tumors of the colorectum. Pathol Int 2003;53:828-36.

57. Kaneko K., Kurahashi T., Makino R., Konishi K., Mitamura K. Growth patterns of superficially elevated neoplasia in the large intestine. Gastrointest Endosc 2000;51:443-50. 
58. Sugimoto T., Ohta M., Ikenoue T., Yamada A., Tada M., Fujishiro M., Ogura K., Yamaji Y., Okamoto M., Kanai F., Kawabe T., Omata M. Macroscopic morphologic subtypes of laterally spreading colorectal tumors showing distinct molecular alterations. Int J Cancer 2010;127:1562-9.

59. Yagi O. K., Akiyama Y., Ohkura Y., Ban S., Endo M., Saitoh K., Yuasa Y. Analyses of the APC and TGF-beta type II receptor genes, and microsatellite instability in mucosal colorectal carcinomas. Jpn J Cancer Res 1997;88:718-24

60. Kaneko K., Kurahashi T., Makino R., Konishi K., Ito H., Katagiri A., Kumekawa Y., Hirayama Y., Yoneyama K., Kushima M., Kusano M., Tajiri H., Rembacken B. J., Mitamura K., Imawari M. Pathological features and genetic alterations in colorectal carcinomas with characteristics of nonpolypoid growth. $\mathrm{Br} \mathrm{J}$ Cancer 2004;91:312-8.

61. van Wyk R., Slezak P., Hayes V. M., Buys C. H., Kotze M. J., de Jong G., Rubio C., Dolk A., Jaramillo E., Koizumi K., Grobbelaar J. J. Somatic mutations of the APC, KRAS, and TP53 genes in nonpolypoid colorectal adenomas. Genes Chromosomes Cancer 2000;27:202-8.

62. Olschwang S., Slezak P., Roze M., Jaramillo E., Nakano H., Koizumi K., Rubio C. A., Laurent-Puig P. Thomas G. Somatically acquired genetic alterations in flat colorectal neoplasias. Int J Cancer 1998;77:366-9.

63. Aoki T., Takeda S., Yanagisawa A., Kato Y., Ajioka Y., Watanabe H., Kudo S., Nakamura Y. APC and p53 mutations in de novo colorectal adenocarcinomas. Hum Mutat 1994;3:342-6.

64. Akiyama Y., Arai T., Nagasaki H., Yagi O. K., Nakahata A., Nakajima T., Ohkura Y., Iwai T., Saitoh K., Yuasa Y. Frequent allelic imbalance on chromosome 18q21 in early superficial colorectal cancers. Jpn J Cancer Res 1999;90:1329-37.

65. Fujii H., Ajioka Y., Kazami S., Takagaki T., Gong Zhu X., Hirose S., Watanabe H., Shirai T. Loss of heterozygosity in the clonal evolution of flat colorectal neoplasms. The Journal of pathology 2002;197:298-306.

66. Komura K., Masuda H., Esumi M. Distinct relationship between polypoid growth type and sporadic colorectal carcinomas with microsatellite instability. Hepatogastroenterology 2001;48:706-10.

67. Ogawa T., Yoshida T., Tsuruta T., Saigenji K., Okayasu I. Genetic instability on chromosome 17 in the epithelium of non-polypoid colorectal carcinomas compared to polypoid lesions. Cancer Sci 2006;97:1335-42.

68. Orita H., Sakamoto N., Ajioka Y., Terai T., Hino O., Sato N., Shimoda T., Kamano T., Tsurumaru M., Fujii H. Allelic loss analysis of early-stage flat-type colorectal tumors. Ann Oncol 2006;17:43-9.

69. Okamoto T., Konishi F., Kojima M., Senba S., Kanazawa K., Tsukamoto T. Significance of microsatellite instability in different types of early-stage nonfamilial colorectal carcinomas. Dis Colon Rectum 1998;41:1385-91.

70. Kinney T. P., Merel N., Hart J., Joseph L., Waxman I. Microsatellite analysis of sporadic flat and depressed lesions of the colon. Dig Dis Sci 2005;50:327-30.

71. Harada K., Hiraoka S., Kato J., Horii J., Fujita H., Sakaguchi K., Shiratori Y. Genetic and epigenetic alterations of Ras signalling pathway in colorectal neoplasia: analysis based on tumour clinicopathological features. British journal of cancer 2007;97:1425-31.

72. Nosho K., Yamamoto H., Takahashi T., Mikami M., Hizaki K., Maehata T., Taniguchi H., Yamaoka S., Adachi Y., Itoh F., Imai K., Shinomura Y. Correlation of laterally spreading type and JC virus with methylator phenotype status in colorectal adenoma. Hum Pathol 2008;39:767-75.

73. Nosho K., Yamamoto H., Hamamoto Y., Goto A., Yoshida Y., Arimura Y., Endo T., Imai K. A case of multiple protruding and flat colorectal tumors analyzed by a cDNA array. Int J Colorectal Dis 2007;22:723-4.

74. Postma C., Hermsen M. A., Coffa J., Baak J. P., Mueller J. D., Mueller E., Bethke B., Schouten J. P., Stolte M., Meijer G. A. Chromosomal instability in flat adenomas and carcinomas of the colon. The Journal of pathology 2005;205:514-21.

75. Wolber R. A., Owen D. A. Flat adenomas of the colon. Human pathology 1991;22:70-4.

76. General rules for clinical and pathological studies on cancer of the colon, rectum and anus. Part II. Histopathological classification. Japanese Research Society for Cancer of the Colon and Rectum. The Japanese journal of surgery 1983;13:574-98.

77. Jaramillo E., Watanabe M., Slezak P., Rubio C. Flat neoplastic lesions of the colon and rectum detected by high-resolution video endoscopy and chromoscopy. Gastrointestinal endoscopy 1995;42:114-22. 
78. Kudo S., Tamura S., Nakajima T., Yamano H., Kusaka H., Watanabe H. Diagnosis of colorectal tumorous lesions by magnifying endoscopy. Gastrointestinal endoscopy 1996;44:8-14.

79. Shimoda T., Ikegami M., Fujisaki J., Matsui T., Aizawa S., Ishikawa E. Early colorectal carcinoma with special reference to its development de novo. Cancer 1989;64:1138-46.

80. The Paris endoscopic classification of superficial neoplastic lesions: esophagus, stomach, and colon: November 30 to December 1, 2002. Gastrointest Endosc 2003;58 (Suppl December):S3-43.

81. Kudo S. Endoscopic mucosal resection of flat and depressed types of early colorectal cancer. Endoscopy 1993;25:455-61.

82. Boland C. R., Thibodeau S. N., Hamilton S. R., Sidransky D., Eshleman J. R., Burt R. W., Meltzer S. J., Rodriguez-Bigas M. A., Fodde R., Ranzani G. N., Srivastava S. A National Cancer Institute Workshop on Microsatellite Instability for cancer detection and familial predisposition: development of international criteria for the determination of microsatellite instability in colorectal cancer. Cancer research 1998;58:5248-57.

83. Rondagh E. J., Masclee A. A., van der Valk M. E., Winkens B., de Bruine A. P., Kaltenbach T., Soetikno R. M., Sanduleanu S. Nonpolypoid colorectal neoplasms: gender differences in prevalence and malignant potential. Scandinavian journal of gastroenterology 2012;47:80-8.

84. Sanduleanu S., Rondagh E. J., Masclee A. A. Development of expertise in the detection and classification of non-polypoid colorectal neoplasia: Experience-based data at an academic Gl unit. Gastrointestinal endoscopy clinics of North America 2010;20:449-60.

85. Uraoka T., Saito Y., Matsuda T., Ikehara H., Gotoda T., Saito D., Fujii T. Endoscopic indications for endoscopic mucosal resection of laterally spreading tumours in the colorectum. Gut 2006;55:15921597.

86. Rotondano G., Bianco M. A., Buffoli F., Gizzi G., Tessari F., Cipolletta L. The Cooperative Italian FLIN Study Group: prevalence and clinico-pathological features of colorectal laterally spreading tumors. Endoscopy 2011;43:856-61.

87. Kim B. C., Chang H. J., Han K. S., Sohn D. K., Hong C. W., Park J. W., Park S. C., Choi H. S., Oh J. H. Clinicopathological differences of laterally spreading tumors of the colorectum according to gross appearance. Endoscopy 2011;43:100-7.

88. Yuen S. T., Davies H., Chan T. L., Ho J. W., Bignell G. R., Cox C., Stephens P., Edkins S., Tsui W. W., Chan A. S., Futreal P. A., Stratton M. R., Wooster R., Leung S. Y. Similarity of the phenotypic patterns associated with BRAF and KRAS mutations in colorectal neoplasia. Cancer research 2002;62:6451-5.

89. East J. E., Saunders B. P., Jass J. R. Sporadic and syndromic hyperplastic polyps and serrated adenomas of the colon: classification, molecular genetics, natural history, and clinical management. Gastroenterol Clin North Am 2008;37:25-46.

90. Wang J. Y., Hsieh J. S., Lu C. Y., Yu F. J., Wu J. Y., Chen F. M., Huang C. J., Lin S. R. The differentially mutational spectra of the APC, K-ras, and p53 genes in sporadic colorectal cancers from Taiwanese patients. Hepato-gastroenterology 2007;54:2259-65.

91. Hayashi N., Sugai S., Ito I., Nakamori S., Ogawa M., Nakamura Y. Ethnic difference in the pattern of Kras oncogene mutations in human colorectal cancers. Human mutation 1996;8:258-61.

92. Brenner H., Chang-Claude J., Seiler C. M., Rickert A., Hoffmeister M. Protection from colorectal cancer after colonoscopy: a population-based, case-control study. Ann Intern Med 2011;154:22-30.

93. Singh H., Nugent Z., Mahmud S. M., Demers A. A., Bernstein C. N. Predictors of colorectal cancer after negative colonoscopy: a population-based study. Am J Gastroenterol 2010;105:663-73; quiz 674.

94. Bosman FT, Carneiro F, Hruban RH, Theise ND. WHO Classification of Tumours of the Digestive System. IARC Press, 2010.

95. Grady W. M., Carethers J. M. Genomic and epigenetic instability in colorectal cancer pathogenesis. Gastroenterology 2008;135:1079-99.

96. Hermsen M., Postma C., Baak J., Weiss M., Rapallo A., Sciutto A., Roemen G., Arends J. W., Williams R., Giaretti W., De Goeij A., Meijer G. Colorectal adenoma to carcinoma progression follows multiple pathways of chromosomal instability. Gastroenterology 2002;123:1109-19.

97. Bell D. W. Our changing view of the genomic landscape of cancer. The Journal of pathology 2010;220:231-43 
140 


\section{Chapter 9}

Promoter hypermethylation in colorectal neoplasms according to their clinicopathologic features

Eveline JA Rondagh, Silvia Sanduleanu, Debbie GJ Robbrecht, Mariëlle WE Bouwens, Kim A Wouters, Bjorn Winkens, Gerrit A Meijer, Beatriz Carvalho, Robert G Riedl, Adriaan P de Bruïne, Ad AM Masclee, Manon van Engeland

Submitted 


\section{Abstract}

\section{Background}

Although the molecular profile of nonpolypoid colorectal neoplasms (NP-CRNs) has been extensively studied, data on epigenetic alterations are presently scarce. We therefore aimed to examine the association of DNA hypermethylation with clinicopathologic features of CRNs, i.e. nonpolypoid appearance, location, size and histology.

\section{Methods}

We collected clinicopathologic records from consecutive patients undergoing elective colonoscopy at our institution. All endoscopists were previously familiarized on the recognition and classification of NP-CRNs. Large adenomas were defined as adenomas sized $\geq 10 \mathrm{~mm}$ and advanced histology by the presence of highgrade dysplasia or early cancer. Using nested methylation specific polymerase chain reaction, we determined the methylation status of 11 prominent CRC specific genes, hMLH1, O6 MGMT, APC, p14 ${ }^{a r f}$, p16 ${ }^{\text {INK4A }}$, RASFF1A, RASFF2A, GATA4, GATA5, HLTF and CHFR, as well as the CIMP status.

\section{Results}

One hundred-nine NP-CRNs and 139 polypoid CRNs were examined. Overall, frequencies of DNA methylation for the investigated genes were similar in nonpolypoid and polypoid CRNs. Regarding size and histology, we found differences in methylation status according to colonic location. In the proximal colon, large CRNs showed significantly more often methylation of CHFR and RASSF2A than small CRNs: $74.4 \%$ vs. $41.6 \%$, $P=0.001$ and $84.6 \%$ vs. $47.5 \%, P<0.001$. Likewise, proximal advanced CRNs showed more often methylation of CHFR and RASSF2A than CRNs without advanced histology: $93.3 \%$ vs. $45.6 \%, P<0.001$ and $100 \%$ vs. $52.8 \%$, $P<0.001$. Importantly, the association of CHFR and RASSF2A with large size and advanced histology was not found in the distal colon.

\section{Conclusions}

In proximal CRNs, either nonpolypoid or polypoid, methylation of CHFR and RASSF2A is associated with large size and advanced histology. Methylation of CHFR and RASSF2A may be important for progression of proximal CRNs and progression of proximal CRNs may be driven by other epigenetic alterations than distal CRNs. 


\section{Introduction}

Colonoscopy has been shown to be less effective in protection against proximal than distal colorectal cancer (CRC). ${ }^{1,2}$ This limited protection is in most cases related to unsuccessful detection or removal of precursor lesions, ${ }^{3}$ but different biologic features of CRNs leading to fast progression may also contribute to this outcome. Of note, differences have been described to exist between proximal and distal colorectal neoplasms (CRNs) regarding their clinicopathologic and molecular features. ${ }^{4-6}$ Proximal CRNs may be more likely to progress via nonpolypoid mechanisms, ${ }^{6}$ which may be an important cause of post-colonoscopy CRCs, as these lesions are more easily overlooked $^{7}$ and more challenging to remove. Moreover, some subtypes of nonpolypoid colorectal neoplasms (NP-CRNs), in particular the depressed subtypes, were found to frequently contain advanced histology, ${ }^{8-10}$ suggesting differences in biologic behavior.

Over the past decades, many studies ${ }^{11-34}$ attempted to gain insight into the molecular mechanisms underlying progression of NP-CRNs by examining genetic alterations, in particular KRAS mutation status. ${ }^{13-34}$ However, the outcomes are controversial, which is most probably related to inconsistencies regarding definitions used for NP-CRNs, differences in study designs (i.e. frequently non-consecutive inclusion of tissue samples), and especially to relatively small sample sizes. ${ }^{15-19,27-34}$ On the role of epigenetic alterations in nonpolypoid carcinogenesis, even less information is currently available. ${ }^{11-16}$ These data are of importance as epigenetic alterations may play a significant role in CRC development ${ }^{35}$ and provide the basis for developing fecal and blood markers for DNA testing. ${ }^{36}$

DNA promoter hypermethylation is the most extensively studied epigenetic alteration and an important alternative mechanism for silencing of tumor suppressor genes. ${ }^{37}$ Previous studies on promoter hypermethylation in NP-CRNs suggested that NP-CRNs display less often methylation of $P 16^{I N K 4 A}$, WIF1 and $O^{6} M G M T$ and more often a CpG island methylator phenotype (CIMP) as compared with polypoid CRNs. ${ }^{13-15}$ However, these previous studies have some limitations. First, most of them ${ }^{11-14}$ did not separately analyze conventional and serrated adenomas. Moreover, none of these previous studies were conducted outside Japan and seperate data for the proximal and distal colon were mostly not provided.

In the present study, we therefore aimed to comprehensively examine DNA hypermethylation of prominent CRC specific genes in relation to clinicopathologic features of CRNs, i.e. nonpolypoid appearance, size and histology and specifically focused on differences according to colonic location. 


\section{Methods}

\section{Study design}

The tissue samples included in this study were derived from a large prospective cohort of consecutive patients who attended for routine colonoscopy between February 2008 and February 2009, as described in detail elsewhere. ${ }^{38}$ Prior to commencing this study, we familiarized all endoscopists at the Division of Gastroenterology and Hepatology of the Maastricht University Medical Center in the Netherlands on the recognition and classification of nonpolypoid colorectal lesions. ${ }^{39}$ In this large cohort, the prevalence of NP-CRNs was comparable to data from other Western studies ${ }^{39}$ and the adenoma prevalence was in accordance with current targets for colonoscopy. ${ }^{40}$ Our endoscopy unit provides colonoscopic examinations for both GP referrals and specialist referrals, serving a population of approximately 300,000 inhabitants. Patients aged $<18$ years, having inflammatory bowel disease or hereditary forms of CRC (e.g. Lynch syndrome, FAP, hyperplastic polyposis) were not eligible for the study.

Nonpolypoid lesions were defined as lesions with a height less than half of the diameter, in alignment with previous studies. ${ }^{41}$ Furthermore, we used the ParisJapanese classification to further classify nonpolypoid lesions into slightly elevated (IIa), completely flat (IIb) and depressed (IIc). ${ }^{42}$ According to location, the colorectal lesions were subdivided into i) proximal: from cecum to splenic flexure or ii) distal: from descending colon to rectum and according to size into $<6 \mathrm{~mm}, 6-9 \mathrm{~mm}$ and $\geq 10$ $\mathrm{mm}$. Large colorectal lesions were defined as lesions $\geq 10 \mathrm{~mm}$ in size.

The histological diagnosis was re-evaluated by one experienced gastrointestinal (GI) pathologist (A. de B.), according to the classification of the World Health Organization. ${ }^{43}$ Colorectal neoplasms (CRNs) were defined as either adenomas or early cancers. Advanced histology was defined by the presence of high-grade dysplasia (HGD) or early cancer, limited to the submucosa (T1). CRCs invading the muscularis propria or beyond (T2-T4) were not included in the analyses, as these cancers are considered to be advanced and classified separately. ${ }^{10,42}$ Moreover, serrated polyps were not included in the analyses, as these lesions progress via the alternative, serrated neoplastic pathway. ${ }^{44}$ The study was approved by the Institutional Review Board of the Maastricht University Medical Center.

\section{Tissue samples}

From this large cohort of patients, we included all NP-CRNs which were eligible for molecular analysis, i.e. adenomatous tissue was available and sufficient amounts of DNA could be extracted. For each NP-CRN, we included one polypoid CRN, diagnosed from the beginning of the study period. A total of 129 NP-CRNs were diagnosed during the study period. ${ }^{38}$ Of these, 109 NP-CRNs were eligible for molecular analysis. Of the 1038 polypoid CRNs diagnosed during the study period, ${ }^{38} 139$ polypoid CRNs were 
included for molecular analysis. In total, 248 nonpolypoid and polypoid CRNs were analyzed.

\section{DNA-isolation}

We used formaldehyde-fixed, paraffin-embedded tissue for the DNA isolation. From each lesion, 10 sections of $10 \mu \mathrm{m}$ or 20 sections of $5 \mu \mathrm{m}$ were collected. Two sections were stained with haematoxylin and eosin (H\&E) and microscopically examined (R.R.), which allowed us to mark the adenomatous areas in the tissue specimen. After deparaffinization with xylene and ethanol, the H\&E section was used as a reference for macro-dissection. In case of sufficient amounts of tissue, we incubated the tissue overnight with $1 \mathrm{M}$ of sodium thiocyanate at $37^{\circ} \mathrm{C}$. Next, the tissue was incubated for a period of 5 days with $60 \mu \mathrm{l}$ lysis buffer (ATL buffer, QIAmp, DNA micro- or mini-kit, Qiagen, Venlo, The Netherlands) and $40 \mu \mathrm{l}$ proteinase K. Ten $\mu$ l proteinase $\mathrm{K}$ was added once a day when needed. After the incubation period, DNA was isolated using QIAamp, DNA micro- of mini-kit. DNA concentrations were measured using a Nanodrop.

\section{Promoter methylation}

We analyzed methylation status in the promoter region of prominent CRC specific genes affecting the WNT signaling pathway (APC), Ras signaling cascade (RASSF1A, RASSF2A), TP53 $\left(P 14^{\text {arf }}\right)$, cell cycle regulation $\left(P 16^{I N K 4 A}\right)$, transcription regulation (GATA4, GATA5, HLTF) and DNA repair mechanisms ( $h M L H 1, O^{6} M G M T, C H F R$ ) as well as the CIMP panel according to Weisenberger (Cacna 1G, RUNX3, SOCS1, NeuroG1, IGF-2). ${ }^{45}$ The methylation status was determined by nested (two stage) methylation specific polymerase chain reaction (MSP), as described in detail elsewhere. ${ }^{46}$ In brief, bisulfite modification to convert unmethylated cytosines into uracils was performed using an EZ DNA Methylation Kit (ZYMO Research, Irvine, CA). In the first PCR reaction, the bisulfite-treated DNA was amplified with flanking PCR primers (Supplementary Table S9.1), which are not specific for methylated or unmethylated DNA. In the second PCR, the first product was amplified by PCR primers specific for methylated or unmethylated DNA (Supplementary Table S9.1). All PCR reactions were performed with negative (human umbilical vein endothelial cells) and positive (in-vitro methylated DNA) controls. PCR products were electrophoresed on $2 \%$ agarose gels stained with GelStar and visualized using ultraviolet light. Promoter methylation analysis succeeded in $>99 \%$ of the cases (Supplementary Table S9.2). A total of 613 duplicates were performed starting from the first PCR reaction, showing a reproducibility of $88 \%$. We classified adenomas as CIMP positive when $\geq 3$ of the 5 CIMP markers were methylated, according to Weisenberger. ${ }^{45}$ 


\section{Data analysis}

The primary outcome measure of this study was the frequency of DNA hypermethylation in NP-CRNs compared with polypoid CRNs. As a secondary outcome measure, we examined the association of promoter hypermethylation with size and presence of advanced histology. To examine potential differences according to colonic location, we performed separate analyses for the proximal and distal colon.

We used a significance level of $<0.004(0.05 / 12)$, to adjust for multiple testing (11 genes and CIMP) by Bonferroni correction. We aimed to detect a difference of $>25 \%$ between NP- and polypoid CRNs regarding the frequency of promoter hypermethylation of the investigated genes. Depending on the gene, the frequency of DNA hypermethylation may vary from approximately 25 to $90 \% .{ }^{36,47}$ On the basis of these data, we calculated that at least $100 \mathrm{NP}-\mathrm{CRNs}$ and 100 polypoid CRNs were needed to detect a difference of $>25 \%$ with $80 \%$ power and at a significance level of 0.004 . The sample size analysis was based on a frequency of $40 \%$ in the control group, as this required the largest sample.

Differences in dichotomous variables were examined using the chi-square test or Fisher's exact test, where appropriate. All statistical analyses were performed using SPSS statistical software package 17.0 (SPSS, Chicago, Illinois). Two-sided $P$ values $<0.004$ were considered statistically significant.

\section{Results}

\section{Study population and colorectal neoplasms}

A total of 109 NP-CRNs in 88 patients (mean age 67.3 years (SD 11.2), 64.8\% men) and 139 polypoid CRNs in 98 patients (mean age 66.3 years (SD 10.5), 58.2\% men) were analyzed. The demographic data of the study patients are presented in Table 9.1, showing no significant differences between patients with NP-CRNs and those with polypoid CRNs. One patient had both a NP- and polypoid CRN included in the study. The clinicopathologic features of the CRNs are presented in Table 9.2, which shows that NP-CRNs were significantly more often located in the proximal colon than polypoid ones: $69.7 \%$ vs. $46.0 \%, P<0.001$. The present study included 4 depressed type (Paris type 0-Ilc) lesions.

Table 9.1 Demographic data of the study patients.

\begin{tabular}{llll}
\hline & Nonpolypoid & Polypoid & P-value \\
\hline Number of patients & 88 & 98 & \\
Mean age, years (SD) & $67.3(11.2)$ & $66.3(10.5)$ & 0.54 \\
Men, no. (\%) & $57(64.8)$ & $57(58.2)$ & 0.36 \\
\hline
\end{tabular}


Table 9.2 Clinicopathologic features of the colorectal neoplasms.

\begin{tabular}{llll}
\hline & Nonpolypoid & Polypoid & P-value \\
\hline Number of adenomas & 109 & 139 & \\
Proximal location, no. (\%) & $76(69.7)$ & $64(46.0)$ & $<0.001$ \\
Size $>9$ mm, no. (\%) & $38(39.4)$ & $39(28.1)$ & 0.25 \\
Presence of advanced histology, no. (\%) & $16(14.7)$ & $15(10.8)$ & 0.36 \\
\hline
\end{tabular}

\section{Promoter hypermethylation in nonpolypoid and polypoid colorectal neoplasms}

Overall, we found comparable frequencies of DNA hypermethylation methylation and CIMP in NP-CRNs versus polypoid CRNs (Table 9.3). Methylation of the RASSF2A gene, which was found more often in nonpolypoid (63.3\%) than polypoid CRNs (47.4\%), although the $P$-value did not reach statistical significance $(P=0.01$, after Bonferroni correction: NS).

Separate analyses for the proximal and distal colon showed differences in frequency of RASSF2A methylation in nonpolypoid versus polypoid CRNs for the proximal colon only only: $68.4 \%$ vs. $45.2 \%$ ( $P=0.006$, after Bonferroni correction: NS) compared with $51.5 \%$ vs. $49.3 \%$ ( $P=0.83$ ) (Table 9.3). In the proximal colon, we found a trend toward more methylation of CHFR in nonpolypoid than in polypoid CRNs ( $P=0.01$, after Bonferroni correction: NS) and in the distal colon there was a trend toward more methylation of $p 16^{I N K A A}$ in nonpolypoid than polypoid CRNs ( $P=0.01$, after Bonferroni correction: NS) (Table 9.3).

Table 9.3 Frequency (\%) of promoter CpG island methylation in nonpolypoid and polypoid adenomas according to anatomical location.

\begin{tabular}{|c|c|c|c|c|c|c|c|c|c|}
\hline & \multicolumn{2}{|c|}{ ALL } & \multirow{2}{*}{$\begin{array}{c}P \\
\text { value }\end{array}$} & \multicolumn{2}{|c|}{ PROXIMAL } & \multirow{2}{*}{$\begin{array}{c}P \\
\text { value }\end{array}$} & \multicolumn{2}{|c|}{ DISTAL } & \multirow{2}{*}{$\begin{array}{c}P \\
\text { value }\end{array}$} \\
\hline & NP-CRN & P-CRN & & NP-CRN & P-CRN & & NP-CRN & P-CRN & \\
\hline & $n=109$ & $n=139$ & & $n=76$ & $n=64$ & & $n=33$ & $n=75$ & \\
\hline$h M L H 1$ & $80(73.4)$ & $94(68.1)$ & 0.37 & $58(76.3)$ & $40(63.5)$ & 0.10 & $22(66.7)$ & $54(72.0)$ & 0.58 \\
\hline$O^{6} M G M T$ & $96(88.1)$ & $117(84.8)$ & 0.46 & $68(89.5)$ & $50(79.4)$ & 0.10 & $28(84.8)$ & 67 (89.3) & 0.53 \\
\hline$A P C$ & $88(80.7)$ & $121(87.7)$ & 0.13 & $62(81.6)$ & $54(84.4)$ & 0.66 & $67(90.5)$ & $26(78.8)$ & 0.12 \\
\hline$p 14^{\text {arf }}$ & $94(86.2)$ & $120(87.0)$ & 0.87 & $68(89.5)$ & 55 (85.9) & 0.52 & $26(78.8)$ & $65(87.8)$ & 0.25 \\
\hline$p 16^{I N K 4 A}$ & $82(76.6)$ & $92(66.2)$ & 0.07 & $52(70.3)$ & 41 (64.1) & 0.44 & 30 (90.9) & $51(68.0)$ & 0.01 \\
\hline RASSF1A & $19(17.6)$ & $37(27.0)$ & 0.08 & 11 (14.7) & $11(17.2)$ & 0.68 & $8(24.2)$ & $26(35.6)$ & 0.25 \\
\hline RASSF2A & $69(63.3)$ & $64(47.4)$ & 0.01 & $52(68.4)$ & $28(45.2)$ & 0.006 & $17(51.5)$ & $36(49.3)$ & 0.83 \\
\hline GATA4 & 87 (80.6) & $102(73.4)$ & 0.19 & $64(85.3)$ & 46 (71.6) & 0.05 & $23(69.7)$ & $56(74.7)$ & 0.59 \\
\hline HLTF & $76(70.4)$ & $90(65.2)$ & 0.40 & $50(66.7)$ & $36(57.1)$ & 0.25 & $26(78.8)$ & $54(72.0)$ & 0.46 \\
\hline CHFR & $60(55.0)$ & $60(43.2)$ & 0.06 & $46(60.5)$ & 25 (39.1) & 0.01 & $14(42.4)$ & 35 (46.7) & 0.68 \\
\hline GATA5 & 105 (95.7) & $133(95.7)$ & 0.80 & 75 (98.7) & 62 (96.9) & 0.46 & 30 (90.9) & 71 (94.7) & 0.47 \\
\hline CIMP & $83(76.1)$ & $107(77.0)$ & 0.88 & 62 (81.6) & $48(75.0)$ & 0.34 & $21(63.6)$ & 59 (78.7) & 0.10 \\
\hline
\end{tabular}

$\mathrm{NP}-\mathrm{CRN}=$ nonpolypoid colorectal neoplasm, $\mathrm{P}$-CRN $=$ polypoid colorectal neoplasm. $\mathrm{P}$-values $<0.004$ were considered statistically significant (Bonferroni correction) 
Overall, methylation frequencies in the proximal versus the distal CRNs were comparable, except for RASSF1A methylation, which was significantly less often shown in proximal than distal CRNs: $15.8 \%$ vs. $32.1 \%, P=0.003$ (Supplementary Table S9.3).

With regard to sex, we found no significant differences in the frequency of promoter hypermethylation in NP-CRNs from men versus those from women. In particular, we found no difference in the frequency RASSF2A hypermethylation: $63.4 \%$ of the NPCRNs from men vs. $63.2 \%$ of those from women, $P=0.98$.

\section{Promoter hypermethylation in relation to presence of large size}

We next analyzed the association of promoter hypermethylation with adenoma size. Table 9.4 shows that the CHFR and RASSF2A gene are significantly more often methylated in CRNs sized $\geq 10 \mathrm{~mm}$ in than in those $\geq 10 \mathrm{~mm}: 64.9 \%$ vs. $40.9 \%(P<0.001)$ and $76.3 \%$ vs. $44.6 \%(P<0.001)$, respectively. Furthermore, we found that large CRNs had a lower frequency of methylation in the $h M L H 1$ and $A P C$ gene: $51.9 \%$ vs. $78.8 \%$ $(P<0.001)$ and $72.4 \%$ vs. $90.1 \%(P<0.001)$.

Table 9.4 Frequency (\%) of promoter CpG island methylation in adenomas with large or small size according to anatomical location

\begin{tabular}{|c|c|c|c|c|c|c|c|c|c|}
\hline & \multicolumn{2}{|c|}{ ALL } & \multirow{2}{*}{$\begin{array}{c}P \\
\text { value } \\
\end{array}$} & \multicolumn{2}{|c|}{ PROXIMAL } & \multirow{2}{*}{$\begin{array}{c}P \\
\text { value }\end{array}$} & \multicolumn{2}{|c|}{ DISTAL } & \multirow{2}{*}{$\begin{array}{c}P \\
\text { value }\end{array}$} \\
\hline & $\geq 10 \mathrm{~mm}$ & $<10 \mathrm{~mm}$ & & $\geq 10 \mathrm{~mm}$ & $<10 \mathrm{~mm}$ & & $\geq 10 \mathrm{~mm}$ & $<10 \mathrm{~mm}$ & \\
\hline & $n=77$ & $n=171$ & & $n=39$ & $n=101$ & & $n=38$ & $n=70$ & \\
\hline$h M L H 1$ & 40 (51.9) & $134(78.8)$ & $<0.001$ & $23(59.0)$ & $75(75.0)$ & 0.06 & $17(44.7)$ & $59(84.3)$ & $<0.001$ \\
\hline$O^{6} M G M T$ & 64 (84.2) & $149(87.1)$ & 0.54 & 35 (92.1) & $83(82.2)$ & 0.15 & $29(76.3)$ & $66(94.3)$ & 0.01 \\
\hline$A P C$ & $55(72.4)$ & $154(90.1)$ & $<0.001$ & $25(64.1)$ & $91(90.1)$ & $<0.001$ & $30(81.1)$ & $63(90.0)$ & 0.23 \\
\hline$p 14^{\text {arf }}$ & 63 (82.9) & $151(88.3)$ & 0.25 & $34(87.2)$ & 89 (88.1) & 0.99 & $29(8.4)$ & $62(88.6)$ & 0.16 \\
\hline$p 16^{I N K 4 A}$ & $50(64.9)$ & $124(73.4)$ & 0.18 & $25(64.1)$ & $68(68.7)$ & 0.61 & $25(65.8)$ & $56(80.0)$ & 0.10 \\
\hline RASSF1A & $18(23.7)$ & $38(22.5)$ & 0.84 & $7(17.9)$ & $15(15.0)$ & 0.67 & $11(29.7)$ & $23(33.3)$ & 0.70 \\
\hline RASSF $2 A$ & $58(76.3)$ & 75 (44.6) & $<0.001$ & $33(84.6)$ & $47(47.5)$ & $<0.001$ & $25(67.6)$ & $28(40.6)$ & 0.008 \\
\hline GATA4 & $62(80.5)$ & $127(74.7)$ & 0.32 & $34(87.2)$ & $76(76.0)$ & 0.15 & $28(73.7)$ & 51 (72.9) & 0.93 \\
\hline HLTF & $53(70.7)$ & $113(66.1)$ & 0.48 & $24(64.9)$ & $62(61.4)$ & 0.71 & $29(76.3)$ & 51 (72.9) & 0.70 \\
\hline CHFR & $50(64.9)$ & $70(40.9)$ & $<0.001$ & $29(74.4)$ & $42(41.6)$ & 0.001 & $21(55.3)$ & $28(40.0)$ & 0.13 \\
\hline GATA5 & $76(98.7)$ & $162(94.7)$ & 0.18 & $39(100.0)$ & $98(97.0)$ & 0.56 & 37 (97.4) & $64(91.4)$ & 0.42 \\
\hline CIMP & 60 (77.9) & $130(76.0)$ & 0.74 & 31 (79.5) & 79 (78.2) & 0.87 & $29(76.3)$ & 51 (72.9) & 0.70 \\
\hline
\end{tabular}

$P$-values $<0.004$ were considered statistically significant (Bonferroni correction)

We performed separate analyses for the proximal and distal colon, which showed that promoter hypermethylation of CHFR was significantly associated with large size in proximal colon: $74.4 \%$ vs. $41.6 \%$ ( $P=0.001)$, while not in distal colon: $53.3 \%$ vs. $40.0 \%$ $(P=0.13)$ (Table 9.4). Likewise, large CRNs showed significantly more often methylation of RASSF2A in the proximal colon: $84.6 \%$ vs. $47.5 \%(P<0.001)$, while no statistical significant difference was found in the distal colon: $67.6 \%$ vs. $40.6 \%(P=0.008$, after Bonferroni correction: NS). Also regarding $h M L H 1$ and $A P C$ differences were found according to location (Table 9.5). Of the 39 proximal adenomas with large size, 30 were nonpolypoid and 9 polypoid, whereas 9 contained advanced histology and 30 showed only low-grade dysplasia. Of note, only 3 patients had 2 large proximal adenomas. 


\section{Promoter hypermethylation in relation to the presence of advanced histology}

We analyzed the association of promoter hypermethylation with presence of advanced histology. Table 9.5 shows that the CHFR gene was significantly more often methylated in CRNs containing HGD or early cancer compared with CRNs showing low-grade dysplasia: $74.2 \%$ vs. $44.7 \%$ ( $P=0.002$ ). Furthermore, we observed a trend toward more methylation of RASSF $2 A$ in CRNs containing advanced histology: $77.4 \%$ vs. $51.2 \%$ ( $P=0.006$, after Bonferroni correction: NS).

Again, we analyzed the proximal and distal colon separately. Herewith, we found that promoter hypermethylation of CHFR was significantly associated with the presence of advanced histology in proximal CRNs: $93.3 \%$ vs. $45.6 \%(P<0.001)$, while not in distal CRNs: $56.3 \%$ vs. $43.5 \%(P=0.34)$ (Table 9.5). Likewise, RASSF2A was significantly associated with advanced histology in proximal CRNs: $100 \%$ vs. $52.8 \%(P<0.001)$, but not in distal CRNs: $56.3 \%$ vs. $48.9 \%(P=0.58)$. Of the 15 proximal CRNs with advanced histology, 11 were nonpolypoid and 4 polypoid CRNs, whereas 9 were large $(\geq 10 \mathrm{~mm})$ and 6 small $(<10 \mathrm{~mm})$ in size. Of note, none of them were found in the same patient.

Table 9.5 Frequency (\%) of promoter CpG island methylation in adenomas with and without advanced histology according to anatomical location.

\begin{tabular}{|c|c|c|c|c|c|c|c|c|c|}
\hline & \multicolumn{2}{|c|}{ ALL } & \multirow{2}{*}{$\begin{array}{c}P \\
\text { value }\end{array}$} & \multicolumn{2}{|c|}{ PROXIMAL } & \multirow{2}{*}{$\begin{array}{c}P \\
\text { value }\end{array}$} & \multicolumn{2}{|c|}{ DISTAL } & \multirow{2}{*}{$\begin{array}{c}P \\
\text { value }\end{array}$} \\
\hline & HGD/T1 & LGD & & HGD/T1 & LGD & & HGD/T1 & LGD & \\
\hline & $n=31$ & $n=217$ & & $n=15$ & $n=124$ & & $n=16$ & $n=92$ & \\
\hline$h M L H 1$ & $20(64.5)$ & $154(71.3)$ & 0.44 & $11(73.3)$ & $87(70.2)$ & 0.99 & $9(56.3)$ & $67(72.8)$ & 0.24 \\
\hline$O^{6} M G M T$ & $27(90.0)$ & $186(85.7)$ & 0.77 & 13 (92.9) & $105(84.0)$ & 0.70 & $14(87.5)$ & $81(88.0)$ & 0.95 \\
\hline$A P C$ & $24(77.4)$ & 185 (85.6) & 0.28 & 10 (66.7) & $106(84.8)$ & 0.14 & 14 (87.5) & $79(86.8)$ & 0.99 \\
\hline$p 14^{\text {arf }}$ & $28(90.3)$ & $186(86.1)$ & 0.77 & $14(93.3)$ & $109(87.2)$ & 0.69 & $14(87.5)$ & 77 (84.6) & 0.99 \\
\hline$p 16^{I N K 4 A}$ & $17(54.8)$ & $157(73.0)$ & 0.04 & $7(46.7)$ & 86 (69.9) & 0.08 & $10(62.5)$ & $71(77.2)$ & 0.22 \\
\hline RASSF1A & $7(22.6)$ & 49 (22.9) & 0.97 & $3(20.0)$ & $19(15.3)$ & 0.71 & $4(25.0)$ & $30(33.3)$ & 0.51 \\
\hline RASSF $2 A$ & $24(77.4)$ & $109(51.2)$ & 0.006 & $15(100.0)$ & $65(52.8)$ & $<0.001$ & $9(56.3)$ & 44 (48.9) & 0.58 \\
\hline GATA4 & $23(74.2)$ & 166 (76.9) & 0.74 & $13(86.7)$ & $97(78.2)$ & 0.45 & $10(62 . .5)$ & $69(75.0)$ & 0.30 \\
\hline HLTF & $22(73.3)$ & $144(66.7)$ & 0.47 & $9(64.3)$ & $77(62.1)$ & 0.87 & $13(81.3)$ & $67(72.8)$ & 0.48 \\
\hline CHFR & $23(74.2)$ & $97(44.7)$ & 0.002 & 14 (93.3) & $57(45.6)$ & $<0.001$ & $9(56.3)$ & $40(43.5)$ & 0.34 \\
\hline GATA5 & $30(96.8)$ & 208 (95.9) & 0.99 & $15(100.0)$ & $122(97.6)$ & 0.99 & 15 (93.8) & $86(93.5)$ & 0.99 \\
\hline CIMP & $23(74.2)$ & $167(77.0)$ & 0.73 & $11(73.3)$ & 99 (72.9) & 0.60 & $12(75.0)$ & 68 (73.9) & 0.99 \\
\hline
\end{tabular}

$\mathrm{HGD}=$ high-grade dysplasia, LGD = low-grade dysplasia. $P$-values $<0.004$ were considered statistically significant (Bonferroni correction)

\section{Discussion}

In this study, we examined DNA hypermethylation of prominent CRC specific genes in relation to the clinicopathologic features of CRNs. Herewith, we found comparable frequencies of DNA hypermethylation in nonpolypoid and polypoid CRNs. However, we 
found differences according to colonic location. In the proximal colon, methylation of CHFR and RASSF2A was associated with large adenoma size and presence of advanced histology, whereas this association was not found in the distal colon. These findings suggest that progression of adenomas in the proximal colon may be driven by other epigenetic alterations than in the distal colon.

Previous studies addressing DNA hypermethylation in NP-CRNs suggested that they display less often methylation of $P 16^{I N K 4 A},{ }^{13,14}$ WIF $^{14}$ and $O^{6} M G M T^{14}$ and more often CIMP, ${ }^{15}$ whereas for RASSF $1 A^{16}$ and RASSF2 ${ }^{11,14}$ comparable frequencies of DNA hypermethylation were found. However, many of these previous studies included only adenomas with large size or with $\mathrm{HGD}^{11-14,16}$ or combined adenomatous and serrated polyps. ${ }^{11-14}$ In this study, we consecutively included all nonpolypoid adenomas diagnosed during the study period and an experienced GI pathologist re-evaluated the histological diagnosis. For the investigated genes, we observed no differences in the frequency of DNA hypermethylation in nonpolypoid versus polypoid CRNs, suggesting that nonpolypoid and polypoid CRNs may represent a continuum, rather than completely (epigenetically) distinct types of lesions.

Although, studies addressing the malignant potential of NP-CRNs initially suggested that all NP-CRNs harbor a more aggressive biologic behavior, ${ }^{9,10}$ more recent studies found this for the depressed type lesions only. ${ }^{48,49}$ In contrast to the studies on NPCRNs in general, data regarding the molecular profile of depressed type lesions are very consistent, with all studies showing low KRAS mutation frequencies in the depressed type CRNs. ${ }^{20,24-26,31}$ Large, multi-center studies that comprehensively address genetic and epigenetic alterations may clarify whether NP-CRNs, and in particular the depressed type ones, have a distinct underlying biology.

Regarding the association of promoter hypermethylation with adenoma size and histology, we found differences according to location. In the proximal colon, CRNs with HGD or early cancer show significantly more often methylation in CHFR (93.3\%) and RASSF2A (100\%) than proximal CRNs without these advanced histologic features (45.6\% and $52.8 \%$, respectively). Interestingly, in the distal colon, such difference was not found. Likewise, CHFR and RASSF2A methylation were significantly associated with large size of proximal CRNs, whereas no significant association was found for the distal ones. These results suggest that methylation of CHFR and RASSF2A may be important for progression of adenomas, and that progression in the proximal colon may be driven by other epigenetic alterations than in the distal colon. Previous studies already pointed out important differences between proximal and distal CRNs. ${ }^{4,5}$ Proximal CRCs occur at an older age, predominantly in women and are characterized by a high frequency of microsatellite instability and CIMP, whereas distal CRCs occur predominantly in men and are characterized by chromosomal instability. ${ }^{5}$ Future studies addressing potential biomarkers for CRNs at risk for progression should consider CHFR and RASSF2A methylation status, and separately analyze the proximal and distal colon. 
The checkpoint with forkhead-associated and ring finger domain, CHFR, is a mitotic checkpoint protein that arrest the cell cycle in response to mitotic stress and thereby functions as a tumor suppressor. ${ }^{50}$ CHFR is frequently downregulated by epigenetic inactivation in colorectal neoplasms, while not in normal colonic tissue. ${ }^{51}$ It has been suggested that CHFR decreases invasiveness and angiogenesis, thereby regulating cancer metastasis. ${ }^{52,53} \mathrm{~A}$ study by Tanaka et al on CRC specimens showed that promoter hypermethylation of CHFR is associated with proximal location and recurrence of the disease..$^{54}$ The current observation that CHFR methylation is associated with advanced histology and large adenoma size in the proximal colon is in line with these previous findings and suggests that CHFR may be a potential risk marker.

The RASSF2A gene is mainly silenced by promoter CpG island methylation and is suggested to have important tumor suppressor functions, such as regulation of apoptosis and suppressing colony growth. ${ }^{55}$ Silencing of the RASSF2A gene has been described to frequently occur together with KRAS/BRAF mutations and these alterations may work synergistically. ${ }^{55}$ Harada et al found that the simultaneous presence of RASSF2A methylation and KRAS/BRAF mutation was significantly higher in cancers than in adenomas of the proximal colon. ${ }^{11}$ These findings are in line with our results, and suggest that disturbance of the Ras signaling pathway is an important mechanism in malignant transformation in the proximal colon. ${ }^{11}$

A strength of the current study was the consecutive inclusion of CRNs at a routine GI endoscopy unit, thereby avoiding a potential inclusion bias. Moreover, the endoscopists were familiar with the recognition and classification of nonpolypoid lesions and all adenomas were histologically revised by an experienced GI pathologist, in an attempt to ensure reliability and generality of these data. However, some limitations of the current study should be discussed, as well. First, we used a nonquantitative nested MSP to evaluate the methylation status. Although MSP has been used by many recent studies, ${ }^{56}$ this technique has been challenged to overestimate the frequency of methylation due to its high sensitivity. However, the advantage of nested MSP is that this technique allows analysis of the methylation status of multiple genes using only small amounts of paraffin embedded tissue. ${ }^{46}$ Moreover, the frequency of methylation of in particular CHFR and RASSF2A was comparable to other reports using quantitative MSP. ${ }^{55,57}$ Furthermore, this potential bias would affect proximal and distal CRNs to a similar extend. Secondly, in this study we investigated epigenetic alterations only. It has been shown that genetic and epigenetic alterations may interact and work synergistically. ${ }^{35}$ Future studies should aim to provide a full overview and potential interactions between genetic and epigenetic changes.

In conclusion, methylation of CHFR and RASSF2A may be important steps in progression of proximal colorectal neoplasms, either nonpolypoid or polypoid. Moreover, the present findings suggest that progression of colorectal neoplasms in the proximal colon is driven by other epigenetic alterations than in the distal colon. 
Table S9.1 Primer sequences.

\begin{tabular}{|c|c|c|c|c|}
\hline Gene & & $\begin{array}{l}\text { Primer sense } \\
\text { Primer antisense }\end{array}$ & $\begin{array}{l}\text { Annealing } \\
\text { temp }\left({ }^{\circ} \mathrm{C}\right)\end{array}$ & PCR cycles \\
\hline \multirow[t]{5}{*}{$h M L H 1$} & \multirow[t]{2}{*}{ flank } & TTT TGA YGT AGA YGT TTT ATT AGG GT & \multirow[t]{2}{*}{56} & \multirow[t]{2}{*}{35} \\
\hline & & AAA ACR ATA AAA CCC TAT ACC TAA TCT ATC & & \\
\hline & unmethylated & $\begin{array}{l}\text { TGT GTG TTT GTT GTT TGT TAT ATA TTG TTT } \\
\text { ACC ACC TCA TCA TAA CTA CCC ACA }\end{array}$ & 60 & 35 \\
\hline & \multirow{2}{*}{ methylated } & GTT CGT CGT TCG TTA TAT ATC GTT C & \multirow{2}{*}{60} & \multirow{2}{*}{35} \\
\hline & & СCT CAT CGT AAC TAC CCG CG & & \\
\hline \multirow{6}{*}{$O^{6} M G M T$} & \multirow{2}{*}{ flank } & GYG TTT YGG ATA TGT TGG GAT AGT T & \multirow{2}{*}{56} & \multirow{2}{*}{35} \\
\hline & & AAA CTC CRC ACT CTT CCR AAA AC & & \\
\hline & \multirow{2}{*}{ unmethylated } & TTT GTG TTT TGA TGT TTG TAG GTT TTT GT & \multirow{2}{*}{60} & \multirow{2}{*}{30} \\
\hline & & AAC TCC ACA CTC TTC CAA AAA CAA AAC A & & \\
\hline & \multirow{2}{*}{ methylated } & TTT CGA CGT TCG TAG GTT TTC GC & \multirow{2}{*}{60} & \multirow{2}{*}{30} \\
\hline & & GCA CTC TTC CGA AAA CGA AAC G & & \\
\hline \multirow{6}{*}{$A P C$} & \multirow{2}{*}{ flank } & TGG GYG GGG TTT TGT GTT TTA TT & \multirow{2}{*}{56} & 35 \\
\hline & & TAC RCC CAC ACC CAA CCA ATC & & ככ \\
\hline & unmethylated & GTG TTT TAT TGT GGA GTG TGG GTT & 60 & 25 \\
\hline & ummectrylated & CCA ATC AAC AAA CTC CCA ACA A & 00 & 20 \\
\hline & & TAT TGC GGA GTG CGG GTC & & \\
\hline & metnylated & TCG ACG AAC TCC CGA CGA & 60 & 25 \\
\hline $14^{\text {arf }}$ & flank & GYG TTG TTT ATT TTT GGT GTT AAA GG & 56 & 35 \\
\hline & MdIIK & AAA TAT AAA CCA CRA AAA CCC TCA CT & 50 & \\
\hline & unmethvlated & TTT TTG GTG TTA AAG GGT GGT GTA GT & 60 & 25 \\
\hline & unmetnyrated & CAC AAA AAC ССТ САС TCA CAA CAA & 00 & $\angle 0$ \\
\hline & & GTG TTA AAG GGC GGC GTA GC & & \\
\hline & metnylated & AAA ACC CTC ACT CGC GAC GA & 60 & 25 \\
\hline $16^{I N K 4 A}$ & flank & GGG TTG GTT GGT TAT TAG AGG GT & 56 & 35 \\
\hline & Tlanis & RAC CRT AAC CAA CCA ATC AAC C & 30 & כנ \\
\hline & unmethylated & GTT GGT TAT TAG AGG GTG GGG TGG ATT GT & 62 & 25 \\
\hline & unmetnyrated & AАC CAA AAA СТС САТ АСТ АСТ ССС САС СА & 02 & 20 \\
\hline & methylated & TTA TTA GAG GGT GGG GCG GAT CGC & 62 & 25 \\
\hline & metnylatea & GAA AAC TCC ATA CTA CTC CCC GCC G & 02 & 20 \\
\hline RASFF1A & flank & GTT TAG TTT GGA TTT TGG GGG AG & 56 & 35 \\
\hline SA & Trank & CCC RCA ACT CAA TAA ACT CAA ACT C & 30 & כנ \\
\hline & unmethylated & GGG GTT TGT TTT GTG GTT TTG TTT & 64 & 30 \\
\hline & unmetnylated & AAC ATA ACC CAA TTA AAC CCA TAC TTC A & 64 & 30 \\
\hline & methvlated & GGG TTC GTT TTG TGG TTT CGT TC & 64 & 30 \\
\hline & metnyıated & TAA CCC GAT TAA ACC CGT ACT TCG & 64 & 30 \\
\hline SEFPA & flank & GTT TGT TTA GTT TGG TTG GAT T & 56 & 35 \\
\hline NAJTRZA & IIIIIK & AAA ACC RTA AAA AAT AAA AA & 50 & ככ \\
\hline & unmethvlated & TTG GAT TTG AGT TTG GTT TGT TG & 61 & 30 \\
\hline & unmetnylated & TAA AAT TAA AAA ATA AAA ACA CCA CA & 01 & 30 \\
\hline & methvlated & GAT TTG AGT TCG GTT CGT CG & 61 & 30 \\
\hline & & TTA AAA AAT AAA AAC GCC GCG & & \\
\hline GATA4 & flank & GGG AGT TTT TYG TAT AGT TTY GTA G & 56 & 35 \\
\hline & mank & CCR ACC RCC TCC AAA TCC CCA AC & 50 & 33 \\
\hline & unmethylated & TTT GTA TAG TTT TGT AGT TTG TGT TTA GT & 64 & 30 \\
\hline & unmetnyrated & CCC AAC TCA СAA СТС AAA TCC CCA & 04 & 30 \\
\hline & methvlated & GTA TAG TTT CGT AGT TTG CGT TTA GC & 68 & 25 \\
\hline & & AAC TCG CGA CTC GAA TCC CCG & & $2 J$ \\
\hline
\end{tabular}




\begin{tabular}{|c|c|c|c|c|}
\hline Gene & & $\begin{array}{l}\text { Primer sense } \\
\text { Primer antisense }\end{array}$ & $\begin{array}{l}\text { Annealing } \\
\text { temp }\left({ }^{\circ} \mathrm{C}\right)\end{array}$ & PCR cycles \\
\hline \multirow[t]{3}{*}{ GATA5 } & flank & $\begin{array}{l}\text { TAG ATA YGG AGT TYG TTT TTA GGT TAG } \\
\text { CRA AAC CCR AAC CAA TAC AAC TAA AC }\end{array}$ & 56 & 35 \\
\hline & unmethylated & $\begin{array}{l}\text { TGG AGT TTG TTT TTA GGT TAG TTT TTG GT } \\
\text { CAA ACC AAT ACA ACT AAA CAA ACA AAC CA }\end{array}$ & 64 & 25 \\
\hline & methylated & $\begin{array}{l}\text { AGT TCG TTT TTA GGT TAG TTT TCG GC } \\
\text { CCA ATA CAA CTA AAC GAA CGA ACC G }\end{array}$ & 64 & 25 \\
\hline \multirow[t]{3}{*}{ HLTF } & flank & $\begin{array}{l}\text { GTA GGT ATY GTA GTY GTA TTT TTG GG } \\
\text { CAA AAC ACA AAA AAA AAA ACA ACT CC }\end{array}$ & 56 & 35 \\
\hline & unmethylated & $\begin{array}{l}\text { GGT TTT GTG GTT TTT TTG TGT GTT T } \\
\text { CCC CAC TAC CAT TCA AAA ACA ACA }\end{array}$ & 65 & 30 \\
\hline & methylated & $\begin{array}{l}\text { GTG GTT TTT TCG CGC GTT C } \\
\text { CGC TAC CAT TCA AAA ACG ACG }\end{array}$ & 65 & 30 \\
\hline \multirow[t]{3}{*}{ CHFR } & flank & $\begin{array}{l}\text { TTT TYG TTT TTT TTG TTT TAA TAT AAT ATG G } \\
\text { CRC TCA CCA AAA ACR ACA ACT AAA AC }\end{array}$ & 56 & 35 \\
\hline & unmethylated & $\begin{array}{l}\text { GAT TGT AGT TAT TTT TGT GAT TTG TAG GTG AT } \\
\text { AAC TAA AAC AAA ACC AAA AAT AAC CCA CA }\end{array}$ & 66 & 30 \\
\hline & methylated & $\begin{array}{l}\text { GTT ATT TTC GTG ATT CGT AGG CGA C } \\
\text { CGA AAC CGA AAA TAA CCC GCG }\end{array}$ & 66 & 30 \\
\hline \multirow[t]{3}{*}{ Cacna1G } & flank & $\begin{array}{l}\text { GGT YGG TTT TTT TTT ATT TTG TT } \\
\text { CRC CRC TAC CCC CCT TTT C }\end{array}$ & 56 & 35 \\
\hline & unmethylated & $\begin{array}{l}\text { TTT TTT TGT TTT GTG TTT AGG TTT T } \\
\text { CCC TCT CAA AAC AAC TTC ACC A }\end{array}$ & 64 & 35 \\
\hline & methylated & $\begin{array}{l}\text { TCG TTT CGC GTT TAG GTT TC } \\
\text { CTC GAA ACG ACT TCG CCG }\end{array}$ & 64 & 35 \\
\hline RUNX3 & flank & $\begin{array}{l}\text { GTT YGA TGG TGG AYG TGT TGG } \\
\text { AAT CCC RCA CTC ACC TTA AAA AC }\end{array}$ & 56 & 35 \\
\hline & unmethylated & $\begin{array}{l}\text { GTT GGT GGA TTA TGT AGG TGA GTT T } \\
\text { ACT CAC CTT AAA AAC AAC AAA CAA CA }\end{array}$ & 66 & 35 \\
\hline & methylated & $\begin{array}{l}\text { GCG GAT TAC GTA GGC GAG TTC } \\
\text { ACC TTA AAA ACG ACG AAC AAC G }\end{array}$ & 66 & 35 \\
\hline SOCS1 & flank & $\begin{array}{l}\text { GTT YGT GGG TAT TTT TTT GGT G } \\
\text { TAA ATC CCR AAA CCA TCT TCA C }\end{array}$ & 56 & 35 \\
\hline & unmethylated & $\begin{array}{l}\text { GGG TAT TTT TTT GGT GTG TGA TAG TT } \\
\text { CCA AAA CCA TCT TCA CAC TAA AAA CA }\end{array}$ & 66 & 35 \\
\hline & methylated & $\begin{array}{l}\text { TTT TTT TGG TGC GCG ATA GTC } \\
\text { GAA ACC ATC TTC ACG CTA AAA ACG }\end{array}$ & 66 & 35 \\
\hline NeuroG1 & flank & $\begin{array}{l}\text { GTT YGG GTA TTT GTA TAA TTT ATG TT } \\
\text { AAC RCC CTA ACC AAC TTA ACC C }\end{array}$ & 56 & 35 \\
\hline & unmethylated & $\begin{array}{l}\text { TGT ATA ATT TAT GTT TGT GGG AGG TT } \\
\text { CCA ACA ATA ATT ACA AAC ACA CTC CA }\end{array}$ & 66 & 35 \\
\hline & methylated & $\begin{array}{l}\text { ATT TAT GTT CGC GGG AGG TC } \\
\text { GAC GAT AAT TAC GAA CAC ACT CCG }\end{array}$ & 66 & 35 \\
\hline IGF-2 & flank & $\begin{array}{l}\text { GTA GTT TYG GGT YGT TTT TTT TT } \\
\text { AAA AAA CRA AAT AAA AAC TAC ACC C }\end{array}$ & 56 & 35 \\
\hline & unmethylated & $\begin{array}{l}\text { GGA GTG GTT TTG GTG TTG TTA TT } \\
\text { CCC AAC TCA ATT TAA ACC AAC A }\end{array}$ & 66 & 35 \\
\hline & methylated & $\begin{array}{l}\text { GCG GTT TCG GTG TCG TTA TC } \\
\text { CCA ACT CGA TTT AAA CCG ACG }\end{array}$ & 68 & 30 \\
\hline
\end{tabular}


Chapter 9

Table S9.2 Promoter methylation success rate.

\begin{tabular}{|c|c|c|c|c|}
\hline \multirow[t]{2}{*}{ Gene } & & \multirow{2}{*}{$\begin{array}{c}\text { Results } \\
\mathrm{N}\end{array}$} & \multicolumn{2}{|c|}{ Missing data } \\
\hline & & & $\mathrm{N}$ & (\%) \\
\hline$\overline{h M L H 1}$ & 248 & 247 & 1 & $(0.4)$ \\
\hline$O^{6} M G M T$ & 248 & 247 & 1 & (0.4) \\
\hline$A P C$ & 248 & 247 & 1 & $(0.4)$ \\
\hline$p 14^{a r f}$ & 248 & 247 & 1 & $(0.4)$ \\
\hline$p 16^{I N K 4 A}$ & 248 & 246 & 2 & (0.8) \\
\hline RASSF1A & 248 & 245 & 3 & (1.2) \\
\hline RASSF $2 A$ & 248 & 244 & 4 & (1.6) \\
\hline GATA4 & 248 & 247 & 1 & $(0.4)$ \\
\hline HLTF & 248 & 246 & 2 & (0.8) \\
\hline CHFR & 248 & 248 & 0 & $(0.0)$ \\
\hline GATA5 & 248 & 248 & 0 & $(0.0)$ \\
\hline CIMP & 248 & 248 & 0 & $(0.0)$ \\
\hline CACNA1G & 248 & 245 & 3 & (1.2) \\
\hline RUNX3 & 248 & 246 & 2 & $(0.8)$ \\
\hline SOCS1 & 248 & 247 & 1 & $(0.4)$ \\
\hline NEUROG1 & 248 & 248 & 0 & (0.0) \\
\hline IGF2 & 248 & 246 & 2 & $(0.4)$ \\
\hline
\end{tabular}

Table S9.3. Frequency (\%) of promoter CpG island methylation in adenomas according to colonic location.

\begin{tabular}{lccc}
\hline & Location & $\begin{array}{c}P \\
\text { value }\end{array}$ \\
\cline { 2 - 3 }$h$ Proximal & 140 & Distal & 0.98 \\
O $^{6}$ MGMT & $98(70.5)$ & $76(70.4)$ & 0.49 \\
APC & $118(84.9)$ & $95(88.0)$ & 0.38 \\
$p 14^{\text {arf }}$ & $116(82.9)$ & $93(86.9)$ & 0.52 \\
p16 & $123(87.9)$ & $91(85.0)$ & 0.19 \\
RASSF1A & $93(67.4)$ & $81(75.0)$ & $\mathbf{0 . 0 0 3}$ \\
RASSF2A & $\mathbf{2 2 ( 1 5 . 8 )}$ & $\mathbf{3 4 ( 3 2 . 1 )}$ & 0.22 \\
GATA4 & $80(58.0)$ & $53(50.0)$ & 0.27 \\
HLTF & $110(79.1)$ & $79(73.1)$ & 0.05 \\
CHFR & $86(62.3)$ & $49(74.1)$ & 0.40 \\
GATA5 & $71(50.7)$ & $101(93.5)$ & 0.12 \\
CIMP & $137(97.9)$ & $80(74.1)$ & 0.41 \\
\hline
\end{tabular}




\section{References}

1. Baxter NN, Sutradhar R, Forbes SS, Paszat LF, Saskin R, Rabeneck L. Analysis of administrative data finds endoscopist quality measures associated with postcolonoscopy colorectal cancer. Gastroenterology 2011;140:65-72.

2. Singh H, Nugent Z, Demers AA, Bernstein CN. Rate and predictors of early/missed colorectal cancers after colonoscopy in manitoba: a population-based study. Am J Gastroenterol 2010;105:2588-96.

3. Pabby A, Schoen RE, Weissfeld JL, Burt R, Kikendall JW, Lance P, Shike M, Lanza E, Schatzkin A. Analysis of colorectal cancer occurrence during surveillance colonoscopy in the dietary Polyp Prevention Trial. Gastrointestinal endoscopy 2005;61:385-91.

4. Distler P, Holt PR. Are right- and left-sided colon neoplasms distinct tumors? Digestive diseases 1997; 15:302-11.

5. lacopetta B. Are there two sides to colorectal cancer? Int J Cancer 2002;101:403-8.

6. Rondagh EJ, Bouwens MW, Riedl RG, Winkens B, de Ridder R, Kaltenbach T, Soetikno RM, Masclee AA, Sanduleanu S. Endoscopic appearance of proximal colorectal neoplasms and potential implications for colonoscopy in cancer prevention. Gastrointestinal endoscopy 2012.

7. Kaltenbach T, McGill SK, Kalidindi V, Friedland S, Soetikno R. Proficiency in the diagnosis of nonpolypoid colorectal neoplasm yields high adenoma detection rates. Digestive diseases and sciences 2012;57:764-70.

8. Kudo S, Lambert R, Allen JI, Fujii H, Fujii T, Kashida H, Matsuda T, Mori M, Saito H, Shimoda T, Tanaka $\mathrm{S}$, Watanabe H, Sung JJ, Feld AD, Inadomi JM, O'Brien MJ, Lieberman DA, Ransohoff DF, Soetikno RM, Triadafilopoulos G, Zauber A, Teixeira CR, Rey JF, Jaramillo E, Rubio CA, Van Gossum A, Jung M, Vieth $M$, Jass JR, Hurlstone PD. Nonpolypoid neoplastic lesions of the colorectal mucosa. Gastrointest Endosc 2008;68 (Suppl October):S3-47.

9. Rembacken BJ, Fujii T, Cairns A, Dixon MF, Yoshida S, Chalmers DM, Axon ATR. Flat and depressed colonic neoplasms: a prospective study of 1000 colonoscopies in the UK. The Lancet 2000;355: 1211-1214.

10. Soetikno RM, Kaltenbach T, Rouse RV, Park W, Maheshwari A, Sato T, Matsui S, Friedland S. Prevalence of nonpolypoid (flat and depressed) colorectal neoplasms in asymptomatic and symptomatic adults. JAMA : the journal of the American Medical Association 2008;299:1027-35.

11. Harada K, Hiraoka S, Kato J, Horii J, Fujita H, Sakaguchi K, Shiratori Y. Genetic and epigenetic alterations of Ras signalling pathway in colorectal neoplasia: analysis based on tumour clinicopathological features. British journal of cancer 2007;97:1425-31.

12. Nosho K, Yamamoto H, Takahashi T, Mikami M, Hizaki K, Maehata T, Taniguchi H, Yamaoka S, Adachi Y Itoh F, Imai K, Shinomura Y. Correlation of laterally spreading type and JC virus with methylator phenotype status in colorectal adenoma. Hum Pathol 2008;39:767-75.

13. Takahashi T, Nosho K, Yamamoto H, Mikami M, Taniguchi H, Miyamoto N, Adachi Y, Itoh F, Imai K, Shinomura Y. Flat-type colorectal advanced adenomas (laterally spreading tumors) have different genetic and epigenetic alterations from protruded-type advanced adenomas. Mod Pathol 2007;20:139-47.

14. Nosho K, Yamamoto H, Takahashi T, Mikami M, Taniguchi H, Miyamoto N, Adachi Y, Arimura Y, Itoh F, Imai K, Shinomura Y. Genetic and epigenetic profiling in early colorectal tumors and prediction of invasive potential in pT1 (early invasive) colorectal cancers. Carcinogenesis 2007;28:1364-70.

15. Hiraoka S, Kato J, Tatsukawa M, Harada K, Fujita H, Morikawa T, Shiraha H, Shiratori Y. Laterally spreading type of colorectal adenoma exhibits a unique methylation phenotype and K-ras mutations. Gastroenterology 2006;131:379-89.

16. Noda H, Kato Y, Yoshikawa H, Arai M, Togashi K, Nagai H, Konishi F, Miki Y. Frequent involvement of ras-signalling pathways in both polypoid-type and flat-type early-stage colorectal cancers. J Exp Clin Cancer Res 2006;25:235-42.

17. Sada M, Mitomi H, Igarashi M, Katsumata T, Saigenji K, Okayasu I. Cell kinetics, p53 and bcl-2 expression, and c-Ki-ras mutations in flat-elevated tubulovillous adenomas and adenocarcinomas of the colorectum: comparison with polypoid lesions. Scand J Gastroenterol 1999;34:798-807. 
18. Mukawa K, Fujii S, Takeda J, Kitajima K, Tominaga K, Chibana Y, Fujita M, Ichikawa K, Tomita S, Ono Y, Imura J, Kawamata H, Chiba T, Hiraishi H, Terano A, Fujimori T. Analysis of K-ras mutations and expression of cyclooxygenase-2 and gastrin protein in laterally spreading tumors. J Gastroenterol Hepatol 2005;20:1584-90.

19. Watari J, Saitoh Y, Obara T, Fujiya M, Maemoto A, Ayabe T, Ashida T, Yokota K, Orii Y, Kohgo Y. Natural history of colorectal nonpolypoid adenomas: a prospective colonoscopic study and relation with cell kinetics and K-ras mutations. Am J Gastroenterol 2002;97:2109-15.

20. Mikami M, Nosho K, Yamamoto H, Takahashi T, Maehata T, Taniguchi H, Adachi Y, Imamura A, Fujita M, Hosokawa M, Itoh F, Imai K, Shinomura Y. Mutational analysis of beta-catenin and the RAS-RAF signalling pathway in early flat-type colorectal tumours. Eur J Cancer 2006;42:3065-72.

21. Noro A, Sugai T, Habano W, Nakamura S. Analysis of Ki-ras and p53 gene mutations in laterally spreading tumors of the colorectum. Pathol Int 2003;53:828-36.

22. Sugimoto $T$, Ohta M, Ikenoue T, Yamada A, Tada M, Fujishiro M, Ogura K, Yamaji Y, Okamoto M, Kanai F, Kawabe T, Omata M. Macroscopic morphologic subtypes of laterally spreading colorectal tumors showing distinct molecular alterations. Int J Cancer 2010;127:1562-9.

23. Watanabe T, Muto T. Colorectal carcinogenesis based on molecular biology of early colorectal cancer with special reference to nonpolypoid (superficial) lesions. World Journal of Surgery 2000;24: 1091-1097.

24. Yamagata S, Muto T, Uchida Y, Masaki T, Sawada T, Tsuno N, Hirooka T. Lower incidence of K-ras codon 12 mutation in flat colorectal adenomas than in polypoid adenomas. Jpn J Cancer Res 1994;85:147-51.

25. Kobayashi M, Watanabe H, Ajioka Y, Honma T, Asakura H. Effect of K-ras mutation on morphogenesis of colorectal adenomas and early cancers: relationship to distribution of proliferating cells. Hum Pathol 1996;27:1042-9.

26. Umetani N, Sasaki S, Masaki T, Watanabe T, Matsuda K, Muto T. Involvement of APC and K-ras mutation in non-polypoid colorectal tumorigenesis. Br J Cancer 2000;82:9-15.

27. George SM, Makinen MJ, Jernvall P, Makela J, Vihko P, Karttunen TJ. Classification of advanced colorectal carcinomas by tumor edge morphology: evidence for different pathogenesis and significance of polypoid and nonpolypoid tumors. Cancer 2000;89:1901-9.

28. Hirata I, Wang FY, Murano M, Inoue T, Toshina K, Nishikawa T, Maemura K. Histopathological and genetic differences between polypoid and non-polypoid submucosal colorectal carcinoma. World J Gastroenterol 2007;13:2048-52.

29. Hasegawa H, Ueda M, Watanabe M, Teramoto T, Mukai M, Kitajima M. K-ras gene mutations in early colorectal cancer ... flat elevated vs polyp-forming cancer. Oncogene 1995;10:1413-6.

30. Kurahashi T, Kaneko K, Makino R, Mitamura K. Colorectal carcinoma with special reference to growth pattern classifications: clinicopathologic characteristics and genetic changes. J Gastroenterol 2002;37:354-62.

31. Sakashita M, Aoyama N, Maekawa S, Kuroda K, Shirasaka D, Ichihara T, Kuroda Y, Minami R, Maeda S, Kasuga M. Flat-elevated and depressed, subtypes of flat early colorectal cancers, should be distinguished by their pathological features. Int J Colorectal Dis 2000;15:275-81.

32. Yashiro M, Carethers JM, Laghi L, Saito K, Slezak P, Jaramillo E, Rubio C, Koizumi K, Hirakawa K, Boland $\mathrm{CR}$. Genetic pathways in the evolution of morphologically distinct colorectal neoplasms. Cancer Res 2001;61:2676-83.

33. Konishi K, Takimoto M, Kaneko K, Makino R, Hirayama $Y$, Nozawa H, Kurahashi T, Kumekawa $Y$ Yamamoto T, Ito H, Yoshikawa N, Kusano M, Nakayama K, Rembacken BJ, Ota H, Imawari M. BRAF mutations and phosphorylation status of mitogen-activated protein kinases in the development of flat and depressed-type colorectal neoplasias. Br J Cancer 2006;94:311-7.

34. Yoshida S, Ikehara N, Aoyama N, Shirasaka D, Sakashita M, Semba S, Hasuo T, Miki I, Morita Y, Tamura T, Azuma T, Yokozaki H, Kasuga M. Relationship of BRAF mutation, morphology, and apoptosis in early colorectal cancer. Int J Colorectal Dis 2008;23:7-13.

35. van Engeland M, Derks S, Smits KM, Meijer GA, Herman JG. Colorectal cancer epigenetics: complex simplicity. Journal of clinical oncology : official journal of the American Society of Clinical Oncology 2011;29:1382-91. 
36. Hellebrekers DM, Lentjes $M H$, van den Bosch SM, Melotte V, Wouters KA, Daenen KL, Smits KM, Akiyama Y, Yuasa Y, Sanduleanu S, Khalid-de Bakker CA, Jonkers D, Weijenberg MP, Louwagie J, van Criekinge W, Carvalho B, Meijer GA, Baylin SB, Herman JG, de Bruine AP, van Engeland M. GATA4 and GATA5 are potential tumor suppressors and biomarkers in colorectal cancer. Clinical cancer research : an official journal of the American Association for Cancer Research 2009;15:3990-7.

37. Baylin SB, Herman JG. DNA hypermethylation in tumorigenesis: epigenetics joins genetics. Trends in genetics : TIG 2000;16:168-74.

38. Rondagh EJ, Masclee AA, van der Valk ME, Winkens B, de Bruine AP, Kaltenbach T, Soetikno RM, Sanduleanu S. Nonpolypoid colorectal neoplasms: gender differences in prevalence and malignant potential. Scandinavian journal of gastroenterology 2012;47:80-8.

39. Sanduleanu S, Rondagh EJ, Masclee AA. Development of expertise in the detection and classification of non-polypoid colorectal neoplasia: Experience-based data at an academic GI unit. Gastrointestinal endoscopy clinics of North America 2010;20:449-60.

40. Rex DK, Petrini JL, Baron TH, Chak A, Cohen J, Deal SE, Hoffman B, Jacobson BC, Mergener K, Petersen BT, Safdi MA, Faigel DO, Pike IM. Quality indicators for colonoscopy. Gastrointestinal endoscopy 2006;63:S16-28.

41. Soetikno R, Friedland S, Kaltenbach T, Chayama K, Tanaka S. Nonpolypoid (flat and depressed) colorectal neoplasms. Gastroenterology 2006;130:566-576.

42. The Paris endoscopic classification of superficial neoplastic lesions: esophagus, stomach, and colon: November 30 to December 1, 2002. Gastrointest Endosc 2003;58 (Suppl December):S3-43.

43. Hamilton S, Aaltonen, LA. WHO Classification of Tumours: Pathology and Genetics: Tumours of the Digestive System IARC Press, 2000.

44. East JE, Saunders BP, Jass JR. Sporadic and syndromic hyperplastic polyps and serrated adenomas of the colon: classification, molecular genetics, natural history, and clinical management. Gastroenterol Clin North Am 2008;37:25-46.

45. Weisenberger DJ, Siegmund KD, Campan M, Young J, Long TI, Faasse MA, Kang GH, Widschwendter M, Weener D, Buchanan D, Koh H, Simms L, Barker M, Leggett B, Levine J, Kim M, French AJ, Thibodeau SN, Jass J, Haile R, Laird PW. CpG island methylator phenotype underlies sporadic microsatellite instability and is tightly associated with BRAF mutation in colorectal cancer. Nature genetics 2006;38:787-93.

46. Derks S, Lentjes MH, Hellebrekers DM, de Bruine AP, Herman JG, van Engeland M. Methylation-specific PCR unraveled. Cellular oncology : the official journal of the International Society for Cellular Oncology 2004;26:291-9.

47. Derks S, Postma C, Moerkerk PT, van den Bosch SM, Carvalho B, Hermsen MA, Giaretti W, Herman JG, Weijenberg MP, de Bruine AP, Meijer GA, van Engeland M. Promoter methylation precedes chromosomal alterations in colorectal cancer development. Cellular oncology : the official journal of the International Society for Cellular Oncology 2006;28:247-57.

48. Bianco MA, Cipolletta L, Rotondano G, Buffoli F, Gizzi G, Tessari F. Prevalence of nonpolypoid colorectal neoplasia: an Italian multicenter observational study. Endoscopy 2010;42:279-85.

49. Chiu HM, Lin JT, Chen CC, Lee YC, Liao WC, Liang JT, Shun CT, Wang HP, Wu MS. Prevalence and characteristics of nonpolypoid colorectal neoplasm in an asymptomatic and average-risk Chinese population. Clinical gastroenterology and hepatology : the official clinical practice journal of the American Gastroenterological Association 2009;7:463-70.

50. Scolnick DM, Halazonetis TD. Chfr defines a mitotic stress checkpoint that delays entry into metaphase. Nature 2000;406:430-5.

51. Toyota M, Sasaki Y, Satoh A, Ogi K, Kikuchi T, Suzuki H, Mita H, Tanaka N, Itoh F, Issa JP, Jair KW Schuebel KE, Imai K, Tokino T. Epigenetic inactivation of CHFR in human tumors. Proceedings of the National Academy of Sciences of the United States of America 2003;100:7818-23.

52. Oh YM, Kwon YE, Kim JM, Bae SJ, Lee BK, Yoo SJ, Chung CH, Deshaies RJ, Seol JH. Chfr is linked to tumour metastasis through the downregulation of HDAC1. Nature cell biology 2009;11:295-302.

53. Kashima L, Toyota M, Mita H, Suzuki H, Idogawa M, Ogi K, Sasaki Y, Tokino T. CHFR, a potential tumor suppressor, downregulates interleukin-8 through the inhibition of NF-kappaB. Oncogene 2009;28:2643-53. 
54. Tanaka M, Chang P, Li Y, Li D, Overman M, Maru DM, Sethi S, Phillips J, Bland GL, Abbruzzese JL, Eng C. Association of CHFR promoter methylation with disease recurrence in locally advanced colon cancer. Clinical cancer research : an official journal of the American Association for Cancer Research 2011;17:4531-40.

55. Akino K, Toyota M, Suzuki H, Mita H, Sasaki Y, Ohe-Toyota M, Issa JP, Hinoda Y, Imai K, Tokino T. The Ras effector RASSF2 is a novel tumor-suppressor gene in human colorectal cancer. Gastroenterology 2005;129:156-69.

56. Hughes LA, Khalid-de Bakker CA, Smits KM, van den Brandt PA, Jonkers D, Ahuja N, Herman JG, Weijenberg MP, van Engeland $\mathrm{M}$. The $\mathrm{CpG}$ island methylator phenotype in colorectal cancer: progress and problems. Biochimica et biophysica acta 2012;1825:77-85.

57. Nosho K, Kure S, Irahara N, Shima K, Baba Y, Spiegelman D, Meyerhardt JA, Giovannucci EL, Fuchs CS, Ogino S. A prospective cohort study shows unique epigenetic, genetic, and prognostic features of synchronous colorectal cancers. Gastroenterology 2009;137:1609-20 e1-3. 
Chapter 10

General discussion 
Chapter 10

160 


\section{General discussion}

Colonoscopy plays a key role in the nationwide colorectal cancer (CRC) screening program that will be implemented in the Netherlands in 2013. In this program, individuals from 55 to 75 years of age will be offered a fecal blood test and those with a positive test result will undergo a diagnostic colonoscopy. ${ }^{1}$ High quality colonoscopy, targeted on accurate detection and removal of (pre)cancerous lesions, is a requisite for effectiveness of this screening program.

Although targets for adenoma detections rates have been introduced already in $2002,{ }^{2}$ in daily practice still wide variations (up to 30\%) exist among endoscopists. ${ }^{3,4}$ The adenoma detection rate has been shown to be an important predictor of postcolonoscopy CRCs. ${ }^{5}$ Morever, studies based on colonoscopies performed under optimal (scientific) circumstances ${ }^{6}$ show a 3 -fold lower incidence rate of postcolonoscopy CRCs than studies including colonoscopies performed in community practices. ${ }^{7}$ The remarkable variation among endoscopists in the detection of adenomas in daily practice indicates that quality of colonoscopy is strongly operator dependent ${ }^{8}$ and therefore a modifiable cause of post-colonoscopy cancers.

This thesis shows that three-fourths of the proximal advanced adenomas are small or have a nonpolypoid appearance compared with only one-fourth of the distal ones. Likewise, two-thirds of the proximal large or dysplastic serrated polyps (SPs) are nonpolypoid compared with only one-fourth of the distal ones (Figure 5.1). ${ }^{9}$ Furthermore, we found that proximal adenomas in patients with Lynch syndrome are 4 times more likely to be nonpolypoid than those in average-risk subjects (Figure 6.3). We presume that endoscopists in the lower range with respect to adenoma detection rates run a higher risk to overlook these subtle, i.e. nonpolypoid and diminutive, lesions in the proximal colon. This hypothesis has been supported by Baxter et al ${ }^{10}$ showing that a higher polypectomy rate of the endoscopist was associated with a lower incidence of post-colonoscopy cancer in the proximal colon (OR $0.61,95 \% \mathrm{Cl}$ 0.42-0.89), whereas such association was not found for the distal colon. In addition, Singh et al $^{11}$ demonstrated that colonoscopy performed by a gastroenterologist provides protection against death from proximal CRC (OR $0.41,95 \% \mathrm{Cl} 0.13-0.96$ ), while this was not found for colonoscopies performed by endoscopists from other specialties. It therefore seems likely that performance of the endoscopist, in particular overlooking subtle but relevant neoplasms in the proximal colon, may in part explain why colonoscopy provides less protection against proximal than distal CRC and, more importantly, that protection against proximal cancer thus can be improved.

Training of the endoscopists on the recognition of nonpolypoid colorectal neoplasms (NP-CRNs) has been shown to improve the detection of nonpolypoid, ${ }^{12,13}$ but also of diminutive colorectal neoplasms. ${ }^{14}$ The relatively small variations in adenoma prevalence rates among gastroenterologists (5.6\%) and gastrointestinal (GI) trainees $(9.0 \%)$ in our study ${ }^{9}$ compared with others (up to $\left.30 \%\right),{ }^{3,4}$ may reflect the effect of education on nonpolypoid colorectal lesions and quality indicators for colonoscopy, 
prior to the start of this study. In addition, we found no significant differences in detection of NP-CRNs between GI trainees (3.7\%) and gastroenterologists $(4.6 \%){ }^{15}$ suggesting that education and awareness may prevail over experience. Previous studies showed that the years of experience or number of colonoscopies performed do not predict the adenoma detection rate ${ }^{5}$ or outcome of colonoscopy. ${ }^{16}$ Importantly, the majority of currently practicing gastroenterologists accomplished their education before the existence of NP-CRNs was generally recognized in the West. Educational programs targeted on the recognition and treatment of nonpolypoid colorectal lesions may therefore be essential to improve the quality of colonoscopy in average- and highrisk populations and should be offered to all practicing endoscopists.

In addition to quality of colonoscopy, biologic factors may impact the outcome of colonoscopy, as well. In contrast to some earlier studies suggesting that all NP-CRNs are more likely to contain high-grade dysplasia (HGD) or early cancer, ${ }^{17-19}$ we found nonpolypoid appearance not to be an independent predictor for advanced histology, in line with more recent studies. ${ }^{20,21}$ In agreement with previously published data, ${ }^{22,23}$ we found that the depressed type (Paris type 0-IIC) colorectal lesions are uncommon, but when present, frequently contain HGD/early CRC. By systematically analyzing current studies addressing the molecular profile of NP-CRNs, it became clear that large heterogeneity exists regarding the methodology, definitions and populations used, which precluded us from drawing definitive conclusions. Nevertheless, the studies consistently described a low frequency of KRAS mutation in the depressed type colorectal neoplasms (Chapter 8). Our study on epigenetic alterations in NP-CRNs, showed no differences in frequency of DNA hypermethylation, for the investigated genes, between nonpolypoid and polypoid neoplasms (Chapter 9). Unfortunately, we were not able to specifically address the molecular profile of depressed type lesions, due to their low prevalence. So far, the present data suggest that some subtypes of NP-CRNs may have a distinct molecular profile. It is conceivable that NP-CRNs may represent a morphological continuum with polypoid neoplasms, of which a subset harbor distinct biologic features. Large, multi-center studies are needed in the future to clarify the molecular pathways underlying nonpolypoid colorectal carcinogenesis and elucidate whether the depressed type neoplasms are truly different biologic entities.

Studies addressing the molecular profile of post-colonoscopy CRCs showed that these cancers are 3 times more likely to demonstrate microsatellite instability and 2 times more likely to demonstrate a $\mathrm{CpG}$ island methylator phenotype, characteristics that have been highly associated with the recently discovered serrated neoplastic pathway. ${ }^{24}$ This thesis shows that nearly half $(43 \%)$ of the SPs at risk for malignant progression, i.e. high-risk SPs, have a nonpolypoid endoscopic appearance. ${ }^{25}$ It therefore seems likely that overlooked ${ }^{26,27}$ or incompletely removed (high-risk) SPs are at the origin of some of the post-colonoscopy CRCs. Moreover, we found that patients with high-risk SPs have an increased risk to contain synchronous advanced colorectal 
neoplasms. ${ }^{25}$ In line with data from other studies, ${ }^{28-30}$ these findings indicate that patients with high-risk SPs have an increased risk to develop colorectal neoplasms through both traditional and alternative neoplastic pathways. Recently, it has been proposed to repeat colonoscopy in patients with proximal, large or dysplastic SPs within three years. ${ }^{31}$ In view of the accumulating evidence and while waiting for more longitudinal data, it seems reasonable to provide colonoscopic surveillance to patients with SPs according to these recommendations.

As early as 1990, Bufill described the idea that CRC can be roughly classified into two different subtypes: proximal CRC and distal $\mathrm{CRC}^{32}$ Proximal and distal colorectal neoplasms show distinct epidemiological, clinical, histological and molecular characteristics. ${ }^{32-35}$ In the present thesis, we describe some additional differences between the proximal and distal colon. First, we found differences in growth pattern of adenomatous and SPs according to the anatomical location (Figure 5.1). ${ }^{9}$ Adenomas in the proximal colon contained HGD or early cancer without growing meaningfully in

size. ${ }^{9}$ Similarly, we found that proximal SPs with a large size or dysplasia were flatter in appearance than the distal ones. ${ }^{9}$ Furthermore, we found that the association of promoter hypermethylation with advanced adenomas was dependent upon colonic location (Chapter 9). In the proximal colon, methylation of RASSF2A and CHFR was associated with large adenoma size or presence of high-grade dysplasia or early cancer, whereas this was not found in the distal colon. These findings may suggest that progression of adenomas is driven by other epigenetic alterations in the proximal than in the distal colon. In conclusion, the data in this thesis support the existence of biological differences between proximal and distal colorectal neoplasms ${ }^{35}$ and these differences may partly explain the disparity between the proximal and the distal colon with regard to colonoscopic cancer prevention.

\section{Implications for the clinical practice and suggestions for future research}

The benefits and disadvantages of CRC prevention by colonoscopy are ideally addressed in a randomized control trial. Such initiatives are currently ongoing, ${ }^{36}$ and the results of these studies may bring more insights in the next years. Until then, we should rely on observational, case-control studies, which so far provide indications that colonoscopy offers less protection against proximal than distal CRC. As the majority of these studies are based on everyday endoscopy practice, including low and high quality colonoscopies, these studies could provide important information regarding potential reasons for failure of colonoscopy to prevent CRC. As outlined in the previous section, we presume that low quality colonoscopy may especially result in overlooking nonpolypoid adenomatous and serrated colorectal lesions, ultimately favoring the development of post-colonoscopy CRCs.

To conclude, efforts should be made to optimize the effectiveness of cancer prevention by colonoscopy. Colonoscopists should aim to continuously improve detection of precursor lesions by updating their knowledge and skills, improving bowel 
cleansing regimes and quality of imaging. Future research should aim to elucidate the clinical significance and biologic behavior of depressed type colorectal neoplasms and subtypes of serrated colorectal lesions to possibly develop tailored management and follow-up strategies for patients having these lesions. In all these efforts, colonic location should be taken into consideration, as it became clear that important differences exist between the proximal and the distal colon.

\section{Key messages of this thesis}

- Nonpolypoid colorectal neoplasms play an important role in the colorectal carcinogenesis, both through the adenoma-carcinoma route and the recently discovered serrated neoplastic pathway.

- Nonpolypoid colorectal neoplasms predominate in the proximal colon. This finding suggests that colorectal carcinogenesis may differ according to colonic location and that nonpolypoid mechanisms may partly explain the proximal predominance of post-colonoscopy cancers.

- Educational programs for endoscopists should therefore include recognition and treatment of nonpolypoid colorectal lesions, as this may be essential to improve quality of colonoscopy and thereby the effectiveness of a nationwide colorectal cancer screening program. 


\section{References}

1. Health Council of the Netherlands. A national colorectal cancer screening programme. The Hague: Health Council of the Netherlands, 2009; publication no. 2009/13E.

2. Rex DK, Bond JH, Winawer S, Levin TR, Burt RW, Johnson DA, Kirk LM, Litlin S, Lieberman DA, Waye JD, Church J, Marshall JB, Riddell RH. Quality in the technical performance of colonoscopy and the continuous quality improvement process for colonoscopy: recommendations of the U.S. Multi-Society Task Force on Colorectal Cancer. Am J Gastroenterol 2002;97:1296-308.

3. Hetzel JT, Huang CS, Coukos JA, Omstead K, Cerda SR, Yang S, O'Brien MJ, Farraye FA. Variation in the detection of serrated polyps in an average risk colorectal cancer screening cohort. Am J Gastroenterol 2010;105:2656-64.

4. Kahi CJ, Hewett DG, Norton DL, Eckert GJ, Rex DK. Prevalence and variable detection of proximal colon serrated polyps during screening colonoscopy. Clin Gastroenterol Hepatol 2011;9:42-6.

5. Kaminski MF, Regula J, Kraszewska E, Polkowski M, Wojciechowska U, Didkowska J, Zwierko M, Rupinski M, Nowacki MP, Butruk E. Quality indicators for colonoscopy and the risk of interval cancer. N Engl J Med 2010;362:1795-803.

6. Winawer SJ, Zauber AG, Ho MN, O'Brien MJ, Gottlieb LS, Sternberg SS, Waye JD, Schapiro M, Bond JH Panish JF, Ackroyd F, Shike M, Kurtz RC, Hornsby-Lewis L, Gerdes H, Stewart ET, and The National Polyp Study Workgroup. Prevention of colorectal cancer by colonoscopic polypectomy. New Engl J Med 1993;329:1977-81.

7. Zauber AG, Winawer SJ. High-quality colonoscopies must be an integral part of screening and surveillance programs. Gastroenterology 2006;130:620-621.

8. Chen SC, Rex DK. Endoscopist can be more powerful than age and male gender in predicting adenoma detection at colonoscopy. Am J Gastroenterol 2007;102:856-61.

9. Rondagh EJ, Bouwens MW, Riedl RG, Winkens B, de Ridder R, Kaltenbach T, Soetikno RM, Masclee AA, Sanduleanu S. Endoscopic appearance of proximal colorectal neoplasms and potential implications for colonoscopy in cancer prevention. Gastrointest Endosc 2012 Epub ahead of print.

10. Baxter NN, Sutradhar R, Forbes SS, Paszat LF, Saskin R, Rabeneck L. Analysis of administrative data finds endoscopist quality measures associated with postcolonoscopy colorectal cancer. Gastroenterology 2011;140:65-72.

11. Singh H, Nugent Z, Demers AA, Kliewer EV, Mahmud SM, Bernstein CN. The reduction in colorectal cancer mortality after colonoscopy varies by site of the cancer. Gastroenterology 2010;139:1128-37.

12. Church JM, Muto T, Appau K. Flat lesions of the colorectal mucosa: differences in recognition between Japanese and American endoscopists. Dis Colon Rectum 2004;47:1462-1466.

13. Kaltenbach T, McGill SK, Kalidindi V, Friedland S, Soetikno R. Proficiency in the diagnosis of nonpolypoid colorectal neoplasm yields high adenoma detection rates. Dig Dis Sci 2012;57:764-70.

14. Saitoh Y, Waxman I, West AB, Popnikolov NK, Gatalica Z, Watari J, Obara T, Kohgo Y, Pasricha PJ. Prevalence and distinctive biologic features of flat colorectal adenomas in a North American population. Gastroenterology 2001;120:1657-1665.

15. Rondagh EJ, Masclee AA, van der Valk ME, Winkens B, de Bruine AP, Kaltenbach T, Soetikno RM, Sanduleanu S. Nonpolypoid colorectal neoplasms: gender differences in prevalence and malignant potential. Scand J Gastroenterol 2012;47:80-8.

16. Rabeneck L, Paszat LF, Saskin R. Endoscopist specialty is associated with incident colorectal cancer after a negative colonoscopy. Clin Gastroenterol Hepatol. 2010;8:275-9.

17. Rembacken BJ, Fujii T, Cairns A, Dixon MF, Yoshida S, Chalmers DM, Axon A. T. R. Flat and depressed colonic neoplasms: a prospective study of 1000 colonoscopies in the UK. Lancet 2000;355:1211-1214

18. Soetikno RM, Kaltenbach T, Rouse RV, Park W, Maheshwari A, Sato T, Matsui S, Friedland S. Prevalence of nonpolypoid (flat and depressed) colorectal neoplasms in asymptomatic and symptomatic adults. JAMA 2008;299:1027-1035.

19. Tsuda S, Veress B, Toth E, Fork FT. Flat and depressed colorectal tumours in a southern Swedish population: a prospective chromoendoscopic and histopathological study. Gut 2002;51:550-5.

20. Bianco MA, Cipolletta L, Rotondano G, Buffoli F, Gizzi G, Tessari F. Prevalence of nonpolypoid colorectal neoplasia: an Italian multicenter observational study. Endoscopy 2010;42:279-285. 
21. Chiu HM, Lin JT, Chen CC, Lee YC, Liao WC, Liang JT, Shun CT, Wang HP, Wu MS. Prevalence and characteristics of nonpolypoid colorectal neoplasm in an asymptomatic and average-risk Chinese population. Clin Gastroenterol Hepatol. 2009; 7:463-70

22. Kudo S, Lambert R, Allen JI, Fujii H, Fujii T, Kashida H, Matsuda T, Mori M, Saito H, Shimoda T, Tanaka S, Watanabe H, Sung JJ, Feld AD, Inadomi JM, O'Brien MJ, Lieberman DA, Ransohoff DF, Soetikno RM, Triadafilopoulos G, Zauber A, Teixeira CR, Rey JF, Jaramillo E, Rubio CA, Van Gossum A, Jung M, Vieth $M$, Jass JR, Hurlstone PD. Nonpolypoid neoplastic lesions of the colorectal mucosa. Gastrointest Endosc 2008;68 (Suppl October):S3-47.

23. Soetikno R, Friedland S, Kaltenbach T, Chayama K, Tanaka S. Nonpolypoid (flat and depressed) colorectal neoplasms. Gastroenterology 2006;130:566-576.

24. East JE, Saunders BP, Jass JR. Sporadic and syndromic hyperplastic polyps and serrated adenomas of the colon: classification, molecular genetics, natural history, and clinical management. Gastroenterol Clin North Am 2008;37:25-46.

25. Rondagh EJ, Masclee AA, Bouwens MW, Winkens B, Riedl RG, de Bruine AP, de Ridder R, Kaltenbach T, Soetikno RM, Sanduleanu S. Endoscopic red flags for the detection of high-risk serrated polyps: an observational study. Endoscopy 2011;43:1052-8.

26. Harrison M, Singh N, Rex DK. Impact of proximal colon retroflexion on adenoma miss rates. Am J Gastroenterol 2004;99:519-22.

27. Rex DK, Cutler CS, Lemmel GT, Rahmani EY, Clark DW, Helper DJ, Lehman GA, Mark DG. Colonoscopic miss rates of adenomas determined by back-to-back colonoscopies. Gastroenterology 1997;112:24-28.

28. Hiraoka S, Kato J, Fujiki S, Kaji E, Morikawa T, Murakami T, Nawa T, Kuriyama M, Uraoka T, Ohara N, Yamamoto K. The presence of large serrated polyps increases risk for colorectal cancer. Gastroenterology 2010;139:1503-10.

29. Li D, Jin C, McCulloch C, Kakar S, Berger BM, Imperiale TF, Terdiman JP. Association of large serrated polyps with synchronous advanced colorectal neoplasia. Am J Gastroenterol 2009;104:695-702.

30. Schreiner MA, Weiss DG, Lieberman DA. Proximal and large hyperplastic and nondysplastic serrated polyps detected by colonoscopy are associated with neoplasia. Gastroenterology 2010;139:1497-502.

31. Terdiman JP, McQuaid KR. Surveillance guidelines should be updated to recognize the importance of serrated polyps. Gastroenterology 2010;139:1444-7.

32. Bufill JA. Colorectal cancer: evidence for distinct genetic categories based on proximal or distal tumor location. Ann Intern Med 1990;113:779-88.

33. Baker K, Zhang Y, Jin C, Jass JR. Proximal versus distal hyperplastic polyps of the colorectum: different lesions or a biological spectrum? J Clin Pathol 2004;57:1089-93.

34. Torlakovic E, Skovlund E, Snover DC, Torlakovic G, Nesland JM. Morphologic reappraisal of serrated colorectal polyps. Am J Surg Pathol 2003;27:65-81.

35. lacopetta B. Are there two sides to colorectal cancer? Int J Cancer 2002;101:403-8.

36. ClinicalTrials.gov. "The Northern-European Initiative on Colorectal Cancer (NordICC)." Retrieved April 24, 2012, from http://clinicaltrials.gov/ct2/show/NCT00883792. 
Summary 
168 


\section{Summary}

Colorectal cancer (CRC) is the second most common cancer and cause of cancerrelated death in the Netherlands. As the majority of CRCs are considered to originate from colorectal polyps, colonoscopy with polypectomy offers excellent potential to reduce the CRC incidence and mortality. Nevertheless, a significant number of postcolonoscopy CRCs still develop in routine practice in patients at average- as well as in patients at high-risk for CRC, i.e. Lynch syndrome patients. Nonpolypoid colorectal neoplasms (NP-CRNs) have been suspected to explain some of these cancers occurring after colonoscopy, as they are more easily overlooked, their removal requires technical expertise, and some of them are more likely to contain advanced histology, i.e. highgrade dysplasia or early CRC.

Although NP-CRNs were described already in 1985 in Japan, these lesions have just recently been recognized in the West and other Eastern countries. So far, the prevalence of these lesions in the Netherlands has not been examined. In 2013, a nationwide CRC screening program will be implemented in the Netherlands, in which colonoscopy will be offered to persons aged $>55$ years having a positive fecal test. In view of this forthcoming screening program, more knowledge on the prevalence and clinicopathologic features of NP-CRNs is needed to improve the education and training of the endoscopists thus offering the premises for a highly effective national screening program.

In this thesis, we aimed to investigate the prevalence of NP-CRNs in average- and highrisk populations in the Netherlands and explored their clinicopathologic and molecular characteristics. We studied the contribution of NP-CRNs to colorectal carcinogenesis, with special attention for the traditional adenoma-carcinoma route as well as the recently described serrated neoplastic pathway. Furthermore, we examined factors which might assist the endoscopic detection of (nonpolypoid) colorectal neoplasms.

As NP-CRNs were just recently recognized in the West, we first familiarized the endoscopists at the Maastricht University Medical Center on the recognition, classification and endoscopic treatment of nonpolypoid colorectal lesions using lectures by a dedicated colonoscopist, video demonstrations using accredited educational programs and individual feedback (Chapter 2). Subsequently, we have built up a study population comprising all consecutive patients referred for elective colonoscopy at our GI endoscopy unit between February 2008 and February 2010.

We initially examined the prevalence and malignant potential of nonpolypoid colorectal adenomas in our experience (Chapter 3). As important differences have been described between men and women with regard to the prevalence of colorectal neoplasms and moreover, women have been suspected to be at an increased risk for developing post-colonoscopy CRCs, we paid special attention to sex differences in this study. Overall, we found that $4.2 \%$ of all patients referred for routine colonoscopy had 
at least one nonpolypoid adenoma. The prevalence of nonpolypoid adenomas was lower in women (3.0\%) than in men (5.5\%). However, although women were less likely to have nonpolypoid adenomas, $21.3 \%$ of the nonpolypoid adenomas in women contained high-grade dysplasia or early cancer compared to only $12.2 \%$ of those in men. These findings indicate that prevalence of nonpolypoid adenomas in our experience is comparable to other Western studies and that detection of nonpolypoid lesions is of importance in both men and women.

The serrated neoplastic pathway represents an alternative carcinogenic routine, accounting for up to $15 \%$ of all CRCs. The precursor lesions of this alternative pathway, the serrated polyps (SPs), represent a heterogeneous group of lesions, of which the dysplastic and large, proximal SPs are considered potentially premalignant, i.e. highrisk SPs. High-risk SPs share clinical and molecular characteristics with postcolonoscopy CRCs, i.e. both have a proximal predominance and are characterized by microsatellite instability and $\mathrm{CpG}$ island methylator phenotype (CIMP). It is therefore likely that some of the post-colonoscopy CRCs arise via this serrated neoplastic pathway.

In the study described in Chapter 4, we investigated the endoscopic characteristics of SPs. Herewith, we found that nearly half (43.1\%) of all high-risk SPs have a nonpolypoid endoscopic appearance, rendering them more difficult to detect during colonoscopy. In addition, we found that high-risk SPs are associated with advanced colorectal neoplasms, which may be therefore considered potential red flags for the inconspicuous high-risk SPs. This study highlights the need for educational programs on the detection of high-risk SPs, including practical tips, such as endoscopic appearance and their association with advanced colorectal neoplasms.

Unexpectedly, some recent studies raised significant concerns on the effectiveness of colonoscopic cancer prevention in the proximal colon. While colonoscopy may prevent up to $85 \%$ of the distal CRCs, risk reduction for proximal CRC is considerably lower, ranging from $0 \%$ to $55 \%$. The explanation for this marked disparity is presently unclear. In Chapter 5, we studied differences in size and endoscopic shape between proximal and distal colorectal neoplasms. We found that three-fourths of the proximal advanced adenomas have a diminutive size or nonpolypoid shape compared with only one-fourth of the distal ones. Likewise, two-thirds of the proximal large or dysplastic SPs are nonpolypoid compared with only one-fourth of the distal ones. Differences in endoscopic appearance between proximal and distal colorectal neoplasms may in part explain the disparity in colonoscopic cancer prevention. The findings of this study advocate careful inspection of the proximal colon during colonoscopic examination in an attempt to improve the prevention of CRC.

Also in patients with Lynch syndrome, prevention of CRC by colonoscopy has its limitations. Despite undergoing colonoscopy every 3 years in the past, these patients still had a $10 \%$ risk to develop CRC over a 10 year period. Currently, shortening of the surveillance intervals to 1-2 years has been implemented in the Netherlands to reduce 
the CRC risk in patients with Lynch syndrome. However, improving quality of colonoscopy, and in particular the detection of adenomas, could have additional value. In Chapter $\mathbf{6}$ we examined the role of the nonpolypoid colorectal carcinogenesis in patients with Lynch syndrome. We found that proximal adenomas in Lynch patients are 3-4 times more likely to have a nonpolypoid appearance than those from averagerisk subjects. These findings suggest that colonoscopic surveillance in patients with Lynch syndrome should be performed by endoscopists experienced on the detection and treatment of nonpolypoid lesions, as this may further downsize the risk for CRC in this high-risk population.

In a next study we addressed the association between diverticular disease and colorectal neoplasms.

Diverticulosis and colorectal neoplasms are common findings during colonoscopy and their prevalences increase with age. Some previous studies pointed to an association between these conditions, while others could not confirm this. A positive association between diverticulosis and colorectal neoplasms might be of clinical relevance for CRC prevention strategies, as it may highlight a subgroup of patients at increased risk for CRC.

In Chapter 7, we found that diverticulosis is associated with colorectal neoplasms, either adenomas, serrated polyps and especially with advanced neoplasms, in patients below 60 years of age. In patients aged older than 60 years, we did not found this association. Future studies are needed to clarify whether presence of diverticulosis at young age may be an indication for earlier initiation of CRC prevention programs.

In the last part of this thesis, we studied the molecular profile of NP-CRNs. In Chapter 8, we conducted a systematic review and meta-analysis of current studies on genetic and epigenetic alterations in NP-CRNs. This systematic analysis showed large heterogeneity among the current studies with regard to methodology, definitions and populations used, which precluded us from drawing definitive conclusions. Nevertheless, the studies consistently described a low frequency of KRAS mutation in some subtypes of NP-CRNs, that is, the depressed type and the lateral spreading tumor non-granular type neoplasms, suggesting a distinct, potentially shared molecular pathway. Prospective multicenter initiatives are therefore needed in the future, to further elucidate the biology and potential clinical significance of (subtypes of) NP-CRNs.

In Chapter 9, we addressed the frequency of DNA promoter hypermethylation of prominent CRC specific genes as well as the CIMP genes in relation to the phenotype of colorectal neoplasms, i.e. shape (nonpolypoid versus polypoid), size, colonic location and histology. For the investigated genes, we found comparable frequencies of DNA hypermethylation in nonpolypoid and polypoid CRNs. These findings suggest that nonpolypoid and polypoid CRNs may represent a continuum, rather than completely (epigenetically) distinct types of lesions.

In addition, we found that methylation patterns may differ according to colonic location. Methylation of CHFR and RASSF2A was associated with large adenoma size 
and presence of advanced histology in the proximal, but not in the distal colon. Methylation of CHFR and RASSF2A may therefore be important for progression of proximal neoplasms. Moreover, progression of proximal neoplasms may be driven by other epigenetic alterations than distal neoplasms.

In summary, the studies described in this thesis indicate that NP-CRNs play an important role in the colorectal carcinogenesis through the traditional adenomacarcinoma route and the serrated neoplastic pathway. We suggest that nonpolypoid mechanisms may contribute to the occurrence of post-colonoscopy cancers, most probably through technical factors, such as overlooked or incompletely removed lesions. However, biologic explanations should be explored in the future as well. In view of these data, we recommend systematic and continuous training of all practicing endoscopists with regard to quality colonoscopy, with emphasis on the detection and removal of nonpolypoid neoplasms. This is a sine-qua-non condition to ensure a highly effective nationwide CRC screening program in the Netherlands. 
Samenvatting 
174 


\section{Samenvatting}

Het colorectaal carcinoom (CRC) is de op één na meest voorkomende kanker en de op één na grootste oorzaak van kanker gerelateerde sterfte in Nederland. Het merendeel van alle CRCs ontwikkelt zich uit colorectale poliepen. Gezien deze wijze van ontstaan heeft coloscopie met verwijdering van colorectale poliepen een aanzienlijke potentie om de incidentie en moraliteit van CRC te verlagen. Desondanks ontstaan er in de dagelijkse praktijk een significant aantal CRCs na colonoscopie, zowel bij patiënten met een gemiddeld als bij patiënten met verhoogd risico op CRC (bijv. patiënten met het Lynch syndroom). Een mogelijke bron voor het ontstaan van deze carcinomen na een coloscopie zijn nonpolypoide (vlakke) colorectale neoplasieën (NP-CRN). NP-CRN worden door hun subtiele uiterlijk gemakkelijker gemist, de verwijdering van deze poliepen vereist nieuwe endoscopische technieken en sommige van hen worden vaker in een gevorderd stadium aangetroffen, d.w.z. ze bevatten hooggradige dysplasie of vroeg stadium carcinoom.

NP-CRN werden al in 1985 beschreven in Japan, maar zijn in het Westen en andere Oosterse landen pas recentelijk herkend. In Nederland zijn tot op heden dan ook nog geen gegevens over het voorkomen van NP-CRN in de algemene endoscopie praktijk. In 2013 zal een bevolkingsonderzoek naar CRC van start gaan in Nederland. Hierbij zullen alle personen ouder dan 55 jaar met een positieve ontlastingstest een coloscopie ondergaan. Met het oog op dit screeningsprogramma is het van belang dat we meer kennis verkrijgen over de prevalentie en klinisch-pathologische kenmerken van NP-CRN. Met deze kennis kunnen we de kwaliteit van de coloscopie verbeteren en daarmee de voorwaarde scheppen voor een zo effectief mogelijk bevolkingsonderzoek.

Het doel van dit proefschrift was om de prevalentie van NP-CRN bij individuen met een gemiddeld en bij individuen met een verhoogd risico op CRC te onderzoeken, evenals hun klinisch-pathologische en moleculaire kenmerken. We bestudeerden de rol van NP-CRN in de colorectale carcinogenese, met aandacht voor zowel de traditionele adenoma-carcinoma route als de recent beschreven serrated pathway. Daarnaast onderzochten we factoren die de endoscopist kunnen assisteren in het opsporen van (vlakke) colorectale poliepen.

Aangezien NP-CRN pas recentelijk zijn herkend in het westen, hebben we voorafgaand aan de studies alle endoscopisten in het Maastricht Universitair Medisch Centrum getraind in het herkennen, classificeren en endoscopisch verwijderen van NP-CRN. Dit hebben we gedaan door middel van voordrachten door een ervaren endoscopist, video demonstraties en individuele feedback (hoofdstuk 2). Vervolgens hebben we de klinische en pathologische gegevens verzameld van alle opeenvolgende patiënten die een electieve coloscopie ondergingen tussen februari 2008 en februari 2010.

In hoofdstuk 3 beschrijven we de prevalentie en klinisch-pathologische kenmerken van vlakke adenomen. Aangezien er belangrijke verschillen bestaan tussen mannen en 
vrouwen wat betreft de prevalentie van colorectale neoplasieën en vrouwen daarbij mogelijk een verhoogd risico hebben op het ontwikkelen van post-colonoscopie CRC, hebben we ons in dit hoofdstuk in het bijzonder gericht op verschillen tussen mannen en vrouwen. We vonden dat $4,2 \%$ van alle patiënten die een coloscopie ondergingen op zijn minst één NP adenoom had. Voorts was de prevalentie van vlakke adenomen lager bij vrouwen (3,0\%) dan bij mannen (5,5\%). Hoewel vrouwen minder vaak een NP adenoom hadden, was $21,3 \%$ van de vlakke adenomen bij vrouwen in een gevorderd stadium t.o.v. maar $12,3 \%$ bij mannen. De bevindingen van deze studie laten zien dat vlakke adenomen in onze endoscopie praktijk even vaak voorkomen als in andere Westerse landen en dat detectie van deze poliepen van belang is bij zowel mannen als vrouwen.

De serrated pathway is recent herkend als een alternatieve route in de colorectale carcinogenese en wordt verantwoordelijk gehouden voor ongeveer $15 \%$ van alle CRCs. The serrated pathway en post-colonoscopie CRCs hebben klinische en moleculaire overeenkomsten. Ze komen beide vaak voor in het proximale colon en worden gekenmerkt door microsatelliet instabiliteit (MSI) en CpG island methylator phenotype (CIMP). Het is dan ook waarschijnlijk dat een deel van de post-coloscopie CRCs ontstaat via dit serrated pathway.

In hoofdstuk 4 onderzochten we de endoscopische kenmerken van serrated poliepen (SPs). SPs vertegenwoordigen een heterogene groep van poliepen, waarvan de dysplastische en grote, proximale SPs worden beschouwd als mogelijke voorstadia van CRC, ofwel hoog-risico SPs. Wij vonden dat bijna de helft $(43,1 \%)$ van deze hoog-risico SPs een vlak uiterlijk heeft, waardoor ze lastiger te herkennen zijn tijdens de coloscopie. Daarnaast vonden we dat hoog-risico SPs vaak voorkomen bij patiënten met gevorderde adenomateuze poliepen. Deze studie benadrukt het belang van adequate training van de endoscopisten in het herkennen van vlakke (hoog-risico) SPs, waarbij de aanwezigheid van gevorderde adenomateuze poliepen een mogelijke risicomarker kan zijn.

Uit recente studies blijkt dat colonoscopie aanzienlijk minder effectief is in de preventie van het proximale dan het distale CRC. In het distale colon voorkomt coloscopie ongeveer $85 \%$ van alle CRCs, terwijl in het proximale colon dit percentage beduidend lager ligt variërend tussen de 0 en $55 \%$. De oorzaak van dit opmerkelijke verschil is tot op heden onduidelijk.

In hoofdstuk $\mathbf{5}$ bestudeerden we verschillen in grootte en vorm tussen proximale en distale poliepen. Hierbij vonden we dat driekwart van de proximale adenomen in een gevorderd stadium klein of vlak is t.o.v. een kwart van degenen in het distale colon. Bovendien vonden we dat van de grote of dyplastische SPs in het proximale colon twee derde vlakke is t.o.v. een vierde van degenen in het distale colon. Uiterlijke verschillen tussen poliepen in de proximale en distale darm kunnen mogelijk verklaren waarom coloscopie minder effectief is in de preventie van het proximale CRC. Adequate detectie van deze subtiele laesies zal daarom essentieel zijn voor een optimaal resultaat van een landelijk bevolkingsonderzoek naar CRC. 
Ook bij patiënten met het Lynch syndroom heeft coloscopie zijn beperkingen bij de preventie van CRC. Deze patiënten met een verhoogd risico op CRC ondergingen voorheen elke 3 jaar een coloscopie. Ondanks deze frequente coloscopieën ontwikkelde $10 \%$ van hen gedurende 10 jaar een CRC. Om deze reden is het interval tussen twee coloscopieën verkort naar 1-2 jaar. Naast het verkorten van het interval, kan verbetering van de kwaliteit van coloscopie mogelijk van toegevoegde waarde zijn bij de preventie van CRC bij Lynch syndroom patiënten.

In hoofdstuk 6 onderzochten we de rol van NP-CRN bij patiënten met het Lynch syndroom. Hierbij vonden we dat proximale adenomen bij hen 3 tot 4 keer zo vaak vlak zijn dan bij patiënten met een gemiddeld risico op CRC. Deze bevinding suggereert dat surveillance coloscopieën bij Lynch patiënten uitgevoerd zouden moeten worden door endoscopisten met ruime expertise op het gebied van herkenning en verwijdering van NP-CRN. Mogelijk kan dit mogelijk het risico op CRC in deze populatie in de toekomst verlagen.

In een volgende studie onderzochten we het verband tussen diverticulose en colorectale neoplasieën. Diverticulose en colorectale neoplasieën worden beide vaak gediagnosticeerd tijdens een coloscopie en de prevalentie van beide aandoening stijgt met de leeftijd. Sommige voorgaande studies wezen op een verband tussen beide aandoeningen, doch anderen konden dit niet bevestigen. Een positieve associatie tussen diverticulose en colorectale neoplasieën kan van belang zijn voor preventie van CRC, omdat dit kan helpen patiënten te identificeren die verhoogd risico hebben om een CRC te ontwikkelen.

In hoofdstuk 7 vonden we dat, bij patiënten jonger dan 60 jaar, diverticulose geassocieerd is met colorectale neoplasieën, zowel adenomen, SPs als gevorderde adenomen. Bij patiënten ouder dan 60 jaar vonden we dit verband echter niet. Toekomstig onderzoek zal moeten uitwijzen of de aanwezigheid van diverticulose op jonge leeftijd een indicatie is voor het vroeger starten met screenen op CRC.

In het laatste gedeelte van dit proefschrift bestudeerden we het moleculaire profiel van de NP-CRN. Hoofdstuk 8 presenteert een systematisch review inclusief metaanalyse over de huidige studies die genetische en epigenetische veranderingen in NPCRN hebben onderzocht. Deze systematische analyse laat zien dat er grote heterogeniteit bestaat tussen de huidige studies wat betreft methodologie, gebruikte definities en onderzochte populaties. Hierdoor was het niet mogelijk om definitieve conclusies te trekken wat betreft het (epi)genetisch profiel van NP-CRN. Desondanks lieten de studies consistentie zien ten aanzien van de bevinding dat sommige subtypes van NP-CRN, namelijk de 'depressed type' en de 'non-granular lateral spreading tumor', minder vaak KRAS mutaties vertonen in vergelijking met polypoide neoplasieën. Deze subtypes van NP-CRN vertegenwoordigen dus mogelijk een afzonderlijke moleculaire route.

In hoofdstuk 9 bestudeerden we DNA methylering van belangrijke CRC specifieke genen evenals de aanwezigheid van CIMP in relatie met het fenotype van colorectale adenomen, d.w.z. de vorm (nonpolypoid versus polypoid), grootte, locatie en 
histologie. Hierbij vonden we dat DNA methylering van de onderzochte genen even vaak voorkomt bij NP-CRN als bij polypoide CRN. Deze bevinding suggereert dat het epigenetisch profiel van beide poliepen eerder moet worden beschreven als een glijdende schaal dan als twee of meer verschillende types.

Daarnaast vonden we dat het proximale en distale colon verschillen voor wat betreft methyleringspatroon. In het proximale colon kwam methylering van het CHFR en RASSF2A gen vaker voor bij grootte adenomen en bij adenomen met hooggradige dysplasie of vroeg carcinoom. In het distal colon werd deze associatie echter niet gevonden. Methyerling van CHFR en RASSF2A is daarom mogelijk van belang voor progressie van adenomen in het proximale colon en progressie van proximale adenomen wordt mogelijk gedreven door andere epigenetische veranderingen dan progressie van distale adenomen.

Samenvattend laat dit proefschrift zien dat NP-CRN een belangrijke rol spelen in de colorectale carcinogenese, zowel via de traditionele adenoma-carcinoma route als via de serrated pathway. Nonpolypoide mechanismen zijn waarschijnlijk een belangrijke oorzaak van het ontstaan van post-colonoscopie CRCs. Enerzijds kan dit worden verklaard doordat deze laesies vaker worden gemist of incompleet worden verwijderd. Anderzijds spelen mogelijk ook biologische factoren een rol. De precieze bijdrage van biologische factoren moet echter in de toekomst nog verder worden onderzocht. De resultaten van dit proefschrift wijzen er in ieder geval op dat adequate detectie en verwijdering van nonpolypoide (vlakke) colorectale neoplasiën een belangrijke voorwaarde zal zijn voor een effectief bevolkingsonderzoek naar CRC in Nederland. 
Dankwoord 


\section{Dankwoord}

Kennis is het enige dat zich vermeerdert wanneer je het met anderen deelt (stelling 8). Onderzoek doe je dan ook niet alleen en een dankwoord is op zijn plaats voor iedereen die in de afgelopen periode een bijdrage heeft geleverd aan dit proefschrift.

Silvia, jij staat aan de basis van dit onderzoek. Een aantal jaar geleden was het begrip vlakke poliep een relatief onbekend fenomeen op onze afdeling. Dankzij jouw enthousiasme en doorzettingsvermogen hebben alle endoscopisten hun ogen nu echter gericht op deze poliepen. Ik ben blij dat ik de afgelopen jaren met je heb mogen samenwerken en veel van je heb kunnen leren. Zonder jouw goede ideeën en het snelle en uiterst grondig nakijken van de manuscripten was deze onderzoeksperiode nooit zo voorspoedig verlopen. Bedankt!

Prof. Masclee, Ad, ondanks uw overvolle programma wist $u$ altijd een gaatje vrij te maken om te horen hoe het ging en mij te voorzien van goede adviezen. $U$ wist zelfs nog een gaatje vrij te maken om een rondje te fietsen door het Limburgs heuvellandschap. Bedankt voor de fijne samenwerking!

Prof. de Bruïne, Adriaan, bedankt voor alle uurtjes reviseren en discussiëren. Dit was niet alleen van belang voor het onderzoek (en mijn kennis van pathologie), maar was ook altijd weer erg gezellig!

Prof. van Engeland, Manon, als groentje in de wereld van de pipetten, multiplexen en PCR's was het voor mij in het begin even wennen op het lab. Door jouw begeleiding heb ik mijn weg weten te vinden, bedankt voor je steun en vertrouwen!

Prof. Soetikno and dr. Kaltenbach, Tonya and Roy, your work on NP-CRNs was an inspiration to us. Thank you for sharing your knowledge of nonpolypoid colorectal neoplasms, your interest, support and critical review of articles.

Robert, ondanks de drukte op de afdeling nam jij toch altijd de tijd om me te helpen door het maken van een foto of het reviseren van de coupes. Dank daarvoor!

Bjorn, je maakte het er niet altijd gemakkelijker op, maar wel vele malen beter. Jouw adviezen ten aanzien van de statistische analyses zijn essentieel geweest bij het tot stand komen van dit proefschrift.

Encarna, bedankt voor al je interesse, het meedenken en kritisch nakijken van het Lynch artikel.

Prof. Meijer en Beatriz Carvalho, bedankt voor de inspirerende discussies in Den Bosch. 
Rinus, wat was het een enorme klus! Maar onze samenwerking verliep vlot en we vulden elkaar goed aan, waardoor we het klusje uiteindelijk toch op tijd hebben weten te klaren!

PENTAX Nederland B.V. en in het bijzonder Erwin van Wijck en Peter Logghe, bedankt voor jullie interesse en steun gedurende mijn hele promotietraject.

Stafleden, assistenten en endoscopie verpleegkundigen van de afdeling Maag-, Darmen Leverziekten van het MUMC en in het bijzonder Rogier en Ton: bedankt voor jullie belangrijke bijdrage aan het opbouwen van onze studiepopulatie.

Kim, kleine Kim, Peter, Edith, Corrine en alle andere collega's van de pathologie, bedankt voor het beantwoorden van mijn vele vragen en jullie hulp bij de analyses.

Mietsie en Elly, dank voor jullie ondersteuning bij alle secretariële werkzaamheden en meer.

Tiny, veel dank voor je hulp bij de lay-out van het proefschrift en alle goede tips.

De leden van de beoordelingscommissie wil ik bedanken voor het kritisch lezen en (positief) beoordelen van het proefschrift.

Collega assistenten en specialisten van de afdeling Interne Geneeskunde in Venlo, het is een stukje rijden, maar de goede werksfeer maakt een hoop goed. Bedankt voor de fijne samenwerking de afgelopen maanden!

En dan wil ik nu overgaan tot het bedanken van alle studenten (en later collega's) die een aanzienlijke bijdrage hebben geleverd aan dit proefschrift.

Allereerst, Mirthe, aka de poliependame, jij hebt als geen ander reclame weten te maken voor de vlakke poliepen. Je hebt er zelfs een bijnaam aan overgehouden! Het was een gezellige tijd, met een etentje bij tapas y mas als hoogtepunt ;).

Debbie, wat hebben wij hard gewerkt in jouw stageperiode. En of dat nog niet genoeg was, ging jij op zaterdag ook nog in de slagerij aan het werk! Bedankt voor al je hulp, in het bijzonder op het lab en natuurlijk de gezellige kopjes koffie tussendoor.

Mariëlle, drie jaar op rij samen naar de DDW, met als hoogtepunt een tussenstop in New York! We hebben samen vele uurtjes brieven gevouwen en databasegegevens ingevoerd. Jij hebt zelfs ook nog de kelders van het ziekenhuis doorzocht! Jouw humor maakte tijdens deze (soms) saaie klusjes altijd een hoop goed. $\mathrm{Na}$ al die tijd ben ik blij dat jij vandaag mijn Paranimf bent! 
Sanne, ik bewonder jouw doorzettingsvermogen tijdens en na de moeilijke periode die jij hebt doorgemaakt. Hierdoor hebben we de draad weer op kunnen pakken en uiteindelijk mooie resultaten bereikt. Bedankt voor de fijne samenwerking!

Chantal, al tijdens je co-schappen klopte jij bij ons aan, omdat je er iets bij wilde doen. Jij wist al vroeg wat je wilde en enkele jaren later sloot jij je dan ook bij onze onderzoeksgroep aan. Naast hard werken, kan jij ook genieten van het leven en was je altijd in voor een drankje bij Thembi na het werk! Bedankt voor de gezellige tijd!

Bouke, ook jij moest er aan geloven: vele uurtjes achter de pc gegevens invoeren. Bedankt voor je hulp, maar ook voor al je gezellige verhalen!

Elhaseen, roomie, I would like to thank you for your good advices, nice stories from Sudan and your permanent big smile $:$.

Yvan, bedankt voor de mooie fietstochten, gesprekken (tot het licht in de 043 weer aan ging) en niet te vergeten de wijze levenslessen; de zals ut neet geluive, mer ' $t$ waor de sjoenste tied vaan mien leve!

En dan alle andere collega onderzoekers van de MDL-ziekten in Maastricht: Annemieke, Carolina, Corrine, Daniel, Daisy, Esther, Freddy, Harm-Jan, Jeoffrey, Karen, Kirsten, Kirsten, Mark, Martine, Paul, Renske, Samefko, Sander, Tim, Timo \& Zlatan. Bedankt voor de gezellige lunches, kopjes koffie, borrels in de thembi, fietstochten, reisjes naar Chicago, New Orleans of Mainz ;), het was een fantastische tijd!

Eric, dankzij jou heb ik de stukken van Ellen de Visser leren kennen (en alle anderen die in de Volkskrant over kanker gerelateerde onderwerpen schreven). Het was iedere keer weer interessant om te lezen. Nog leuker zelfs waren de begeleidende brieven waarin jij alle artikelen met een scherp inzicht en vooral veel humor voorzag van jouw eigen commentaar. Bedankt voor jouw interesse!

Bas \& Lieke, Denise, Harmke, Heleen, Janneke, Joep, Jonas \& Anouk, Justin \& Lieke, Koen, Kostan \& Aleida, Linda \& Jeroen, Samira \& Wouter, Sanne \& Maarten, Suzy \& Tom, Ylaine \& Jeroen, inhoudelijk heb ik van jullie weinig geleerd, maar in de vrije uurtjes des te meer!

M6, money is no point. En Susan Boyle een zangeres.

Wim \& Ineke en Sanne \& Roy: een warmere koude kant had ik me niet kunnen wensen! 
Marc, Marieke \& Youri en Robbie, Joyce \& Noura, bedankt voor jullie interesse in mijn vorderingen, maar bovenal voor de vele gezellige momenten! De weekjes in Frankrijk zijn wat dit betreft een hoogtepunt en doen me altijd weer aan vroeger denken. Ik kan niet wachten om dit jaar met zijn 10-en in plaats van met zijn 8-en te gaan!

Pappa en mamma, jullie staan aan de basis van deze weekjes, maar ook aan de basis van nog veel meer. Bedankt voor jullie interesse en goede adviezen, de gezellige avonden met elke keer weer even lekker eten en jullie onvoorwaardelijke steun.

En dan ten slotte, lieve Thomas, de afgelopen periode heb jij meer dan ooit voor me klaar gestaan en op alle vlakken geholpen dit proefschrift tot een goed eind te brengen. Het kon dan ook niet anders dan dat jij vandaag achter me staat als paranimf. De afgelopen 9 jaar waren fantastisch en ik verheug me op alle jaren die nog gaan komen! 
Curriculum vitae 
186 


\section{Curriculum vitae}

Eveline Rondagh was born on August 14th 1984, in Maastricht. In 2002, after graduating the gymnasium at Montessori College, she started her medical training at the University of Maastricht, the Netherlands. During her medical training she accomplished clinical and scientific traineeships at the Division of Gastroenterology and Hepatology at the Maastricht University Medical Center (supervisor: Dr. Silvia Sanduleanu), where the work presented in this thesis was initiated. From September 2008 to November 2011, she worked as a PhD student at this department (Promotor: Prof. dr. Ad Masclee, Co-promotor: Dr. Silvia Sanduleanu). In October 2011, she received the Pélerin award for the data presented in this thesis. From December 2011, she started her residency in Gastroenterology at the Department of Internal Medicine at the VieCuri Medical Center (Venlo, The Netherlands). 
188 
List of publications 


\section{Manuscripts}

Voorham QJM, Carvalho B, Spiertz AJ, van Grieken NCT, Mongera S, Rondagh EJA, van de Wiel MA, Jordanova ES, Ylstra B, Kliment M, Grabsch H, Rembacken B, Arai T, de Bruine AP, Sanduleanu S, Quirke P, Mulder CJJ, van Engeland M, Meijer GA. Chromosome $5 q$ loss in colorectal flat adenomas. Clin Cancer Res. 2012

Rondagh EJA, Bouwens MWE, Riedl RG, Winkens B, de Ridder R, Kaltenbach T, Soetikno RM, Masclee AAM, Sanduleanu S. Endoscopic appearance of proximal colorectal neoplasms and potential implications for colonoscopy in cancer prevention. Gastrointest Endosc. 2012 Jun;75(6):1218-25.

Rondagh EJA, Masclee AAM, van der Valk ME, Winkens B, de Bruïne AP, Kaltenbach T, Soetikno RM, Sanduleanu S. Nonpolypoid colorectal neoplasms: gender differences in prevalence and malignant potential. Scand J Gastroenterol. 2012 Jan;47(1):80-8.

Rondagh EJA, Masclee AAM, Bouwens MWE, Winkens B, Riedl RG, de Bruïne AP, de Ridder R, Kaltenbach T, Soetikno RM, Sanduleanu S. Endoscopic red flags for the detection of high-risk serrated polyps: an observational study. Endoscopy. 2011 Dec;43(12):1052-8.

Rondagh EJA, Sanduleanu S, le Clercq CM, Winkens B, Masclee AAM. Diverticulosis and colorectal polyps at younger age: a possible link? Eur J Gastroenterol Hepatol. 2011 Nov;23(11):1050-5.

Sanduleanu S, Rondagh EJA, Masclee AAM. Development of expertise in the detection and classification of non-polypoid colorectal neoplasia: Experience-based data at an academic GI unit. Gastrointest Endosc Clin N Am. 2010 Jul;20(3):449-60.

\section{Abstracts}

Rondagh EJA, Bouwens MWE, De Ridder RJ, et al. Differences in Endoscopic Appearance of Proximal Versus Distal Colorectal Neoplasms May Potentially Explain the Disparity in Prevention of Colorectal Cancer. Gastroenterology 2011; 140: S-98 Oral presentation - Digestive Disease Week, Chicago, 2011

Rondagh EJA, Bouwens MI, De Ridder RJ, Masclee A, Sanduleanu S. Gender and Indication for Colonoscopy Are Independent Predictors for Cecal Intubation Rate: Potential Implications for Quality Targets. Gastroenterology 2011; 140: S-561-S-562 Poster presentation - Digestive Disease Week, Chicago, 2011 
Rondagh EJA, van der Valk ME, Winkens B, de Bruine AP, Soetikno RM, Masclee AAM, Sanduleanu S. 129 Nonpolypoid (Flat and Depressed) Colorectal Neoplasms in Women are More Likely to Contain Advanced Histology. Gastroenterology, 2010. 2010;138(5):S-24.

Oral presentation - Digestive Disease Week, New Orleans, 2010

Rondagh EJA, Bouwens MWE, Winkens B, Riedl R, de Bruine AP, Masclee AAM, Sanduleanu S. 742 Adenomatous and Serrated Lesions: Co-Factors in Colorectal Carcinogenesis? Gastroenterology, 2010. 2010;138(5):S-101.

Oral presentation - Digestive Disease Week, New Orleans, 2010

Rondagh EJA, de Bruine AP, de Ridder RJ, Masclee AAM, Sanduleanu S. M1173 RightSided Colorectal Lesions With Advanced Histology are Frequently Diminutive. Gastroenterology. 2010;138(5):S-347.

Poster presentation - Digestive Disease Week, New Orleans, 2010

Rondagh EJA, van der Valk ME, van Engeland $M$, de Bruine AP, Masclee AAM, Sanduleanu S. W1960 Non-Polypoid Colorectal Neoplasms: Clinico-Pathological Features in a Dutch Population. Gastroenterology. 2009;136(5):A-762.

Poster presentation - Digestive Disease Week, Chicago, 2009 